\title{
ABORIGINES IN THE
}

NORTHERN TERRITORY

CATTLE INDUSTRY

Frank Stevens
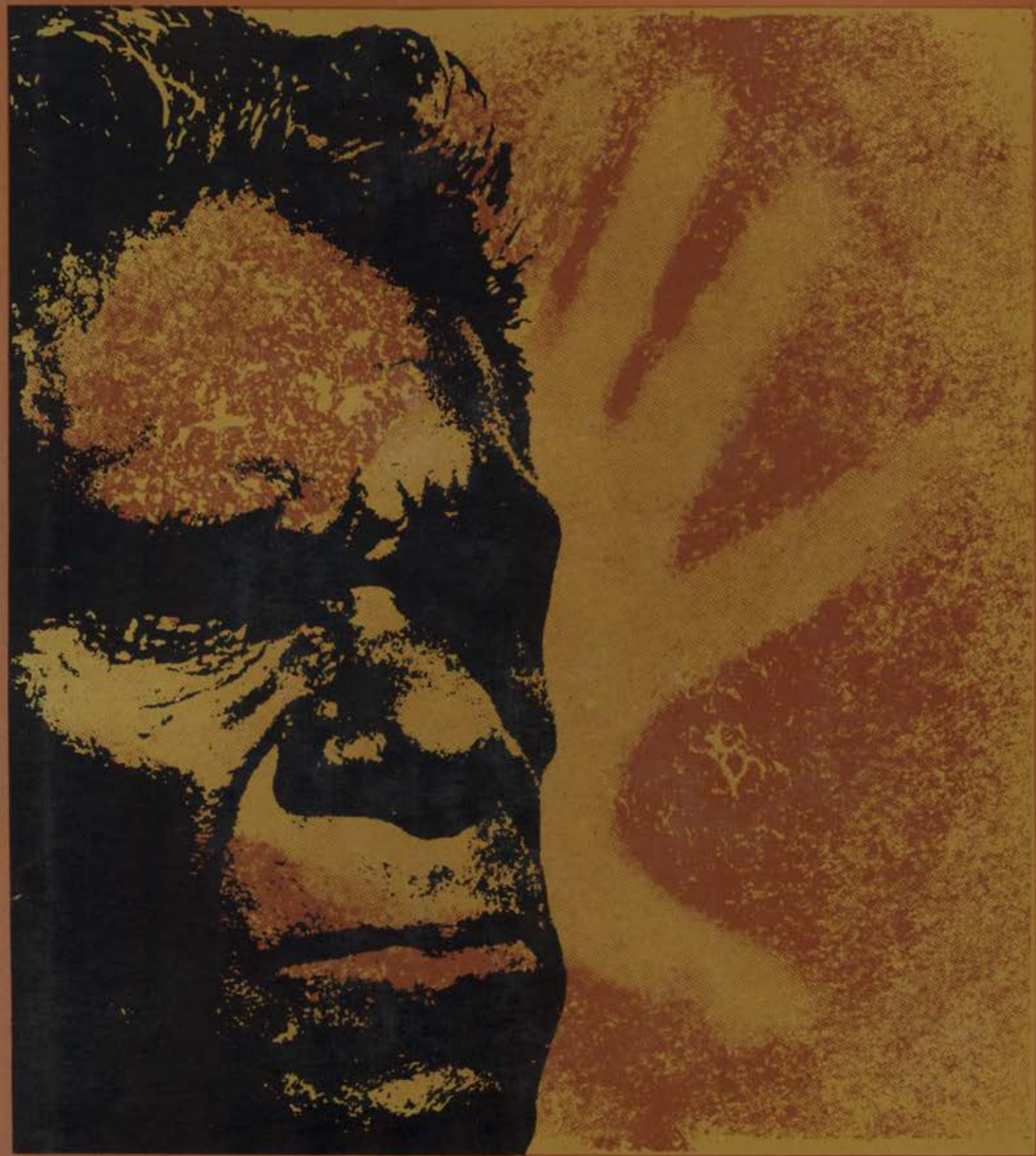
Perhaps nowhere in Australia have working and living conditions for Aborigines been so bad as on Northern Territory cattle stations. Though the Aborigines' skill in handling cattle is acknowledged by their white employers, rarely have they gained recognition in any material way. None were paid full wages, many were fortunate if they received any cash wages at all, almost all lived in appalling conditions, and many were subjected to physical violence.

These facts emerge clearly from Dr Stevens's thorough research into the conditions obtaining on Territory pastoral properties in the 19605 . During surveys in 1965 followed up in 1967, Dr Stevens questioned employers and both black and whitc workers in the industry, eliciting some revealing replies. It was apparent that the Aboriginal workers were fully aware of their degraded position and the way in which they were exploited.

Where possible Dr Stevens visited the Aboriginal station 'camps', though he met with opposition from some station owners, reluctant to allow him free access. In almost all of them the living conditions were primitive, the best of accommodation being little more than a corrugated iron hut. Few camps had running water or cooking facilitics.

In the growing awareness of the Aborigines' plight in Australia, this book is an important testimony of the conditions in which many lived and worked, conditions that must no longer be allowed to exist. 
This book was published by ANU Press between 1965-1991. This republication is part of the digitisation project being carried out by Scholarly Information Services/Library and ANU Press.

This project aims to make past scholarly works published by The Australian National University available to a global audience under its open-access policy. 


\section{ABORIGINES IN THE NORTHERN TERRITORY CATTLE INDUSTRY}

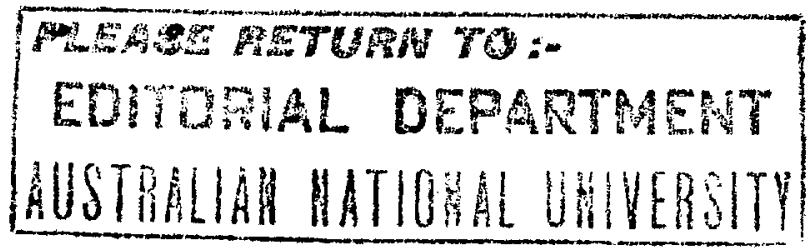

REOOMUEUDED RETAL PROE \& 7.95 PBSHOOH OATE 29.3.74 


\section{Aborigines in Australian Society 11}

A series sponsored by

The Academy of the Social Sciences in Australia 


\section{ABORIGINES IN THE NORTHERN TERRITORY CATTLE INDUSTRY}

\section{Frank Stevens}

With drawings by Bruce Petty 
First published in Australia 1974

Printed in Australia for the

Australian National University Press, Canberra

Overseas

North, South, and Central America: International Scholarly

Book Services, Inc., Portland, Oregon

Southeast Asia: Angus and Robertson (S.E. Asia)

Pty Ltd, Singapore

Japan: United Publishers Services Ltd, Tokyo

(C) The Academy of the Social Sciences in Australia 1974

This book is copyright. Apart from any

fair dealing for the purposes of

private study, research, criticism, or review, as

permitted under the Copyright Act,

no part may be reproduced by any process without written permission.

Inquiries should be made to the publisher.

ISBN 0708106986

Library of Congress Catalog Card no. 73-88685 


\section{ABORIGINES IN THE \\ NORTHERN TERRITORY \\ CATTLE INDUSTRY}

NOTE ON THE SERIES

The Social Science Research Council of Australia (now The Academy of the Social Sciences in Australia), which was founded in its present form in 1952, is the national organisation of social scientists. Some of its major functions are:

to encourage the advancement of the social sciences in Australia;

to act as a co-ordinating group for the promotion of research and teaching in the social sciences;

to foster research and to subsidise the publication of studies in the social sciences.

To these ends the Council has sponsored a number of major research projects. The first related to the role of women in public and professional life in Australia and was carried out by Mr Norman MacKenzie. His report, together with the associated study of the legal status of women in Australia by Dr Enid Campbell, was published in 1962 in a book, Women in Australia (F.W. Cheshire Pty Ltd, Melbourne).

The second major project, carried out by a group of economists, was concerned with the Australian taxation structure and under the authorship of R.I. Downing, H.W. Arndt, A.H. Boxer, and R.L. Mathews, the results were published in 1964 in Taxation in Australia: Agenda for Reform (Melbourne University Press, Melbourne).

In 1963 the Council approved its third and most ambitious major project, Aborigines in Australian Society, with the broad objectives of:

elucidating the problems arising from contacts between Aborigines and non-Aborigines and formulating policy implications from these; 
drawing together existing knowledge in various parts of Australia and undertaking such further original research as can be carried out over a period of three years.

In May 1964, Mr C.D. Rowley, formerly Principal of the Australian School of Pacific Administration in Sydney, was appointed Director of the Project, to work under the general guidance of a Project Committce appointed by the Council. The volumes now being published represent a major research enterprise in which many social scientists collaborated over the length and breadth of Australia.

However, the whole enterprise depended in very large measure on the magnificent support received, from the outset, from the Myer Foundation of Australia and the Sidney Myer Charity Trust. The Council wishes to acknowledge its gratitude for their generosity.

W.D. BORRIE CANBerra 1973 
Jike most Australians, I grew up in an urban environment with little $\mathcal{L}$ experience of rural areas and no contact with Aborigines. During my childhood, in the 1930s, religious sectarianism was such that social tranquillity was rarely breached even by the need to adjust to people of different beliefs, let alone other cultures. Indeed, in American terms, my family background was white, Anglo-Saxon and Protestant, and so too was that of most of my friends.

Australia rarely forced one to adjust to conflict, whether religious, economic, intellectual, or racial. Social stratification ensured that diverse groups rarely came into contact with one another. The welldeveloped system of church schools removed the necessity to examine opposed ethical views. Southern European migrants, although considered capable small businessmen, hardly warranted greater attention than the rather shallow jokes which emphasised their physical appearance, pattern of work, or unusual accents. The Chinese were always referred to as 'Chows' in the most derogatory manner and a standing family joke was made when my mother's maiden name was spelt Ha Lee, instead of the more acceptable British style of Hale.

This is not to suggest that my family was illiberal. On the contrary, my father was a long standing member of both the trade union movement and the Australian Labor Party. They simply reflected the typical values which had grown up in Australian working class families through the peculiar combination of geographical isolation and a competitive economic environment. The little attention that had been given to race prejudice since the turn of the century did not mean that it was not present -more that the problem was kept at arms' length and the major potential sources of conflict were precluded by a strictly interpreted racist immigration policy.

Indeed, the 'White Australia' policy was a cornerstone on which the nation was founded. It reflected too much in the personality of Australians to be written off as a political or economic expedient, as some writers are prone to do. When the A.N.Z.A.C.s stormed the heights of Gallipoli, 
defeat was turned into victory in the minds of most Australians because of the tragic toll of 'oriental' lives which was exacted. It is significant that of all the battles in which my father took part during World War I, the only one discussed in family circles was Gallipoli-the one which had least personal importance to him.

That race prejudice has been a considerable factor in the development of Australian national attitudes can be seen if we measure the significance of the concept of the 'Yellow Peril' in national politics and appraise the real dangers that proximity to Asia posed in the terms of national survival. The racist basis of Australian political attitudes was founded, of course, on the short term expedients of economic opportunism. The outbursts against the Chinese in the goldfields of the nineteenth century were based, in the main, on envy of the products of their labours. The continuing opposition to the employment of Chinese in the furniture trades was fostered by those who could not match oriental craftsmanship and energy. In the same way, too, southern Europeans may have been good fruit-shopkeepers but hardly decent neighbours.

Australian attitudes to the original inhabitants of the continent had their roots in similar ignorance. Brutal decimation had removed the problem from the minds of most city dwellers. Indeed, I can recall only one conversation in my family circle concerning Aborigines. This related to Toby, who was an indigenous employee of my uncle, a peanut farmer in north Queensland. My mother and father had visited him shortly after World War II, and came back to Sydney with two main stories, the shooting of brumbies (wild horses) and the treatment of Toby. As my parents were gentle people, they probably believed the two matters to be somewhat related. They were upset by the senseless slaughter of the horses and the cruelty to Toby, who, from all reports, was an industrious and colourful confidant of my uncle. Apparently Toby played the role of the family dog, never passing beyond the kitchen door to get his food and always ready with a willing ear to listen to the troubles of the aliens' battles with nature.

The ignorance of Australians in relation to race contact was also reflected in the political and educational structure of the nation. I received no instruction about Aborigines at school. The only reference to them that I can remember was in the well thumbed pages of H.H. Finlayson's book, The Red Centre, in the school library. One page was particularly defaced. It contained a photograph of naked Aboriginal women. The photograph became the continued object of schoolboy pranks. That juvenile imagery is readily converted into political form was shown by 
the advice of a relative, when I first started to work in north Australia: "When you are in the bush, always make the blacks walk in front of you. You can't trust them from behind'.

The fear one has of people of different genetic and ethnic background from one's own might account, to some degree, for the late development of many branches of social science in Australia. Anthropology, as a discipline, has only been taught at the University of Sydney since 1923. It did not become a subject at Queensland, where most Aborigines live, until 1964. Indeed, it was ridiculed as an academic discipline at official level in that State until quite recent times. ${ }^{1}$ There is still no well-developed teaching program in race relations in Australia and the social studies curriculum in schools is currently being upgraded to provide balanced reference to the racial heritage of the continent. Indeed, sociology as a discipline has had a hard task establishing itself as a university course and many tertiary educational institutions still do not offer the subject. Because of this, post-graduate work in many interdisciplinary areas has been considerably restricted. Race relations research, accordingly, has been minute. Even in the important area of industrial relations, in which the nation considers itself an innovator, few post-graduate degrees have been awarded.

In similar fashion, most of the academic writing on Aboriginal affairs has concentrated on traditional society, although it is fair to say that the contributions in this area have been considerable. However, until the 1960 s the problems of contemporary adjustment of indigenes were studied mostly by ministers of religion and untrained social workers. It was at that time that I developed an interest in the subject. Stimulation, however, was gained from outside the country.

During 1956 and 1960 I worked in California in various capacities, but mainly as a carpenter or rural worker, chipping weeds out of irrigation channels on cotton plantations. In these jobs I developed close contact with various deprived ethnic minorities. They included Negro, Mexican, and Caucasian Oklahoman semi-skilled labourers. In the cotton fields, in particular, the problems of the American poor became my own. We were all concerned with the question of survival. Despite my white Anglo-Saxon Protestant heritage, I had become a foreigner. My experiences at that time encouraged me to turn my back on American society and return to Australia.

\footnotetext{
'See my paper, 'Parliamentary Attitudes to Aboriginal Affairs' in F.S. Stevens (ed.), Racism: The Australian Experience, vol. 2, Black versus White, Australia and New Zealand Book Co., Sydney, 1971, particularly p. 122.
} 
Shortly after arriving home, I became associated with an American owned organisation which was engaged in land development in north Australia. After assuming responsibility for its economic and industrial policy I travelled widely in my capacity as a director of the company. One of the major problems with which we were faced in the area was labour turnover. As it happened, one of our operating sites was close to an Aboriginal settlement, and the possibility of employing native labour was discussed at board level on a number of occasions. To gain information for these meetings I frequently discussed the value of Aboriginal labour with pastoralists in the region, but never with the Aborigines themselves. The pastoralists' responses to my questions reminded me greatly of my Californian experiences, only here my role was reversed.

The Aborigines, I was informed, were lazy, incompetent, dirty, untruthful, alcoholic, and of low intellect. As the company was operating sophisticated diesel electric equipment, I asked in particular about their mechanical aptitudes. To employ them on moving machinery would lead to disaster, I was assured, partly because of their 'irresponsibility' and partly because of their 'lack of mechanical ability'. My special interest in this area encouraged me to draw my informants out at greater length. It was here that the similarities with California began to show.

Pastoralists in north Queensland believed that Australian Aborigines were impeded in their work by exactly the same failings that the Californian cotton farmers had attributed to Negroes, Mexicans and Oklahomans. It seemed to me that the cotton farmers' allegations were not true, particularly when I was lumped broadly into the same category. Regardless of what I thought of my coloured fellow workers, the complaints seemed to have no real foundation in relation to the Oklahoman employees, where cultural background did not differ greatly from that of the men who were making the complaints against them. The significant difference scemed to be in their mode of dress, accent, and level of literacy. How could it be, I wondered, that Australian Aborigines displayed similar industrial characteristics to Caucasian Oklahoman workers in California? It was clear that it had little to do with the question of race, as the pastoralists kept asserting. Only the social relationships were comparable.

Of particular interest in this respect was the role being played on our development sites by semi-literate bush workers. These people undoubtedly possessed considerable mechanical intuition and were highly praised by the pastoral employers in the various districts. Intellectually and socially, however, there was very little difference between them and the 
Oklahomans I had left in California. Indeed, the total work environment reminded me greatly of California and I began to think of other similarities. However, except for a small study entitled Bush and Backwoods, ${ }^{2}$ I could find no comparative material on which to base any further analysis.

At the same time as the development of my interest in this subject, the Social Science Research Council of Australia (now The Academy of the Social Sciences in Australia), had also recognised the gap in our knowledge and through a grant from the Myer Foundation, commissioned C.D. Rowley to lead a research project on the problems of contemporary adjustment of the Aborigines. He encouraged me to extend my inquiries. Briefly, it seemed to me that native policy in Australia had been founded on the same false premise that had conditioned American racial attitudes for so many centuries-belief in the intellectual inferiority of people of different social, cultural or ethnic origin. From this simple observation a host of important considerations followed, many of them related to the history and development of the administrative system which supported the policy, and the philosophical basis on which it was founded. A quick review of the literature showed, however, that no well integrated history of native policy in Australia existed. Certainly there had been no deep analysis of the reasons for the application of this policy to Aborigines, nor of the results. Working alongside Rowley, I began slowly to piece together the history of native policy in the major area of my interest, north Australia, in order to understand how this affected relationships in the field. ${ }^{3}$ I then made a number of field trips into the area and lived with Aboriginal and European groups for periods of up to six months, to see how, in fact, policy was executed.

I was particularly interested in the response of the indigenes to the administration and implementation of policy, since these were two of the major gaps in our knowledge. Because of almost total illiteracy amongst the Aborigines, there was no possibility of their reactions to the inroads of Europeans being determined from written records. This had to be pieced together from conversations in the freld.

After my first field trip, I concluded that more was wrong with the application of our official policies towards Aborigines than mere maladministration, which was the constant complaint of interested partics. It

${ }^{2}$ H.C. Allen, Bush and Backwoods: A Comparison of the Frontier in Australia and the United States, Michigan State University Press, East Lansing, 1959.

${ }^{3}$ See my papers, 'Parliamentary Attitudes to Aboriginal Affairs', also 'Aboriginal Labour Policy in the Northern 'Territory', mimeo, Department of Economic History, Australian National University, 1967; 'Native Policy in Western Australia', mimeo, Department of Economic History, Australian National University, 1967. 
was obvious that social, economic and political relationships between the two groups took place in an atmosphere of prejudice as deep as any I had experienced in the United States. However, as considerable time, money, and energy had been spent on trying to overcome some of these difficulties, I began to look further. I could understand how the government could erect a system of racial administration containing inherent conflict whilst many of the principals involved continued to adhere to outmoded concepts of organisation and racial inequality. The work of Tatz clearly set this out. ${ }^{4}$

Although I have had no anthropological training, and to avoid expressing opinions on matters which rest in that area, I found that the work of anthropologists had an important influence on Aboriginal policy, particularly since the 1930s. Further research showed that the development of anthropological study and its impact on government decision-making originated, mainly, from the School of Anthropology at the University of Sydney. Professor Elkin, the doyen of Australian anthropologists, who was the head of the school for some thirty years, has had a remarkable effect on the development of Australian attitudes towards Aborigines. Apart from being the principal scholar, writer and educationist in this field, he has been active in an effort to have his work translated into social change. Indeed, since 1935 Elkin's influence on Aboriginal affairs has been unique.

It was necessary, then, that I should become involved in a consideration of the accuracy of his analysis of contact between the two races. Fortunately, he had set this out in almost schematic form in 1952, allowing ready comparison between theory and fact. I was interested, in the main, to determine how faithfully his work described the industrial conditions of Aborigines and to see what additional understanding this would contribute to my appreciation of the situation.

Following my third year of field work, I was able to fill in some of the gaps in my broader understanding of the situation, and came to the conclusion that the erroneous basis of the Elkin analysis was, in fact, one of the major causes for the failure of Aboriginal policy in north Australia. The reasons for this conclusion are contained in the following pages.

Santa Cruz, California,

F.S. 1972

${ }^{4}$ C.M. Tatz, Aboriginal Administration in the Northern Territory, Ph.D. thesis, Australian National University, 1964. 
$A s$ my interest in the pursuit of academic inquiry on the question of A Aboriginal labour in Northern Australia now stretches over some ten years it would be difficult, if not impossible, for me to provide proper acknowledgment to all of the people who have assisted me in the formulation of my ideas during that period. However, as far as the present study is concerned, numerous individuals have contributed in various ways and have earned my gratitude, as well as the small recompense which might be derived from this acknowledgment. My real debt is much greater, of course, than that which can be met in this way.

Firstly, Professors C.D. Rowley and N.G. Butlin were primarily responsible for the initiation of my full time work in the area of Aboriginal labour studies and their influence has been carried over into the completion of the final study. Their appreciation of the difficulties of working with an illiterate people in a poorly documented field has been a source of considerable encouragement. Professors C.M. Tatz and F. Gruen provided direct support in the techniques and methodology of developing 'attitudinal' material into a more substantive format. Their assistance and participation during part of the freld work carried out by me is referred to in greater detail in the chapter entitled Method.

Many individuals assisted me in the more mechanical tasks of preparing the manuscript, transcribing the hours of tape recordings and marshalling the statistical information on which the main foundation of the study is based. Particular acknowledgment, in this respect, is due to Mrs Christine Hartley. She laboured on, frequently in my absence, bringing order out of the chaos of my typing. The staff of the office of the School of Economics at the University of New South Wales were also extremely helpful in the provision of similar facilities.

Production of the manuscript was considerably assisted from funds provided by both the Commonwealth Office of Aboriginal Affairs and The Academy of the Social Sciences in Australia. Without this help the burden of producing the study in its final form would have placed a heavy strain on my own savings. 
The editorial staff of the Australian National University Press and Professor H. Burton of the Academy of the Social Sciences in Australia contributed many ideas to layout and presentation.

My brother, Clive Stevens, Senior Lecturer in the School of Architecture, University of New South Wales, kindly drew the property maps and Mr Edgar Ford, of the Australian School of Pacific Administration, Mosman, N.S.W., drew the regional maps, where they are not otherwise acknowledged.

Mr Bruce Petty, cartoonist with the Australian newspaper, Sydney, kindly allowed me to use his pen sketches of rural life in north Australia. It is hoped that this brilliant contribution will assist in appreciation of the pathos of indigenous society in the broad expanses of Australia's north.

As is usually the case with those who engage in extensive periods of field work, my family has suffered from my long absences away from home. I am hopeful that they will be partly rewarded in the knowledge that completion of the study will contribute in some small way to the development of racial tolerance in Australia.

Except for publication of a series of rather disjointed, and possibly disparate papers, the present work would never have been completed without the support and interest of Professor S. Encel of the University of New South Wales. He was able to isolate consistent themes in my many papers and suggest more cohesive treatment.

Finally, my gratitude should be extended to the many hundreds of people of north Australia, both black and white, who have contributed to my work. I am hopeful that completion of this aspect of my studies will assist them in finding both harmony and justice. Should this not be the case, as with errors of omission or commission, I have only myself to blame. 


\section{CONTENTS}

Note on the Series by W.D. Borrie v Preface vii

Acknowledgments xiii

Method · 1

Who was an Aboriginal Worker? 11

3 The Legal Conditions of Employment 18

4 The Work Force 26

$5 \quad$ Suitability of Aboriginal Labour 57

6 The Station Community 103

7 Aboriginal Attitudes 152

$8 \quad$ Individual Employee's Experiences 163

9 The Aura of Brutality 184

10 The 1965 Equal Wages Case 189

Appendix I Interview Guide 206

Appendix II Mail Survey 211

References 215

Index 223 
Part-Aboriginal employment and wage structure

Aboriginal employment and wage structure

Aboriginal maintenance costs on a Northern Territory cattle station

Mean weekly consumption of foodstuffs per head

Aboriginal wages and sustenance costs 


\section{MAPS}

1

Estimated distribution of Aboriginal population in 1969

2

The Northern Territory

endpapers

Northern Australia rural population

28

3

4

King Ranch, Brunette Downs holding

46-7

A typical homestead community

105

5

Brunette Downs homestead area

130

143 
$\mathrm{T}$ he material contained in this book was collected during journeys through Queensland, the Northern Territory and Western Australia in 1965, 1966 and 1968. For the purpose of my research it was important that initial field work be completed before the calling of witnesses in the 1965 Arbitration Court case mentioned in the text, as the publicity given to the proceedings might have conditioned responses to the survey.

However, meetings of the employers' organisations being represented before the tribunal had already been held to consider policy and appearances relating to the case. By the time of the second visit the case had been concluded, and the industry was beginning to feel the impact of industrial indiscipline which led to the series of strikes by Aboriginal workers at Wave Hill and surrounding areas.

As several employers formally interviewed on the first occasion held responsible positions in these organisations, their replies could have been affected by the impending proceedings. Similarly, all employers were faced with the possibility of higher labour costs if their case was unsuccessful. Some of them may have desired to use the survey as a vehicle for influencing the proceedings although we explained to those interviewed that we had given an undertaking to the various cattlemen's associations connected with the industry that we would not allow any material collected to be used in this way. However, as the analysis of the results of the survey indicate a climate of opinion different from that presented by the employers' counsel to the court, there is little evidence to suggest that the short term advantages of court proceedings conditioned the replies. 
All the formal interviews conducted were carried out with the assistance of the Interview Guide attached hereto (Appendix I). It was designed by Dr Colin Tatz of the Department of Politics and Economics, Monash University, at the request of the United Graziers' Association of Queensland, which was faced with a similar task of obtaining information concerning problems of Aboriginal labour engaged in the cattle industry of that State. The Guide was the subject of several discussions with social scientists in Melbourne who suggested various methods of ensuring that the answers given genuinely reflected the opinions of the people to be interviewed.

As a result of their criticisms, recall questions on vital subjects were included in the schedule.

The discussion outline consisted of fifty-four questions and was administered in the presence of the three persons engaged in the 1965 survey. The other two people involved in the first journey were Dr C.M. Tatz, mentioned above, and Professor F. Gruen, Professor of Agricultural Economics at Monash University.

Although only one of the interviewers filled in the Guide, as discussion developed each of the other members of the team placed himself sufficiently close to the scribe to note his interpretation of the interview. Where there was any difference of opinion the question was asked again and the copy corrected. Where any of the recall questions contradicted earlier statements it was our habit to retrace the discussion to that point to clarify this discrepancy by further questioning.

It is of interest to note that we were often called upon to check consistency. However, we came to accept the fact that a change in the nature of replies to similar questions did not necessarily mean that a person was trying to mislead the interviewer. Very often it meant that he was either confused about the position, reflecting other people's opinions without due consideration of his own position or simply expressing what he considered to be a 'generally accepted fact'.

In 1966, I returned to the Northern Territory with the object of making contact with employees, both white and Aboriginal, on the cattle stations previously visited. However, the Northern Territory Pastoral Lessees' Association, supported by the Northern Territory Administration, opposed the continuation of my survey. ${ }^{1}$

However, regardless of this official opposition, I was able to retrace

1 Northern Territory of Australia Administrator's letter on private file, 28 June 1966, and te lephone conversations with Mr L. de Voss, Secretary of the Northern Territory Pastoral Le ssees' Association at that time. 
most of my steps of 1965 and gained, with certain limitations, reasonable access to employees within the industry. Although I had to abandon my intentions to use a formal interview schedule aimed at determining the attitudes of employees towards their employers, because of the tense state of industrial relations at the time, a considerable amount of material was collected on tape.

My first attempts to interview employees on Northern Territory cattle stations on this second visit were met by a response on their part which indicated a desire to join the strikers in the Wave Hill district. As I did not want to allow my interviews to affect an already delicate situation, I abandoned any attempts at formal techniques and concentrated on making contact with various group and opinion leaders. My efforts in this direction were considerably assisted by a full-blood Aboriginal acting as an intermediary.

Mr Christopher Geoffreys of Mitchell River Mission, North Queensland, accompanied me throughout the Northern Territory leg of my journey. Although there was little or no tribal affinity between the Aboriginal groups we contacted and the Mitchell River people, I was impressed with the spontaneous reception that Christopher received wherever he went. This made initial contact much easier.

Finally, as I wanted to consider the entire social and economic conditions of pastoral employees in northern Australia, I needed to obtain some understanding of the impact of the settlements which were run by various administrations as alternative places of residence for Aboriginal cattle station dwellers. Although I was fortunate in visiting all but one of the missions and settlements in the Northern Territory and Queensland, attempts to obtain permission to enter the Arnhem Land Reserve were not successful. ${ }^{2}$

THE SAMPLE

The sample of stations to be visited was drawn up on the basis of suggestions made by the Secretary of the Northern Territory Cattle Producers' Council and the Secretary of the Centralian Pastoralists' Association. Although they do not represent a statistical random sample, the stations were drawn from every administrative and geographical division of the Territory.

Limitations of both time and travel made it necessary for the selection

2 Northern Territory of Australia Acting Administrator's letter on private file, 10 October 1967. See also 'The Unpermitted Man', Territorian, December 1967. 
of the stations included in the survey to be purposive. As well, to ensure that a reasonable balance of the various methods of management was included a prior knowledge of the ownership characteristics of the stations to be visited was desirable.

Thirty stations out of a total of 210 individual leascholders in the Northern Territory were contacted and their managers or owners interviewed. As the term 'lease' in the Northern Territory embraces only one area of land, several of which may be held together to make up one 'station', the arithmetic basis of my projections has been determined by 'land area held' and not leases. This is discussed at greater length in the study (see pp. 29-30).

Although it is normal in a survey of this nature to disclose the names of the locations at which the interviews were conducted, because of the smallness of the sample and the fact that every station visited violated Northern Territory Ordinances in some way, and comment on this is made in the text, the names of the properties are not disclosed.

The co-operation of pastoral lessees or their managers had an important bearing on the results of the survey. Because of sparse population and vast distances, figures produced on various aspects of rural life in the Northern Territory are always the result of official inquiry and are rarely open to private verification. Pastoralists recognise an obvious affinity between the various government agencies and the revenuc-collecting branches, and are normally fairly cautious about any information that they provide to official bodies. However, I found that our association with university research encouraged a higher degree of frankness to the point where statements concerning the economics of the stations were normally supported by inspection of the books of accounts. Frequently, it was necessary for some managers to explain the real meaning of their accounts, which had been prepared for another purpose.

As both Berndt ${ }^{3}$ and Tat $z^{4}$ had noted various attempts by property owners to mislead the authorities in completing official returns, any invitation by the manager or owner to discuss the relevance of the station's financial and accounting position was accepted and the information given verbally by the owner was taken as a truthful statement of the situation. It is possible, of course, that some information given to the project was equally meant to deceive. However, the fact that we had no official associations and tabulated our own information without

${ }^{3}$ R.M. and C.H. Berndt, 'A Northern Territory Problem: Aboriginal Labour in a Pastoral Area', typescript, Department of Anthropology, University of Sydney, 1948, p. 44.

4. Tatz, Aboriginal Administration, p. 57. 
appending the signatures of those interviewed would seem to make this less likely.

Consequently, although it will be seen that the figures which were collected were, in some instances, at variance with official publications, the difference might not necessarily be due to the inadequacies of our sampling.

Because of the variation between our figures and those issued publicly, I took the precaution, on returning to Canberra, of forwarding a brief questionnaire to the persons interviewed (see Appendix II). Twenty-thr ee out of the thirty stations' managers who were interviewed returned the forms. On checking the information set out in the completed forms, little alteration in the original collection of figures was found to be necessary.

\section{CONTACT WITH EMPLOYEES}

The intention of the first survey was primarily to determine the attitudes of employers towards their employees. The study techniques demanded a considerable amount of control on the part of the interviewers and it was important that good relationships should be maintained with the management. Because of the size of the team and the method of introduction, we were virtually obliged to accept the managers' or owners' offers of hospitality together with whatever limitations of decorum, contact or movement this demanded. In considering the overall environment of native employees on the station this method did have limitations.

For example, on all of the stations our presence was closely watched by members of the Aboriginal camps. Given the limited contact with the outside world, the arrival and departure of guests was somewhat of a major feature in the social day of practically all of the members of the station community. For the homestead domestics it meant the preparation of sleeping accommodation and the setting of another place at the homestead table. This adjustment in the working day was sufficient for the question to be raised as to whom the parties visiting the station were. Were they simply friends of the family or had they come on business, possibly bringing news of a mob of cattle on the move with their attendant menfolk? Possibly they were windmill salesmen going out to have a look at a distant bore and would be in contact with the people at the further end of the run. 
come from. I informed him that we were from a umiversity, but my information left him a little puzzled. I eventually explained to him that

In our case, as I later found out from discussions in the camp, speculation about our first visit was that we were either police or, at the very least, 'gubment men'. The Aborigines' opinion of our position and intentions was reinforced by the enclosed style of our Landrover, the two-way radio in the cabin and the 'strange' A.C.T. number plates. Their speculation was no doubt further increased by the dress of the interviewers: one in a uniform-like 'bib and brace' overall and the other two in normal suburban clothes.

During the first visit managers were clearly informed of the nature of the survey and expected us to interview them at our earliest convenience. In most cases they looked somewhat askance at our request to talk to other members of the staff and normally insisted on accompanying us during contact.

Because of our intentions and the short duration of our visit, little time was spent in the Aboriginal camp. Further, diplomacy seemed to demand that most of our time be devoted to the station executives, as it was their opinions that we had stated we were interested in obtaining. On every station, however, I made a point of visiting the Aboriginal camp and inspecting the housing facilities. On these tours I was normally accompanied by the manager and only occasionally had a chance to pass normal pleasantries with the indigenes. However, an interesting exchange took place on one station. It encouraged me to give consideration to broadening the inquiry.

During the visit to one large company-owned station we sought permission from the manager to inspect the native camp area and he approved our tour. In reply he said that if we wanted to know anything we should approach 'King Brumby', a colourful individual referred to elsewhere in this study. On approaching the camp, King Brumby came forward to introduce himself and asked us if there was anything that we wanted to know. We said that we were just looking around but would be grateful if he would accompany us to answer any questions. We inspected the buildings in the native camp area and the small garden which he had been tending, and eventually began to walk back towards the homestead. During the tour a number of male Aborigines had gathered some distance from us but did not attempt to make any contact. Whilst walking back from the native camp I dropped behind slightly from the rest of the entourage and was approached by one of the small group that had been watching our progress. He asked me where we had 
the university was in Canberra. He seemed to show immediate understanding and wanted to know what our visit was all about. I did not say much to him, merely explaining that we were interested in the work that Aborigines did on the station. To my surprise he retorted: 'Well, take no notice of that old bastard Brumby. He's a bloody liar. Will tell you anything. If you want to know what goes on around here you ask me'. As our group was by then approaching the homestead my informant dropped behind again and we walked into the fenced garden area.

Later on in the day I had the opportunity of discussing this exchange with the manager. He informed me that Brumby had been the traditional intermediary between the management and the Aborigines' camp, but that more recently there had been a "bit of dissent amongst the young bloods'. The manager continued that when he had witnessed a change in the authority structure of the community about two years previously he had endeavoured to restrict it by sending the person referred to by me to one of the outstations. ${ }^{5} \mathrm{He}$ was, however, unable to compel him to stay there and he had drifted back to the homestead again.

From this brief exchange and further experiences, particularly at a country race meeting, at which I was approached by a number of Aboriginal stockmen who had remembered our visit to their station, I concluded that the Aboriginal employees were far from being the amorphous inarticulate group which management normally made them out to be. Indeed, in the contact at the race meeting the group mentioned had concluded that we were 'gubment men' who were going to bring them Award wages. Their inquiry was as to the date of their arrival.

On my return to Canberra I discussed some of these experiences with associates, and it was decided that I should go back into the field during the following year in an endeavour to make contact with employees in the industry.

Although my entry into the field on the second occasion was resisted by the Northern Territory Pastoral Lessees' Association, I felt that the presence of an observer during the period of change, which the secretary had assured us was taking place, might produce some interesting information as to the social, economic and political consciousness of the employees.

The secretary of the employers' association believed that my presence in the area would only add additional problems to an already delicate situation. As the tone of the correspondence of the Welfare Branch also

"For convenience in working the large areas involved some stations have smaller homesteads located at strategic spots around the run. These are known as 'outstations'. 
reflected these views, and following a statement by one of the parties that he 'could not be responsible for my safety if I went to the Northern Territory' at that time, I hesitated to undertake the final journey. However, the official attitude seemed to soften and the journey was undertaken. It should be noted, however, that, compared with my first visit, in which company recognition had been given to the research, on the second occasion it was opposed by most of the major companies and the industry's official spokesman. In these circumstances initial contact with the managements of the properties promised to be an interesting experience.

\section{MANAGEMENT RESPONSE}

As I wished to spend a greater length of time on the properties than was previously possible, visits were made to only ten of the stations involved in the original survey. Difficulty in gaining admission was experienced in only two cases. All managers or owners, however, were hesitant about my requests.

Firstly, I introduced myself and reminded them of the visit of the previous year. I informed them that I was still continuing with the study and that I would like the opportunity of spending some time at the station with a view to observing the routine of work. Once I had established the fact that they were not opposed to my visit I then requested permission to make contact with the Aboriginal camp. At this stage resistance was met.

Most employers thought that the desire to give detailed attention to the camp was strange. One person even replied that he had informed me of the situation during the previous year, and that there was little more to find out. Those that were suspicious of my wish to make contact with the Aborigines had their fears increased by my next request.

In an endeavour to overcome the possibility of either being taken as a 'gubment man' or a confidant of the manager, I wanted to establish independence from the homestead. Consequently I requested permission to set up a camp in the Aboriginal area. Most cmployers were opposed to this. Two openly rejected the proposal, one insisting that I should sleep in the homestead grounds. The others accepted my compromise recommendation that $I$ should set up a camp in the direction of the Aboriginal residences, but not inside their delineated area.

I later established, however, that this independence from the homestead, as well as giving me greater access to the Aboriginal employees, 
also enabled greater freedom of movement amongst the white staff. Consequently, their opinions and attitudes were more readily forthcoming.

\section{ABORIGINAL RESPONSE}

In many of the interviews the response of individuals in the Aboriginal camp to being questioned on their opinions about working in the cattle industry was reserved. However, it was noted that in the main the Aboriginal residents on cattle stations of the Northern Territory were more open to approach, after even casual contact, than Aboriginal residents in town settlements in Qucensland. In the latter situation normally two, and sometimes three visits were necessary before any degree of rapport was established.

In the Northem Territory four factors contributed towards more rcady acceptance. Firstly, Christopher, who was a gregarious, guitarplaying, personable young man, befriended the local community. Little time seemed to elapse in almost every situation before somebody had accepted him into their kin or friendship circle. This considerably allayed their fears as to the intention of the party, as it gave us a channel of approach which might not have been possible under different circumstances.

Secondly, many of the employees remembered our visit during the previous year, and first contact was made through reference to this fact.

Thirdly, the establishment of a base near to their camp gave the Aborigines easy access to me, and they were openly offered hospitality whenever they approached.

Fourthly, the sharing of food, facilities and the camp with an Aboriginal established a pattern of behaviour which clearly marked the interviewer as a person of, at least, different social attitudes from the European management on the station.

Because of these four factors I was normally able to make ready contact with the members of the Aboriginal community, and very early in the association with any one individual was able to pursue inquiries to establish his value as an informant. Certain difficulties were experienced in establishing opinion leaders in any one group, and the informants most heavily relied upon were those more fluent in English. All of the Aborigines interviewed, however, had sufficient grasp of the English language to convey their meaning with sufficient accuracy for the purposes of the survey. 
As these conversations were tape recorded, they form a base on which to interpret the employment relationships within the industry as reliable, at least, as the more formal interviews with managers. 
ne of the greatest difficulties experienced by both employers and the Welfare Branch was to define exactly who was an Aboriginal employee. Part of the confusion was the result of the extremely complex set of laws which was developed during the 1950s and then partially abandoned during the early 1960s.

However, regardless of the law, cattlemen appeared to resolve many of their problems concerning race relations by applying a simple visual test-depending on the colour of the skin a person was more or less likely to be classified as 'an Aboriginal' or a 'white man'. Indeed, the Commonwealth Arbitration Court ran into some difficulty during the 1965 hearing when they endeavoured to define exactly who were the workers they were discussing in the application for equal wages. They approached the problem in this way:

Counsel for the Union: In case there is any ambiguity about the use [of the term] 'white man' in this connection-it may be that [counsel for the employers] and the witness are at cross purposes. In this district a half-caste counts for these purposes as a white man.

Witness: That is so. But this one was not a half-caste. ${ }^{1}$

As the term 'half-caste' was used in similarly loose vein, it was nearly impossible during a period of casual contact, and indeed sometimes even after lengthy association, to determine the exact genetic mixture of the person or group of persons being discussed. This confusion was high-

${ }^{1}$ Commonwealth Conciliation and Arbitration Commission, No. 830 of 1965, p. 255. Emphasis mine. 
lighted in a letter attached to the mail questionnaire used to check Aboriginal population numbers. The manager of a large station replied: 'I have filled out [the questionnaire] as things are today. Also I put some Abos in the part-coloured side but you can run them through the drafting yard and sort them out'. ${ }^{2}$

Not having the time to trace each person's racial background, I was forced into accepting the cattlemen's classification of their own workers. As many of the employers' attitudes towards their Aboriginal employees were determined by their own varying, and sometimes contradictory standards, and not by any legal or genetic formula, this loose procedure had to be sufficient for my purposes.

\section{THE OFFICIAL POSITION}

An 'Aboriginal', in the sense normally accepted in southern Australia, was a person who exhibited any patently Australoid characteristics through a combination of skin pigmentation, facial features or hair. Occasionally the classification hinged on the presence of one of these. People embraced by this broad genus in the Northern Territory could have found themselves covered by any three sets of industrial law. Further, their social, economic, and legal standing might have been affected by the individuals' ancestry, their personal history or the current standards of application of administrative policy.

\section{FULL-BLOOD ABORIGINES}

The Minister for Territories, Mr P. Hasluck, in 1952, foreshadowed the introduction of new legislation covering the legal status of persons of Aboriginal descent. The new policy was embodied in the Welfare Ordinance 1953-1960, and it set out a method of declaring certain indigent persons wards of the State. It also applied to them a standard of laws, both civil and industrial, different from those applying to other Australian citizens. The declaration, however, was supposed to be based on need, not race. ${ }^{3}$

Consequently, the Administrator of the Northern Territory, by recommendation of the Welfare Branch, was empowered to declare any person a ward who by reason of:

\footnotetext{
${ }^{2}$ Letter on private file, 10 January 1966.

${ }^{3}$ Paul Hasluck, Native Welfiare in Australia. Speeches and Addresses by the Hon. Paul Hasluck, M.P., Minister for Territories:, Paterson Brokensha, Perth, 1953, pp. 15 and 22.
} 
his manner of living,

his inability, without assistance, adequately to manage his affairs,

his standard of social habit and behaviour; and

his personal associations

stood in need of special care and assistance.

\section{THE ABORIGINAL WORKER}

At the time of drawing up the Register of Wards, as the list was called, the Director was precluded from including therein any person

... who under Part V of the Northern Territory Electoral Regulations [was] . . entitled to vote at an election of a member of the House of Representatives for the Northern Territory

or, except for the fact that he was under the age of twenty-one, "would... [have been] entitled to ... vote'. ${ }^{4}$

As Part $\mathrm{V}$ of the above Regulations excluded 'aboriginal natives of Australia', only these persons legally could have been declared wards. Because of this it was only possible to place full-blood Aborigines on the Register of Wards up to 1961 when the Welfare Ordinance was amended. However, although there does not seem to have been any court case to determine the exact definition of an Aboriginal, the Welfare Branch apparently based its classification on standards similar to those of the pastoralists, and included persons on the Register with little regard for their racial origin. ${ }^{5}$

Consequently, some people could have been on the Register illegally, but few employers ever seemed to care whether their employees were included or not. Indeed, because of the impact of the Nationality and Citizenship Act of 1948-55, making all persons born in Australia after 26 January 1949 Australian citizens, it was questionable whether the very foundation of the Register of Wards, in imposing restrictions on one racial group, was itself legal. ${ }^{6}$

In 1964 the Social Welfare Ordinance was introduced to repeal the Welfare Ordinance 'under which the majority of Aborigines were declared wards and ... therefore subject to certain restrictions' and to

4 Welfare Ordinance, 1953, S. 14.

5 See, for example, Commonwealth Conciliation and Arbitration Commission, No. 830 of 1965, T'ranscript of Proceedings, p. 504.

B B.E. Christophers, 'Northern Territory', in The Struggle for Dignity, Council for Aboriginal Rights, Melbourne, 1962, pp. 30 and 37. 


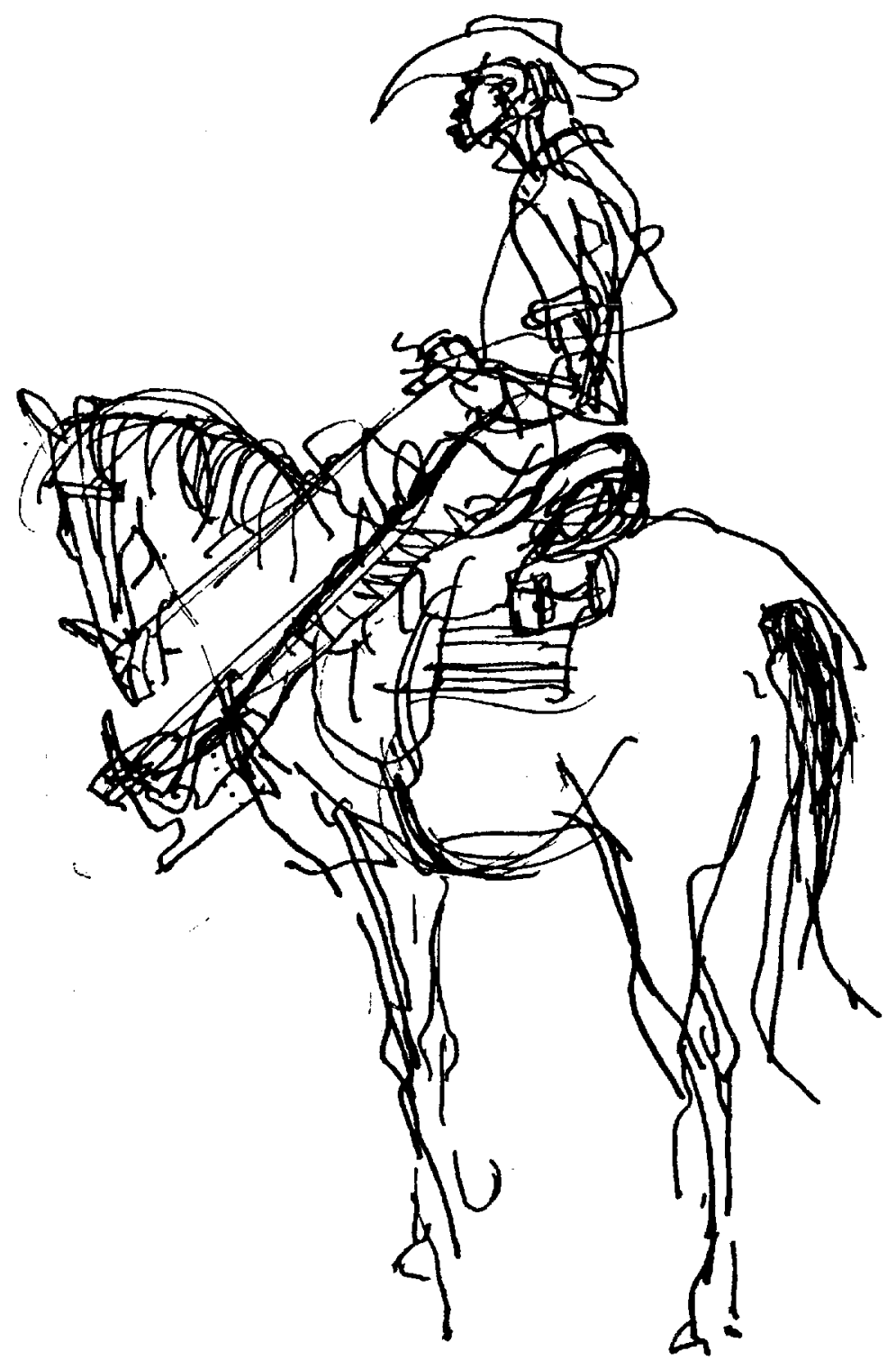


substitute 'a new Ordinance which [would] remove the concept of wardship' but leave the Director able to

$\ldots$ provide relief from poverty and hunger, and such other assistance as he [considered] necessary, to any person socially or economically in need. A number of other Ordinances [were] amended to remove restrictions placed on wards ... .

Of immediate concern was the amendment of the Wards Employment Ordinance 1953-62. That Ordinance was introduced to support the earlier legislation under the Welfare Ordinance and to lay down conditions of work for wards in the various industries of the Northern. Territory.

The original Wards Employment Ordinance contained a definition of a ward identical to that under the Welfare Ordinance of 1953. In the 1964 legislation the definition of a ward was changed to

a person who immediately before the commencement of the Social Welfare Ordinance of 1964 was a ward by virtue of the Social Welfare Ordinance 1953-63.8

Consequently, although the main measure laying down the conditions of wardship had been repealed, the persons to whom it applied were still enumerated for industrial purposes under the Wards Employment Ordinance.

The Register of Wards in 1965 was an out-of-date document. ${ }^{9}$ Those persons who were declared wards prior to the 1964 legislation continued to be wards for the purposes of the Wards Employment Ordinance 1953-64. Those persons who were not so enumcrated were theorctically outside the regulations.

There were three major reasons for the failure of the Welfare Branch to expand the Register of Wards so as to embrace all Aborigines in the Northern Territory. Firstly, the three years that it took the department to compile the original list indicated that the task of enumerating large numbers of illiterate individuals scattered across a vast area proved to be virtually beyond the resources of the department. ${ }^{10}$ Secondly, in 1961 the Administrator of the Northern Territory refused to accept an additional list of 3,000 persons for inclusion in the Register of Wards, as the

\footnotetext{
${ }^{7}$ Annual Report of the Northern Territory, 1963-64, p. 55.

${ }^{8}$ Wards Employment Ordinance, 1964, S. 4(b).

${ }^{9}$ Except for removal of names because of mistakes, double enumeration and death, it had remained unchanged since 1957.

${ }^{10} \mathrm{~F}$. Lancaster Jones, A Demographic Strvey of the Aboriginal Population of the Northern Territory, with special reference to Bathurst Island. Australian Institute of Aboriginal Studies, Occasional Papers in Aboriginal Studies, No. 1, Canberra, 1963, pp. 9-11.
} 
Welfare Branch could not give him an assurance that they were aware of the individual circumstances of each person warranting inclusion. Further, he ruled that in future no person under the age of fifteen or over the age of sixty-five years was to be included. ${ }^{11}$ Finally, the Supreme Court of the Northern Territory, in a case fought by the Welfare Branch in an endeavour to declare a particular individual against his will, rejected the government's attempts at racial prescription. Stating that 'it [was] humiliating for a man able to take care of himself to be told where he [could or could not] go, and what he [could or could not] do,' 12 it refused to place the person concerned under the jurisdiction of the Branch.

To add to the difficulties of determining wardship, the Register of Wards as it stood had 'many limitations' on its accuracy. ${ }^{13}$ Apart from the problems of recalling and recording such intimate details as parentage among mainly illiterate and sometimes polygamous people, duplication of names and lack of precision in the clerical entries placed severe doubts on its value as a legal document. ${ }^{14}$ Even so, the inclusion of a person's name was the foundation of a coloured worker's legal and industrial rights in the Northern Territory.

If we add to the confusion the fact that census takers appeared to have had their own definition of race $^{15}$ and the Registrars of Births, Deaths, and Marriages had another ${ }^{16}$ there was little wonder that cattlemen experienced difficulty at times in classifying their workers and had abandoned any serious attempt to do so.

On this complicated basis many efforts had been made to enumerate 'Aborigines' in the Northern Territory. The 1964 figure published by the Welfare Branch was 19,573.17 However, as this was calculated from an estimate of 18,920 Aborigines in 1961, compared with the census record of 19,704 in the same year, ${ }^{18}$ its accuracy was open to question. Using the Welfare Branch's estimate of the net increase in population per annum $^{19}$ and the 1961 Census figures, the 1965 Aboriginal population of the Northern Territory could have been more than 21,000 .

\footnotetext{
11 Commonwealth of Australia, House of Representatives Debates, vol. 36, 1962, pp. 415-16.

${ }^{12}$ Reported in the Canberra Times, 21 August 1962.

${ }^{13}$ Lancaster Jones, A Demographic Survey, p. 10.

${ }^{14}$ Ibid., pp. 8-12.

${ }^{15}$ Commonwealth of Australia, Yearbook, 1961, No. 47, p. 315.

${ }^{16}$ Letter on private file from District Registrar, Alice Springs, 10 December 1965.

17 Annual Report of the Welfare Branch, 1964-65, p. 12.

${ }^{18}$ Commonwealth of Australia, Yearbook 1965, No. 51, p. 299.

${ }^{10}$ Annual Report of the Welfare Branch, 1964-65, p. 12.
} 
As there were some 15,700 names on the Register of Wards in 1957, and allowing for deaths, somewhere between 5,000 and 6,000 persons of Aboriginal origin were outside the classification of 'wardship'. How many of these persons were resident on rural holdings was unknown. 


\section{THE LEGAL CONDITIONS}

The Wards Employment Ordinance and Regulations set out the 1 conditions of employment and rates of pay for all wards in the Northern Territory. Briefly, the relevant sections of the Ordinance and gazetted regulations were as follows:

\section{The Ordinance}

Imposed a penalty of up to $f_{100}$ on any person employing a ward except under the prescribed conditions of employment and at the prescribed wage.

Required notification to the Director of Welfare for any person engaging wards as employees for the first time.

Required filing of statutory returns concerning the numbers of employees, wages paid, sick leave and recreation leave taken, etc.

Made it an offence to entice a ward to leave his employment.

Made it illegal to employ a ward under the age of fourteen.

The Regulations

Required payment of money due in the same manner as other employees working under Awards.

Provided for payment for loss of work through wet weather.

Established the need for notification in case of injury.

Created a method of terminating employment.

Provided for the reimbursement of the employee for expenditurc incurred in getting to and from his place of employment. 
Established the hours of work.

Made provision for overtime.

Determined conditions for sick and recreation leave.

Required the establishment of a store where the ward could purchase merchandise at a 'price which did not exceed the cost'.

Established the standards of accommodation to be provided for employee wards.

Set out the quantity and quality of food to be provided.

Enumerated the nature of clothing to be issued to the ward, his wife and child. (Later converted to a cash payment.)

Provided for the establishment of special living areas for wards.

Determined a scale of payments to be made in the case of death or permanent injury.

Provided a schedule of wages payable as in Table 1.

Table 1: Schedule of wages for wards

\begin{tabular}{|c|c|c|c|c|}
\hline \multirow[b]{2}{*}{ Industry or calling } & \multicolumn{4}{|c|}{ Adult weekly rates* } \\
\hline & Males & \multicolumn{3}{|c|}{ Females } \\
\hline & E. s. d. & $£$ & & $\mathrm{~d}$. \\
\hline Agriculture & $\begin{array}{lll}2 & 8 & 3\end{array}$ & 1 & & 3 \\
\hline Building & $\begin{array}{lll}5 & 17 & 3\end{array}$ & & & \\
\hline Domestic & 283 & 1 & 5 & 3 \\
\hline Droving with plant and stock & $\begin{array}{lll}11 & 12 & 3\end{array}$ & & & \\
\hline Droving with plant only & $\begin{array}{lll}5 & 17 & 3\end{array}$ & & & \\
\hline Fishing & $\begin{array}{lll}4 & 14 & 3\end{array}$ & 1 & 5 & 3 \\
\hline Mining surface work & 283 & & & \\
\hline underground & $\begin{array}{lll}7 & 0 & 3\end{array}$ & & & \\
\hline Municipal & $\begin{array}{lll}4 & 2 & 9\end{array}$ & & & \\
\hline Pastoral & $\begin{array}{lll}2 & 8 & 3\end{array}$ & 1 & 5 & 3 \\
\hline Pearling & 4143 & & & \\
\hline Timber & $\begin{array}{lll}2 & 8 & 3\end{array}$ & & & \\
\hline Transport & $\begin{array}{lll}2 & 8 & 3\end{array}$ & & & \\
\hline Other & $\begin{array}{lll}2 & 8 & 3\end{array}$ & & & \\
\hline
\end{tabular}

* Northern Territory Government Gazette, 16 September 1959 and 19 December 1962.

Rates for juniors were established on the following percentage of the full adult rate for the calling:

$\begin{array}{llr}\text { Under } 17 \text { years of age } & 40 \% \\ \text { At } 17 \text { years of age } & 60 \% \\ \text { At } & 18 \text { years of age } & 80 \% \\ \text { At } & 19 \text { years of age } & 100 \%\end{array}$




\section{CONDITIONS OF EMPLOYMENT FOR NON-WARD ABORIGINES}

It is obvious from what has been said that some Aborigines were not wards and were consequently not subject to the Wards Employment Ordinance. The criteria of determination of a person's status as an Aboriginal in 1951 were little better than the rule of thumb method used by the Welfare Branch in 1957. Section 60 of the Aboriginal Ordinance, 1918-1954 provided:

In any legal proceedings or enquiry, whether under this Ordinance or otherwise, if the Court, Judge, Coroner, Magistrate, Justice or Justices, do not consider there is sufficient evidence to determine the question whether a person concerned in or in any way connected with the proceedings or enquiry is or is not an Aboriginal or halfcaste... the person is or is not of any specified sex, or is not under any specified age, the Court, Judge, Coroner, Magistrate, Justice or Justices, having seen the person, may determine the question.

Technically then, in one sense, nobody was an Aboriginal in the eyes of the law until he was declared to be so in relation to some proceedings under the control of the court, or a judge, magistrate, coroner, justice or justices. However, as distinct from the situation in 1959 when the Wards Employment Ordinance began to operate, the individual at least had the benefit of appraisal by the court. At the later date, had a Conciliation Commissioner been called upon to consider the applicability of the Award to Aborigines, he may have found that the prescriptive basis of the Register of Wards, determined as it was without personal appraisal, was inconsistent with this earlier ruling and a violation of natural justice. This, at least, was the Administrator's position when he was called upon to exercise his prerogative over the inclusion of additional names.

On the other hand, it was questionable whether the power to determine the rates for Aborigines had been taken away from the Commissioner, and whether in this respect his ruling was erroneous and might have been reversed on an appeal to the Arbitration Court. The grounds for such an appeal would have been based on the fact that, as Section 6 of the Northern Territory Administration Act 1910-1959 extended the power of the Arbitration and Conciliation Commission to the Territory, it had power to overrule inferior tribunals. Further, legislation in conflict with their determinations resulting from a subordinate authority of the Commonwealth, or legislation designed to establish minimum rates of pay and conditions inferior to their determinations for a particular industry might have also been upset (see p. 191). 
Be that as it may, the challenge was never made, and everyone operated in the belief that the determination of rates of pay and conditions under the Wards Employment Ordinance was a valid exercise of delegated authority. However, nobody seemed to give any consideration to the large group of persons who were growing up outside the Register of Wards. As all Awards in the Northern Territory were made as "common rule', providing application regardless of union membership, the group should have been engaged under the minimum conditions of the Cattle Station Industry (Northern Territory) Award. In this way at least one section of the people under consideration was denied the benefits of an Award wage which was legally their right.

\section{CONDITIONS OF EMPLOYMENT FOR WHITE WORKERS}

Most white employees were covered by the Cattle Station Industry (Northern Territory) Award. As every effective European rate was far above those set out in the Award, these conditions had little relevance to the employment of Caucasian workers.

The Cattle Station Industry (Northern Territory) Award appeared to have had a chequered history. The Award margins in 1965 were formulated in 1952 and the total was based on a 1961 Arbitration Court ruling covering a basic wage, including keep, of $f 10.4 \mathrm{~s} .8 \mathrm{~d} .{ }^{1}$ No application for marginal increases was made during the various extensions of Commonwealth Court rulings on margins in 1959 and 1963. Consequently, the Award was patently inadequate for the industry, and out of keeping with the then current standards of remuneration as well as with some broader concepts of industrial equity. A ruling by Commissioner Portus in 1952 might serve to emphasise this point.

In considering the margins payable for the classification of stockmen he ruled:

I consider the stockmen's work of mustering and branding cattle is more arduous and calls for more skill, than the work of a general station hand. I am not satisfied, however, that a long hours loading is justified in the case of other employees who work away from the homestead. ${ }^{2}$

The margin awarded was 10 s., although evidence was brought to bear of work programs extending over seventy and eighty hours per week. The Commissioner determined that the additional hours did not warrant

197 C.A.R. 713.

274 C.A.R. 511. 
special remuneration, and omitted to place in the Award a basic hours or overtime clause for stockmen.

The legal rates for the various categories of European workers were: ${ }^{3}$

General station hands

Stockmen

Head stockmen

Drovers with stock

Truck drivers

Bookkeepers or storekeepers

Tradesmen

f11. 5s.10d.

11.15s.10d. + 3s.6d.

per hour for night watch on cattle

f12 0s. Od.

f13.16s.10d. with plant only:

half rate

f12. 7s. 6d.

E12. 6s.10d.

E14.16s.10d.

As a comparison, the rates for certain urban workers in the Northern Territory were as follows:

Fitter (married) Darwin

Bricklayer (married) Darwin

£26.19s.

Carpenter (north of 20th parallel) 22 . 3s.

Excavator (north of 20th parallel) $f^{22.18 s^{4}}$

Possibly more significant for the establishment of new rates for rural workers in the Northern Territory were the Awards relating to the pastoral industry in other States.

A selection of these were:

N.S.W. Pastoral Employees (State) Award

General station hands

Queensland Station Hands Award

f,19. 4s. 2d. (all found) ${ }^{5}$

General station hands

Stockmen (Northern Division-

Western District)

Commonwealth Pastoral Industry Award

(Applicable N.S.W., Victoria,

Tasmania, S.A., W.A.)

General station hands f14.16s. (all found) $^{7}$

The Annual Report of the Northern Territory, 1964-65 emphasised a further discrepancy between the Award rate and actual payments by drawing attention to the fact that "it [was] the practice of many private

${ }^{3} 71$ C.A.R. 319,74 C.A.R. 513 and 97 C.A.R. 713.

4 Annual Report of the Northern Territory, 1964-65, p. 54.

${ }^{5}$ N.S.W. Industrial Gazette, vol. 155, pp. 818-19.

${ }^{-}$Queensland Industrial Gazette, vol. 56, pp. 683-4.

7106 C.A.R. 1124. Commonwealth Pastoral Industry Award, 1965. 
employers to pay above the Award rates' ${ }^{8}$ As will be seen from the results of the survey this was true in the cattle industry. In the case of some white employees, the 'above Award' payments were as high as $£ 18$ per week, making a total cash payment of up to $\AA^{30}$. This practice was also common in towns where the Awards were of more recent determination.

Although the question of management salaries is treated in greater detail later in the study, it is appropriate to mention here that, in the main, they seemed inadequate. They ranged from $\AA^{25}$ to $\AA^{80}$ per week for persons responsible for capital investment frequently in excess of $\{1,000,000$. The chief executive of many of the stations visited was, accordingly, sometimes paid less than skilled labourers in Darwin, although 'fringe' benefits and the provision of accommodation and food offset the disadvantage.

The Award concerning white pastoral workers, although rarely resorted to by either employer or employee, laid down other standards which, if applied to Aboriginal workers, would have had considerable impact on their standard of living. A comparison between the two sets of conditions might place the Aborigines' rewards for labour in better perspective.

CONTRAST BETWEEN THE LEGAL CONDITIONS OF EMPLOYMENT FOR WHITE AND ABORIGINAL WORKERS

The wage rates established under the Wards Employment Ordinance were maximum rates which could not be varied without the prior approval of an officer of the Welfare Branch (S38, penalty $f^{100)}$. The wages due to white workers under the Cattle Station Industry (Northern Territory) Award, were minimum rates. ${ }^{9}$

The rates payable under the Wards Employment Ordinance (with the exception of drovers) were approximately one-fifth of the rate payable to whites under the Cattle Station Industry (Northern Territory) Award.

Agreements for Aboriginal 'slow workers' to be paid below the prescribed rates of the Wards Employment Ordinance could have been negotiated by a welfare officer on behalf of the ward. ${ }^{10}$ To enable a white employee to be paid below the Award agreement had to be reached with

\footnotetext{
${ }^{8}$ Annual Report of the Northern Territory, 1964-65, p. 54.

${ }^{9}$ Commonwealth Conciliation and Arbitration Act, 1904-1964, S. 51, Gas Employees Case (1919), 13 C.A.R. 437, 1964.

10 Wards Employment Ordinance, 1959, S. 5 (3) (b).
} 
the union and approved by the Court. Failing such consensus, appeal could be made to a magistrate or police officer. ${ }^{11}$

The Award contained a penalty rate of $12 \frac{1}{2}$ per cent for short time engagements and mustering. ${ }^{12}$ The Wards Employment Ordinance contained no such provision.

Most classifications for white workers under the Award were granted a minimum working week of either 40 or 44 hours with provision for overtime penalty rates. ${ }^{13}$ The Ordinance provided a general reference to the hours of work for wards and stated that they shall be the same as for similar callings under the Award. ${ }^{14}$ As most wards were classified as either stockmen or general hands, and no minimum hours or compensation for overtime was provided in the Award for these categories, there was no limit to the hours or days per week which they might have been required to work. ${ }^{15}$

The Award provided for ten additional public holidays to be granted to white workers or, if worked, to be compensated by an additional day's recreation leave for each day so spent. ${ }^{16}$ The Ordinance had no such provision.

The Award provided for three weeks annual recreation leave and two weeks sick leave on full pay to be granted to white workers. ${ }^{17}$ The Ordinance provided for two weeks and one week respectively. ${ }^{18}$

The Award set out a standard of food 'to be of sufficient quantity, sound and well cooked and properly served' which aimed at an assured balance in nutritional range and variety. The list contained fifty separate items which were to be made available. ${ }^{19}$ The Regulations contained a 'scale of food to be supplied to wards' which embraced eighteen individual items, and specifying meat at $1 \mathrm{lb}$ per day. ${ }^{20}$

Provision for accommodation provided by both the Award and the Regulations under the Ordinance were similar. White workers, however, were to be provided-in addition to the facilities allowed to wardswith such comforts as 'delf plates and mugs' and artificial light. ${ }^{21}$

11 Cattle Station Industry (N.T.) Award (1951), 71 C.A.R. pp. 320-30, S. 10.

12 Ibid., S. 9.

${ }^{13}$ Ibid., S. 11.

14 Wards Employment Regulations, No. 4 of 1959, S. 14.

15 See survey results below, p. 38.

${ }^{16}$ Cattle Station Industry (N.T.) Award, S. 13.

${ }^{17}$ Ibid., Ss. 14 and 15.

18 Wards Employment Regulations, No. 4 of 1959, Ss. 18 and 19.

${ }^{19}$ Cattle Station Industry (N.T.) Award, S. 18.

${ }^{20}$ Wards Employment Regulations, No. 4 of 1959, Second Schedule.

${ }^{21}$ Cattle Station Industry (N.T.) Award, S. 17. 
The Ordinance made it an offence 'to entice or persuade a Ward to leave his lawful employment' (penalty $\left.f^{50}\right) .{ }^{22} \mathrm{~A}$ white worker was not subject to any such restrictions.

The Regulations under the Ordinance provided for the establishment of a native camp and prohibited the entry of any persons into the area with the exception of the owner of the station, the manager or persons specially authorised by them or a welfare officer (penalty $f_{100}$ or imprisonment for six months, or both). ${ }^{23} \mathrm{~A}$ white employee had no legal limitations placed upon his social life. 


\section{THE POPULATION}

O f the 19,334 Aborigines officially described in 1964 as living in the Territory, 6,499 were believed to be in pastoral or agricultural areas, 5,979 were referred to as being 'in contact with Missions' and 5,540 as being 'in contact with Government settlements and depots'. ${ }^{1}$

The term 'pastoral or agricultural areas' embraced persons who were outside the scope of this study. Firstly, some account had to be made of persons who lived in agricultural areas but who were not covered by any award for the cattle industry. Secondly, further consideration had to be taken of those Aborigines who resided on pastoral properties, but who, for all practical purposes, did not come into contact with the management or who were not thought of by the management as being part of their potential resident labour force.

The exact number of persons in these categories was unknown. However, Aborigines were engaged in agricultural employment in the north of the Territory, and I was informed of several groups resident on northern properties which virtually remained out of contact with the homestead. For the purposes of this study I have estimated this category to embrace some 1,000 persons, making approximately 5,500 Aborigines in contact with pastoral employers.

From official records it was difficult to obtain a clear picture of the structure of this work force. In 1959 the Welfare Branch of the Northern Territory Administration reported that:

Despite the existence of statutory provisions requiring employers of wards to submit employment returns ... the response has been poor to date and it has not been

1 Annual Report of the Northern Territory, 1963-64, p. 141. 
Table 2: Aboriginal population Northern Territory by 'contact' groups-31 December 1964

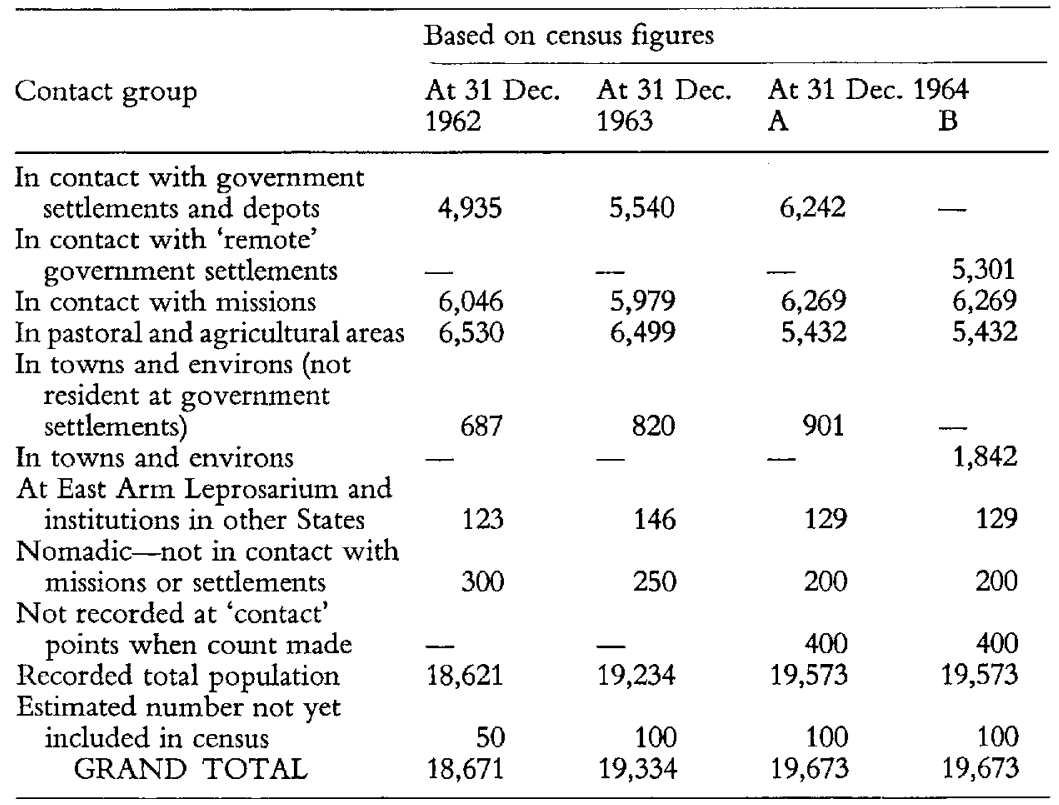

A Figures include all settlements together irrespective of location.
B Figures separate settlements according to location and include Darwin and Alice Springs Town settlements in 'town areas'.

Source: Northern Territory Annual Report of the Welfare Branch, 1964-65, Appendix A. Explanatory notes not included.

possible to develop any worthwhile or reliable statistics from the meagre data available. ${ }^{2}$

More recently, the branch reported that it is generally estimated [that] 1,200 to $1,500^{\prime}$ Aborigines were employed in the pastoral industry. ${ }^{3}$

The 1963-64 Annual Report of the Northern Territory was a little more positive in its figures and it made reference to "1,500 [Aborigines] . . . employed in the pastoral industry'. ${ }^{4}$

The Report of the Welfare Branch for the same year was not as definite as the Annual Report of the Administration, as it stated that the 'recording of population levels on individual pastoral properties was begun during the year'. ${ }^{5}$

2 Annual Report of the Welfare Branch, 1959-60, p. 21.

${ }^{3}$ Annual Report of the Northern Territory, 1962-63, p. 50.

4 Ibid., 1963-64, p. 63.

5 Annual Report of the Welfare Branch, 1963-64, p. 40. 


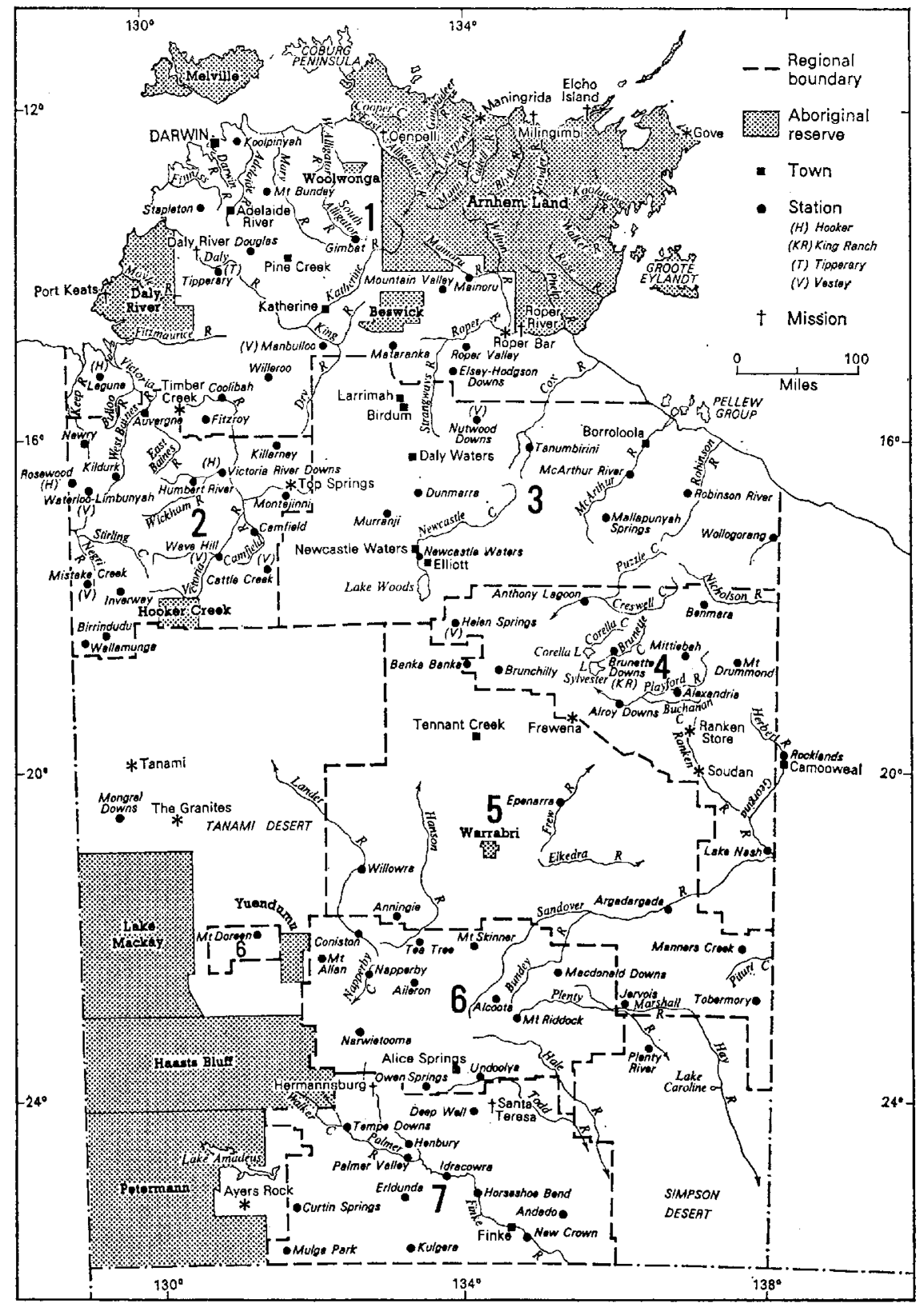

Map 2. The Northern Territory. (Reproduced from J.H. Kelly, Beef in Northern Australia, Australian National University Press, Canberra, 1971.) 
The actual progress of this count, however, was unknown. On checking the statistics which the Welfare Branch had compiled to present to the Arbitration Court hearing, it was found that some of the stations included had not been visited for the purpose of compiling population statistics since 1958, and that of the majority of stations which had been visited since 1960 few had provided figures in the two years prior to 1965.

Apart from a reference to the introduction of the Regulations under the Wards Employment Ordinance in the Report of the Welfare Branch in 1959-60, no further reference was made in these reports either to the number of returns being received, the figures obtained therefrom, or the number of prosecutions under the Ordinance for failure to furnish Aboriginal employment returns.

In the absence of further evidence, it would appear that the contact of officers of the Welfare Branch with approximately one-third of their charges was either fairly cursory or made without the assistance of the system so carefully laid out in the Regulations.

The 1965 Statistical Summary of the Northern Territory listed 1,558 persons, other than full-blood Aborigines, as being engaged in primary production in the Northern Territory. ${ }^{6}$ Official figures tendered at the Arbitration Court hearing referred to 879 in the 'total permanent nonAboriginal workforce at the last count'. ${ }^{7}$ The 1961 Census returns recorded 1,011 non-Aboriginal males and 87 females as being so employed in the pastoral industry. As many persons interviewed in the Centre mentioned the necessity to retrench white staff because of drought conditions, it is probable that the later figure produced by the Northern Territory Administration was more accurate. The Statistical Summary, however, did not indicate whether it included females, who are normally employed in a domestic capacity.

\section{NATURE OF THE STATIONS}

The figures presented in this report are estimates based on the thirty properties visited. These pastoralists held leases over 79,510 square miles out of a pastoral area of 278,445 square miles in the Northern Territory. ${ }^{8}$ For the purposes of this paper this has been taken as 30 per cent of the total pastoral area of the Northern Territory, and industry figures have

\footnotetext{
'Northern Territory Statistical Summary, 1965, Commonwealth Bureau of Census and Statistics, Darwin, p. 32.

${ }^{7}$ Commonwealth Conciliation and Arbitration Commission, No. 830 of 1965, p. 13.

${ }^{8}$ Annual Report of the Northern Territory, 1964-65, p. 122.
} 
been determined on this basis; in considering these figures the purpose of the survey sample should be recalled.

Of the thirty stations visited, fifteen were managed by their owners or persons having a substantial interest in the property concerned, and fifteen were managed by persons on behalf of companies in which the managers apparently did not have any financial interest. Thirteen of the thirty stations were not associated with any other holding in the Northern Territory. As the attitudes of management might vary, dependent on either their executive or ownership role, it was necessary for the survey to reflect the overall distribution of ownership and management of cattle stations in the Northern Territory. Although the original survey structure was based on unofficial sources of information, judgment on this matter was later verified from official sources. ${ }^{\ominus}$

The stations we visited ranged in size from properties as small as 118 square miles or 72,520 acres to the largest single holding in the world: 8,776 square miles or $6,216,640$ acres.

Only six stations reported normal rainfall. Except for the Central Australian area this was not considered to be a factor of great significance in interpreting the results of the survey. Although employment figures were reduced by drought in the Centre it was considered that conditions in the north offset these losses. One of the reasons for this conclusion was that several pastoralists informed us that in the northern part of the Territory the best seasons were experienced with slightly below average rainfalls. This factor, combined with the inability of some stations, because of drought, to move their cattle to eastern properties, as was normal, would predicate a relatively high cattle population.

Drought conditions in the Centre had a bearing, no doubt, on the attitudes of cattlemen towards the value of native labour, and possibly influenced their anticipation of the number needed and the cattlecarrying capacity of their properties.

The station managers informed us that they were carrying 472,400 head of cattle. Thus the total number of cattle for the Northern Territory, based on our survey figures, would be some 1,574,000. The crude extension of the figure relating to cattle population resulting from the survey might be contrasted with the official estimates of cattle numbers in the Northern Territory for 1965 of $1,049,000$ head. ${ }^{10}$ There were several reasons which might explain the divergence between the survey results and official statistics. In many ways the taxation and bookkeeping

* Department of Territories Press Release, 22 July 1965.

${ }^{10}$ Annual Report of the Northern Territory, 1964-65, p. 31. 
needs of the stations were of greater importance to management than arithmetic accuracy in the submission of official returns of cattle numbers. Should an owner have desired to understate the numbers of cattle on a property-if he knew them-excluding the possibility of a "bangtail muster', ${ }^{11}$ there appeared to be little the government could do but accept his word.

That understatement of cattle numbers was a common practice among cattlemen was explainable by taxation procedures. Taxation was paid on 'natural' increases. When a natural increase figure was required it was calculated on the estimated cattle numbers, adjusted by an estimate of the number of calvings and deaths. Outside of the slim possibility of a taxation inventory of the cattle population of the property the manager's or owner's calculation of the numbers had to be accepted. For taxation purposes there was an obvious encouragement to understate these.

Even when the properties were sold it was not possible for government authorities to obtain an accurate assessment of the cattle numbers short of being present at a muster. The price of a property on changing hands was based on a number of factors and normally expressed as a gross figure. It was in the interests of both parties to place the cattle numbers as low as possible and for the seller to take the profit out as a 'capital gain'. This was, of course, non-taxable. Had a realistic figure been placed on the cattle numbers he might have been faced with a taxation claim for the underestimated natural increase of previous years.

Many properties had changed hands in the Territory in recent years, and I was informed by would-be purchasers that this approach to domestic bookkeeping was very common among sellers. In many cases private agreement was reached between the buyer and the seller to split the difference between the stated cattle numbers and what was found in muster, if such was ever possible. The number of cattle that the incoming purchaser might take onto his books for taxation purposes, of course, depended on the advice of his accountant and not necessarily the number that there was, in fact, on the property. This was fairly normal business procedure, with the exception that on the Northern Territory cattle stations it was virtually impossible to undertake an accurate inventory. At the best all one could say about the official calculations of cattle numbers was that they were based on fictional figures produced for accounting purposes. Furthermore, in discussion with pastoralists and company representatives it was noted that a common practice on com-

${ }^{11}$ A 'bangtail muster' is a muster in which the tails of the cattle are chopped off to prevent multiple counting. 
pany stations was for the manager purposely to understate the cattle and calvings at hand, as it gave him a margin for lean years or for times when extraordinary demands were made on him by distant executives. Consequently, there were several fairly strong reasons for management to underestimate their cattle population figures-both officially and for internal bookkeeping purposes.

As the estimates of cattle numbers in the Northern Territory werc of significance in determining labour demand, the above relationship of estimated cattle numbers to official records was of some importance. Further inconsistencies appeared in official sources; government estimates recorded the numbers of cattle in the Territory since 1955 as in Table 3.

Table 3: Northern Territory cattle numbers, 1955-69

\begin{tabular}{|c|c|c|c|c|c|}
\hline \multirow[b]{2}{*}{ Year } & \multicolumn{5}{|c|}{ Cattle regions } \\
\hline & $\begin{array}{l}\text { Arnhem- } \\
\text { N.T. Gulf }\end{array}$ & Victoria & Barkly & Centre & $\begin{array}{l}\text { Total } \\
\text { N.T. }\end{array}$ \\
\hline 1955 & 157,165 & 258,764 & 276,509 & 276,337 & 968,775 \\
\hline 1956 & 164,692 & 263,220 & 305,879 & 294,028 & $1,027,819$ \\
\hline 1957 & 170,647 & 359,744 & 345,375 & 300,231 & $1,175,997$ \\
\hline 1958 & 187,037 & 343,063 & 368,740 & 353,174 & $1,252,014$ \\
\hline 1959 & 192,747 & 344,602 & 327,734 & 273,073 & $1,138,156$ \\
\hline 1960 & 199,298 & 330,461 & 313,142 & 246,081 & $1,110,520$ \\
\hline 1961 & 220,812 & 348,135 & 343,530 & 204,350 & $1,116,827$ \\
\hline 1962 & 204,006 & 334,242 & 339,804 & 176,617 & $1,054,669$ \\
\hline 1963 & 215,911 & 338,534 & 367,223 & 165,371 & $1,096,039$ \\
\hline 1964 & 193,686 & 332,640 & 381,265 & 160,130 & $1,067,721$ \\
\hline 1965 & 208,880 & 317,724 & 385,895 & 136,032 & $1,048,531$ \\
\hline 1966 & 206,783 & 311,218 & 398,326 & 134,412 & $1,050,739$ \\
\hline 1967 & 210,304 & 304,563 & 436,464 & 154,405 & $1,105,736$ \\
\hline 1968 & 201,000 & 331,000 & 425,000 & 173,000 & $1,130,000$ \\
\hline 1969 & 179,000 & 347,000 & 440,000 & 219,000 & $1,185,000$ \\
\hline Average & 194,131 & 338,327 & 363,659 & 217,748 & $1,100,190$ \\
\hline
\end{tabular}

Source: Northern Territory Administration Annual Reports and Bureau of Census and Statistics; J.H. Kelly, Beef in Northern Australia, Australian National University Press, Canberra, 1971, p. 212.

The static nature of the official estimates was probably accounted for by the fall of some 193,000 head of cattle in the Alice Springs district. ${ }^{12}$ Whilst it was appreciated that the ten-year drought affecting the Alice Springs area had been the worst on record, climatic conditions had not been so disastrous elsewhere in the Territory. Indeed, given the diversity of climatic conditions in the Northern Territory, only in abnormal

12 Annual Report of the Northern Territory, 1963-64, p. 30. 
circumstances would each regional area be found to be enjoying an 'average' season at the same time. In this respect the Territory as a whole might have been considered as enjoying normal seasons.

Some account must also be taken of the gradual improvement in propertics since 1948. For example, in 1951 it was estimated that there were 950 artificial watering places throughout the Northern Territory and to realise the estimated carrying capacity of the country an additional 3,150 watering points were needed-or 4,100 all told. ${ }^{13}$ By 1964 4,946 bores had been sunk in the Northern Territory, of which approximately 4,000 were operating in pastoral areas. ${ }^{14}$

The figures issued in relation to bores, of course, did not include other watering places such as earth dams. If these were included, pastoral properties were probably approaching the optimum number of watering places suggested in 1951. On the basis of these facilities it was considered that cattle-carrying capacity would be $1,650,000 .{ }^{15}$ If one added to these factors the general buoyancy of the cattle industry, the desire to build up herds and the anticipation of early sales of properties, it is difficult to see how the cattle industry had regressed during the seventeen years under consideration.

Failure to concede this point must lead one to the rather less complimentary conclusion that grazing practices have produced a remarkable deterioration in the ability of the pastures of the Territory to support previous herd numbers, and that considerable public funds have been spent on subsidising the sinking of bores which have no practical effect on lifting the cattle-carrying capacity. J.H. Kelly seems to subscribe to this conclusion. ${ }^{16}$

DEVELOPMENT POTENTIAL AND FUTURE DEMAND FOR LABOUR

The current cattle population of the Territory and the anticipated future increase had an important bearing on the demand for labour, both black and white. With this in mind, we asked about the future plans for the

${ }^{13}$ J.H. Kelly, Report on the Beef Cattle Industry in Northern Australia, Bureau of Agricultural Economics, Canberra, 1952, p. 120.

14 Press Release, Administrator of the Northern Territory, 30 November 1965.

${ }^{15} \mathrm{Kelly}$, Report on the Beef Cattle Industry, p. 120. As no Federal taxation was paid on earnings in the Northern Territory, little motivation would have existed for station owners to disguise cattle numbers at that time. Few would grant that such is the case today.

${ }^{16}$ J.H. Kelly, 'Absentee Holding of Cattle Lands in Northern Australia', a paper presented at a Symposium on the Development of Northern Australia, University of N.S.W., 15 February 1966, mimeo. 
respective properties. Because of the drought in the Centre we inquired of managers and owners in the area as to what they considered would be a reasonable cattle-carrying capacity on their properties, assuming average seasons and prices during the coming years. Alternatively, in the north, we asked "what cattle population figures are you aiming at in the foreseeable future?' Given the recent developments in tropical pastures, new meatworks and increased prices, we felt that an optimistic question was warranted in the circumstances.

The answers to our inquiries in this respect showed an expected increase in cattle-carrying capacity of approximately 50 per cent-or a cattle population of $2,360,000$ for the whole of the Territory. This increase in cattle numbers was commensurate with the official estimate of planned and possible increases, with the exception that our estimate of the total number of cattle at the end of the year was proportionately higher than the official calculations.

The relationship between these various figures encouraged me to conclude that the cattle population of the Northern Territory was higher than that normally conceded by the Administration, and that therefore the immediate demand for labour was also proportionately greater. Further, based on the increased cattle numbers, the optimum cattle population would be reached sooner than officially estimated, and this in turn would sustain greater demand for labour in the short run than the official calculations allowed for.

CATTLE STATION LABOUR AND WAGES STRUCTURE

THE WHITE ENVIRONMENT

Official sources referred to 879 whites as being employed in the pastoral industry of the Northern Territory. Our survey showed that there were 350 persons considered as whites residing on the stations visited. Using the simple extension of this figure, based on 30 per cent of the total industry, there were some 1,160 whites resident on the stations. A similar extension for employed whites provided a figure of 860 , which was in close accord with the official estimates. This, however, included some females who might have been otherwise engaged in 'domestic duties' and possibly not included in the official figures. As the responsibilities of adult women in the Northern Territory were so great that only with the greatest disrespect could one classify them as 'not employed', we included them in the work force where the white working population on any one station was more than five. 
As we did not have powers of inspection, figures tendered on wages paid to white staff proved to be rather unreliable. For example, not one manager offered to inform us of his salary during the formal survey. A number, however, mentioned it in casual discussions.

From later inquiries (the mail survey) it appeared that the average wage for a manager in the industry was approximately $£ 1,600$ per annum, all found. Under the title of 'all found' many benefits accrued to both managers and white employees. However, as the responsibility of the individuals was great, the conditions of work exacting, and the isolation considerable, one might expect that the ability of the management would be roughly commensurate with the salary offered.

For example, the salary of one manager interviewed was stated by other persons as being $£ 1,250$ per annum, or say $£ 25$ per week. This cash figure was approximately $£ 10$ per week less than that received by the average skilled tradesman in Darwin for a 40 hour week. The property concerned ran 15,000 head of cattle, and annual production was estimated at $£ 150,000$. As the capital value of the property was in the region of

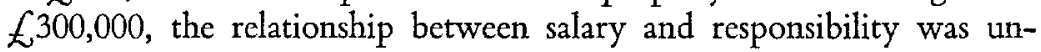
realistic.

However, at the other end of the scale one person informed me that he was paid a salary of $£ 4,000$ per annum. The property concerned turned off beef valued at $\mathcal{E}^{300,000}$ per annum from an investment

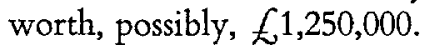

Considering the physical demands, isolation, responsibility and the hours of work involved, however, cattle station managers on the whole were obviously poorly paid.

The wage policy of the owners in relation to whites also had a bearing on industrial relationships. Indeed, several persons interviewed referred to the constant turnover of managers on Northern Territory cattle stations. One station visited had its fifth manager in about four years. Undoubtedly this had an unsettling infuence on white and Aboriginal staff alike.

Several writers have commented on the generally low standard of management of the stations, and considered that the system of absentee landholding was primarily responsible for the difficulties. ${ }^{17}$ In addition to this many of the persons interviewed, including some managers of

${ }^{17}$ Kelly, Report on the Beef Cattle Industry', p. 164. See also Department of Territories, Prospects of Agriculture in the Northern Territory, Minister for Territories, Canberra, 1961, p. 55, and the Northern Territory Investigation Committee Report (Payne-Fletcher Report), Government Printer, Canberra, 1937, pp. 52-3. 
company holdings, were critical of the investment programs of their employers. One typical comment was 'the object [of absentee leaseholders] is to screw as much as possible out of the country and not to put anything back in'.

On the question of management techniques and the general level of productivity, the comment of one potential buyer of a property in the Territory was of interest. After inspecting several properties and rejecting the idea of purchase he said:

I'd have to get up too early in the morning. These fellows don't grow cattle-they simply hunt them once they have grown up to spite the management. As the locals are better hunters than I am, I reckon that they would get two cows for every one I could track down in one muster. ${ }^{18}$

The Forster Committee in 1960 passed the following comments on management difficulties:

[The labour position in the Northern Territory] is very bad indeed. The climate, particularly in the top half of the Territory, is not a pleasant one and the isolation is very real. There is an absence of contact with any kind of cultural organisation, and this is a handicap discouraging young men who might otherwise go there. Women face many difficulties in the tropics, and the standard of housing that has been available has been low. Consequently, good labour is hard to obtain ... The industry has depended in the past almost entirely on Aboriginal labour. ${ }^{19}$

The low rates of remuneration, and the ensuing frequent turnover of managerial staff, provided an extremely poor basis for any improvement in the industrial conditions of Aborigines. Firstly, the poor wages paid to managers normally indicated a fairly low educational standard, and a rather inadequate appreciation of the complex problems which they were facing in relation to their native staff. Secondly, it was noted that the longer a manager had been in the Territory, the greater was his appreciation of the value of Aboriginal skills and, normally, the greater was his acceptance amongst the indigenes.

Frequent turnover of managerial staff also had an unfortunate impact on Aboriginal conditions, as normally a new manager attempted to gain control over cattle production before giving much attention to the human side of his responsibilities. Often this became all-consuming, and

${ }^{18}$ Although I do not want to suggest that rustling was common, I was informed by one authority that it is not unusual at muster time for stations to detail 'out-riders'. The job of these people is to travel on the extremities of the muster to see that no 'foreign' camp is moving alongside and drafting cattle driven away from the centre of the muster. For additional criticism of open range cattle techniques see Kelly, Report on the Beef Cattle Industry, pp. 142-8. ${ }^{18}$ Department of Territories, Prospects of Agriculture in the Northern Territory, p. 52. 
even managers of good intent left the field before having succeeded in the rather difficult task of convincing their distant owners that the station should spend more on their Aboriginal workers. As there were but few stations which had taken this radical step, advocacy of the Aboriginal cause was difficult.

Overall we found that the social and economic conditions of white cmployees were fairly depressed in relation to other areas of Australia. In some cases housing facilities for white employees, and indeed for some owners and managers, were only slightly better than those provided for Aborigines. Aboriginal living conditions suffered as an indirect result of the overall standards of aspiration. An example of the attitude might be illustrative: on questioning one employer about his adherence to the range of foodstuffs laid down by the Welfare Branch for Aboriginal employecs, we received the reply: 'Feed those bastards on oranges? Why, we never see any fresh fruit ourselves, let alone give any to the blacks' camp'. In these circumstances it would need more than human compassion for managers to provide their employees with benefits that they themselves did not enjoy, even though it was their obligation at law to do so.

\section{WHITE EMPLOYMENT AND WAGE STRUCTURE}

Our survey results produced the statistics on occupation and wage structure for Europeans shown in Table 4.

The figures in Table 4 do not set out the full conditions of employment. In all cases the salary range mentioned was cash payment only. Every station visited provided single employees with full board and lodgings. Occasionally a station was required to provide accommodation for the wife and family of an employee. Invariably, they also were provided with food free of charge. However, the employees involved may have been prepared to accept a lower cash wage at the time of negotiation than they would have otherwise demanded because of the 'all found' nature of their remuneration. Unfortunately no precise figures were available.

If we leave out the category of jackeroo, which was taken as a transitory position for young people training for broader responsibility, ${ }^{20}$ 160 persons out of a total of 733 male white employees, or only 23 per cent, were engaged directly in cattle production. The balance of the white work force was distributed throughout varying skilled occupations ranging from manager through to carpenter and pilot.

${ }^{20}$ A 'jackeroo' was defined in the Cattle Station Industry (N.T.) Award, S. 3 as a person 'employed with a view to becoming an owner, overseer, manager, etc.' 
Table 4: European employment and wage structure

\begin{tabular}{|c|c|c|c|}
\hline & $\begin{array}{l}\text { Survey } \\
\text { No. }\end{array}$ & $\begin{array}{l}\text { Estimated } \\
\text { industry figure } \\
\text { No. }\end{array}$ & $\begin{array}{l}\text { Salary Range-- } \\
\text { weekly (all found) } \\
£\end{array}$ \\
\hline \multicolumn{4}{|l|}{ European females } \\
\hline Cook & 5 & 17 & $8-12$ \\
\hline Housekeeper & 18 & 60 & $8-12$ \\
\hline Sister & 4 & 12 & $16-20$ \\
\hline Teacher & 5 & 17 & $16-20$ \\
\hline Governess & 3 & 10 & $8-12$ \\
\hline Total & 35 & 116 & \\
\hline \multicolumn{4}{|l|}{ European males } \\
\hline Manager & 30 & 100 & $25-80$ \\
\hline Bookkeeper & 11 & 38 & $20-25$ \\
\hline Garage mechanic & 13 & 43 & $22-27$ \\
\hline Bore mechanic & 13 & 43 & $20-22$ \\
\hline Engineer & 3 & 10 & N.A. \\
\hline Plant operator & 8 & 27 & $23-30$ \\
\hline Truck driver & 3 & 10 & $20-25$ \\
\hline Carpenter & 7 & 23 & $22-25$ \\
\hline Handyman & 4 & 12 & $15-22$ \\
\hline Saddler & 4 & 12 & $24-28$ \\
\hline Head stockman & 19 & 63 & $20-30$ \\
\hline Stockman & 29 & 97 & $17-23$ \\
\hline Jackeroo & 28 & 93 & $5-14$ \\
\hline Cook & 11 & 37 & $15-20$ \\
\hline Boundary rider & 2 & 7 & $18-20$ \\
\hline General hand & 15 & 50 & $15-20$ \\
\hline Storekeeper & 5 & 15 & $18-23$ \\
\hline Fencer & 7 & 23 & $18-23$ \\
\hline Horse breaker & 3 & 10 & $17-22$ \\
\hline \multicolumn{4}{|l|}{ Pumper } \\
\hline \multicolumn{4}{|l|}{ Butcher } \\
\hline Pilot & 9 & 30 & N.A. \\
\hline \multicolumn{4}{|l|}{ Blacksmith } \\
\hline \multicolumn{4}{|l|}{ Builder } \\
\hline Total & 224 & 743 & \\
\hline
\end{tabular}

Note: N.A. = Salary range not given.

\section{PART-ABORIGINES}

The Aboriginals Ordinance of 1918-1952 declared that certain categories of half-caste persons were to be subject to the control of the Director of Native Affairs in a similar manner to full-blood Aborigines. The halfcaste people who were to be controlled included those:

(a) living with an Aboriginal spouse;

(b) who habitually lived or associated with full-bloods;

(c) who were apparently under twenty-one years of age; 
(d) who in the opinion of the Director were incapable of managing their own affairs;

(c) females who were living with but not married to a European. ${ }^{21}$

As has been pointed out, following agitation from the Australian. Half-Castes Association, the Administration decided to remove all half-castes from the legislation other than those living with full-blood Aborigines and those specifically declared by the Director of Welfare to be in need of aid. ${ }^{22}$

In 1965 half-castes were subject to the same rights and duties as any other Australian citizen living in the Northern Territory, including coverage of the Award appropriate to the industry. However, as I already stated, considerable difficulty was experienced in defining the various gradations of colour, so that legal rights and classifications could be ascribed to the persons involved. I have also pointed out that cattlemen overcame this complex problem by visually grouping their work force by the colour of the skin, a person's background or his current affinity with the 'Aboriginal camp'. A corresponding grading for remuneration was made.

Of all the complaints concerning Aboriginal labour listed by pastoralists none-cxcept occasionally illiteracy-were levelled against half-castes. They were, however, frequently referred to as being more 'cunning' or more 'cheeky' than Aborigines and as inheriting either the 'best of both races' or the 'worst of both races' depending on the employers' recent experiences. At no stage was it considered that racial admixture detracted from the employces' productive value. Verbally at least, pastoralists seemed roughly in agreement with the official appraisal of their contribution to the Territory's economy.

Because of the closer racial affinity of half-castes to whites, and the representations of employers before the Arbitration Court that the exclusion of Aborigines from Awards 'had never been racial', ${ }^{23}$ it was of interest to see what practical administrative policies were pursued on cattle stations in relation to part-Aboriginal workers.

Taking the above limitations into account, and endeavouring to calculate the number of known part-Aboriginal employees, even though some managements classified them as 'Aboriginal', approximately 100

21 Northern Territory, Aboriginals Ordinance, 1918-1952, S. 3.

${ }^{22}$ Northem Standard, Darwin, 21, 28 September 1951, 11 April, 8 August 1952. Northern Territory, Aboriginals Ordinance, 1953, S. 3.

${ }^{23}$ Commonwealth Conciliation and Arbitration Commission, No. 830 of 1965, Minutes of Evidence, p. 65 . 
such persons were resident on the properties visited. The numbers, employment classifications and salary range were as in Table 5.

Table 5: Part-Aboriginal employment and wage structure

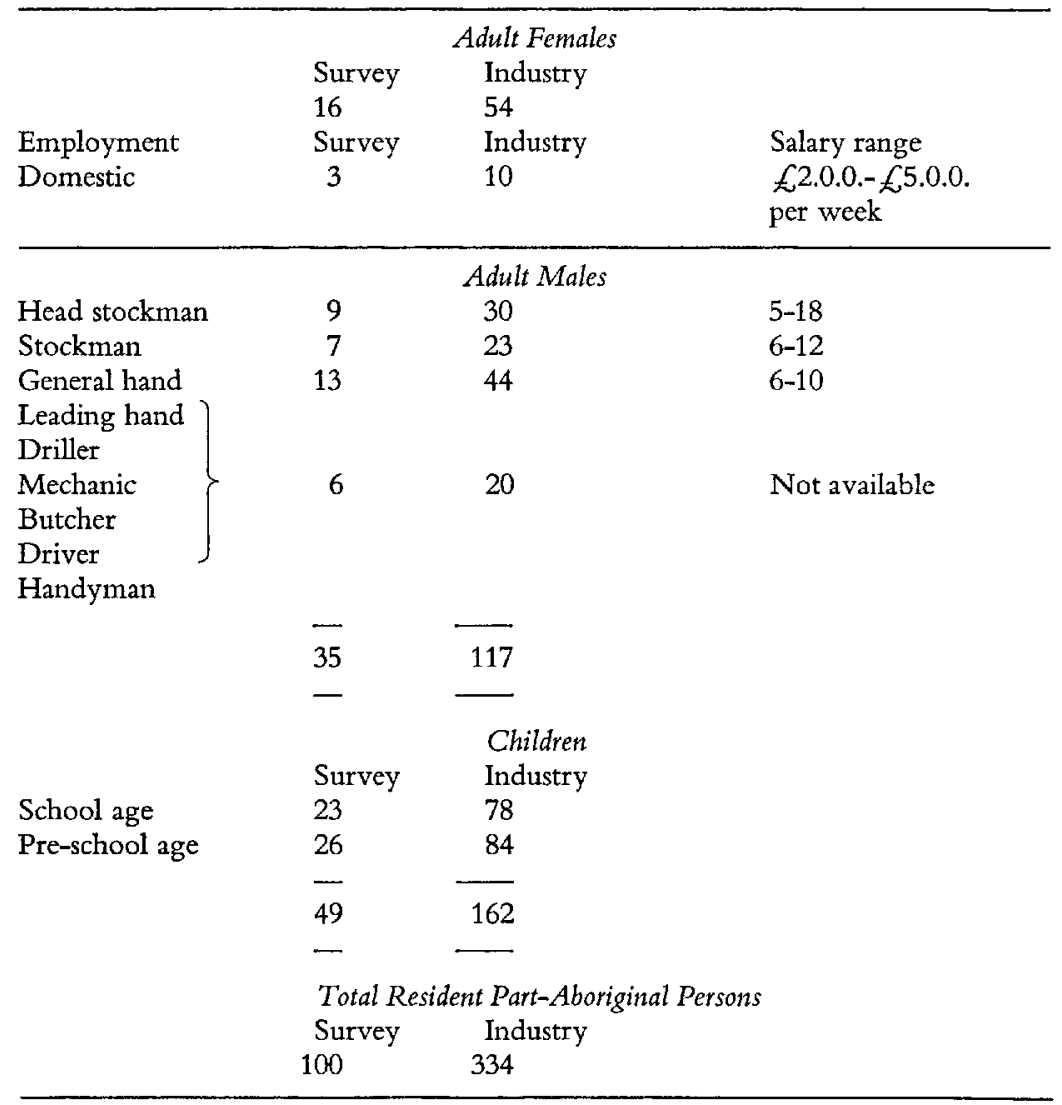

Of these figures it is interesting to note:

(a) the relatively high percentage of head stockmen;

(b) the broadening of employment opportunity into skilled and semi-skilled grades;

(c) an average salary range approximately two-thirds of that of European workers with a correspondingly low average base rate;

(d) the relatively low numbers of adult females and the high percentage of children. 
Comparative figures for the 'Aboriginal' population present an equal ratio of males to females and a ratio of approximately 6 children to 9 adults $^{24}$ compared with the part-Aboriginal figures of 117 adult males to 54 adult females and an equal ratio of children to adults. This would appear to indicate:

(a) that female part-Aborigines find employment and reside outside of the industry; or

(b) that male part-Aborigines from towns seek employment in the industry; or

(c) that the fertility rate of part-Aboriginal workers is higher than that of full-blood Aborigines; or

(d) that the fertility rate is assisted by 'unions' between full-blood Aboriginal women and white males;

(c) that an increasing number of part-Aboriginal workers will take full-blood wives.

Official policy also seemed to have given an 'unfortunate' bias to the above statistics. Since the 1920 s the part-Aboriginal population of the Territory has been singled out as the recipient of an extended program of assimilation 'aid'. This has been proffered through the creation of special schools and scholarships, preferential treatment in urban housing, segregation of females at an early age from 'harmful' environmental circumstances, etc. ${ }^{25}$

Docker pointed out in 1954 that: although the half-caste no longer [exists] . . . in law he still [exists] ... in fact. If the legal disabilities of the half-caste [have] been removed the social disabilities still [remain]. ${ }^{26}$

This is still the case today. Socially and economically the half-caste continues to exist in a world which is neither quite white nor quite black, and in many ways he is denied the warmth and membership of either group. Cattlemen obviously exercise a pattern of discrimination against them both in the payment of wages and in accommodation. Except in so far as all are friends in adversity, the full-blood groups also look askance at the person who so often is the product of sexual promiscuity.

One person in the Territory said: 'I suppose we will have another

${ }^{24}$ Lancaster Jones, A Demographic Survey, p. 67.

${ }^{25}$ J.P.M. Long, "The Administration of Part Aborigines in the Northern Territory', Oceania, vol. 37, No. 3, 1967, pp. 186-201.

${ }^{28}$ E.G. Docker, 'Native Administration in the Northern Territory', typescript, Australian National University, 1956, p. 524. 
bunch of chocolate bastards after the race meeting'. This often seems to be the case, and apparently they are treated accordingly.

Finally, some mention should be made of the apparently small number of half-castes who were discovered to be present in the cattle industry. In many respects, because of sexual exploitaton, which is discussed in more detail later in this study, the limited numbers of offspring of the sexual union between the black and white groups is surprising.

Although I have already directed attention to the official practice of the removal of half-caste children from the stations, frequent reference was made during interviews with both whites and Aborigines of actions which were taken by the Aborigines themselves to check the growth of large half-caste groups. Many managers referred to the continuing preference of Aboriginal women to give birth to their children away from the homestead, and invariably in bush surroundings with only one or two Aboriginal midwives present. More than one white and several full-blood Aboriginal males considered that in the circumstances of isolation Aboriginal women practise infanticide if the child which is born has 'European' features.

During one visit to a station in the Victoria River district my presence coincided with the anticipated arrival of the child of one of the white stockmen. As was expected the Aboriginal mother-to-be was absent from the camp for a period of about thirty-six hours around the time of the anticipated birth. When she reappeared it was obvious that the child had been born. The manager approached her and asked about its condition. She replied without any evidence of emotion or distress: 'Oh, him bin finish up, boss'.

It is of interest to note in this respect that Berndt discovered a high incidence of psychological morbidity amongst cattle station Aborigines. $\mathrm{He}$ believed that the oppressiveness of their circumstances had considerable effect on their fecundity through a significant reduction in their desire for reproduction. He claimed also that contraceptive and abortion practices were common on the station he studied. ${ }^{27}$

Berndt's opinion on attitudes to morbidity was supported by interviews with nursing sisters during the survey. One sister in particular stated that it was the practice of Aboriginal women to kill illegitimate children at birth. Without being present at the birth it would be difficult to say whether the child was the product of a mixed union or one which was fully Aboriginal.

27 Berndt, 'A Northern Territory Problem', pp. 53-4. 
Having endeavoured to differentiate 'white' from 'black', one can go on to enumerate and discuss the structure of the work force commonly referred to as 'Aboriginal'. It must be recalled that the term was not co-extensive with 'ward', although most Aboriginal residents of cattle stations have been so declared.

The Welfare Branch of the Northern Territory Administration calculated that there were 1,374 male 'Aboriginal' employees engaged on rural holdings in $1965 .{ }^{28}$ Rural holdings included agricultural properties and sundry other occupations connected with the land. The rural holdings devoted to agriculture were not as extensive as those devoted to pastoral pursuits and were known not to contain large establishments of Aborigines. ${ }^{29}$ However, some weight must be given to agricultural occupations and in the absence of any other information I allocated 100 persons to this form of occupation, leaving a net official figure of 1,274 male Aborigines employed in the pastoral industry. The same source referred to 466 female Aborigines as being employed but added that, as there had been no estimate made since 1961, the figure could not be taken as accurate. The results of the survey and industry projections were as in Table 6.

Although remuneration is referred to as having a salary range, in fact cash payments were more consistent, being 10 s. to $f_{1} 1$ 'cash a longa pinga' (money in the hand) per week, the balance being credited to the employee's account at the station store. In the more extreme cases, the employee only received a cash allowance on special occasions-race meetings or at Christmas. All sums mentioned included a clothing allowance of $15 \mathrm{~s}$. per week.

Several features of the job classifications and salary scales call for comment. However, before doing this, an explanation of the employment categories might assist general understanding.

Head stockman. Few Aborigines had achieved this position-the most responsible and demanding in the employee hierarchy. As will be seen later on, this was a result of cattlemen's reservations about the Aborigines' concept of responsibility and problems concerning illiteracy. These, and other factors, had an important bearing on the employer's appreciation of the employee's reliability.

${ }^{28}$ Commonwealth Conciliation and Arbitration Commission, No. 830 of 1965 , p. 14.

${ }^{20}$ No mention of such employment is made in the Annual Report of the Welfare Branch, 1964-65. 
Table 6: Aboriginal employment and wage structure

\begin{tabular}{|c|c|c|c|}
\hline \multicolumn{4}{|c|}{ Aboriginal Population } \\
\hline & Survey & \multicolumn{2}{|c|}{ Estimate of industry } \\
\hline Resident & 1,647 & \multicolumn{2}{|l|}{5,490} \\
\hline Previous years & 1,766 & \multicolumn{2}{|l|}{5,890} \\
\hline Employed & 650 & \multicolumn{2}{|l|}{2,167} \\
\hline Previous years & 710 & \multicolumn{2}{|l|}{2,310} \\
\hline Children & 463 & \multicolumn{2}{|l|}{1,543} \\
\hline \multirow[t]{3}{*}{ Pensioners } & 112 & 374 & \\
\hline & & \multicolumn{2}{|c|}{ Employed Females } \\
\hline & & & Salary range \\
\hline $\begin{array}{l}\text { Cook } \\
\text { Housekeeper }\end{array}$ & 2 & 7 & $2.15 .0 .-3.0 .0$ \\
\hline Domestics & 202 & 673 & 1.5.3.-3.15.3. \\
\hline \multicolumn{4}{|c|}{ Employed Males } \\
\hline Head stockman & 2 & 7 & 5.0.0.-11.15.0. \\
\hline Leading hand & 16 & 53 & 5.0.0.-10.0.0 \\
\hline Stockman & 289 & 963 & 3.3.3.-8.0.0. \\
\hline Cowboy & 3 & 10 & 3.3.3.-4.0.0. \\
\hline $\begin{array}{l}\text { Garage mechanic's } \\
\text { offsider }\end{array}$ & 7 & 23 & 4.0.0.-7.0.0. \\
\hline $\begin{array}{l}\text { Bore mechanic's } \\
\text { offsider }\end{array}$ & 4 & 13 & Not available \\
\hline Driver & 3 & 10 & $6.0 .0 .-10.0 .0$ \\
\hline Gardener & 34 & 113 & 3.3.3.-4.0.0. \\
\hline Pumper & 19 & 63 & 3.3.3.-5.5.0. \\
\hline Woodcutter & 9 & 30 & 3.3.3.-5.0.0 \\
\hline General hand & 30 & 100 & 3.3.3.-5.0.0 \\
\hline Yard builder & 4 & 13 & 3.3.3.-8.0.0 \\
\hline Youth & 5 & 16 & 10.0.-3.0.0. \\
\hline Slow worker & 12 & 40 & 2.8 .3 \\
\hline Handyman & 2 & 6 & Not available \\
\hline Boundary rider & 3 & 10 & $3.0 .0 .-4.0 .0$ \\
\hline \multicolumn{4}{|l|}{ Butcher } \\
\hline \multirow{3}{*}{$\begin{array}{l}\text { Cook } \\
\text { Bore man } \\
\text { Fencer's offsider }\end{array}$} & 4 & 17 & Not available \\
\hline & & & \\
\hline & & & \\
\hline Total & 446 & 1,487 & \\
\hline
\end{tabular}


Leading hand. A reasonable number of Aboriginal employees were classified as leading hands. This position appeared to be intermediate between that of head stockman and stockman, the first being reserved for either part-Aboriginal or white employees. These individuals were paid more than the ordinary Aboriginal stockman. In the sense it is used here, a leading hand was normally the person who was considered the "head boy'. He received the orders from the manager or the head stockman or, as was the case in many situations, he actually performed the duties of head stockman, but was only awarded the title of leading hand or 'head boy'. Occasionally the privilege of being ascribed any title was withheld and the persons bearing the responsibility of intermediary between the white and black camp were simply listed as stockmen, although possibly paid at a higher rate than the rest of the employees. Invariably the person referred to as 'head boy' or 'leading hand' had a little more advanced grasp of English and in fact acted as interpreter for his less fortunate fellow workers. Often he had a rudimentary formal education and his ability to count was recognised by his employer. These characteristics undoubtedly increased his usefulness. Often the 'head boy' was the best stockman, but the two were not necessarily the same. Occasionally he had gained primacy because of tribal considerations, but this was rare. Tribal leadership was normally related to age, and, as advanced years adversely affected performance in the field, this aspect was of decreasing importance.

Stockman. This person was the main employee in the industry: without him there was no production. I have already made reference to the fact that only about 23 per cent of white workers were engaged in working with cattle. Some 68 per cent of the Aborigines were so engaged. Howcver, if we added this number and the number of persons listed as general hands, many of whom were stockmen for most of the time, 76 per cent of the Aboriginal male work force was directly engaged in cattle production. That the role of stockman involved a reasonable degree of skill was recognised by Commissioner Portus in the 1952 hearing into the Cattle Industry (Northern Territory) Award. This has been referred to above. That Aborigines exercise this skill at a level as high, if not higher, than white workers may be assessed from the results of our inquiry into this aspect of cattle operations.

Cowboy. Contrary to the impressions instilled by 'western' movies, this category of worker was probably the least glamorous in the industry. 


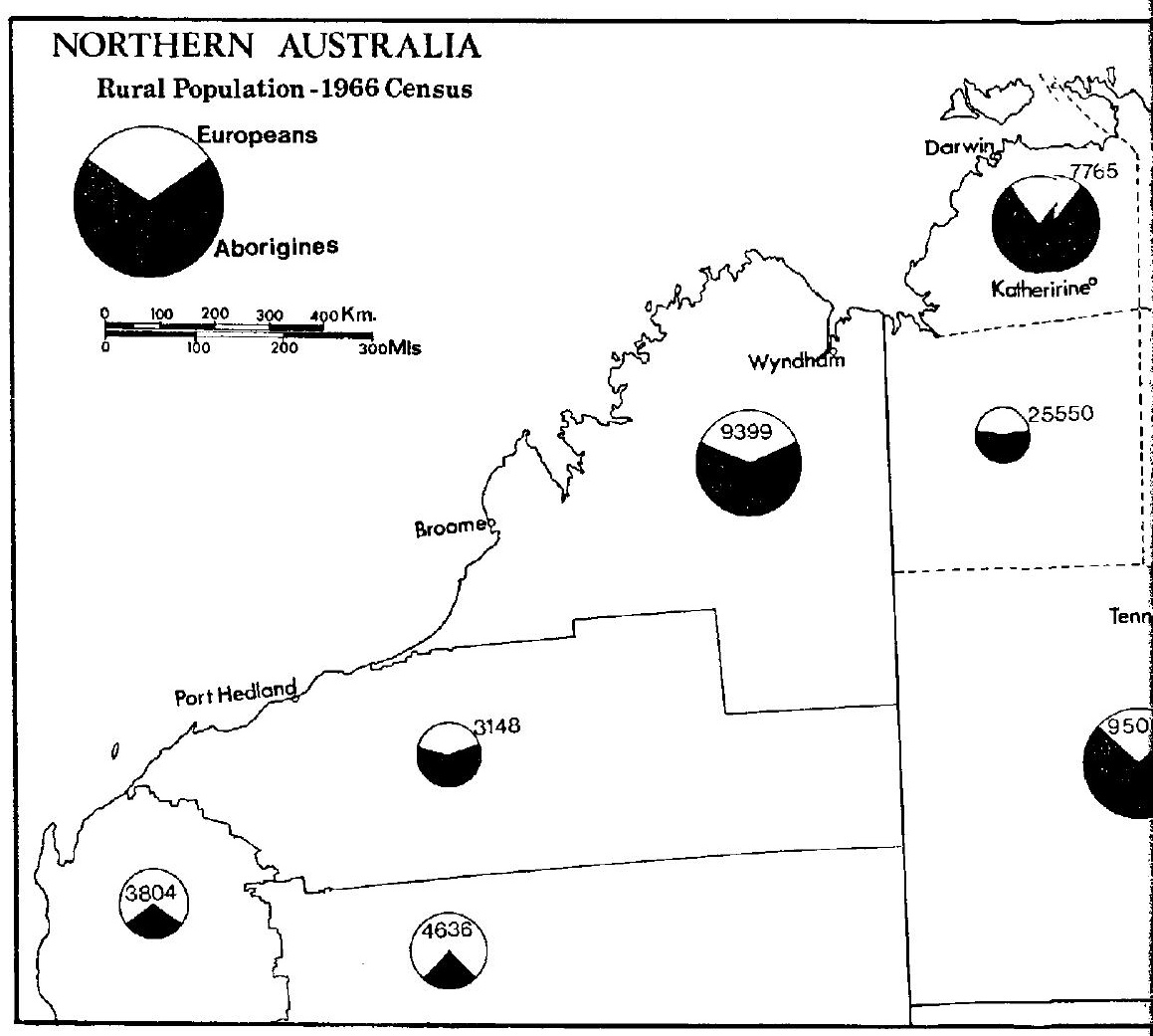

Map 3. Northern Australia, rural population, 1966 Census.

It was often the last resort for persons who had been tried on other tasks and found wanting. The position was equivalent to that of cow-herd.

Garage mechanic's offsider. Although this category appeared to indicate some degree of assimilation and exposure to Western technology, on closer examination this position was more akin to that of the traditional industrial 'grease monkey'. In the main the post entailed sweeping up, washing down dirty parts or acting as additional weight when tightening nuts. Occasionally Aborigines had made reasonable progress and had picked up some simple automotive skills. In several cases we heard glowing references to the mechanical ability of a few individuals. However, one mechanic answered our question concerning the progress of his Aboriginal assistant in the following way: 


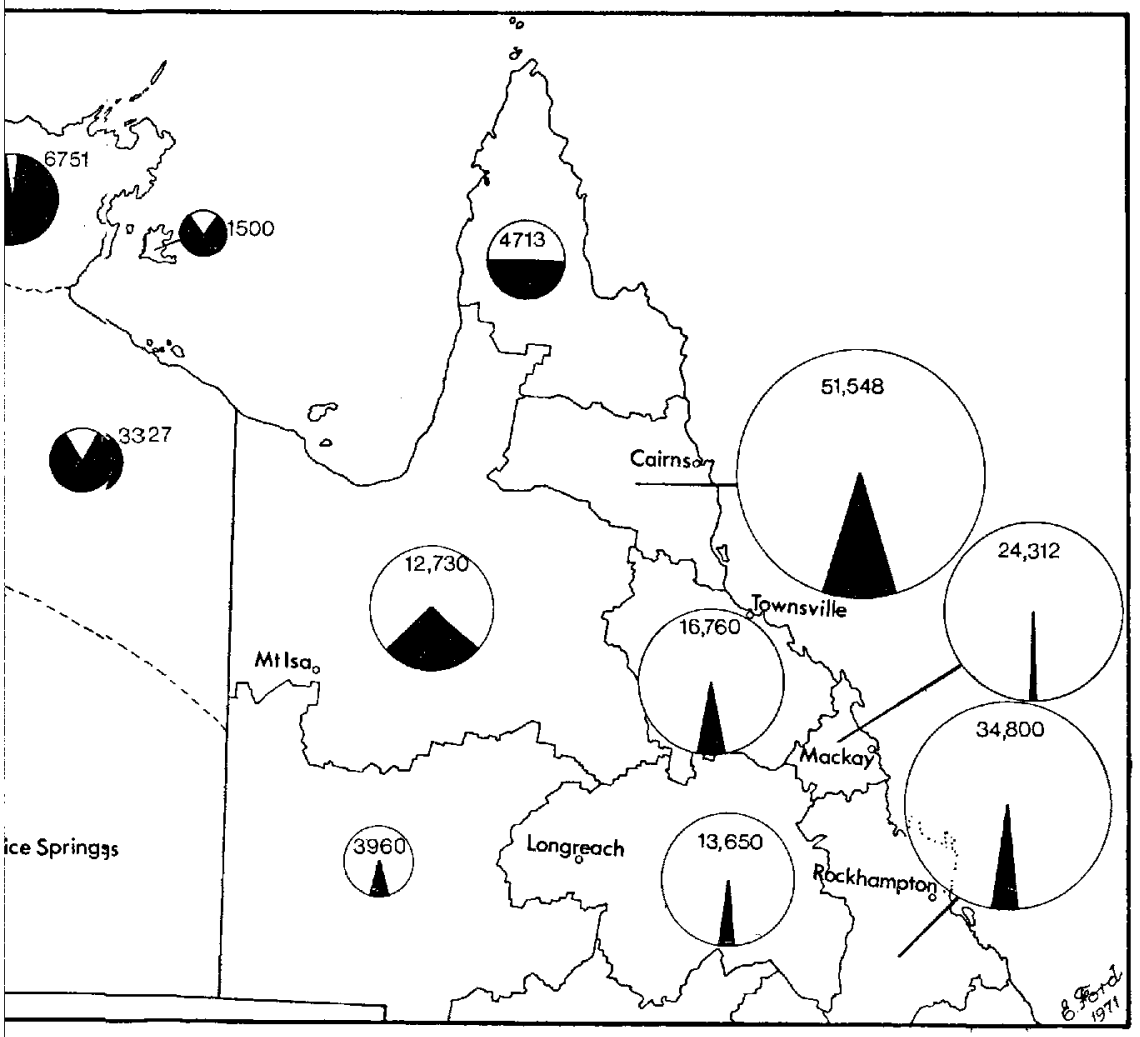

How can he possibly go anywhere when he hasn't got a clue what a three-eighths brolt is? Although he is willing and shows reasonable aptitude, he's illiterate. Because off this I can never let him do anything very complicated and as a result he never learns anything new.

On the other hand some full-blood Aborigines were known to have accquired a high level of technical skill and might have been considered 'scelf starters' in technical matters. In these cases it was noted that their hiigh degree of initiative had practical limits in the absence of training and theoretical knowledge. During the survey the existence of a number off independent Aboriginal contractors and work crews was noted.

Bbore mechanic's offsider. Although this post required less skill but more burawn than the previous position, the above comments are valid here as 
well. There were, however, few openings as the number of properties employing persons on bore work alone was limited.

Bore mechanic. On two stations it was noted that completely Aboriginal bore crews operated. Whereas the role of offsider to a bore mechanic was one demanding little sophistication, the successful extraction and replacement of faulty bore casing was a highly skilled operation. Considerable expense and inconvenience arose if the bore casing or tools were lost down the hole during the operation. The development of responsibility and skill in this exacting, if repetitive, task was never rewarded either by acknowledgment of the Aborigines' role or through monetary reward.

Driver. The position of driver illustrates some interesting problems. Although the posts available were limited, it was advantageous for all station hands to be able to drive. Because of literacy problems the number of Aborigines. who had drivers' licences was small. However, there was no need for licences on pastoral properties and a greater number drove than those who were formally licensed to do so. ${ }^{30}$ Cattlemen's attitudes to Aboriginal drivers seemed to be either strongly condemnatory, in which case they would not let them handle vehicles, or selectively encouraging. Those who had drivers on their staff were normally pleased with them. Those who would not let them handle vehicles had often had some unfortunate experience in which the native worker had failed to exercise normal precautions in relation to the equipment. A common complaint was that they had frequently run out of petrol, put water in the motor instead of oil, failed to check the radiator, etc. One manager summed it up by saying 'that they think a car is the same as a horse. All you have to do is simply jump on and go'. All police authorities, and one judge we spoke to, regarded Aboriginal drivers highly. Most cattlemen who allowed selected individuals to drive, praised their handling of the equipment. It is possible, however, that those managements allowing Aborigines to drive vehicles were more sympathetically disposed towards their native staff and consequently less critical of the processes of adjustment of illiterates to a fairly complex mechanical situation. Obviously the privilege of driving station vehicles was regarded as a status symbol. Indeed this fact, together with increasing Aboriginal ownership of automobiles, opens up the possibility of conquering geographical immobility. This would appear to be one of the fruitful directions along which assimilation policy could travel.

${ }^{30}$ Separate figures for licensed Aboriginal drivers were not available. 


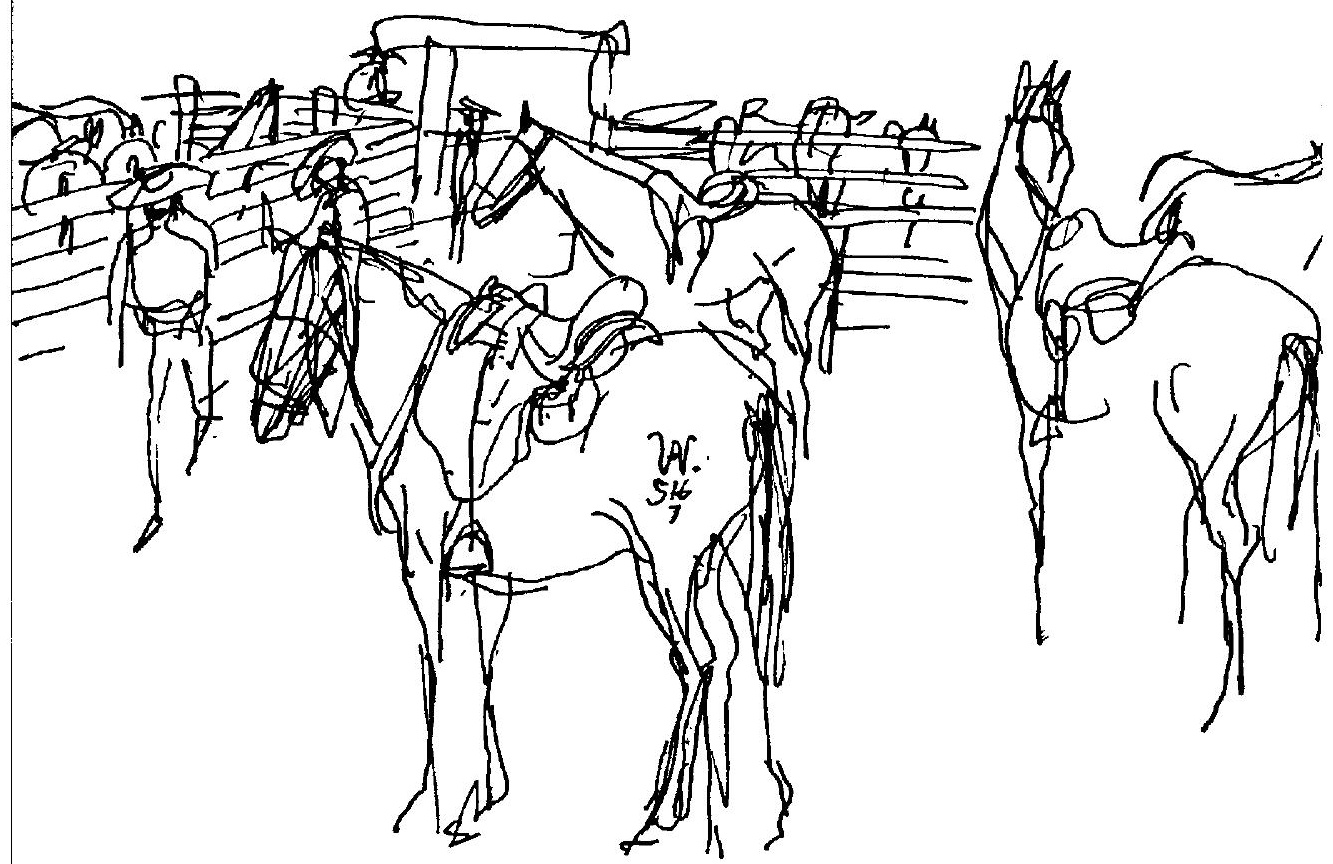

Although on the surface the possession of consumer durables by impoverished rural workers might appear to be an extravagance, their bencfit in the processes of practical educational experiences and their contribution to broadening social and economic horizons cannot be underestimated. Whilst working with immigrant Mexican labour in the United States I noticed that their first purchases always included an automobile and a television set. These items were frequently bought before provision had even been made for their families in the way of food or clothing. Reference to this 'extravagance' was often used by ranchers to demonstrate the immigrants' apparent lack of sophistication. On reflection, however, it would seem as though the possession of these two items in the circumstances of migratory labour provides a considerable buffer to the exigencies of their environment. The automobile releases the worker from the containment of any work situation and the television set allows him to escape from the oppression of his enforced poverty.

It was also noticed that both in the United States and north Australia the radio was serving a similar purpose. The contribution of audiovisual devices to the elevation of illiterate groups needs little amplification. 
Gardener. A substantial number of Aborigines were employed as gardeners. In many cases the title was a euphemism. As there was no yearround water supply on most properties, few had well-developed vegetable gardens. Most gardens were confined to the immediate vicinity of the homestead, and were limited to decorative and shady trees. As a consequence gardening meant simply watering and weeding. Because of this the post was normally the preserve of the elderly or of people who were considered unemployable elsewhere. In many cases the occupant of the position was considered an industrial pensioner having either been injured at work or having passed his prime for more arduous tasks. It was noted that some companies created sinecures for faithful white servants; Aborigines were frequently treated in the same way although in their case management motivation was often conditioned by a desire to keep family units together as a source of future labour.

Pumper. A pumper was normally a person who resided at distant bores to ensure that the water level in troughs and dams was maintained. His duties consisted of keeping up the oil level of the engine and stopping and restarting it when necessary. The job presupposed a limited technical knowledge although few workers were expected to carry out repairs on the equipment. There was a degree of responsibility, however, as the lives of the cattle depended on the bore in his care. If any problem arose with the equipment, he had to exercise sufficient initiative to contact the management or make running repairs. Indeed, it was not uncommon for cattlemen to leave stock of a value of $f^{20,000-}, 30,000$ in the hands of Aborigines who might in other circumstances be described as unreliable.

The unique combination of isolation and initiative which was present in the appointment of Aborigines to the position of pumper seemed to run counter to the many allegations of the unreliability of the native work force.

The continued occupation of these posts by Aborigines, combined with the generally low appreciation of their mechanical aptitude by the majority of employers, strikes one as being contradictory in nature. When put to the test, and the area of responsibility clearly defined, it would seem as though fairly unsophisticated and illiterate employees were able to satisfy even the most exacting masters. Possibly the isolation of most pumps with Aboriginal attendants made management's adjustment to the situation a prime requisite for the appointment. Few, if any, whites welcomed the task. 
The pump sites visited during the survey were occasionally up to 100 miles from the homestead and frequently more than 30 miles from the nearcst habitation. The pumper's accommodation, invariably with his family, or at least a wife, was a corrugated iron shed, without lining or flooring. This he shared with the diesel motor which operated most of the time-its stcady chugging sending up oil fumes and rattling the loose sheets of iron in a continuous quiver.

In the summer the end of the shed, where the belt delivered the drive to the motor, was kept open. However, during the winter the gap was stopped up with scrap material leaving only a small hole for the belt to poke through. With the hinged corrugated iron 'windows' firmly clamped shut, the atmosphere inside might have been warm but was obviously toxic.

Food was delivered to these locations about once a week. As the supervisor of the pumping operations on the stations normally made a circuit of pump sites, being away from the homestead for several days, the fare delivered to the pumper consisted of salt beef, flour, sugar and tea; fresh beef was a rarity.

Only in a few locations did I witness any attempts to provide pumpers with the simple civilised comforts of even a bed or a chair. Rest was taken during the day sitting on the top of an upturned oil drum. At night the employee would sleep either on two hessian bags slung between saplings or on the ground on a swag or ground sheet.

The obvious ability of Aborigines to master the mechanics of pumps, and the carefully monitored responsibility for this facet of the station's operations, was demonstrated on one of the largest properties visited. Following an inspection of the Aboriginal camp the manager pointed out to me a pump which he had installed solely for supplying water to the camp. He shook his head somewhat in amazement and said:

You know that bloody pump has been working continuously now for five years and has never missed a beat. Somehow they just keep the damned thing going. But if you send them out on the run to bring in a mob of cattle they will ride straight past a pump that they know should be working, and will never try and do a damn thing about it. What is worse, they will come back home and never let on that there is something wrong for fear that I will send them out to fix it.

When necessary it seemed as though both management and Aboriginal staff had the ability to adjust, and the cultural gap was pushed aside for common survival. Co-operation, however, seemed limited to the accomplishment of those things which had to be done, and went no further. 
Butcher and cook. Few employees were in these categories as very often different employees would take turns in carrying out the tasks. For reasons of hygiene the white management usually insisted on butchering its own beef. The position in the Northern Territory was different from that in Queensland where most properties employing Aborigines had at least one indigene reasonably proficient in the butchering trade.

Yard builder. Few stations employed yard builders solely on this task. However, there are contract teams of Aboriginal yard builders in the Northern Territory. As most employees lacked measurement knowledge, employers complained that their work was not as good as that which was executed under white supervision. However, many of the yards constructed by Aborigines were noted to be both functional and sturdily built.

Fencer's offsider and boundary rider. These two categories were similar in responsibility and had the object of maintaining the fences in a strong state. Given the size of northern properties this was no mean task. Many employees listed as stockmen and general hands were also called upon to do this work. The erection of a sound fence presupposed a limited mastery of certain technological skills. It necessitated knowledge of the use of wire strainers and snips as well as manual dexterity. It was also an advantage to have a knowledge of mensuration as one had to be able to string the wires evenly along a great number of posts over undulating countryside. The development of 'blackfella proof' systems for this work made an interesting commentary of the problems faced by illiterates in approaching even the most simple mechanical tasks. Indeed, on hearing this story, I could not help thinking of certain difficulties experienced by manual arts teachers when endeavouring to combine manual dexterity and formal geometric education in the young.

A 'blackfella proof' system was described to us in this way:

If you want a selection of posts five feet long do not try and explain it to an Aborigine. Cut one post a foot longer than what you want, but of the right thickness, and then ask him to bring you back posts similar to the sample. You should then have a worker at the camp whose job it is to cut the posts to size, alongside another sample. When boring the holes for the wires do not ask an Aborigine to push holes through with a drill every eighteen inches, but give him a board as a guide with three holes drilled in it and let him go ahead on this basis. Only in this way will you be assured of getting a fence which does not look too much like a dog's hind leg.

Improvisation by management in this way was not particularly common. There was a tendency for employers to assume that the tech- 
nology they had inherited was immediately transferred to their Aboriginal staff. However, in all but a few cases, they had never extended to them the education, literacy and training that they themselves had obtained, and which is a vital part of industrial orientation. However, when the gap was recognised a practical response to the problem in a manner similar to that outlined above was bound to raise productivity not only with illiterate Aborigines but also with unskilled and inexperienced whites.

Quite frequently, it appeared, it was not the Aborigines' fault that the standard of endeavour had not come up to expectation, but the failure of the employer to equip him properly for the task at hand.

Youth. The Wards Employment Ordinance precluded the employment of wards under the age of fourteen years. It was customary, however, on properties without schools for persons under this age to 'help out'. Their duties ranged from opening and shutting gates, lighting camp fires and, depending on age and strength, they were even assigned to tailing horses, heating branding irons and droving. As only a small percentage of the properties visited had schools, child labour seemed to be an important aspect of operations.

Slow worker. The Wards Employment Ordinance allowed for the declaration of certain individuals as slow workers on agreement with a welfare officer and the payment of a lower rate. We only met one reference to this type of employee, but were unable to determine whether the employees concerned were formally declared slow workers or were receiving their lower rate simply by the decision of the management.

Domestic. Domestics had a wide variety of duties around the homestead. However, as many of the posts are interchangeable clear delineation was difficult. Consequently, I have simply referred to most female homestead employees as domestics.

As with other categories, the pattern of work and the skill and reliability of the employees varied considerably. However, as much as these factors varied so too did the attitudes of the European women towards the Aboriginal domestic help. In many cases one found Aboriginal staff preparing meals and waiting on table in a faultless fashion. In other cases they went about their duties in a slovenly and indifferent manner. Obviously training and motivation had much to do with employees' attitudes. They were also considerably conditioned by the employers' own standards and attitudes to their work forces. Many properties, since 
they provided only substandard accommodation for both white staff, as well as the Aborigines, were hardly conducive to a high level of efficiency or the application of sophisticated policies towards the integration of the native work force. Combined with poor managerial salaries the industry appeared to operate at a very low level of expectation, both in human relations and animal husbandry techniques.

The cultural and social gap between the homestead and the Aboriginal camp seemed to complete the cycle of restraint which neither party was prepared to breach.

One station manager's wife made an unwitting reference to this when she said that she could not understand how her girls, so reliable in the homestead kitchen, could readily return to the filth and the lackadaisical ways of the camp where no water or kitchens were installed. Indeed, it appeared that little thought had even been given by the management throughout their entire operation to insisting on the maintenance of equal standards of hygiene. Where native habits were likely to impinge on white comfort, appropriate reactions were quickly taught. Where Aborigines were the only ones who suffered by neglect, no action was taken.

However, in the process strange relationships often came to light. Standing on the verandah of the staff quarters of a large property after inspecting their expensive modern kitchen in which full-blood Aboriginal women worked with advanced equipment-baking bread, mixing cakes, producing food to the satisfaction of all-I recall seeing the same employees at the rotary clothes hoist immediately outside the kitchen take clothes from the line and drop the pegs into the mud, trampling them under foot as they went. The cook at the station did not see the laundry activity as his domain and had no reason to insist on the same standards as applied in the kitchen.

\section{COMMENT ON THE GENERAL STATISTICS}

The extended results of our survey produced a figure for the total Aboriginal population resident on pastoral properties which was close to the estimates of the Welfare Branch of the Northern Territory Administration. This seemed to add support to the projections of cattle numbers and to confirm the balanced nature of the sample group.

The total numbers of persons employed, however, varied slightly from official estimates. The figures relating to females employed were issued by the department four years previously and were consequently 
out of date. However, that fact could not have accounted for the difference of 45 per cent. It was interesting to note that the estimates of Aboriginal males employed did not vary to the same degree, there being a difference of only 8 per cent to 10 per cent, depending on the numbers ascribed to employment in the agricultural industry.

That there could have been other reasons for the discrepancy became evident in the section devoted to social services and subsidies (pp. 83, $91,97)$. In that section the basis on which allowances were paid for certain Aboriginal residents on pastoral properties was examined. As the sums paid under this head were quite substantial, there appeared to be an open encouragement for managements to over-estimate the number of unemployed Aborigines as far as official returns were concerned.

The relationship of children to adults in the figures taken out by me gave support to the work done by Miss B.H. Watts of the Education Department in the University of Qucensland in the Watts-Gallagher report on education in the Northern Territory.

Increasing numbers of parents who find employment off the settlement[s] [were] tending to place their children in the care of relatives remaining on the settlement so that the children might not suffer interruption to their schooling ... When we [examined the situation] in relation to children under 16 years we [found] . . . this age group [on selected settlements constituted] $50 \%$ or more of the total population... ${ }^{31}$

Comment should also be directed to the fact that, by deducting the numbers of children and pensioners from the total population, there was a surplus of 1,406 adults resident on the stations who were not apparently engaged in production. This number was made up of 1,108 females and 298 males. The figure, however, should be considered in light of the practice of pastoral managements to use the Aboriginal camps as a pool of readily available labour, changing their recruitment practices as the work load on the properties fluctuated. The deliberate understatement of the number of Aborigines employed by managements, as witnessed by Berndt, must also be recalled when endeavouring to appraise the influence of this group on the station economies. ${ }^{32}$

Looking at the overall balance of 'productive' workers to resident population, little support could be given to the constant criticism of many cattle station managers that it is not the workers we mind so much but it is all the "hangers-on" that we have to look after'.

${ }^{31}$ B.H. Watts and J.D. Gallagher, Report on an Investigation into the Cuiriculum and Teaching Methods Used in Aboriginal Schools in the Northern Territory, Department of Territories, Darwin, 1964, p. 6.

${ }^{32}$ Berndt, 'A Northern Territory Problem', pp. 57-60. 
As 40 per cent of the Aboriginal residents of Northern Territory cattle stations were employed, and this approximated the level of employment in the broader Australian community, ${ }^{33}$ little support can be given to the pastoralists' criticism of their native work force in this way. Indeed, as the conditions of employment offered by the cattle stations were substandard in European Australian terms, it could not have been considered an imposition for them to offer greater benefits to the families of employees than in fact they were prepared to provide.

${ }^{33}$ Commonwealth of Australia, Yearbook 1968, No. 54, p. 1154. 


\begin{abstract}
A report of the Arbitration Commission hearing on equal wages for A Aborigines described the approach by the employers' advocate as follows:
\end{abstract}

What he did ... was to present the Commission with views and opinions of anthropologists, of the Federal Government, of missionaries, of doctors, of pastoralists, which together added up to a picture in which the bulk of Aborigines in the North were not equipped for or disposed to working to the level of a member of the white community'. 1

It was with the idea of obtaining an objective view of the value of Aboriginal labour to the cattle industry of the Northern Territory that our questionnaire was designed. The answers can be used to test the validity of the views of the employers, as presented to the Commission, from the experience of the people who were actively cmploying and utilising the labour referred to but who were not subject to the selective procedures of courtroom practice.

The suitability of Aboriginal labour was investigated through the administration of a series of formal questions. As mentioned previously these were designed more to give direction to our inquiries than to limit discussion by placing artificial restraints on replies.

Not all employers were consistent in their replies. Answers to the first series of questions were often later contradicted. Initial general impressions were occasionally changed to directly opposite attitudes as discussion expanded and individual cases were discussed.

1 Brian Johns, 'Beyond Kalumburu', Bulletin, Sydney, 21 August 1965, pp. 17-18. 
For example, one cattleman was asked his impression of Aboriginal workers and his immediate reaction was that 'they're a bunch of "no-hopers"'. Later on in the discussions we asked him how many of his employees were worth an Award wage, and he replied 'the lot'. When questioned a little more deeply, and asked why he had given this answer in view of his earlier statement, he said that he considered that his Aboriginal workers were worth the Award because 'they work hard'. The first response, accordingly, seemed to be the result of the initial gruffness cattlemen frequently extend to strangers.

I have purposely singled out this case to emphasise the uncertainty of some of the replies. Apart from the fact that there appeared to be almost two aspects of each reply received-one in support of Aboriginal labour and one against-there was an ever-present overtone of opinion almost amounting to folklore. The concept that 'this is their country and something more ought to be done to help them' usually conditioned a cattleman's reply to our inquiries. Regardless of how harshly an employer desired to portray himself, there appeared to be in most cases a deep concern for the future of the Aboriginal race, in particular his employees. Only on two occasions did we experience the callousness, noted by Berndt, in which he mentioned that some managements expressed either 'indifference or positive pleasure at the thought of [the Aborigines'] ultimate extinction'.2

Aborigines have been part of the industrial labour force of the Northern Territory for over a century, and have also been one of its most colourful social groups. Because of this, it was difficult clearly to separate an employer's opinion of the economic value of his labour force from the multitude of other factors which conditioned his opinion of his workers as 'desirable employees'. Because of this we were forced to rely on some replies which were generalisations and conditioned by factors which were external to the problem at hand.

For example, one employer was highly critical of Aboriginal labour, not because of its ability, but because of a fight which had developed on his property some years previously. His answer to the question concerning productivity was conditioned by his thoughts that 'they were not worth the trouble'. Consequently a problem of social discipline was superimposed on a question demanding appraisal in economic terms.

Whilst on the question of social environment, the general picture concerning political activity on Aboriginal problems, Australia's affinity

2 Berndt, 'A Northern Territory Problem', p. 66. 
with the United States, and the impact of mass media cannot be overlooked.

If Texan hats and shoes were fashionable how did other 'Americanisms' condition the mind and, as a consequence, affect the answers to our questions? For the first time in my travels in Australia I heard the common use of derisive expressions such as 'niggers' and 'coons'.

Because of this I cannot help feeling that some of the replies simply displayed a person's concept of race theory and were unrelated to the problem at hand.

'Suitability' for the Arbitration System. Before proceeding to present tabulation of the replies received from pastoral employers concerning the value of their Aboriginal labour force, it might be of assistance to distinguish the principles of wage fixation which form the basis of industrial practice in Australia.

The development of Commonwealth arbitration law in this respect is normally traced back to the Harvester Judgement, ${ }^{3}$ in which the court laid down the first 'basic wage'. ${ }^{4}$ In this case the foundation of wage determination was accepted as being that any wage paid to an employee was to be 'fair and reasonable' and that this meant sufficient to cover the 'normal needs of the average employee, regarded as a human being living in a civilised community'.

Although litigation over the years has considerably refincd this principle, it was restated in the Commonwealth Arbitration and Conciliation Act in 1949 in the following way:

the basic wage for adult males [is to be] . . that wage . . . which is just and reasonable for an adult male, without regard to any circumstances pertaining to the work upon which or the industry in which, he is employed $\ldots .^{5}$

Earlier the Arbitration Court considered the principles involved and stated:

the basic wage is the amount which the Court awards to an adult male worker, considered apart from the particular industry in which he works, requiring and displaying nothing in the nature of experience or skill, sufficient to warrant any additional recompense, and enduring no particular conditions which in the eyes of the wage fixing authority would call for some special compensation .... . ${ }^{6}$

${ }^{3} 2$ C.A.R. 1 ex parte H.V. McKay (1907).

${ }^{4}$ C.P. Mills, Nolan and Cohen's Federal Industrial Laws, 3rd ed., Butterworth, Sydney, 1963, p. 193.

${ }^{5}$ Commonwealth Conciliation and Arbitration Act, 1904-1961, S. 33.

- Commonwealth Conciliation and Arbitration Commission, in re Metal Trades Award, 29 July 1948; unreported, quoted in Mills, Federal Industrial Laws, p. 192. 
Consequently, the court had ruled that the wage determined in those circumstances was to be the minimum wage payable-regardless of the industry in which the employee worked, or his ability or skill. The question was one 'of social justice' in the first place, and then an appraisal of the skill, experience or onerousness of the job leading to the determination of the total minimum wage.

As we have seen, Aborigines by an inexplicable decision had been kept outside the Arbitration system at least since 1951 and there was no genuine attempt to appraise their individual skills.

By a similar omission the 'basic wage' by which they might have been covered was approximately two-thirds of the weekly legal minimum rates applicable to other Australians. This was the Award rate in the Cattle Station Industry (Northern Territory) Award which at the time of the study was eleven years behind other awards.

It should also be borne in mind that when there is reference to such factors as productivity and skill we are discussing a situation which fell outside the principles of basic labour rate fixation. Skill and productivity, however, were considerations by which Aborigines were to be judged as worthy or not worthy of the basic wage. For Australians of European ancestry it was their inalienable right as members of the work force. The ready accommodation of numerous persons of varying social, racial and educational backgrounds into the work force since World War II, and the extension to them of the standards and protection enjoyed by all other Australians, indicated that questions of productivity and skill were of little importance in the first determination of the 'just wage' although they might have effectively prevented the elevation of the individual to the category in which additional margins were payable.

\section{THE DIALECTICAL CONSIDERATIONS}

The replies to our questions were abstracted from discussion which often lasted for many hours. However, each individual's views have been abbreviated to enable the essence of their replies to be compared with the thoughts of others. All three interviewers independently appraised the answers and agreed with the abstractions and their enumeration. However, it could be argued that by abstracting in this way, the answers have been oversimplified to the point where they are meaningless. Where individual replies contained a number of separate and distinguishable terms they were abstracted and included in the tabulation.

Thus, to enable balance to be brought back to these views, an endea- 
vour should be made to explain the dialectic of the individual replies.

(1) In the past five years have you tended to employ more whites?

$\begin{array}{lr}\text { More } & 9 \\ \text { Fewer } & 9 \\ \text { Same number } & 12\end{array}$

The answer to this question reflected, in part, the varying pattern of development of the cattle industry in the Northern Territory. Whilst the Top End was expanding, the Centre had cut back production because of the drought.

However, it was of interest to note that although the overall carrying capacity was rising it did not appear as though there was a proportionate increase in the demand for white labour.

Given the comparative wage levels-between white and blackincreases in production tended to be brought about by the application of a higher percentage of Aboriginal labour than white. Employers showed this intention by their concern over the shortage of Aboriginal labour in the north-west areas of the Territory, ${ }^{7}$ and through statements made in connection with the Forster Committee Report in 1960.8 An indication of employers' preference for increased European labour in these circumstances would have required a larger number of replies favouring the displacement of Aborigines.

Whilst cattle management techniques in the Northern Territory remained unchanged, the indigenous skills and endurance displayed by Aboriginal workmen had considerable advantage over those of the more sophisticated training of European workers. The open range method of cattle grazing was still the dominant form of pastoral activity. This required the application of local knowledge and a way of life passed in what are often gruelling climatic conditions.

Regardless of the preference of management for either black or white workers, the introduction of European workers demanded an increase in investment in facilities not always commensurate with the returns involved. One famous property in the Territory had increased its staff amenities to a stage where management could make a decision whether to employ either Aborigines or Europeans, and had reduced the numbers of Aborigines employed by one-third. Turnoff, however, remained below that which was achieved by the previous owners who operated the station almost entirely on Aboriginal labour. ${ }^{9}$

7 Annial Report of the Weljare Branch, 1963-64, p. 83.

${ }^{8}$ Department of Territories, Prospects of Agriculture in the Northern Territory, p. 52.

${ }^{9}$ Commonwealth Conciliation and Arbitration Commission, No. 830 of 1965, p. 654, where 
Although a decision by management to change over to white employees might have increased the flexibility of the work force, it did not necessarily increase cattle turnoff. Regardless of investment, cattle still had to be handled physically. Equipment did not replace the necessity for contact between the employee and the herd, and, except in certain special circumstances, property improvement actually increased the demands on field labour. This was brought about by an increased investment in improving herd quality and the need to control joining and turnoff to reach revenue projections.

Indeed, in most cases it would appear that additional investment brought with it increased responsibilities for both labour and management, and that the special skills which were the prerogative of whites, because of literacy and other factors were only a partial solution to increased production. The necessity for balance in the work force was evident from the following circular issued by the office of the inspector of a substantial pastoral group; this group had been engaged in a property development program in north Australia of some magnitude for over two decades.

\section{$L A B O U R$}

\section{'CIRCULAR'10}

As a matter of interest, herewith is the composition of the work force on the various properties as at the end of October together with a comparison of labour this time last year.

\begin{tabular}{lcccc} 
& \multicolumn{2}{c}{1965} & & 1964 \\
Property & White & Native & White & Native \\
A & $\%$ & $\%$ & $\%$ & $\%$ \\
B & 57 & 43 & 52 & 48 \\
C & 100 & - & 100 & - \\
D & 52 & 48 & 56 & 44 \\
E & 58 & 42 & 32 & 68 \\
F & 66 & 34 & 63 & 37 \\
G & 55 & 45 & 45 & 55 \\
H & 86 & 14 & 83 & 17 \\
I & 95 & 5 & 86 & 14 \\
All stations percentage & 100 & - & 100 & - \\
Numbers & 72 & 28 & 68 & 32 \\
\hline
\end{tabular}

the new proprietors optimistically hope for 8,000-10,000 turnoff. See also Kelly, Report on the Beef Cattle Industry, pp. 141-2 and Struggle for the North, Australasian Book Society, Sydney, 1966, p. 25. Confirmed in private discussions 13 November 1967.

${ }^{10}$ Letter from major pastoral company on private file, 23 September 1965. 
For some time past it has been apparent that there has been a gradual decline in the native work force for reasons which are possibly too complex for simple conclusions to be drawn.

Whatever the rcasons, some of the properties can and do still employ a significant proportion of native labour, while it is known that other properties outside the Group employ native labour to a larger extent than we do.

Although total numbers in the work force in the Group of Companies remain substantially the same as for this time last year, our native labour is down by $12 \%$ of the total. ${ }^{11}$ In addition to this, there is ample evidence which points to a greater turnover of total labour.

Both these factors are detrimental

(a) to wage costs,

and (b) to efficiency.

This circular is intended to direct the attention of managers to the obvious need to stabilize, as far as possible, the work force of experienced station hands and also to attempt, where possible, to redress the imbalance between white and native labour. Your comments on this problem would be appreciated.'

The normal adjustment brought about by increased production was to spread the available skilled labour over a wider range of activities; additional Aboriginal labour under white supervision was then added. There was occasionally an upward shift of Aboriginal work responsibility, but this was infrequent. On smaller stations, particularly, managers tended to elevate individual Aboriginal workers to semi-managerial positions by ascribing a distinctive title- 'camp boss', 'leading hand', etc. This rarely occurred on the larger properties. On these, the racial division was more pronounced.

It should also be noted that elevation in title and status of members of the Aboriginal work force was rarely joined with a proportionate increase in salary. However, other rewards in the form of responsibility for drawing of supplies from the store, for the cattle camp, or the apportioning of beef in which the individual concerned could favour himself with better cuts or quantities provided at least partial compensation for the increased responsibilities.

There were several ways by which cattle stations might have overcome the increased need for labour. In the main this was done by recruiting additional native workers and not by increasing the number of white

21 The original letter reads ' $9 \%$ '. As this is an arithmetic error the percentage has been changed. 
employees. Uncertainty of seasons, unreliability of white workers and their comparative geographic mobility were factors in the decision making of station managers.

The section of our questionnaire in which we asked the reasons for employing more or fewer Aborigines did not produce any clear trends. Eight stations reported less demand for white labour (and black) because of the drought. Four stations stated that they were employing more whites because they were developing their particular property. They did not refer so much to increases in cattle numbers as to increased capital investment in plant, equipment, pastures, buildings, etc. Such development increased the demand for skilled and semi-skilled tradesmen, virtually excluding Aboriginal applicants, but it did not decrease the number of persons who 'work' the herd.

One person summed the situation up by saying:

My boss wants to press on with a program of pasture improvement. The Abos wouldn't have a clue what we would be talking about.

(2) Can you get sufficient white labour?

$\begin{array}{lr}\text { Yes } & 15 \\ \text { No } & 9 \\ \text { No comment } & 6\end{array}$

The general impression was that sufficient white labour could have been recruited. There were, however, reservations about its suitability. A strong preference was displayed for recruitment of persons from outside the Territory. Indeed, many of the comments on the suitability of local European labour contained similar remarks to those given to our inquiries concerning Aboriginal labour. Laziness, lack of skill and drunkenness were all features attributed to whites who might have been recruited locally.

Some employers were conscious of the fact that they had been able to recruit labour in the past from southern areas, primarily because their requirements were small. They were also ready to point out that, if there was a large increase in their need to recruit white labour, their usual sources would not have been sufficient.

Other employers mentioned the associated recruitment costs of travel and improvement of residential facilities which militated against engaging additional white labour.

(3) Can you get sufficient suitable Aboriginal labour?

No 
There was an overwhelming answer in the affirmative. People answering in the negative, although recognising the availability of Aboriginal labour, did not consider it suitable for many reasons. The large number of stations which reported an adequate supply of suitable Aboriginal labour might be compared with the figures referring to the productivity of Aboriginal labour in questions 5 and 6 .

(4) If you could get sufficient suitable white labour would you replace your Aboriginal labour?

$\begin{array}{lr}\text { Wholly } & 0 \\ \text { Partially } & 17 \\ \text { Not at all } & 10 \\ \text { No answer } & 3\end{array}$

The answers to this question displayed the inconsistency of many of the managers' attitudes towards Aboriginal labour. If seventeen station managers replied that they would replace their Aboriginal labour partially if they could get suitable white labour, and fourteen stated that they could get suitable white labour, why did they not replace Aboriginal labour? The fact that there were no significant moves to replace Aboriginal labour indicated that under the conditions operating the existing mixture of native and white labour was the most desirable method of operation.

Every station manager interviewed felt that he was content to keep native employment at the then current level if wages did not rise. It was also of interest to note in this respect that of the stations employing Aboriginal labour, only one manager stated that he would do without native labour entirely if he was forced to pay Award rates.

(5) \& (6) In your opinion are Aborigines more productive workers than whites?

Yes

16

No

No answer

2

In the light of the learned onslaught of counsel before the bench of the Arbitration Commission, I have placed the above figures on record with some hesitation. Indeed, it was not without a great degree of simplification and abstraction that the above conclusions would be reached. Possibly it will be of assistance here if I explain the term 'productive'. In this situation productivity could only apply to the two aspects of station work: it could apply to the work actually carried out by Aborigines; or it could mean productive in the sense of potential for overall contribution to the stations' work programs.

The second standard necessarily presupposes a degree of technical 
skill and flexibility for which Aborigines are, firstly, not trained and, secondly, not employed.

Consequently, I have accepted the first criterion and have tried to assess the answers accordingly. The accuracy of the abstractions and tabulations was formally discussed with the other members of the initial survey and received their endorsement.

Further, in many cases the persons who answered in the negative were not openly condemnatory of Aboriginal labour. Although these station managers were not prepared to concede that Aborigines were more productive than whites, they granted that they were as good as whites in the job for which they were employed-cattle work.

An interesting example of the diverse opinions held on the stations was obtained in an interview of a white 'camp boss' shortly after we had spoken to the manager of a large property. The employer had stated that only about one-third of his employees could justify an Award wage. The camp boss believed that more than 50 per cent of the 'boys' in his camp were worth an Award wage. Possibly one interviewee was applying the broader concept of productivity and the other was applying the narrower.

There was also considerable reference to individual abilities. Indeed, this was a surprising departure from the tendency to depersonalise Aboriginal workers in other circumstances. Such comments as 'Johnson would be supreme' or that 'no white man could match X' were fairly common.

(7) If you feel that Aborigines fall short of the mark can you say why and in what respects?

Reason

Management

(a) Need constant supervision

Number replying

Unreliable

Cannot supervise one another 3

Lack initiative 2

No incentive 2

Educational

(b) No mechanical aptitude 4

Unable to follow complex instructions 2

Cannot tell the time 1

Cannot drive 1

Cannot make reports 1

Not responsible with equipment 1

Cannot write 


$\begin{array}{ll}\text { Technique } & \\ \text { c) Bad horsemen } & 1 \\ \text { Bad horsebreakers } & 1 \\ \text { Cruel with stock } & 1 \\ \text { Do not know stockwork } & 1 \\ \text { Do not like stockwork } & 1 \\ \text { Social } & \\ \text { d) They go walkabout } & 1 \\ \text { Get drunk } & 1 \\ \text { Get bored with work other than cattle } & 1 \\ \text { Too much trouble } & 1 \\ \text { Liars } & 1 \\ \text { Not interested in work } & 1\end{array}$

The answers to this question were intriguing. The two main reasons why Aborigines 'fell short of the mark' were given as their need for supervision and the fact that they were unreliable. Both of these answers were based on similar considerations.

One of the reasons given as to why an Aboriginal needed constant supervision was that he could not follow complex instructions, and that this in turn was conditioned by some or all of the other factors mentioned in the second category set out above. There were obviously genuine problems of communication in the everyday running of cattle stations. But only rarely did we note that any of the managers had become fluent in an Aboriginal language.

Difficulties in expression and comprehension are frequently associated with illiteracy. The problem becomes greater where there is a language difficulty as well. I have experienced similar comprehension gaps whilst working with illiterate rural labour in California. In this latter case, however, the problem of communication was not the sole preserve of alien employees as there were many Caucasian Oklahomans involved in the confusion. However, it was interesting to note that many of the attributes alleged to be the special preserve of Australian indigenes were also applied by management to the shortcomings of migrant labour in California.

In the north Australian context the problem was highlighted by a windmill salesman casting doubts upon the work of a European maintenance man on one of the stations. After having inspected a malfunctioning mill he called the parentage of the European mechanic into doubt informing the manager that "he must be a silly bastard as the operating instructions were clearly marked on the base of the mill'. The manager 
rose to his employee's defence, informing the salesman that he was one of the few illiterate whites that he had met and consequently needed more sympathetic consideration. Rarely was a similar defence raised on behalf of Aborigines. Their lapses were normally considered to be genetic in origin.

A sample of the replies further emphasised these problems:

they could not work out the stages of a cattle project;

they had no mechanical ability;

the time factor was of no importance to them;

you could give a half-caste two or three days grace on a job, but a full-blood needed constant supervision;

they could count but not apply the figures to simple practical solutions;

if constantly supervised they worked as well as whites.

Unreliability and the need for supervision could, of course, relate to industrial morale. That this was an obvious point of concern was evident from some of the answers to our next question.

In few instances was it possible to report management techniques designed to maximise Aboriginal labour potential. However, in the few examples of optimum deployment of the native work force morale seemed to be appreciably higher than the average. That an increasing consciousness of the futility of their situation appeared to be growing amongst cattle station Aborigines will be discussed later on.

Those managements which had given thought to the processes of acculturation with which they were faced frequently had greater rapport with the native work force. This usually went hand in hand with better food and accommodation.

During our survey it was noted that only few stations had provided accommodation even roughly in accord with their legal requirements under the Wards Employment Ordinance. However, where reasonable facilities were provided, and management displayed some interest in maintaining their appearance and cleanliness and clearly imparted their desire in this regard to the work force, Aborigines appreciated the facilities. ${ }^{12}$ There were, of course, other cases where improved facilities had been installed and which had deteriorated over a fairly short period of time. In these cases there normally appeared to be a correlation between the neglected physical state of the white homestead, the deterioration of physical plant and yards, and the unkempt state of the Aboriginal camp. In one particular case, which was outstanding for the impeccable order of

${ }^{12}$ Berndt, "A Northern Territory Problem', p. 8, also confirms this point. 
the Aboriginal quarters, management showed a high appreciation of the value of their Aboriginal work force. We also noted that this particular property was unique in the well-ordered way in which the daily tasks were carried out. Everybody was conscious of their contribution to the station's operations and their responsibility and went about their tasks each morning with little instruction, direction, force or encouragement. The manager at this property summed his personnel policy up succinctly:

There's no room for Bludgers on this property. Everyone's employed. They all have a job to do or they can get off. We don't want people sitting around the camp stirring up trouble. It's better that they have got something to occupy their minds.

There was also a close correlation between the managements which had developed some rapport with the native work force and those which stated that they would be prepared to retain a relatively large number of their full-blood employees should Award wages be granted.

One can also see from the figures that few managers have referred directly to education or literacy as a factor affecting productivity amongst Aborigines. As the work of about 76 per cent of the Aboriginal employees required mainly physical dexterity there was little scope for mental or educated skills.

Walkabout. One of the most colourful alleged attributes of Australian Aborigines appeared, on analysis, to be of little consequence. Indeed, more persons referred to the ready availability of Aborigines as one of the major attractions of employing them and not that walkabout made them unreliable. Walkabout seemed no more mysterious than industrial workers desiring a break from a gruelling physical task. Given the inadequate diet on most stations, one could not exclude the possibility that the 'inexplicable' wanderlust of Aboriginal employees was considerably induced by a craving for increased vitamin intake. It was significant that in many areas walkabout took Aboriginal groups to areas favoured for their native produce, and not necessarily to the towns where greater excitement and educational experience could be found.

Most managements, however, had contained the 'desire' to go walkabout and exploited it for their own purposes by releasing employees when it was convenient for them. This release was often without notice and occasionally without food, or even the proper wages which had accrued to them.

Supervision. Management technique has two different aspects depending on whether you are a manager or one who is managed. It is a human 
failing for most individuals to consider that they are efficient in their allocated tasks. However, criticism by management that employees need too much supervision seems to be endemic to most white industrial situations.

The need for supervision might arise either from the lack of application of the employee or through the inability of the manager effectively to impart instructions. We have already seen that few managers were able to converse with Aboriginal employees in their own language. Similarly, few Aborigines were literate in the English language-an indication that their range of verbal comprehension was also limited. In these circumstances the ability to impart instructions clearly, and the employee's skills in interpreting management's requirements, were undoubtedly impaired. Exactly where responsibility should rest for an improvement of the situation was difficult to determine. Obviously an improvement in the standards of English education of the work force would be of great assistance. However, at the time of the survey, as will be seen later in the study, the stations were inadequately provided with educational facilities and some employers even resisted their introduction.

Many cattlemen also complained of Aborigines' inability to carry out a complex sequence of tasks on their own. It was possible that in these situations an understanding of the problems at hand was an integral part of executing the job to the employer's satisfaction. Where communication was difficult, brevity was often the result. The more complex the task, therefore, the greater the misunderstanding.

Further, some employers claimed that they often returned to the work site where Aborigines had been entrusted with a particular program, and found them resting or asleep under a tree without having completed the assigned duty. Lethargy might be psychological or physically induced. Later in this study the dietary intake of Aborigines is considered. It was obviously insufficient for individuals engaged even in a sedentary occupation, let alone the gruelling physical tasks of the cattle industry.

Incentive must also be taken into consideration. In the limited cash economy which exists on cattle stations there is little encouragement for Aborigines to do more than is absolutely necessary for survival. Over the years Aborigines have determined the balance between employment and rest that is necessary to survive on any particular station, and have conditioned their application accordingly. In the absence of incentive to work, the pursuits of leisure frequently seem more attractive. One pastoralist indicated this aspect of the relationship when he complained 
that Aborigines would frequently go off and chase a goanna when they were tracking cattle.

The encouragement and reward system in any industrial situation must also be preceded by a certain degree of induction or training, no matter how rudimentary the task involved might appear. The need for orientation in any particular industry is greater where ethnological or illiteracy factors are present. Training in the techniques and disciplines of the cattle industry in northern Australia was very limited. As will be demonstrated later in this study, however, the requirements are quite complex. The necessity for training was often indicated although not one station visited had any formal training program. On most stations it was even impossible for native children to gain experience in the cattle industry-either through riding lessons or more formal inductionuntil they were actually lifted into the saddle in a work situation. This experience was alluded to in the 1965 Arbitration Commission hearing in the following way:

Kirby C. J.: When they first start to ride, I suppose they ride bareback just like other Australian children.

Cattleman: That is right.

Kirby C.J.: And they just ride on and develop bad habits?

Cattleman: If you can ride bareback that is the essential part, as you get your balance, and when you get a saddle, it is much better.

Kirby C. J.: That is what makes it so strange: if they start on bareback then get a saddle they are then heavy handed and tend to worry the horses? It seems that there is a complete lack of training there ... if children get on the horse's back and they are not told that, they have the tendency of becoming heavy handed, and this would be the case whether they be black or white. ${ }^{13}$

It would also scem that the gap which existed between black and white groups on the cattle stations precluded the normal communal educational processes experienced by the young in Western society. The lack of practical experience in learning situations necessarily led to the need for greater application of work site education supervision techniques in the early stages of employment. As this was not carried out, various undesirable habits developed. The practices then became firmly entrenched and, thus, were even harder to eradicate.

For example, one person complained about the habit of his Aboriginal workmen of throwing their saddles and saddle cloths on the ground at the end of a day's work. As a consequence the saddle became full of dust and the cloth covered in burrs. This then irritated the animal. When

${ }^{13}$ Commonwealth Conciliation and Arbitration Commission, No. 830 of 1965, p. 275. 
horses were plentiful and men tired, it was an easily understood reaction. How long the actions had been tolerated by their white supervisors was unknown, but obviously there was a causal relationship between past training and present habits.

There also appeared to be some degree of balance between the attitudes of the managers and the managed. Most cattlemen had an understanding of how far they could 'push' their employees, and when they had either to do the job themselves or leave it for another day. The Aborigines in turn knew just how far they could test the patience of their employer. Not unlike similar situations in factories when morale was strained the work still seemed to get done, albeit at a slower rate.

Finally, the preponderance of management replies suggested that any improvement in the acceptance of Aborigines as employees would come through the narrowing of the gaps in communication and response on the indigenes part. Notwithstanding the overwhelming importance attached to these considerations, it was doubtful whether an improvement in educational and technical knowledge would lead to any revolutionary change in acceptance of Aborigines as employees. Although an improvement in this direction would undoubtedly decrease the necessity for supervision of certain of the more sophisticated aspects of station work, the very high standard of Aboriginal endeavour in practical cattle work seemed to more than compensate for their deficiencies in other areas. As most stations visited in the Northern Territory were sufficiently large to organise their work force on a specialist basis, there was little outlet for diversification of skills. This, in turn, brought about a further reduction in Aboriginal work site opportunities. The confinement of Aboriginal experience in this respect is dealt with at greater length later in this study.

(8) If you feel that Aborigines are more productive than white workers can you say why and in what respects?

Reasons

Number of Replies

Traditionally Oriented Skills

Stock work $\quad 8$

Tracking 6

Bushmanship 5

Mustering 3

Knowledge of local country 3

Horse work 2

Less likely to get lost 1

Branding 1 
Management Oriented Skills

Better suited climatically 2

Good at supervising others 5

Do not need supervision 2

Do not knock off at 5.00 p.m. 1

Better at repetitive work 1

Technically Oriented Skills

Good pumpers 1

Good at yard work $\quad 2$

Good at fencing 2

Good at bore work 1

Have mechanical ability $\quad 8$

In Stock Work

As good as European workers $\quad 10$

Superior to European workers 7

Worse than European workers 13

Better at certain aspects of stock work 27

In this question it became obvious that employers considered their Aboriginal workers more productive in the particular area for which they were engaged. If one added this figure to the slight preference shown for Aborigines in question 5 it appeared that employers were more than satisfied with Aborigines as stock workers, whatever reservations they may have had about their other qualities. As 76 per cent of the total Aboriginal male work force was employed in this category, it was on that basis that they had to be judged.

One should also note that in the answers placed together in the first group there were many aspects of native ability which might have been considered a direct product of the Aborigines' own particular social education. These were bushmanship, mustering, tracking, knowledge of own country, etc. However, given the developing pattern of Aboriginal education and the decline of tribal influences these advantages are bound to diminish. Indeed, many cattlemen commented on their decreasing importance.

In some respects development was both increasing employment potential and at the same time decreasing job opportunity for Aborigines. Only a reversal in current education trends could solve this problem as far as the cattle industry is concerned. It was difficult, however, to determine at what stage, if any, 'innate' Aboriginal characteristics would be outweighed by more sophisticated Western skills. 
Good at supervising others. The reply to this question was always conditioned by the fact that the person answering meant 'other Aborigines'. For many reasons employers considered it questionable whether white employees would take readily to Aboriginal supervision, although some properties did have full-blood head stockmen or leading hands.

Many employers replying positively commented that to obtain good supervision of Aborigines by an Aboriginal one had to allow the leading hand to choose his own workers. Many station owners who stated that Aborigines were unable to supervise others conducted their black/white staff relations in a stiff and formal manner that precluded any possibility of adaptation to changing social or economic circumstances. Many were also convinced that tribal considerations prevented one Aboriginal taking primacy over another and consequently did not try to develop any leadership potential.

It was debatable whether any tribal seniority order still existed on the stations and, if it did, what effect it had on industrial relationships. The studies of kinship systems, etc. on missions and settlements had no necessary bearing on cattle station tribal bonds, although their presence in these other areas and the wide publicity given to them conditioned managements' attitudes. In this way the dominance of Australian anthropological studies in Aboriginal affairs over other social disciplines has emphasised racial disparities, somewhat discouraging management to appraise realistically their employees' broader human needs.

Berndt, in considering this aspect of employment relationships, believed that employers took advantage of the fact that Aborigines when living in bush conditions placed very little stress on personal property.

When they come to work for stations such as these, and take up a relatively settled life, their former habits are declared to be ample reason for limiting the return they receive for labour. ${ }^{14}$

Eight persons offered the opinion that Aborigines had mechanical aptitude. This reply was normally given in response to our direct inquiry. One person summed up his opinion this way: "There is no doubt that these fellows have mechanical aptitude but they are never given the opportunity to show it'. This reply seemed to be in accord with a fairly widely held view that Aborigines were good drivers. Those employers, however, who did not subscribe to this view were most critical of the Aborigines' handling of vehicles.

14 Berndt, 'A Northern Territory Problem', p. 45. 
(9) If Aborigines are not up to the mark what do you think can be done about it? Answers Change Welfare program 7 Educate them 6

Take children away from parents for training 5

Train them for stock work 5

Train them mechanically 5

Take them away from camp environment 3

Instil sense of responsibility 1

Create more incentive 1

Dilute with more whites 1

No reply or could not care less 6

Welfare Policy. Most people thought that the present policy of the Welfare Branch was wrong. Although it is not possible to consider the program in this report, the attitude of cattlemen as employers of labour was of importance.

Almost every cattleman we spoke to was critical of the pattern of development of settlements. Not only did they feel that the Welfare Branch's attitudes were wrong in relation to employment and training but they felt that the very presence of settlements, as an alternative method of existence for their labourers, decreased the desire to work on the property.

The comment that 'the blacks are not as good today as they used to be' was common. The complaint may not have been based on the traditional lack of appreciation that elderly people have for the young. One typical and colourful comment of a cattleman will emphasise the point. He claimed:

An Abo who grows up on a mission or settlement can draw an aeroplane and sing 'Springtime in the Rockies', but he's got no chance of throwing his leg over a horse and for my purposes he is useless.

If one returns to the answers in question 8 one readily appreciates that settlement life does little to assist Aborigines to develop the skills most sought after and valued by employers. The Welfare Branch ran what was euphemistically called 'training schemes for cattle work'. Colin Tatz, in his thesis Aboriginal Administration pointed out the deficiencies of these training schemes and concluded that they had 'a value only in the limited sphere of the trainee's settlement or mission'.$^{15}$ As the

${ }^{15}$ P. 64. 
settlement's training program in the five years of existence had only graduated six persons considered 'proficient' in cattle work, this program was unlikely to have had any general effect on the industry.

Settlement life was constantly referred to by pastoralists as demoralising 'where Abos sit down all day and get paid and fed'. Under such circumstances, the cattlemen asked: 'Why should they go out of their way to do a hard day's work?' A cattleman informed us of the history of one of his most respected and most highly paid workers who had left the property to live on a settlement. No amount of enticement could get him to return although he agreed that he was well treated on the property. Every time the employer visited the settlement and asked his worker to return he was met with the reply 'Yes, boss. Me bin thinkum about this tomorrow'. At the time of writing tomorrow had still not arrived. As the person in question had been paid a cash wage averaging $f^{12}$ per week for some years the attraction of settlement life must have been very strong.

The stories concerning administration of settlements, their attempts at cattle production, their 'feather bedding' techniques in relation to so-called 'employment' practices, were legion. Every move of the Administration in this respect was closely watched by cattlemen. Its attempts at assimilation and the numerous failures associated therewith were the source of much mirth.

Education. Most people referred to the need to educate Aborigines. Some, of course, suggested education in matters that were important to them. There was general acceptance of the fact that Aborigines could learn. Most people interviewed believed that Aborigines were as intelligent as themselves. No doubt their respect for Aboriginal bushcraft had some bearing on this.

Remove them from the camp environment. Many cattlemen were conscious of the restricting influence of social forces operating in the camp. Few could see any association between the physical nature of the camp, and its location or even their own attitudes to 'the blacks'. A large number conceded that, whilst conditions remained as they were there could be no progress for the Aborigines. Most felt that the older people were beyond training, but that there was hope for the younger ones if some kind of program, other than those promoted by the Welfare Branch, could be started. Most employers stated that they would be willing to co-operate in any reasonable scheme. 
Responsibility and incentive. Reference to these two factors loomed larger in discussion than appears in the tabulations.

Some employers claimed that Aborigines did not respond to monetary incentives; others gave examples of schemes they had introduced where some response was evident. In the first case the managements concerned had never tried an incentive program, and on questioning usually replied 'what's the use, money doesn't mean anything to these people'. The experiments which some stations had carried out proved that this was wrong. Answers to other questions about savings and spending in the station store and with the occasional hawker also contradicted this opinion.

The attitude of cattlemen to the so-called 'lack of responsibility' was hard to explain. To them it meant a lot of things normally summed up by a description of how, at one time or the other, their workers had failed to carry out a particular task. In this light it is interesting to relate the interview with a half-caste Aboriginal station owner who stated that he would not employ white men 'because they let you down'. When questioned on this he referred to an experience he had once when two white stockmen left his employ in the middle of droving a large mob of cattle. From this experience it would seem as though lapses in work application by a person of another ethnic group drew attention to racial differences, and made recall of the experience by the party which had been inconvenienced much easier. White management more readily accepted the shortcomings of their white employees as misfortunes or, alternatively, these employees were more adept at explaining away their lapses. Rarely, if ever, was it possible for an Aboriginal employee to argue with an employer about the propriety of his actions. The social and industrial responses between the two groups precluded this type of intercourse. However, there was some justification in the comment that Aborigines did not have the same scale of values as ourselves. This is explicable by the very nature of the conditions under which Aborigines live. Theirs has not been a money economy, and value and worth have a different conceptual meaning. This meaning could relate more to their own physical environment than to such abstract concepts as the economy, markets, bargaining, etc. Alternatively, with a cash wage of, firstly, 5s. per week and then, theoretically, $£^{2.8 s .3 d}$., little opportunity had been extended to them to develop monetary skills and appraisal of economic activity.

Two examples of problems experienced may illustrate the position. Many cattlemen referred to the apparently loose way in which Aborigines 
handled money. They claimed that Aborigines did not have the same concept of its purpose, of its ability to purchase desired commodities, or of the necessity to husband and spend wisely in relation to both the needs and resources available, as was the case with whites. In one example of this reference was made to the incessant card playing that goes on amongst Aborigines. The predominance of the gambling instinct was believed to give Aboriginal society a foundation of irresponsibility. Cattlemen also pointed out the mechanical nature of money handling of Aborigines as further proof. They claimed that on purchasing goods from a store, for example, Aborigines would approach the counter with a full hand of cash, having little appreciation of how much it was or how much it would buy. They would then point out what they wanted to purchase and hand over the total sum in their possession. If there was any left they would make another selection. These procedures, of course, also allowed a dishonest storekeeper to exploit the situation. Personal observation of hawkers in the Northern Territory indicated that they, at least, succumbed to the temptation.

Reference was also made during the survey to employers and storekeepers on stations, and individuals in official capacity, who took advantage of Aborigines in this way. It was difficult on limited information, however, to determine whether these reactions by Aborigines were simply the result of numerical illiteracy or of their inability, because of cultural considerations, to grasp the meaning and purpose of money. However, one man considered that:

When an Aborigine asked the price of anything, or started to bargain over the price of goods, you knew he was well on the way to becoming one of us.

Cattle station managers believed that a genuine lack of appreciation of the complex social and economic organisation of modern society was the reason why Aborigines had failed to develop attitudes consistent with the responsibilities of their employment. One particular reference of this nature continually recurring in our discussions was what they considered 'irresponsible actions towards equipment'. However, the belief was shown in other ways, as the following statement indicates:

We had just finished rounding up some cattle alongside a range of difficult hills, and several cattle broke loose from the mob and darted back into the scrub. I shouted to one of the men to bring them back but he did not make any move. By the time I had got around to the other side of the mob the cattle had disappeared back into where we had spent all day getting them from. I asked the Aborigine why he had not made any effort to stop them and he replied: 'Him alright boss, he can't climb over that range-me pick him up next year'. 
Irresponsibility may find its cause in other factors, possibly in laziness or even debility, passed off as 'the strange workings of the Aboriginal mind', and allowed to gather institutional acceptance.

Finally, it should be emphasised that most people granted that the main problem was training, but a common theme running through their replies was that they were there to run cattle stations, not to train Aborigines. Similar attitudes were also common in government departments in the Territory.

Most cattlemen believed that without some dramatic change in Aborigines' social or material conditions there was little possibility of them progressing beyond their present state. A consensus of replies to our questions underlined the fact that there was neither motivation nor institutional framework whereby they could improve.

THE PROSPECTS FOR ABORIGINAL WAGES

The question in this section was designed to determine the response of cattlemen to the possibility of a ruling by the Arbitration Court that Aborigines should be paid the same Award wages as European workers. I have already shown that any equality of Award conditions between whites and Aborigines would not necessarily bring about equality in fact, as white employees were paid, on average, almost twice the current Award in the Northern Territory and several pounds above the Award operating in otller States.

In considering the answers to these questions one must also realise that, at the time of our interviews, the Arbitration Court was hearing evidence on the subject. Consequently, any arithmetic appraisal of the rcplies in this section must take into account responses recorded elsewhere in the questionnaire, especially those concerning labour suitability. One reason for this caution was emphasised in the response to question 3 and 4 . In those two questions the majority of managers said that they would employ fewer Aborigines and more whites in the event of equal wages, but few had considered the problems of obtaining suitable white labour if all stations wanted them at the same time. Also, few managers had considered the effect of the practical differential in rates between white and Aboriginal labour if they were to pay the latter the Award rate.

(1) Are you in favour of keeping Aboriginal wages and rations as they are?

Yes

No

No answer
20 
Most managers tempered their reply with the comment that they did not consider Aborigines worth any more. How their answers to this question measured up to their admission that, in cattle work, Aborigines were more productive than whites, required explanation.

Obviously, the fact that the existing wage system was extremely profitable to cattlemen was of great importance. Indeed, several interviewees made reference to the relatively low cost of Aboriginal labour. That this was a 'reasonable' management attitude needs little explanation. People supporting a change in the payment system were also conscious of the need for a change in management and Aboriginal attitudes. Indeed, one person even went as far as to take the radical position that Aboriginal equality was a necessary foundation for the efficient use of both native labour and full development of the industry's potential. Consideration of this theme presents problems of considerable interest, and would provide an excellent foundation for further inquiry.

A stock and station agent summed up this view by stating that cheap Aboriginal labour was the most serious impediment to the development of Northern Territory cattle stations. He claimed that cattlemen could only afford to produce beef on the open range whilst they had access to a pool of cheap labour. Increased wage rates in the Territory would force the stations into development programs, which would in turn increase their overall productivity and indeed their ability to pay the wages they claimed they were unable to afford. Illustrating this example he made reference to the situation which existed in Queensland before Aborigines were granted their relatively substantial wage of $£ 10$ cash per week. $\mathrm{He}$ claimed that it was not coincidental that the increase in fenced and subdivided properties went hand in hand with the growth in Aboriginal wage status. An interesting extension of this analysis was submitted to me by an informant in government employ. He claimed that one of the main reasons for the intervention of the Commonwealth in the 1965 Arbitration Commission case was the demand by the Queensland Graziers Association that the Northern Territory pastoral industry be forced to meet labour costs comparable with their own.

(2) Are you in favour of Award wages for Aborigines and why?

$\begin{array}{lr}\text { No } & 18 \\ \text { Some } & 1 \\ \text { Very few } & 2 \\ \text { All } & 3 \\ \text { No answer } & 6\end{array}$

The answers to this question were necessarily the reverse of those in 
(1) above. The managers replying in the negative in this case normally relied on the reasons given earlier in the questionnaire. However, further comment was elicited on the alleged inability of Aborigines to accommodate themselves to a cash economy. Many managers considered that their employees did not have the necessary sense of responsibility, or the desire to spend their money wages 'economically'. ${ }^{16}$ They believed that increased wages would be spent on purchasing liquor or gambling.

(3) Are you in favour of a graduated system starting midway between the present and Award wages. If so, why?

$\begin{array}{lr}\text { Yes } & 15 \\ \text { No } & 4 \\ \text { No answer } & 11\end{array}$

This question was included to allow cattlemen to express their opinions on the proposition which we believed the Federal Government was going to place before the Arbitration Court. The system, it was suggested, would either embrace a graduated wage scale covering all Aborigines, or a wage scale for certain classes of work which would be progressively increased until equal to white rates.

The first method envisaged a system whereby the cattlemen judged the work value of each individual and applied a proportionate percentage of the ruling Award rate thereto. The weakness of the system would have been, of course, the position of employer/judge, and his obvious temptation to downgrade his employees to save costs. This probably explains why the Commonwealth Government never pursued the subject before the court.

The second alternative was a gradual raising of all Aboriginal wages until they were equal to white wages. Our inquiry could have covered any of these situations and was responded to accordingly with mixed motives.

Regardless of the reason for answering, the replies for a graduated system were as heavily in favour as those for no change in the system. Undoubtedly the motive for answering was similar.

It is interesting to note in this respect that many stations already operated a system of graduated payment. For example, some half-caste and full-blood head stockmen we discussed earned more than $£^{8}$ per week, and even some stockmen earned twice the minimum amount payable under the Wards Employment Ordinance. However, in no

\footnotetext{
16 'Economically', in this sense, was always equated with what the management considered to be a desirable pattern of expenditure.
} 
case were white rates paid to Aboriginal workers, half-caste or full-blood even though employees were worthy of them.

(4) If Aborigines were to get Award wages this year would you employ the same, more or less?

$\begin{array}{lr}\text { None } & 2 \\ \text { Same } & 2 \\ \text { More } & 0 \\ \text { Less } & 26\end{array}$

An overwhelming percentage of employers stated that they would employ fewer Aboriginal workers if equal wages were granted. The important question was how many workers would be replaced?

Significant in this respect was the hidden unemployment in the labour system. For many reasons the Aboriginal work force on cattle stations was not fully employed, partly because of the seasonal nature of the work, the lack of flexibility of Aboriginal skills, traditions which have grown up on various stations and poor management techniques. In some cases it was a direct result of the station only achieving work output roughly equivalent to the sum paid. Occasionally there wcre genuine physical and organisational reasons why there was under-employment. Frequently this came about through sickness in the Aboriginal camp, or the presence of a large number of pensioners on the property.

The social and economic consequences of the existence of surplus labour is considered in greater detail later in this study.

\section{DEPENDANTS}

As pointed out earlier the wages paid and sustenance granted by cattle station managements under the Wards Employment Ordinance were designed to provide for the employee, his wife and one child. Under the Social Welfare Ordinance of 1964, the Director of Welfare was empowered to pay out sums of money for 'relief from poverty or hunger'. ${ }^{17}$ These moneys were paid to assist in the upkeep of Aborigines on cattle

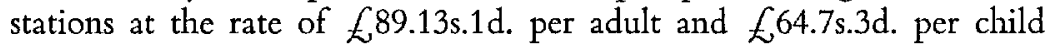
per annum, other than employed persons and their families and those who received payment by way of Commonwealth pensions. Annual sums received by the stations in the Northern Territory for the purpose of feeding their non-working populations were as follows: 
Age and invalid pensions

Wives' allowances

Widows' pensions

Child endowment

Maternity allowances

Welfare Branch payments

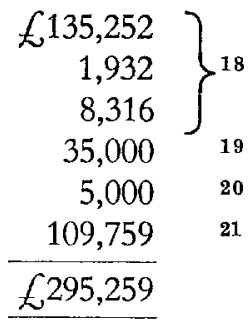

The funds involved were not paid evenly throughout the industry. Of the thirty stations visitcd thirteen reported they did not claim on the Welfare Branch for assistance. Occasionally some stations did not apply for this assistance for all indigent persons on the property. They were prepared to maintain a small number of Aborigines on their properties without assistance, but were not prepared to house and feed large groups.

However, allowing for the working population, and not taking into account the uneven distribution of the payments, the cattle industry was paid an average of approximately $£^{2}$ per week for each person not employed. If we take into account those stations not applying for subsidy the sum available to the applicant stations amounts to more than $\AA^{2}$ per head per week.

There was also a wide range in the numbers present on any one station. The largest number of Aborigines living on any station we visited was 155. Another station reported 109 residents with only 5 being employed. Consequently the income per head on the larger stations was greater than the average indicated. The methods of payment of these funds were also of importance.

Aborigines living on pastoral properties were classified as inmates of an institution, and the pension payments went direct to the management. By agreement with the Administration pension payments were supposed to be split into components representing a cash allowance of $\AA^{1}$ per fortnight to the individual, and 10s. per fortnight to be placed into a trust fund for the building of housing for such pensioners. ${ }^{22}$ Out of $£ 12$ per fortnight this left $£ 10$ for the disposal of the management.

Payments from the funds received for pensioners varied widely on the properties. The manager of one property had no idea of what the entitlement of pensioners was, and stated that the cheques were sent direct to

\footnotetext{
${ }^{18}$ Letter on private file from Department of Social Services, 12 October 1965.

${ }^{19}$ Estimate.

${ }^{20}$ Estimate.

${ }^{21}$ Annual Report of the Welfare Branch, 1964-65, p. 27.

${ }^{22}$ Tatz, Aboriginal Administration, p. 86.
} 
the head office and that was all he knew about the situation. Cash payments out of pension funds ranged from 'a few shillings a week' to $f^{3} .10$ s. The average payment was $f_{1.10}$ s.6d. In the case of one property we were informed that the management 'gibbit a quid when we go to town'. This was once or twice a year.

Only 30 per cent of the stations visited appeared to be conscious of their responsibilities concerning the establishment of a trust fund for pensioners' housing, and only some 20 per cent of them had spent the money on accommodation for their charges.

The payment of child endowment was in a category different from that of pension money. Although it was paid to the management the station received it only as agent for the intended legal recipient. These funds, however, appeared to be treated in the same way as pension moneys. The stations looked at the income as part compensation for the upkeep of wards. In only a few cases was the whole amount paid to the parents of the children. At best the amount was credited to the person's account with the store and they were allowed a limited selection of goods in return. Some managements, which were more concerned with their Aborigines' welfare, carefully controlled the issue of clothes and food for a sum covered by receipts. Others completely ignored the necessity for any relationship between receipts, payments or account credits.

\section{THE COST OF KEEPING DEPENDANTS}

As pointed out earlier the Welfare Branch had laid down strict standards of rations to be issued to wards. The Branch estimated that the payments of cash, provision of food, clothing and accommodation, amounted to $f_{11} 11.3$ s.3d. per week for each male Aboriginal employee. ${ }^{23}$ During our survey we were able to make several inquiries concerning this estimate and publish the results below.

On a station renowned for its favourable treatment of Aborigines we were supplied with the following figures: ${ }^{24}$

\begin{tabular}{lrrr} 
Wages & $£ 2$ & 8 & 3 \\
Employee's clothing & 0 & 15 & 0 \\
Dry rations & 2 & 6 & 6 \\
Beef at 2s.6d. lb & 2 & 10 & 6 \\
Refrigeration, Buildings, & & & \\
$\quad$ Water, Wood, Electricity & 0 & 10 & 0 \\
\cline { 2 - 4 } & $£$ & 9 & 0
\end{tabular}

${ }^{23}$ Commonwealth Conciliation and Arbitration Commission, No. 830 of 1965, p. 121.

${ }^{24}$ Letter on private file, 26 August 1965. 
This particular station claimed that it cost them 12s.8d. per week to maintain each child, which seemed to cast doubt on the accuracy of the other figures.

Another station informed us that, after costing beef at $1 \mathrm{~s}$. per $\mathrm{lb}$, their

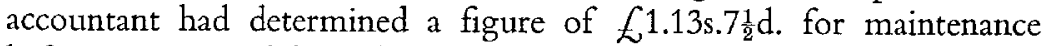
bcfore payment of the cash allowance.

In yet another case we were allowed to inspect the station's books for issues made to the Aboriginal camp and for what was described as an average month. The following was recorded:

Table 7: Aboriginal maintenance costs on a Northern Territory cattle station

\begin{tabular}{|c|c|c|c|c|}
\hline & Size & $\begin{array}{c}\text { Unit } \\
\text { s. }\end{array}$ & Price & $\begin{array}{l}\text { Total cost } \\
f \text { s. d. }\end{array}$ \\
\hline $\begin{array}{l}3 \text { tins syrup } \\
4 \text { bags sugar } \\
24 \mathrm{lb} \text { tea } \\
18 \text { drums flour } \\
37 \mathrm{lb} \text { fine salt } \\
2 \text { small tins curry powder } \\
4 \text { tins Sunshine milk } \\
4 \text { tins custard powder } \\
16 \text { tins jam } \\
3 \text { packets cornflour } \\
24 \text { packets sultanas } \\
11 \text { tins dry balm } \\
6 \text { packets raisins } \\
4 \text { tins treacle }\end{array}$ & $\begin{array}{c}2 \mathrm{lb} \\
70 \mathrm{lb} \\
\frac{1}{2} \mathrm{lb} \\
40 \mathrm{lb} \\
2 \mathrm{ozs} \\
3 \mathrm{lb} \\
12 \mathrm{ozs} \\
24 \mathrm{ozs} \\
16 \mathrm{oz} \\
12 \mathrm{ozs} \\
16 \mathrm{ozs} \\
12 \mathrm{ozs} \\
2 \mathrm{lb}\end{array}$ & $\begin{array}{r}20 \\
63 \\
7 \\
40 \\
10 \\
22 \\
164 \\
32 \\
32 \\
25 \\
35 \\
83 \\
31 \\
19\end{array}$ & $\begin{array}{l}6 \text { doz. } \\
0 \text { each } \\
0 \text { lb } \\
0 \text { each } \\
0 \text { lb } \\
0 \text { doz. } \\
9 \text { doz. } \\
9 \text { doz. } \\
3 \text { doz. } \\
9 \text { doz. } \\
6 \text { doz. } \\
0 \text { doz. } \\
6 \text { doz. } \\
9 \text { doz. }\end{array}$ & $\begin{array}{rrr}0 & 5 & 1 \\
12 & 12 & 0 \\
8 & 8 & 0 \\
36 & 0 & 0 \\
1 & 10 & 0 \\
0 & 3 & 8 \\
2 & 14 & 11 \\
0 & 10 & 11 \\
2 & 3 & 0 \\
0 & 6 & 5 \\
3 & 11 & 0 \\
3 & 16 & 1 \\
0 & 15 & 9 \\
0 & 6 & 7\end{array}$ \\
\hline 4 tins treacle & & & & $\begin{array}{lll}73 & 3 & 9\end{array}$ \\
\hline
\end{tabular}

*Unit price in shillings appears to be expressed decimally, Slight errors in extension have been left.

The issue was costed by a leading company of wholesale grocers in Darwin and their prices are indicated at the side. ${ }^{25}$ As the above costs are 'ex Darwin' one should allow a cartage figure of say 25 per cent

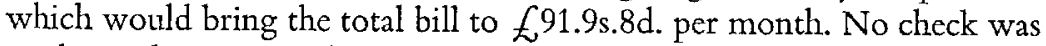
made to determine whether the items marked as issued were actually handed out to Aborigines. Evidence of the fraudulent practices of some bookkeepers in this regard is presented elsewhere.

The camp involved consisted of 152 Aborigines of whom 65 were employed. Forty of these workers were classified as stockmen, and were probably absent from the homestead for a substantial period of each

${ }^{25}$ Letter on private file, 15 September 1965. 


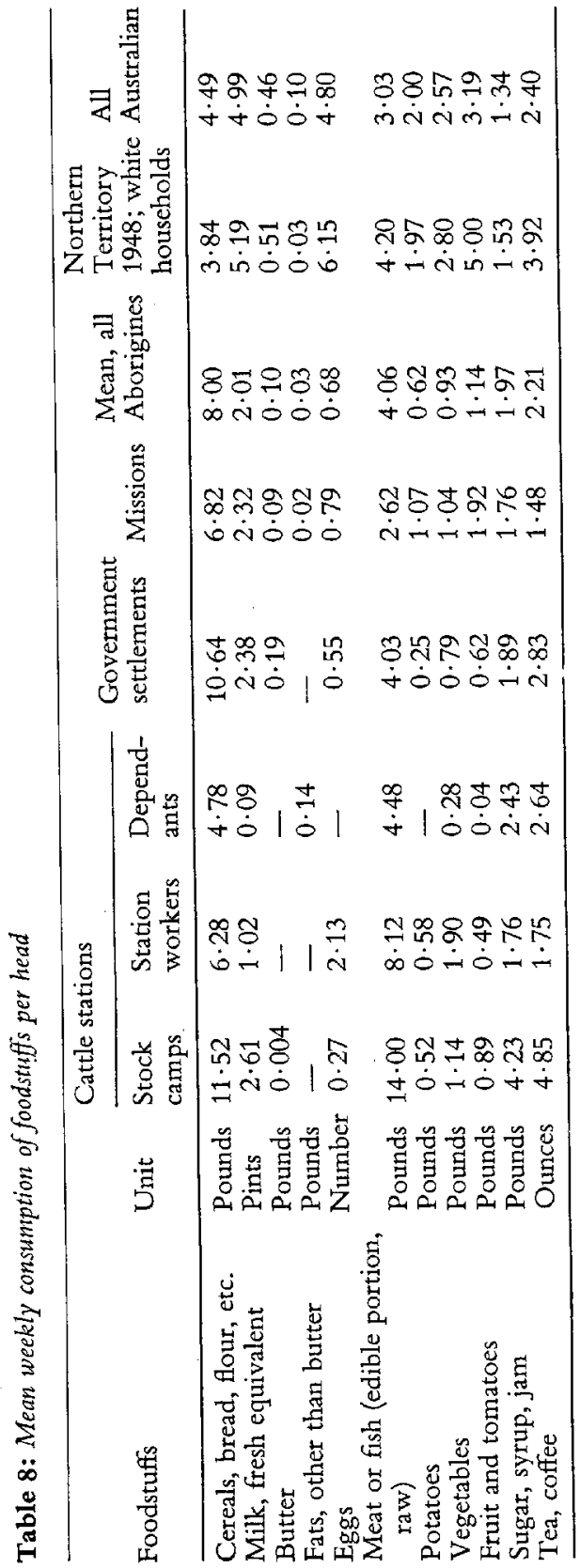


month. However, assuming that all were eating at the camp, the value of the dry ration scale amounted to $16 \mathrm{~s} .6 \mathrm{~d}$. per month per person or $4 \mathrm{~s} .2 \mathrm{~d}$. per week. To this must be added beef costs at, say, $2 \mathrm{~s}$. per $1 \mathrm{~b}$. Conceding a book cost of beef supplied as $2 \mathrm{~s}$. per $1 \mathrm{~b}$-although most of that supplied to the Aboriginal camp in the case under discussion was offal-and an issue of approximately $1 \mathrm{lb}$ per head per day, the maintenance cost of Aborigines at the station amounted to 18s. 2d. per week.

In the particular case under discussion the accommodation provided by the company was so rudimentary as to be virtually inconsequential in affecting the economic cost of maintaining the labour force.

In the items provided there was no issue of potatoes, rice, dried peas, tinned or fresh fruit, or margarine as required by the Regulations. In no cases were the weights demanded by the Welfare Branch met.

Another station allowed us to view the quarterly returns which they submitted to the company's accountants. The figures covered a resident Aboriginal population of seventy. Twenty-two males and ten females in this group were employed. There were twenty-six children and twelve pensioners on the station. Although the station received $f^{6}$ per week for each pensioner, no claims were made either for child endowment or on the Welfare Branch for a subsidy for maintaining more than the employee, a wife and child. Each pensioner received 10s. cash per week which was drawn from the total wages fund applicable to the Aboriginal community. One assumed from this action that the station management treated the pension received by the twelve individuals concerned as general revenue, against which they deducted the cash allowance of $10 \mathrm{~s}$. per week per person, using the balance to defray running expenses, presumably wages.

The station concerned issued the following items of clothing, charging the sums mentioned to the individual employee's account:

Adult males: Clothing to the value of $f, 3.7 \mathrm{~s} .6 \mathrm{~d}$. cvery ten weeks, or a shirt every two months (value $\left.f^{5}\right) .{ }^{26}$ One pair of trousers every two months (value $f_{1} 1.15 \mathrm{~s}$.). One sweater per annum (value $f^{2}$ ). One blanket per annum (value $\delta^{1.15 s}$.).

Adult females: One dress every two months (value $f_{1.5}$ s.). One pair of pants every two months (value $9 \mathrm{~s}$.).

Children, male: One pair of trousers and shirt every two months (value fi).

Children, female: One dress every two months (value: small 12s.6d., medium 15s.).

${ }^{28}$ Pricing of this item supports the earlier observations on costs of maintaining Aborigines. 


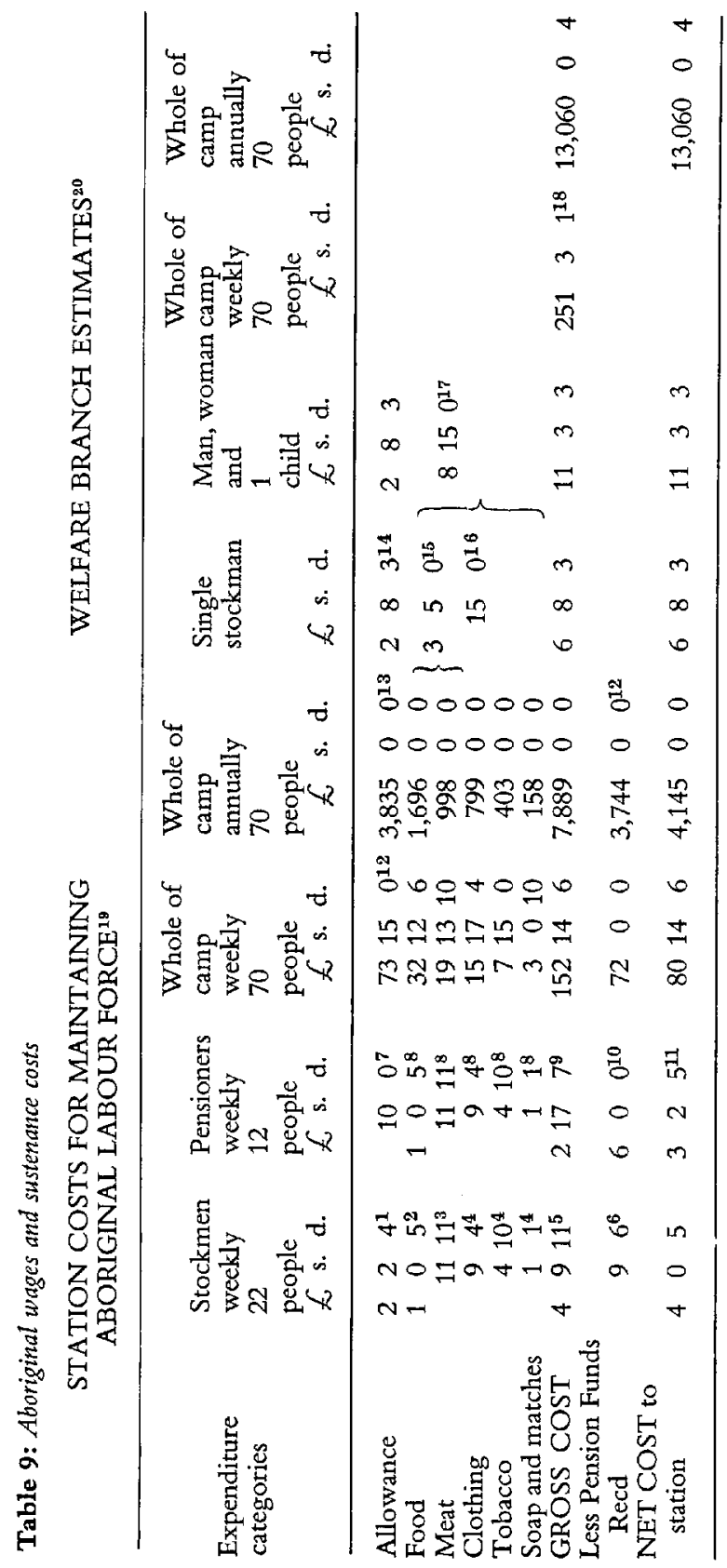


In addition the station claimed to issue the following items as part of the ration scale:

Males: Two tins of tobacco and papers per week (value 12s.), soap (value 1s.), 2 boxes matches (value $6 \mathrm{~d}$.), $1 \mathrm{lb}$ trade tobacco (value $f_{1} 1.2 \mathrm{~s} .6 \mathrm{~d}$.). Females: One third the tobacco ration of men.

As the clothing and tobacco allowances at the station appeared generous by even white standards, the storekeeper was questioned about the frequency of issue of the items mentioned on his instructions. He stated that he used his own discretion as to the actual items given at any particular time, ensuring that there 'was no wastage'. When questioned further, he was unable to provide accurate information as to the real intervals of issue of garments, merely repeating 'when necessary'. As the interview became tense at that stage, discussion on the subject was discontinued.

In the case under consideration, accommodation was provided in the form of corrugated iron 'garage' type structures with concrete floors

\section{FOOTNOTES: ABORIGINAL WAGES AND SUSTENANCE COSTS}

1. Issued in credit at the store with surpluses paid twice annually.

2. Calculated at cost to the station.

3. Local beef at book value.

4. Issue varied with individual, but always paid in kind. Probably an average for employed males.

The book value of the book entries did not match the issuing instructions mentioned below.

5. Total real cost.

6. As old age pensions were paid direct into station revenue the cost of maintaining each individual was reduced by total pension received divided by 70 .

7. Paid in cash or store credit, varying with individuals.

8. Based on adult male employee issue but known to be less and dependent on the needs of the pensioner, his demands and the storeheeper's attitude towards each individual claimant.

9. Undoubtedly inflated as pensioners known to be issued with less than working adult males.

10. Actual pensions received for each claimant.

11. Pensioners were reventue producing for the station and keep was less than the sums received on their behalf.

12. The lower averages are a refiection of the cost of keeping the whole camp.

13. Annual figures extracted from reports to the head office of the company. The lower annual cost as compared to the weekly figures presented could be accounted for by fewer demands being made on the store during the 'wet'.

14. To be paid in cash.

15. To be paid in kind.

16. To be paid in cash.

17. Calculated as follows:

Employees clothing allowance (cash)

Food for employee (kind)

Food for wife (kind)

Clothing for wife (kind)

Food and clothing for child (kind) Total

18. Based on 221 families: 22 working adult males

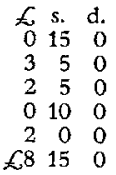

10 working adult females

26 children

12 pensioners

This is a generous calculation.

19. Slight errors and variations in calculations have been left in as they could be accounted for by seasonal and population movements and requirements.

20. Soutce: Exhibit D [HI], Common Exhitit Book, Commonwealth Conciliation and Arbitration Commission, No. 830 of 1965 . 
but no furniture. The structures measured $12 \mathrm{ft} \times 8 \mathrm{ft}$ with 'push out' type corrugated iron windows on two sides and a corrugated iron door. Capitalisation of these items stood at $£ 250$ per unit. Allowing a ten-year write-off period, the provision of accommodation cost 10s. per week per unit. An unknown sum from accumulated pension funds, however, had been spent on providing the shelter. The money was outlayed in this way at the suggestion of the Welfare Branch. As there were only ten units for the entire camp, the average accommodation in case of inclement weather was $7 \cdot 2$ persons per unit. This provided floor space of $10 \cdot 5$ square feet, approximately, for each person-or barely sufficient for each individual to roll out his swag on the concrete floor.

Only seven out of the thirty stations visited followed the ration scale outlined by the Wards Employment Ordinance. In those cases the managers were conscious of their responsibility and normally made some reference to a set pattern of rations which accorded very roughly with the Regulations. In eight cases stations were not aware of there being any standard at all and simply made reference to issuing 'sufficient rations', or 'issued as they require it'.

In nine cases Aboriginal workers received the same food as white workers although the food was usually dispensed at different points, and in four cases special 'black kitchens' had been established. On these stations we had no reason to doubt that nutritious food was provided.

When questioned about his rations one person answered that he 'Often shot a few 'roos for them besides there being plenty of native tucker around', but made no mention of issuing white commodities.

Many cattlemen complained of the amount of beef consumed by their Aboriginal workers. In most cases there did not appear to have been any limit on the amount eaten. The average consumption for the properties visited was stated to be approximately $2 \mathrm{lb}$ per person per day. There was a lot of wastage-the camps abounding with dogs-but an adequate meat supply, in the absence of other foodstuffs, would appear almost vital for survival.

There were obviously genuine problems of both dietary balance and sufficiency of food provided for the Aboriginal work force on every station we visited. This was a problem which affected the white and black community alike.

\section{'NIGGER FARMING'}

A person was said to engage in 'nigger farming' in the Northern Territory when he relied on income from Aboriginal subsidies to keep his station 
solvent. The above figures on dependants and costs of maintenance, together with further evidence which will be noted under housing, leads one to believe that there were many ways by which some of the stations could have come out on the credit side when handling government allowances and subsidies. ${ }^{27}$ That this was an aspect of the economies of several properties in the Territory was commented on by some of the interviewees. However, none of the persons who directed our attention to the fact could give us any information about the actual cost of keeping his own resident work force, and as a consequence always made reference to 'some [other] stations'.

The fact that pensions, child endowment and welfare allowances usually disappeared into general station funds made misappropriation easy. The infrequency of Welfare patrols and the illiterate and inarticulate nature of the recipients made abuses hard to prove.

WELFARE BRANCH ESTIMATES AND THE COST OF

MAINTAINING ABORIGINAL WORKERS

As can be seen from the analysis of station costs the figures presented by the Welfare Branch of the Northern Territory as to the maintenance of Aboriginal employees cannot be substantiated. Even given most sympathetic treatment the station claims were at least one-third below their estimates. In other cases the discrepancy was as high as 85 per cent.

Because of this wide differentiation it seemed obvious that either the Welfare Branch's figures were based on erroneous information or were produced to mislead inquirers.

It is possible that in the first instance the Branch had been given wrong information by pastoral companies. Berndt noted this practice in $1948,{ }^{28}$ and I had no doubt that similar practices continued in 1965. Acceptance of this theory must presuppose that the Branch was not aware of conditions on the cattle stations or was unaware that they were being misled. Although discussions with Welfare Branch officers in Darwin indicated that inspection of stations by patrol officers of the Branch was infrequent and cursory, it was difficult to believe that the officers in the Administration were sufficiently naïve as to subscribe to such a divergence from the truth.

A more plausible explanation of the gap might be found in the interest of the Welfare Branch in defending itself from the criticism that it was

${ }^{27}$ See Centralian Advocate, Alice Springs, 27 October 1966, where these claims were made public by the Secretary of the Northern Territory Workers' Union, Mr Paddy Carrol.

${ }^{28}$ Berndt, 'A Northern Territory Problem', pp. 55-61. 
allowing the pastoral industry of the Northern Territory to exploit Aboriginal labour through substandard wages and conditions.

Viewed in the light of the fact that not even the employers of Aboriginal labour supported the Welfare Branch estimates of the cost of keeping Aborigines on the station, one can only assume that the estimates were based either on erroneous material or designed for some purpose other than the objectives of the Arbitration Court hearing. ${ }^{29}$

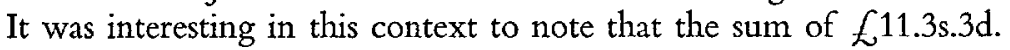
produced by the Welfare Branch as being the cost to the station of maintaining an Aboriginal employee was roughly equivalent to the existing, though out-of-date, European Award.

\section{THE PATTERN OF PAYMENT}

Since the introduction of the Truck Acts it has normally been conceded that an employee has a right to his wages and should be able to spend the money in any way he deems fit. With this in mind we asked managements to answer the following question:

Do you think that wages plus rations for Aborigines are more suitable for them than wages alone?

$\begin{array}{lr}\text { Yes } & 20 \\ \text { No } & 6 \\ \text { No answer } & 3\end{array}$

Most employers considered that their Aboriginal staff were not capable of handling money. However, given the low incidence of numerical literacy, and the associated need to acquire quantitative skills, the withholding of the means whereby individuals could learn money values and the techniques of fiscal husbandry would only appear to have reinforced the pattern of ignorance.

Since the minimum wage payable to Aborigines (if any was paid) between 1943 and 1957 was 5s. per week, Aboriginal employees had little opportunity to develop the techniques of the market which whites have taken many centuries to acquire, and which some have still not mastered. To claim that because they do not have such skills they should therefore be deprived of the means of acquiring them is surely to perpetuate a vicious circle under which the Aboriginal is bound to remain in his alleged present state of ignorance.

That Aborigines were more appreciative of money values than most

${ }^{29}$ Australian, 20 October 1966. Letter from P.S. Morris, Pastoral Manager, 'The Vestey Organisation'. 
cattlemen would grant will be considered later in this study. However, appreciation of the complexities of the wages and savings system seemed beyond the ability of some employees, as the following simple story indicates.

On one station I was approached by a colourful fellow by the name of King Brumby. King Brumby is one of the intermediaries-described elsewhere in this study-whose position in the community had been endorsed by the placement around his neck of an anodised aluminium plaque bearing the title 'King Brumby'. Some eighteen months before our visit to the station a full-blood Aboriginal by the name of Beetaloo Bill had visited the camp. Beetaloo Bill was employed by the Commonwealth Department of Works at full white Award rates and lived in a fashion somewhat similar to other Australian citizens. However, the startling event for the Aboriginal camp was Beetaloo Bill's arrival in a new Holden utility which, like some other Australians, he purchased each year.

His possession of the vehicle and the knowledge that he owned it was looked upon incredulously by King Brumby. Almost without introduction the following exchange took place between myself and Brumby:

Where you fella come from? Canberra.

Where this Canberra? Ah-a long way away.

Where your country then? Ah-along the bitumen.

You know this fella Beetaloo Bill? Yes.

That him car? Yes.

Where he get that car? I guess he saved up for it.

What this save up? Ah--He worked for a long time and kept the money, not spent it, so that he could buy the car.

How long he work? About three or four years.

What this three or four years? Ah-say, many, many walkabouts.

May be King Brumby buy car. Yes-I suppose, if you work long enough.

\section{CANTEENS AND STORES}

Do you run a store or canteen?

Yes

No

2

The attitude of station managers to the administration of their store and the influence that this had on the native population gave rise to many interesting reflections on the contemporary life of workers in the cattle industry. Unfortunately, a detailed analysis of these falls outside the scope of this report. 
The practical application of management theories about Aborigines was often related to the administration of the company store. In most cases it was used as the final point of exploitation or paternalism, depending on the feelings of the management involved.

The administration of the store was of singular importance to the Aboriginal worker as it offered one of the few opportunities of achieving variety in what was otherwise either a fairly limited diet or unexciting consumption pattern. Little as his choice was on a cash allowance of as small at 5 s. or 10 s. per week, the ability to apply limited sums to his own ends was virtually the sole preserve of individual freedom that existed for him. Illiteracy and isolation provided effective barriers to the worker looking further afield to exercise discretion.

In such circumstances it was little wonder that on most stations the store assumed an importance far beyond that of similar facilities in more diverse societies.

But the store was a company store and was subject to whatever management decreed as acceptable for the natives. Some stations used the store as a powerful weapon of administration by not paying the Aboriginal any cash wage at all. They simply allowed credit for the equivalent of the wage due.

Other stations went even further than this. Although they credited the full wage to the employee in the books of the store, they only allowed him to draw up to a certain amount per month. These sums were short of the amount due under the terms of his hiring. The balance was then allowed to accumulate and was paid to the employee at a special time. The most common practice in these cases was to allow the worker a sum of money when he was able to go to town on the station truck, at race time or before walkabout.

In this situation, the illiterate employee had to rely entirely on the employer's honesty that funds due to him were properly accumulated. Indeed often the sum due was dependent on the honesty of a storekeeper who was unlikely to be with the station for very long. We did not witness any cases of dishonesty. However, our limited ability to communicate with the Aboriginal workers was an impediment to obtaining an accurate picture of all employment conditions.

Most stations added a percentage to the cost of the goods sold in the store even though this was contrary to the Wards Employment Regulations. We were not able to determine, however, if the stated prices were the ones actually charged to Aborigines in the rather clumsy purchase procedures mentioned on $\mathrm{p}$. 78 . Obviously there were many 
opportunitics for the storekeeper to overcharge his illiterate clientele.

If the Aboriginal work force were paid a larger cash wage, clearly the administration of the store could become a focal point of friction, possibly giving rise to difficulties not unlike those which have happened in the so-called 'company towns' and other areas where workers rely on their employers for the provision of the small luxuries of life. Control of the store available to Aborigines frequently depended on the personal whim of the management. In many cases we found that stations did not stock sweets or soft drinks as the management did not consider these 'proper' articles for the natives. Sometimes management took a different approach and encouraged purchase of items with a popular market appeal, and not infrequently a high profit mark-up. In other situations the station storekeeper took it upon himself to determine the need for any particular purchase by the Aborigines.

However, we found that Aborigines were spending their money reasonably intelligently, albeit under supervision and with restricted fields of purchase. Normally money went to items to boost the taste of their otherwise dull diet. Sweet goods were in great demand. Purchases of tinned fruit and juices appeared to be rising rapidly. The purchase of canned baby foods also seemed somewhat incongruous in the impoverished circumstances under which most of the work force lived.

\section{SAVINGS}

In connection with our inquiries concerning stores we made reference to savings amongst Aborigines. Twelve of the stations visited stated that some Aborigines saved voluntarily. In other cases, as explained above, there was a form of compulsory saving.

Further evidence of savings in the Aboriginal community was seen during the regular visits of hawkers. Many of these traders carried goods primarily designed for the Aboriginal trade. They included colourful shirts, loose cotton dresses, stockman's clothes, etc.

The general fecling of managements was that the hawkers exploited the Aborigines' ignorance of comparative prices. However, the fact that they were patronised at all was evidence of the workers' desire for a wider variety of goods and the fact that money was 'hoarded' for special occasions.

DRINKING ON STATIONS

Whilst on the subject of stores it is also convenient to discuss the problem of alcoholic liquor on cattle stations. We asked: 
Would you allow Aborigines to drink on your station?

$\begin{array}{lr}\text { No } & 24 \\ \text { Yes } & 3\end{array}$

No answer-or had not been considered

The Northern Territory Legislative Council passed a law in 1964 which allowed full-blood Aborigines, for the first time, to drink under circumstances similar to those of other citizens. ${ }^{30}$ However, contained in the legislation permitting Aborigines to purchase liquor were conditions which effectively limited the very rights they had been granted. ${ }^{31}$

As shown some 90 per cent of the Northern Territory's Aboriginal population lived either on cattle stations or government settlements or missions. It was in these areas that the Legislative Council restricted the extension of drinking rights.

Under the 1964 Act cattle station proprietors were given the right to declare their stations 'dry'. This necessitated the notification of the Administrator in Darwin of their intention to do so, and the erection of notices on the main roads entering the homestead area that it had been so declared. These notices stated that the property had been declared 'dry' and that it was an offence for a person to bring alcoholic beverages onto the premises without the permission of the owner.

Those stations which had so declared themselves 'dry' only intended the notices to be applied to Aboriginal workers and to those who would trade with them. Not only did the white staff drink behind the barriers, but often in full view of the less privileged Aboriginal employees. Only on two stations during our survey did we find drinking banned for both white and black workers. In only one case did we meet a manager who believed that this also applied to himself.

This is not to say, however, that Aborigines did not drink. It meant only that in practice it was more expensive for them to obtain a drink. We were reminded of this on several occasions.

We arrived at one station late at night and mistook the road to the native camp for the road to the homestead. The manager informed us that he had seen us but thought that we were probably 'running grog' and had accordingly ignored our intrusion.

At another station, where drink was theoretically banned, the cook ran a flourishing 'black market' traffic in various alcoholic beverages. His trading was carried out in an overt $f_{d s}$ shion, encouraging one to reach

${ }^{30}$ Northern Territory, Licensing Ordinance, No. 35 of 1964.

${ }^{81}$ Ibid., S. 6. 
the conclusion that his actions had the approval of the management. I was unable to determine the price charged to the Aborigines for the drink.

Outside the properties many managers had agreements with storekeepers and road house operators not to supply alcohol to their Aboriginal workers. In isolated communities a threat of non-patronage from an important customer was often sufficient to keep the store in line. Not all stores and road houses, however, accepted such pressure, and occasionally liquor was supplied regardless of the feelings of the nearby managers.

In many places within the Northern Territory the police interpreted the licensing laws as they considered the demands and problems of race relations required it. In the towns it was unusual for whites to be arrested for drunkenness, whereas it meant certain gaol for an Aboriginal. Even police of high rank added their own variations to the laws when they were called upon to interpret them. Invariably the decisions led to Aborigines being deprived of their newly gained rights. ${ }^{32}$ This was either by publicans refusing to serve them or police harassment on public or licensed places.

But where it was dispensed to Aborigines, alcohol was often supplicd under conditions not applicable to white clients or at inflated prices. Consequently, even the amber fluid-often the basis of bonhomie and comradeship-was not freely available.

\section{SUBSIDIES}

The questionnaire included a section on the desirablity of subsidies and the various methods of administration. Persons interviewed recorded their preferences for subsidies in the following order:

$\begin{array}{lr}\text { Housing } & 12 \\ \text { Education } & 12 \\ \text { Rations } & 8 \\ \text { Health } & 8 \\ \text { No answer } & 6 \\ \text { Not in favour of any } & \\ \text { subsidies } & 5 \\ \text { Wages } & 2\end{array}$

32 See Australian, 2 July 1965, 'Australia's Deep North'. A roadhouse keeper in the Northern Tetritory, describing a dispute which had arisen between various Aboriginal drinkers on the evening before my arrival, said that he had informed the police that the next time anything of a similar nature occurred he was going to shoot the first 'bloody black fella' he saw. He 
HOUSING

The reply in relation to housing brought forth considerable discussion. Station managers wanted to know who would own and maintain the buildings. Some rejected the suggestion of housing subsidies by stating that they would encourage increased intervention by government agencies and they were therefore opposed.

At the beginning of this study I referred to the standards of accommodation established by the Wards Employment Regulations in 1959. In 1965 only three of the thirty stations visited could be described as having attained a standard approaching the minimum requirements.

The rest of the stations varied from no shelter at all (except for the issuc of tent flies), to rudimentary shacks pieced together by their inhabitants from scrap iron left lying around the homestead. Normally, structures of garage-like proportions and manufacture predominated. With few exceptions these had earthen floors and it was difficult to decide whether more people were housed in these or the scrap-heap-like wurlies by their side. Most of the accommodation could be described as primitive and disgusting.

When we questioned the managers on their legal obligations in this respect many replied that they had ignored the Regulations as the Welfare Branch was unable to house their own people any better and consequently were unlikely to take any action against them.

Although the Annual Reports of the Welfare Branch as far back as 1959 mention 'little progress [is] being made', no employers had been prosecuted for violations.

Training in the use of housing facilities would appear to be a basic part of any assimilation program. ${ }^{33}$ The failure of the Welfare Branch adequately to deal with this problem on their own settlements, and the abandonment of any attempt to implement the law on cattle stations, would make it seem as though little or no progress had ever been contemplated in this regard.

Even provision of crudely decent toilet facilities was ignored. It was common for the latrine, if there was one, to be at least 500 yards from the native shacks. In such circumstances the Aborigines were in the habit

said that the police agreed with him that it was probably the only way to handle the situation but requested that he should try and shoot him in the legs. The roadhouse keeper replied 'I'll bloody well shoot alright-and who knows where I'll hit the bastard'.

${ }^{23}$ A start in this direction was made in 1969 through the appointment of this first "community adviser' on cattle stations. Northern Territory Administration, Press Information, 25 November 1969, No. D-82. 
of defecating immediately outside their homes. Otherwise, they would retire to the nearest creek bed or depression which, in the north, was often used during the 'wet' as a source of drinking water for the camp. ${ }^{34}$

Where kitchens were not provided meals were prepared on a simple bush fire. Only three station camps had running water. In other locations it had to be carried from the homestead, sometimes over a quarter of a mile distant.

In few cases were means of artificial light provided. In only one instance was the native camp linked to the homestead power supply.

Except in three cases no furniture of any kind was supplied. Occasionally blankets were issued. Sleeping habits normally followed the traditional line with all the members of the family huddled together on the ground with dogs scattered in between.

When attention was drawn to the degrading circumstances, one was met by the retort that the Aborigines do not know any better, and would destroy any type of white facility provided for them.

However, experience on those stations which had endeavoured to solve this problem indicated that the position was more a result of the lack of managerial concern than the destructive behaviour of the Aboriginal employees. Aborigines on the three stations that provided furniture did live in reasonable surroundings and, in Queensland, where standards of Aboriginal workers' accommodation were policed, the alleged destructiveness of the workers was not apparent. Employers undoubtedly found it convenient not to provide even the simplest requirements for human decency.

\section{EDUCATION}

The replies to the inquiry into education indicated considerable dissatisfaction. Most managements realised that there could be little progress by their native population without education, and were prepared to co-operate in its introduction. Many were openly critical of the little which had been done up to that date.

This is not to suggest that all station managements were prepared to co-operate in the introduction of an educational system. One station visited refused to have anything to do with the Welfare Branch and in particular their school system. The manager, accordingly, had organised private tuition for a number of white children on the property and the

${ }^{34}$ On the educational aspects of sanitary systems, see C.M. Tatz, "The Relationship Between Aboriginal Health and Employment, Wages and Training' in I.G. Sharp and C.M. Tatz (eds.), Aborigines in the Economy, Jacaranda Press, Melbourne, 1966, pp. 51-68. 
children of an Aboriginal leading hand. He charged each family $f^{5}$ per week for the service. ${ }^{35}$

A Welfare Branch teacher on another station informed us that his relationship with the management was quite strained and that he had been refused permission to use the station facilities of power and water although there was ample in both cases.

\section{RATIONS}

The favourable response to the continuation of subsidies for rations reflected the current administration policy of support for the pastoralists' activities in this area. All stations receiving bencfit under the scheme approved of its continuation. It is interesting, however, that it was accorded lower priority than education and housing.

\section{HEALTH}

Counsel for the Employers: When you select a number of Aborigines to go out to the stock camp, are those you pick affected by what happens to them, in their attitudes to work over the period of the muster?

Cattleman: We always feel that we [should] take one or two spares if we can get them because the incidence of getting ill is far greater than what it is among white[s]. ${ }^{\mathbf{3 6}}$

Answers to the questions concerning health were not particularly succinct. The interviewers were poorly qualified to discuss the subject and, with certain exceptions, the people interviewed were not sufficiently qualified to report their experiences accurately. The result was that we did not gain a great deal of information, and what was obtained must be considered subjective.

Our overall impression was that one could not place reliance on the replies that indicated that the stations were satisfied with the present medical services.

The aerial medical organisation of the Northern Territory prided itself on providing one of the most advanced services of its kind in the world. This might well have been so but the actual condition of some of their charges on the ground seemed to deny their claims. There was ample superficial evidence that this was the case. The following points arising from the survey are worthy of mention:

1. One station, with its own aircraft, stated that it found difficulties in obtaining white employees because of the inadequate staffing of the health services.

${ }^{35}$ The Aboriginal concerned received $£ 11$ 15s. per week.

${ }^{36}$ Commonwealth Conciliation and Arbitration Commission, No. 830 of 1965, p. 231. 
2. Our inquiries concerning native health brought many references to sore throats, chest complaints, pussy ears, dysentery, malnutrition, eye complaints, scabies, ringworm, trachoma and diarrhoea. The references indicated that if these were being experienced in suburban situations they would have been of virtual epidemic proportions.

3. There had never been a chest survey of Aborigines living on cattle stations.

4. Only 20 per cent of the properties made regular demands on the Flying Doctor Service on the periodical six weekly calls, although many of the above problems were frequently experienced. Obscrvation of the work of this service indicated that there were no preventive health measures undertaken, merely 'salvage' operations after illness had developed.

5. A different standard of medical care was applied to Aboriginal residents compared to that for Europeans.

6. The aerial medical service did not collate and publish adequate statistics or allow independent observers to study their operations, which indicated the caution with which they themselves viewed the situation.

7. The general pattern of work of aerial medical doctors did not allow sufficient time for proper clinical inspection, or for the investigation necessary for preventive medicine.

8. From a general visual survey the Aboriginal work force did not look well. For example, a high percentage of Aborigines have the blue smear of trachoma in their eyes; children wander around with obvious nasal and car infections; older employees still bear the marks of childhood malnutrition, etc.

9. Jones, in his study of the demography of Aborigines in the Northern Territory, referred to an infant mortality rate in Central Australia of 208 per 1,000 live births and commented that it 'must be amongst the highest infant mortality rates in the world'. ${ }^{37}$

10. The work of Gandevia, Maxwell, Kirke, Moodie, Kalokerinos, and Jose and Welch since the date of the survey has indicated that the health ecology of Aboriginal communities in rural Australia presents a picture of 'human waste and incipient "high output failure"' 38

Although there was no information available on cattle stations to indicate the standard of health, except from the process of selection of the physically strongest individuals for the work involved, there seem few

${ }^{37}$ Lancaster Jones, A Demographic Survey, p. 96.

${ }^{38}$ P.M. Moodie, 'Mortality and Morbidity in Australian Aboriginal Children', Medical Journal of Australia, vol. 1, no. 4, 25 January 1969, pp. 180-5. 
grounds for believing that the cattle station Aboriginal communities were better off than other Aboriginal groups in the area. Obviously Aboriginal living conditions gave rise to a high incidence of communicable diseases and the epidemiological consequences of the environment bore heavily on the resident community. However, it was difficult, if not impossible, for a lay observer clearly to delineate the effect Aboriginal ill-health had on the output of the employees. Longitudinal studies on the impact of ill-health on output are rare, even in European circles, but their potential contribution to the improvement of race relations in the cattle industry of the Northern Territory appears fairly obvious.

The answers on the question of health subsidies conflicted somewhat with the opinions of pastoralists as to the state of health services in rural communities. Whilst on the one hand most people interviewed considered that health matters were adequately and properly attended to, eight stations stated that they wanted to see greater government subsidies in this area. The inconsistency on this matter was because station managers and owners believed that their wives should be paid for the medical services that they rendered to the Aborigines. Consequently, although there was only little demand for an improvement in the provisions made for health services (a response which seemed to be inconsistent with the condition of Aboriginal health), requests were made for the remuneration of white housewives, many of whom were either paid direct by the company or, at least, provided taxation advantages in the case of owner managers.

\section{W A GES}

It was suggested that if equal wages were to be paid by the stations, and Aborigines were proven economically inadequate to such award, then the government might consider making up the difference between their real worth and the Award rate. It is interesting that practically every station rejected this suggestion as being either impossible to administer, or undesirable. 
$\mathrm{T}$ he fabric of any system of industrial relations is not woven entirely from the opinions of employers. The feelings and thoughts of the employees, their pattern of, and incentives to work, their communal life and integration with the environment, providing both the purpose for and the reason to labour, are equally as important as the employers' understanding of the situation. In certain circumstances the thoughts and desires of the management might be secondary to the other factors with which it has to deal. Indeed, the very attitude of management itself may be one of the conditioning factors which affect the character of life and provide one of the boundaries within which the employee has both to exist and to earn his living. When men work in isolation, and are entirely dependent on each other for survival, relationships are often developed which have no parallel in more diverse societies.

More commonly, however, the circumstances simply magnify those aspects of dependency between the parties inherent in any industrial system. The absence of alternative social and economic outlets and restraints provides management with greater opportunities to develop patterns of control which would not be tolerated in a broader community. The employee, in turn, may respond to the changed relationships either by increased application to his work in an endeavour to serve short term objectives to remove himself if he feels them too restraining, or by devoting himself to increased union or employee associational activities in an endeavour to counteract dependence on management if he is committed to staying in the area a long time. 
Where neither of these two adjustments can be achieved accommodation must be mental. This occurs through an acceptance of the pattern of total dependence. If there is no practical alternative but to continue working and living in total confinement then the individual must become subservient to it, and accept whatever advantages and restraints it offers.

The fact that most Northern Territory cattle stations have developed in isolation needs little emphasis. Even today, in the age of four-wheel drive vehicles and modern 'beef roads', many of them are several days journey from the nearest urban community. Because of this, and the extraordinary rights which were extended to station managements to operate outside the confines of industrial law, as it was known to other Australian citizens, the insularity of the communities was even further emphasised. For outside the rule of law and the restraint which may be placed on personal excesses by strong communal opinion, individuals have frequently made an impression on dependent people in conflict with their normal behaviour in more diverse society.

A prominent and authoritative commentator on Northern Territory affairs recently summed up this phenomenon in the following way:

Dislike, distrust and maltreatment have regrettably survived away from the towns, notably on pastoral properties. A few enlightened station managements have given Aborigines a fair go. The majority - and they include some of the world's wealthiest people-still regard Aborigines as less than human chattels.

I believe much of this stems from a sense of guilt. I would not like to be leaving the Northern Territory troubled by the kind of conscience that must burden those who have exploited the Aborigines most, and yet have done least to help them.

Aboriginal girls have been used as bait for white men in the outback for as long as I can remember. Recent episodes of this have led to murder.

But the skills of native stockmen, the backbone of the cattle industry and often the husbands of these girls, have been disputed and decried, even in situations where the properties concerned could not have carried on without them.

There has been meanness, malevolence and lack of charity unequalled in few civilised societies. ${ }^{1}$

Reports of this nature made it necessary to look at the employee's total situation before appreciating the employer's consideration of his value to industry. To enable some degree of comparison to be maintained between the employer's response to our series of interviews, consideration of the employee's position will be treated in similar, although not identical, categories.

1 Douglas Lockwood, 'Goodbye to God's Best Country', Sydney Morning Hetald, 2 November 1968. 


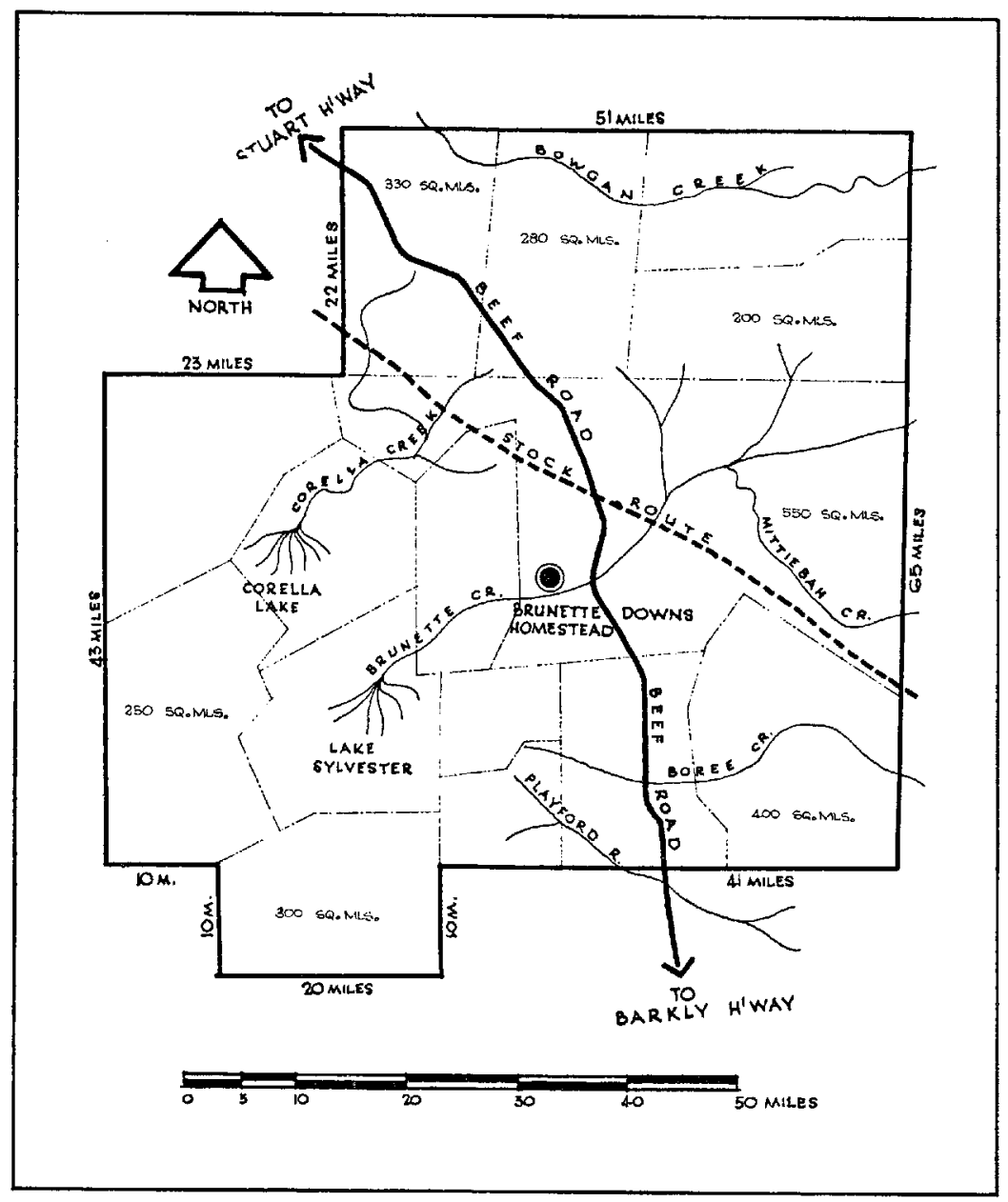

Map 4. One of King Ranch Pastoral Co.'s properties, Brunette Downs, 4730 sq. m. One of the smaller and better developed Northern Territory Properties. Approximately half of internal fencing shown. Internal areas not to scale.

\section{PHYSICAL LOCATION}

To assist in making the station buildings as flood-free as possible, most Northern Territory homesteads are situated on a hill or a small rise. The outbuildings and the Aborignal quarters are scattered around the slope in 
no particular order, unless it is that machinery sheds and garages dominate the higher ground to the exclusion of the indigenes' camp.

As most elevated areas in the ancient geology of the Territory have resulted from the residue of ironstone outcrops, the soil is frequently a combination of rock slivers and powdery ironstone dust. Other than being flood-free the sites rarely have any attractions, with the exception of the possibility of proximity to fresh water. The advantage of this has been considerably reduced by access to underground artesian sources.

Socially, however, the need for an elevated position does have an important bearing on the lives of the people-particularly the Aborigines. Any natural advantages in the location are dominated firstly by the homestead, secondly by the machinery sheds, thirdly by the white employees' quarters and lastly-almost as an afterthought-the Aborigines.

Anyone who has travelled in the normally arid north, where approximately nine months of the year are passed in what would be considered as a blistering summer by European standards, knows that even a modicum of advantage taken from the prevailing wind or natural shade can lift the daytime hours from inferno-like conditions to those that can be marginally tolerated. But universally it is the European buildings which are situated to collect the breeze, or to take advantage of the limited shade which appears on the rocky outcrops. If there has not been sufficient soil cover to sustain any plant life other than the straggling scrub, considerable energy was spent in carting soil and planting shady trees. Given a combination of constant attention and the application of water in massive quantities, the wilderness can frequently be turned into an oasis of green. Where white women were resident one normally found that the highly cultivated quarter-acre lot was a condition for their presence.

The garden not only acted as a social centre for visiting whites, but served as a necessary buffer to keep back the sea of dust which developed around the unmade roads, cattle pads and paddocks of the homestead area.

In white circles the influence of the homestead in the surrounding district might be gauged by the developed state of its gardens and homestead areas. The ownership of a tennis court, for example, ensured the continued social attention of the other properties. There were, of course, different standards of European social equipment and decoration. These ranged from highly elaborate barbecue areas (most favoured), to one station which was proud of its collection of peacocks and pheasants strutting around the fountain displaying their brilliant plumage.

The reward for the expenditure of all the time and money on the garden area came in the height of the summer, when one could sit in the grounds 
surrounded by a sea of lawn or look out over the verdant quarter-acre into the shimmering heat of the day. But out there, somewhere in the billow of haze, and across a dusty paddock, was the area devoted to the employees who were responsible for keeping the peacocks fed, the lawns cut and the trees in bloom.

As often as not the area set aside for the Aborigines was marked off by no particular division in the range which stretched to the horizon. For all visual purposes it was part of the run, being used by milking cows and pet horses in this way if the homestead kept such animals. Occasionally quieter cattle would move into the area to nibble at patches of grass and to be chased away by a flurry of dogs.

None of the stations visited had tried to improve the physical circumstances of their indigene staff in any way in keeping with whites' facilities.

The area of most Aboriginal camps gave the impression of being completely neglected by the management. Occasionally there was evidence that improvements had been planned in the form of shade trees or other decorative features, but interest in them had been abandoned for many years. In some situations individual Aborigines endeavoured to develop garden plots but the ravaging sun and the lack of ready access to water usually frustrated their efforts. However, frequent attempts were made and persisted with over considerable periods of time only to be beaten by the energy needed constantly to carry supplies of water a great distance in kerosene tins slung across the shoulders on a sapling.

At none of the stations visited was it conceivable that the knowledge gained by the Aborigines in developing the homestead gardens could be turned to their own advantage. Where there might have been a chance of this-and in some locations serious endeavours had taken place-the results were primarily decorative in nature and rarely fruitful.

The only stations visited which displayed interest in their overall responsibilities, including the maintenance of the Aboriginal camp, limited their attention to forcing the inhabitants to keep the area clean. Even in this only four or five of the stations visited made the effort. All it meant in fact was an insistence on the normal standards of hygiene-that garbage be buried; that the papers and debris which accumulate in almost every human situation be kept to a minimum; that defecation take place in the allocated areas and that a reasonable degree of respect be shown for station property in the form of the rudimentary galvanised iron sheds which had been erected for winter shelter. The standard of maintenance given to these areas might be judged by the fact that the Aboriginal huts were rarely painted. 


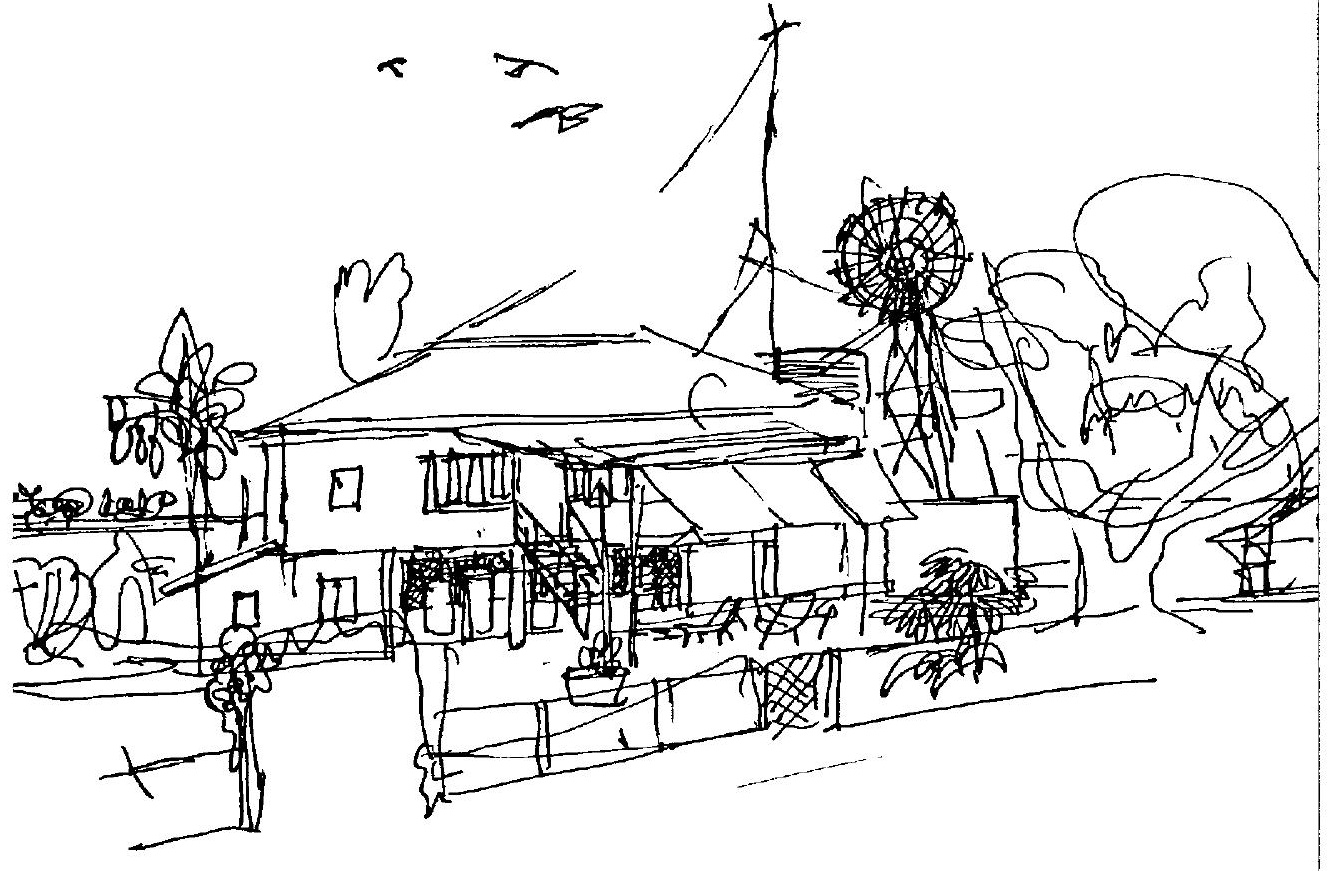

The contrast between peacocks in full plume and the crude provision made for the accommodation of the native work force seemed generally typical of the small importance attached to the physical circumstances of the employees primarily responsible for the industry. Indeed, the social and economic gap existing between management and labour on properties in the Northern Territory must have very few parallels throughout the world. For whilst the masters at some stations sat down to dine in virtual baronial splendour, being waited on by up to as many as six highly trained domestics, occasionally decked out in monogrammed aprons and caps, the husbands and children of the maids sat in the dust picking at the offal from their disgusting pottage and eventually crawling into 'dogkennel-like' structures to sleep.

Even apart from the obvious physical demonstration of Aboriginal subservience very little opportunity was allowed to pass to demonstrate the menial nature of the indigenes' position. For example, one large property visited possessed an Indian style punkah. Every mealtime an Aboriginal woman was allocated the task of pulling the cord which waved the bat-like fan over the heads of the dining whites. Depending on 
the manager's state of sobriety, but at least once every mealtime during my several visits, the chief executive of the ranch screamed out at the top of his voice: 'More fucking gin power. More fucking gin power'. This was normally followed by an cxplosion of laughter from the head of the table and a degree of self-conscious mirth from the assembled guests. The punkah wallah by this time was in a lather of sweat and the beads of perspiration were seen trickling down her spindly arms and across her emaciated face. She in turn gave a rather pained smile and looked down at her bare feet.

The experience with the punkah wallah typified the standard of respect normally displayed to Aboriginal female staff on properties in the Northern Territory. It was rare to witness the same degree of social decorum used in the prescence of white women being extended to female Aborigines. Indeed, there was normally a proliferation of obscenities and crude gestures whenever they were present. At times this did not stop short of the protagonist physically interfering with the employee.

Similarly, domestic staff were the constant object of buffoonery which varied from station to station with the personality of the manager. It was unusual to witness an Aboriginal female employee being accorded the full credit for her accomplishments in the homestead although white women were more appreciative of their assistance than the men.

\section{THE PATTERN OF WORK}

As is common with many rural pursuits the habits and demands of the work dominated the pattern of life. In the Territory, however, the very harshness of the climate tended to stretch the long work day even further. On most stations breakfast was served between 6 a.m. and 6.30 a.m. The waking hour of the Aboriginal employees who prepared the brcakfast was, of course, even earlier.

In the cattle camp the day began at $4 \mathrm{a} . \mathrm{m}$. as the cook stirred to start the substantial meal for the workers who were planning to make the most of the coolness of the 'piccaninny' dawn. Only the depths of the Territory winter changed the pattern. The chill south winds were enough to intimidate even the hardy.

On most days the employees working cattle were seen stumbling around the bush in the dark, waiting for the first glimpse of grey so that they might unhobble the horses and ride to the herd. A common sight in winter during these dawn exercises was the cattlemen sitting on the fence of the horse paddock, their posteriors protruding over the rail, puffing 
disconsolately at cigarettes and occasionally slapping their numbed hands together to encourage circulation.

Once the horses were saddled up they rode throughout the day mustering, throwing, branding, spaying and culling. Invariably the hearty breakfast was followed by a substantial 'smoko' around 9.30 a.m. By 10.00 a.m. the flies had appeared, buzzing into the nostrils, humming around the ears and settling at the corners of the eyes in an endeavour to deposit the eggs which would break out into painful trachoma or some other minor, but nonetheless irritating, infection.

Lunch was normally taken with the flies and probably a load of dust and debris sifted up and deposited on the plate by an inopportune 'willy willy'.

In the hotter summer months lunch was taken over a two hour break as the men propped themselves up against trees or lay under scraggy shrubs in an endeavour to escape the heat.

Except for the days on which fresh beef was brought into the camp most of the meals consisted of salt beef which was cut off in great hunks from its repository under wraps in a hessian bag. The food supply was either thrown under a tree-frequently to pick up dirt, leaves and antsor hung in the low branch of a tree if there were dogs around. As an alternative the Aboriginal stockmen would endeavour to make the fresh beef supply spin out as long as possible, even devouring it with relish almost up to the stage of putrefaction or throwing it into a pot on an open fire, adding flour, and making a crude stew. As green vegetables were rarely witnessed, only potatoes, salt and flour were added to the pottage. A simple damper, cooked under similar circumstances, completed the meal.

The cooking was normally done by an Aboriginal taking his turn from his fellow employees. The food was doled out in a disconsolate fashion, or individuals helped themselves to a plate full of the frequently disgusting looking mess. Even with the most skilled attention salt beef is rarely appetising. If the camp had been away from the homestead for a long time a 'killer' would be taken from the herd and proficiently butcheredto be eaten fresh or salted down; the offal would go to the invariable collection of camp dogs. If a neighbour's beast could be found amongst the stock, there was rarely any hesitation in supplementing the diet.

By 2.00 p.m. it was back in the saddle again and riding into the herd until only the lateness of the hour and the failing light brought the camp boss to call a halt. Sometimes the workers, both black and white, spent as long as fourteen hours in the saddle. 


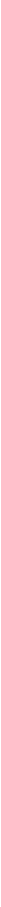

On receiving their allocated share of the inevitable beef the Aboriginal workers settled on their swags, crouched on their haunches or on a rock or stump some distance from where the head stockman was eating alone. Rarely was there a camaraderie leading to the sharing of the meal, or the exchange of intelligence and stories about the day's work. The only bridge to the social gap came through the strumming of a guitar or the halting strain of a tune which knew no racial bounds.

In some camps the more compassionate head stockman offered his fellow workers a tot of rum to ease the pain of exhaustion and to ensure a deep and satisfying rest. With a light breeze rippling the mitchell grass plains, or billowing the mulga in desert sails, the quick twilight broke out the stars in a turquoise heaven of startling depth. Sleep came quickly and easily.

On the larger stations there were two or three cattle camps of up to twenty men, complete with cook and camping facilities, at various points of the property. Normally the camp boss was white but the majority of workers were black. 
Occasionally they would split up into smaller groups or individuals would be detailed to ride into the hills to round up stock. The boss selected his workers, gave them general instructions, and nominated an experienced hand as leader. Less frequently the camp foreman approached his most respected employee, discussed the problems of the day with him and assigned him to a task, letting him pick the men he needed for the job. Most experienced cattlemen we spoke to considered that this was the best way to 'work' Aborigines, as they normally picked friends or relatives over whom the leader had some influence. Only infrequently was leadership dependent on tribal considerations. Those who ignored this rule often complained about the difficulties of supervision and the inability of Aborigines to supervise each other. Whites in this group also referred to the 'Abos' in general terms and were rarely prepared to conceded individual differences. Most of them also subscribed to the 'tough' approach referred to elsewhere in this report.

One other axiom concerning 'working Abos' also seemed to be clear. Aborigines, like their white confreres, have great respect for physical prowess. If a man could outmatch them in the saddle he could earn their respect. If he could compete with them in the muster and throw a difficult steer, he went up in their estimation. As one wizened old Territorian put it:

Ride with the Abos and you'll have no trouble. But try and remain aloof and give orders only and you'll be headed for difficulty.

It is interesting to reflect that some of the gravest complaints about the quality of Aborigines' work came from the young 'professional cattle managers' and not from the people who had grown up with them.

Only one person informed us that he would 'bush all his blacks' and he was dressed in extreme 'Western' style, high heeled boots with pointed toes, silk shirt with plaited scrolls and a 'ten gallon' hat.

Life as described above continued on the northern stations for eight months of the year. In the south such activities were limited to the muster period, with this being dependent on the season, but usually lasting about two months. In both areas the remaining months were taken up with yard building, fence construction and maintenance work. When working the cattle the pattern continued seven days a week.

Only in the 'off' season was the traditional day of rest given. Even then it was a six day week for all concerned; a six day week which might involve 72 hours of the most exacting physical exertion.

It was little wonder that some managers mentioned to us that their 
native employees 'started to become a bit edgy around walkabout time'. They claimed they were more difficult to handle, less likely to take instructions and prone to lose interest in the work at hand.

Prior to walkabout time the station work pattern swung over to the jobs for which cattlemen claimed the Aborigines had less aptitude. During this period there was increased demand for semi-technical skills. Yard building had a degree of applied precision foreign to the Aborigines' way of life. Fence building and pump maintenance often necessitated the use of equipment which they did not understand and had never been trained to handle.

But apparently there was some resistance experienced until the employees were released for their vacation. Conveniently for the station managements this period coincided with the season in which it was impossible to work cattle.

In many cases the workers went off to see their relatives on other stations, or to take part in some ceremonial activity on a government settlement. Alternatively they visited areas and stations in the north which have taken on the aspect of holiday camps. Sometimes the attraction was the geographical environment of the people permanently resident there. Victoria River Downs Station was an example of the latter. On this property the walkabout population was sometimes as high as 500 people.

Borroloola, on the Gulf, also seemed to be taking the role of the 'Blackman's Brighton'. Stations on the Barkly Tablelands often drove their workers to Borroloola for the 'wet'. The trucks were loaded down with food, camping gear and happy children.

The less thoughtful managers would simply 'turn the Abos loose'. By this they meant that they would not want them for some months and considered that their responsibility was ended. In many cases the manager or owner flew south or to the Queensland coast for the summer, leaving the station unattended, or with one white stockman to act as caretaker. Provisions may or may not have been brought in to cater for the Aborigines' mess during the high rainfall months. Possibly the Aborigines themselves would not stay around the homestead but set out for some more attractive spot on the property. Frequently the need to move was brought about by the craving for a better nutritional balance built up after 8 to 10 months on 'white man's tucker'. They would stay in the chosen spot until the monsoon front pulled back.

In very few cases were we informed of any planned activity on the part of the cattle managements to cater for these holiday periods. In a few cases the workers were paid. Some had part of their wages compulsorily 
withheld during the year so that they would have money for walkabout. Others were given a supply of food which might or might not be sufficient to see them through the 'wet'; yet others were simply turned loose to survive as best they could.

One bookkeeper informed me that a common method of cutting down station wages bills was to pay for a shorter period of employment than that actually worked by the Aboriginal staff. In the absence of any check by authorities, the continuance of the truck system in the company store and illiteracy on the part of the natives could lead to this obvious abuse.

Such was the pattern of life of the majority of Aboriginal workers. Childhood for them ended as early as nine years of age.

At this stage they could be expected to start to learn 'the cattle business'. This could mean helping in the cattle camp by collecting firewood and 'boiling the billy', or riding as assistant to the station foreman to open and close gates.

On several occasions managers made reference to 'the few youngsters' they had on their books. When asked what they paid them they answered 'a few bob-at least it keeps them out of trouble'. By the age of twelve or thirteen it was expected that the boy wanted to learn more about the cattle business and would be doing so. It was then that he was lifted into a saddle to undertake an increasing load of the complex skills of "working the herd'.

Rates of 'pay' rose from the 'few bob a week' to around 30s. at the age of sixteen, and, if he showed signs of skill and courage, he was drawing full pay of $f^{3}$ per weck by the age of eighteen.

He would normally stay on this sum until he became too old to ride cattle. If he was well thought of the management might find him a form of sinecure around the homestead. At first it might be chopping wood. He might later graduate to garden work. In this activity he could take his own time to train a hose on straggling citrus trees and pull out an occasional weed.

If the management was not so kind he disappeared into the oblivion of the native camp, to idle away his life living on what food was provided and remaining dependent on the benevolence of his relatives for the simple joys of 'Nikky Nikky' (tobacco) and 'Crog' (alcohol).

The only alteration to this pattern was when the station drew his pension. As explained elsewhere what he received in cash was dependent on the generosity of the management.

Relief in the end probably came from a bronchial infection and its aftermath-a simple bush grave. 
There was no clear pattern presented in the employers' response to our inquiries concerning their recent employment of Aborigincs. The majority said that they continued to employ the same number in recent years as in the past. The balance of the responses to the interviews were equally divided between those employing more and those employing less. The figures presented early in the study showed that in recent years there seems to have been a reduction of about 1,000 in the number of pcople offering themselves for employment on cattle stations in the Northern Territory. However, this could have been the result of two factors. One was the drought in the Centre and the other the location of the government settlements.

Normally, settlements have been set up in response to a clear demand for relief in the area selected, and not established in any way to act as a magnet to attract labour away from the cattle industry. It might be noted that the majority of settlements were situated in Central Australia where there had been a vast reservoir of Aboriginal labour surplus to the requirements of the cattle industry. Where there had been continuing employment opportunities for Aborigines the Welfare Branch had not found it necessary to establish provisioning centres. Indeed, in the northern part of the Territory there were only two Welfare settlements operating which had any bearing on the cattle industry. One was at Beswick, north of Katherine, and the other was at Hooker Creek.

The settlement at Beswick was established to provide accommodation for the people who had originally congregated in the area during the operation of the Maranboy tin and gold mines. ${ }^{2}$ It also contained a considerable number of families which had been compulsorily repatriated to country areas out of the various towns of the north.

Hooker Creek, to the south-west of Wave Hill Station, was established in 1961 in an endeavour to relieve pressure on the Central Australian settlements. Consequently it was inhabited by mainly Central Australian and desert people, although some of the previous employees of the Victoria River District stations were becoming resident.

Except for Central Australia the Welfare Branch settlements were not conveniently located to attract the majority of employees in the cattle industry.

${ }^{2}$ A partly accurate account of the establishment of the Beswick Atoriginal Reserve is included in the publication of that name issued by the Welfare Branch of the Northern Territory Administration, May 1965. 
This aspect of the Welfare Branch system was both a reflection of the demands for their services and a result of the determination of Aborigines resident on the stations to continue in their employment. Indeed, most station Aborigines viewed the possibility of residence on settlements with dismay. Two reasons appeared to be at the base of this rejection of the alternative of settlement life. One was distrust of the Welfare Branch, and the other was a belief that the residents of settlements were not as well off economically as the employees on the cattle stations.

This was supported by comments that people on the settlements were not as well dressed as the cattle station employees, or that they lived on 'bush tucker'.

Aboriginal appreciation of the respective advantages of residence of the two locations was reasonably in accord with the facts of the situation as they were known to the writer.

Although official permission was denied, visits were made to all of the settlements of interest to the survey. The Aboriginal residents were obviously worse off than the employees on the stations. Settlement Aborigines looked more unkempt. Their clothes were frequently secondhand items of doubtful European origin, and ill-fitting if new. Housing was rarely better than on the cattle stations, and even where new facilities had been provided they were frequently unsuited to the requirements and left unoccupied.

One Aboriginal pensioner summed up his attitude to settlements by stating that they might be all right for other Aborigines but not for him. He did not like the beef. "They wanted me to stay there but I said no. I am used to fat cattle. They are all poor . . . and dry like this.' He demonstrated his last point by pulling at the age-wrinkled skin on his arms.

In financial terms the attraction of relocation at a settlement was minimal. Wages, if paid, were determined on a haphazard and variable basis, and were rarely greater than those which were paid on the cattle stations. If, in theory, the cash wage was higher, settlement authorities normally used a voucher or deduction system the end result of which was that there was no appreciable difference between what was received in the hand' on the cattle station and what was received 'in the hand' on the settlements.

Although no research was done on settlement diet the existing sources indicate that nutritionally Aborigines were worse off under government care. ${ }^{3}$ Although on some settlements the diet may have been better

${ }^{3}$ Tatz, Aboriginal Administration, pp. 153-9; Commonwealth Department of Health, Dietary Survey of Aborigines in the Northem Territory, 1946. 
balanced, it was substantially lacking in the protein foods which have played a significant role in traditional Aboriginal society.

There was, consequently, no real attraction in the settlements, with the exception of education. As Watts and Gallagher have pointed out, ${ }^{4}$ those Aboriginal families who were appreciative of the benefits of European education were leaving their children on the settlements whilst they worked on the surrounding stations.

The towns, as well, hardly provided an attractive alternative. Most Aborigines interviewed on the cattle stations looked askance at the drinking habits and general social debility of town residents. Further, with the exception of Darwin, the Welfare Branch had made no real endeavour to develop communal facilities for Aborigines in the towns. Both the Welfare authorities and the police harassed new arrivals and even, occassionally, old residents. Further, various agreements existed between government and private authorities to repatriate Aborigines from Darwin against their will.

The response of the employers, therefore, was merely a reasonably factual statement of the situation as it had existed over the years. The Aborigines resident on the stations had been available for employment and they had been engaged. For the purposes of this study the interesting aspect of the situation is that they have continued to be employed. There had been, apparently, very little fuctuation in the level of employment of Aborigines although the official wage for the engagement of labour had been increased by approximately 1,200 per cent in a period of fifteen years. The significant factor was, of course, that the official remuneration of Aborigines was still only approximately 28 per cent of the legal minimum rate for whites and some 15 per cent of the ruling rate paid to white workers in the industry. At the then current levels of remuneration, at least, there had been no displacement of Aboriginal labour.

\section{REPLACEMENT OF ABORIGINAL LABOUR BY WHITES}

As the industry was organised at the time of the survey it was impossible to replace Aborigines entirely by white employees. This resulted as much from the vital services that Aborigines provided for station managements as it did from the poor supply of white labour available. Even where there was a question of the possibility of paying Award rates at the European level the station managements still considered that there was a vital role for Aborigines to play in the industry.

4 Watts and Gallagher, Report on an Investigation into the Curriculum and Teaching Methods, 1964, pp. 6 and 16. 


\section{AVAILABILITY OF SUITABLE EUROPEAN IABOUR}

The employment of Aborigines continued at a stable level although most employers considered that they could get sufficient white labour. They were, however, very critical of the standard and skill of the majority of whites who were available for employment. The turnover of white labour was an additional point of concern for management.

The reaction of white labour to the work environment was also of considerable importance, as a favourable attitude to the job might have tended to counteract any disadvantage in pay and conditions, as well as assist in softening antagonistic racial attitudes through an overall allegiance to the objectives of the enterprise. However, it was found that most white employees interviewed were inclined to be critical of the conditions under which they worked and the remuneration received considering the disadvantage of the location.

Although the industry had attracted a certain type of person over the years, to whom outdoor life, and cattle work in particular, was appealing, their willingness to continue to pursue this calling was becoming considerably affected by the growth of other occupations in the north which were offering more money for similar types of work. The most frequent source of alternative employment which was mentioned was the mining industry, and plant and equipment operation in particular.

The isolation of the northern cattle stations seemed to be one of the major disadvantages for people coming from more diverse communities. It was claimed, on several occasions, that the confinement led to a deterioration of the average employee's social and career horizons until, in the end, he 'just couldn't give a damn':

Ringers ${ }^{5}$ are a funny breed ... they do not really need a day off a week. If you have a day off and lay on your back you've got time to think of your problems. Since I have been here I have had days off but they don't provide any facilities. You do your washing and then you lay on your back and think-this is a lousy place; what am I doing here?

One person who was interviewed claimed that he had not had a day off for two months, although he was not particularly complaining about it. He seemed to accept it as part of the job. But he was more concerned about the aimless nature of the existence:

What do you have to look forward to?--the races and Christmas. For young blokes there is nothing constructive to think about. I have received [journals] and things up

${ }^{5}$ A colloquialism for a fully trained and proficient stockman. 
here but you just can't get stuck into them. Things like the date-you just don't care any more. You are in your own little hole and there you are. Take yourself coming along. To see you there and to have a yarn with you was like a bloke in the city having a week off. This was really something to have a stranger come along.

In other cases whites showed an extreme fear of the isolation of the bush and reacted strongly to assignments in which they might be separated from companionship for weeks on end, or geographically by anywherc up to 100 miles from the nearest station community. Secondary evidence, in the form of stories of the strange reactions of whites who had worked in isolation at the pumping stations attached to bores, was particularly common. In several of these examples the white attendants were said to have walked off their posts either to perish in an attempt to get back to the homestead, or to disappear without trace.

It was significant that unreliability of Aborigines at pumping locations was never mentioned as an employment disadvantage. For this reason, no doubt, very few whites were employed as pumpers.

Indeed, it was noticed that those whites who preferred to work in isolation on these jobs evidenced considerable mental instability. Of the few white pumpers interviewed one became extremely irritable in company and another had so developed the earthworks of his 'turkey nest' 6 type tank that it was apparent that some form of hydrophobic delusions were present. In yet another case one white attendant had decanted sufficient pint bottles of oil to lubricate the pump for eighteen months 'in case no more oil came out from the station for a while'.

Given their affinity with the countryside, and their ability to survive on native foods should they be isolated from the station for any time, Aborigines were obviously much better adjusted to these locations.

The white employees in the industry were conscious of both the dangers of cattle work and its exacting physical nature. However, most were prepared to take the heavy physical demands of the industry as part of its attraction. One person, for example, claimed that he had just finished a long period of work in a stock camp. During that time his weight had fallen from twclve stone to ten stone. But he claimed 'I'm all the better for it-I am solid-it's tough work'.

But there were the gruelling and physically demanding sides which bore heavily on the individual, forcing, it was believed, early retirement. It was a matter of living on sedatives, one claimed.

${ }^{6}$ A 'turkey-nest' tank is so described because of its appearance. Normally built in plains country, the earth walls of the dam usually rise 20 or 30 feet above the surrounding countryside, holding anywhere up to 20,000 gallons of water. 
When you've been in this game for years everybody's got his scar marks. Sooner or later your nerves have got to go. They don't say you've got no guts or courage. All they say is that his nerves have gone. I've had days where I have been belted around so much that I didn't care what happened to me. This is fair dinkum.

However, the social and physical conditions created by management were of considerable concern.

The trouble with most of the managers up this way is that they have only been used to employing black fellas. They just don't know how to treat a white worker any more. Their wants are simple but do you think that they will provide them? Not on your life. Take the accommodation at [X station]; did you see it? Well, I wouldn't put my chooks in it. One bloke fell through the floor. All a ringer needs is somewhere to put his head down and somewhere to say that he knows where his things are if he goes out on the run for a few weeks. But in this place if you go out for a while and come back in again some bloke will be in your bed and you will be lucky if you can even find a mattress to sleep on.

Apart from the European accommodation, which management could have readily assisted in making more attractive, the white station workers' attitude to the racial mixture at his work was of considerable importance. Undoubtedly the problem of racial association was superimposed on the general difficulty of the lack of common interests between literate and illiterate people. One person summed it up by saying: 'give yourself two months in the stock camp with only black fellas and they'll drive you nuts'. From the rest of this particular person's comments, however, he revealed himself to be fairly liberal in his attitudes to Aboriginal workers as well as in his appreciation of their value to the industry.

But generally the antagonism went further. After explaining a conflict which had taken place on one of the stations between the manager and white stockmen over the claim of an Aboriginal to become head stockman, my informant continued:

The whites jacked up. The management said that they couldn't make him head stockman as he couldn't attend musters. This is drummed into the ringers-the black fella is nothing. Hate the black fella-you see these boys have grown up with Aborigines they loathe them. They may not say that, but behind their backs they hate their guts. For a white man to work under a black fella would be the lowest thing that could happen to a man and yet some of the black fellas are fantastic stockmen and the majority of white men treat them as equals when they are working with them.

In a practical work situation you find that there is an equality of exchange-in mustering, tailing and chasing. But immediately work finishes there is a social gap. Now, take a mustering camp, handling wild cattle is one of the most dangerous games going and needs mateship, when throwing a beast you need a mate there, and if somebody's going to get hurt a bloke will risk his life regardless of who he is and yet he reckons he hates his guts. I've seen it in yards. A bull having cornered a fella and ripping his guts out and he will risk his life for him. 
The European stockman's opinion on the gap which developed between Aboriginal employees and whites, on the completion of work, even in isolated stock camps, was supported by native evidence. One Aboriginal informant put it this way.

You teach em but they don't want to live with you; they live a long way away when you're in the bush. When we finish work we have to make our own camp fire. And when the tucker is ready we have to come in like ants all in a row-one after the other--to get our food-and take it away and eat it.

Other evidence supporting the white stockman's claims might be found in the opinion of Aborigines that 'managers don't trust them' as well as in the almost universal practice of never allowing Aborigines to ride in the cabins of station trucks. This practice continued despite white knowledge that Aborigines were as clean as whites, if not cleaner than most, in their personal habits.

Although employers in the industry considered that they could get sufficient suitable white stockmen, employees were not quite as certain as the management. As already indicated most believed that there would have to be considerable improvement in attitudes and accommodation to ensure continued attraction to the industry in competition with the other expansion which was taking place in the north. Several persons, including two union organisers, freely admitted that good all-round station hands were no longer being attracted to the industry in sufficient numbers to meet the demand. Aboriginal evidence also confirmed the lack of all round skill of available European workers with the comment that 'they are unable to do all the jobs on the station'.

Apart from the limitations imposed by race contact and isolation, the ease with which alternative employment could be obtained in the north affected the attraction of employing Europeans. The short periods of stay of most white station workers was undoubtedly a limiting factor to their suitability for the industry. Except in cases in which a high level of loyalty to the management was shown, the average length of tenure in European positions was eight weeks. This hardly allowed sufficient time for orientation and placed additional strain on the permanently resident work force, mainly Aboriginal. This aspect of European unsuitability was clearly recognised by Aboriginal informants:

Interviewer: Who are the best stockmen?

Aboriginal: Oh, the blackboy. You put him down here and he stays here all the time.

He's here for a lifetime. Work all the time, even on Sunday.

Finally, there was a fairly widely held opinion in the industry that experience in other parts of Australia did not necessarily provide a person 
with competence in the cattle work of the Northern Territory. Because of the vast size of Territory stations most of the cattle were wild and 'tailing wild cattle is something which a green-horn can't pick up. It takes real skill, yes, real skill'.

The problem of white labour availability, and the respective level of skills in cattle work, were clearly emphasised by the experience of one employer shortly before our arrival at his station. He informed us that following a dispute with his Aboriginal employees in which threats of violence were used, he dismissed them all. He then tried to get sufficient whites from the nearby towns to replace them. Although he was able to obtain a full complement of men he ran into considerable difficulty with them. The problems were partly the result of their lack of experience in the industry and on the property in particular, and partly the result of excessive drinking. In the manager's words:

They were a bloody lot of no-hopers. I had to bush the lot of them as well and ended up going into Katherine to apologise to my own blacks to get them to come back. They only agreed to do so after I promised to improve their camp.

AVAILABILITY OF SUITABLE ABORIGINAL LABOUR

Employers were of the opinion that suitable Aboriginal labour was available. This is confirmed by the statistical position outlined earlier in the study. Those answering in the negative were, however, critical of the standard of Aborigines who had been recruited from the settlements. As station labour was normally recruited from the resident population the comment was only of limited significance. However, as the settlements have been established to assist in the task of assimilation their value as training institutions, in the eyes of employers, was of some consequence.

The settlement system in the Northern Territory provided very little opportunity for Aborigines to become skilled in the techniques and art of the cattle industry. Indeed, given the present educational arrangements, the traditional skills of bushmanship were rapidly disappearing and were not being replaced by white training of equivalent utility to the employer.

Although at some locations limited trade training was being extended to indigenes the number of persons involved in these activities was hardly sufficient to make any significant difference to the employers' attitudes to their employment.

The question of 'suitability' of any employee is, of course, fairly subjective. However, the responses of the employers indicated that the 
present level of skills was sufficient for their purposes. This opinion was also supported in interviews with head stockmen and employers in other areas. For, although literacy was a basic necessity for persons enjoying management status, such as head stockman, or storekeeper and clerk, it was of no particular advantage to a stockman.

Satisfaction on the part of employers with both the numerical supply and their suitability possibly accounts for the failure of the properties to develop any training programs for Aborigines. The requirements from this group of workers were fairly narrow and the skills which they already possessed were adequate for their tasks. However, obviously broader training would increase their flexibility in the station work force. At the time of the survey there was apparently no provision for diversity of training.

Aborigines were conscious of the fact that little opportunity was extended to them to broaden their skills and as a consequence increase their work value and opportunity. However, they questioned the desirability of the formal education in the European sense as they could see little or no positive advantage coming from it.

Whilst on the question of suitability it should be noted that the more outstanding of the Aboriginal employees, group leaders and persons employed in the post of the Aboriginal equivalent of head stockman, were extremely critical of their relative position to whites in the industry and treatment in relation to status, pay and housing.

\section{ABORIGINAL COMMUNITY ATTITUDES}

Although the attitudes of management to the value of their native work force varied from station to station, from such diverse positions as "being indispensable' to 'useless', no station visited accorded the Aboriginal community equality of treatment either amongst themselves or with non-managerial European employees. It was noticed also that there seemed to be no direct correlation between the manager's appreciation of the native work force and the conditions under which it laboured. For example, one of the few persons interviewed who considered Aboriginal employees indispensable and who stated that he would employ the same number if they were granted European Award rates, did not provide them with any form of shelter other than an occasional tent fly; nor did he provide European food of any consequence. However, his appreciation of their employment skills and loyalty was almost lyrical. There was, however, very little connection between the attitudes of employers in 
appreciation of their native work force and the rewards accorded to it. Paramount in this respect was food.

Undoubtedly the relationship between native employees and European employers achieved greatest harmony where the food supplied to the camp was adequate to its needs. Adequacy in this sense was normally only conceived in terms of bulk and not dietary balance.

As has been described elsewhere (pp. 85-95) this diet was rarely more than beef being supplied in sufficient quantities, although some managements did support this issue with adequate sugar, flour and tea. None of the stations visited attempted to provide the complete list of provisions required by the Wards' Employment Ordinance.

The importance of food ranked higher than shelter in indigene preference. This needs little explanation when it is appreciated that housing accommodation, in the normal Anglo-Saxon suburban sense, was needed for only approximately four months of any one year. The times of my visits also coincided with what might be considered the most pleasant season in north Australia, although a limited time was also spent in the area during both the most unpleasant winter months and the enervating 'wet'. Consequently, food was of more immediate importance. It may have been of greater concern, also, because of the inadequacy of housing provided.

The attitudes of both management and Aboriginal labour to accommodation, however, stood out as being one of the more complex issues of the relationships within the industry. Its importance was heightencd by the apparent partiality of Aborigines to most European-type foods. For, whilst indigenes showed little reluctance to adopt white eating habits when they were introduced to them, frequently regardless of the standard of food, they obviously rejected the substandard European accommodation.

Where European foods were offered in abundance there seemed to be little resistance to their acceptance. Only occasionally was it noted that difficulties arose where an entircly unknown food item was introduced into the camp. The circumstances of its introduction and occasional rejection were usually associated with the commodity being surplus to white requirements, or in a state unfit-in white opinion-for consumption, and as a consequence it was thrown aside by the Aboriginal residents as well. This was also normally associated with either a lack of knowledge of its treatment or inadequate facilities for its preparation.

In the main, the pattern of food supplied was unchanging. Rarely was there any opportunity extended to the native work force to broaden their 
taste. The only opportunity open to indigenes to improve their diet was achieved on those stations which operated a store with a wide range of goods for sale. Here it was noted that items containing a high sugar content or providing some particularly needed nutritional element, such as canned baby foods, were in high demand. The effective level of cash retained by the employee's family, however, usually placed a low limit of consumption on these items.

By far the most sought after items were biscuits, tinned fruit, dried milk, cordials, juices and sweets. Canned or fresh vegetables, although rarely available, were not given a high order of preference. However, the lcvel of dietary aspiration was low. The occasional access to a wider range of goods was taken as a 'treat' more than a necessity. Indeed, there was no method by which the average daily diet could be varied to any great extent.

But whereas it seemed possible to overcome the social and economic gap in relation to food merely by the provision of additional quantities and varieties, together with limited instruction in their preparation and use, the question of Aboriginal housing was demonsirated to be infinitely more complex. Indeed, the needs of Aborigines for accommodation. remained one of the enigmas of the survey.

As mentioned above, the demands of the climate did not give rise to a great need for housing in the European sense. It should be noted, also, that any solution to the indigenes' housing needs along traditional European lines was more likely to add to their discomfort than to satisfy the real needs for shelter in the tropics.

On the few stations which had made any endeavour to provide accommodation in accord with the standards of the Wards Employment Ordinance, the inhabitants seemed only casually interested in occupying it. Invariably the shelters provided were used more for the storage of personal possessions than for human protection. The only time during which resort was made to the sheds provided was in wet weather. At other times the discomfort of residence far outweighed its advantages.

In this respect it should be recalled that the standards laid down by the Welfare Branch could be met by the provision of a galvanised iron shed with little attention to cross ventilation or insulation. However, the white section of the community had gone through a process of adaptation of suburban design to meet their needs-at least in part. Rarely was the same standard of thought applied to native accommodation, although this could have been achieved at little more cost than the improvements which had been installed in white houses. 


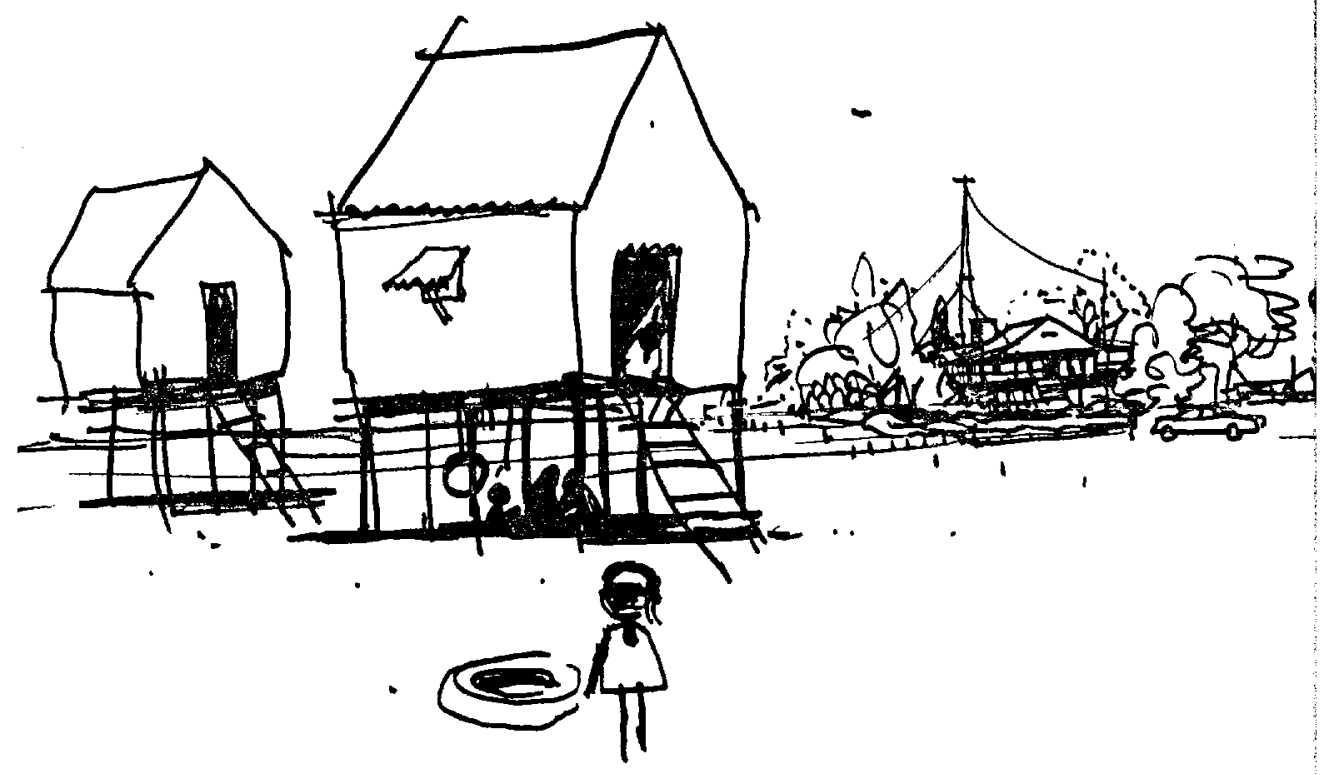

The design of the better constructed European homesteads featured large verandahs and provision for cross ventilation. Management housing concentrated firstly on elevated floor areas, and secondly on cooking facilities which were well protected from the penetrating sunshine. In the latter case removal of the cooking area to a region sealed from the light assisted in excluding both dust and flies. It was noted that none of these features had been adopted in Aboriginal housing. At best, the minimum requirements for 'sleeping' accommodation were met on three stations.

Aboriginal cooking facilities on all stations were crude. These ranged from the provision of a general cooking area, with an occasional clay oven for the baking of bread, to the traditional stick fire outside the Aborigines' shed. In the first instance the general cooking area consisted of an overhead shelter, an open brick fireplace with wire pot holders strung invariably from steel fence posts or bore piping and a receptacle for firewood.

On most stations it was the Aborigines' responsibility to replenish their own firewood supply. This task usually fell onto the shoulders of the pensioners, women and small children, who frequently had to scavenge for firewood up to three miles from the homestead. They then bundled it together with a rope, swung it on to their backs and carried it back to the camp. 
On none of the stations visited were there adequate ablution or fresh water facilities. On six of the stations there was no fresh water supply attached to the camp, and all the water used had to be drawn from the homestead - in one case this was approximately half a mile away. Where fresh water facilities were provided, they normally consisted of one outlet for the entire Aboriginal community whose members lived up to 200 yards from the source of supply.

Where no fresh water was located near the Aboriginal quarters it was noted that some families drew their supplies from the nearest convenient source; in one case this was a cattle trough.

The practical effect of these depressing conditions meant that little or no demand for improvement was evident. Even the best facilities provided wcre substandard by any terms. Few of the facilities provided for Aborigines on any of the stations could have been considered an improvement over their previous accommodation. It seemed to matter little if you moved out of a 'wurley' constructed of scrap iron or trees and grass, into a corrugated iron shed. ${ }^{7}$ Indeed, during most of the year it was found that the 'wurley' provided greater comfort than the sheds designed to meet the letter of the Wards Employment Ordinance.

There was little encouragement by management for the resident Aboriginal groups to demand an improvement in their conditions.

One comment of management, which was frequently repeated, concerned the lack of appreciation by Aboriginal communities of attempts which were made by the management to improve their physical circumstances. Case after case was mentioned where management had endeavoured to provide improved facilities only to be frustrated by Aboriginal neglect or apparent vandalism.

Aboriginal reaction to managements' endeavours to improve their conditions obviously had a cultural origin, which could have been overcome by education about the facilities. ${ }^{8}$ This was rarely attempted.

For example, two employers informed us that they had installed septic toilet systems for their Aboriginal employees and that both systems had broken down under use. No sooner had they got the system working than it broke down again. One of the employers refused to give any more attention to the matter, and just considered it impossible for Aborigines to adjust to European habits in this way. The other analysed the problem.

'A 'wurley' is an Aboriginal shelter built from native trees and grasses. The walls or roof are frequently strengthened with European scrap materials.

${ }^{8}$ Tatz, 'The Relationship Between Aboriginal Health and Employment, Wages and Training', pp. 51-68. 
more closely and found that it was a habit of Aborigines always to deposit solid matter on human waste after it had been passed and, as often as not, the most convenient item close at hand would be a stone. Accordingly, they continued the same habit in the septic system and it was soon clogged.

The employer who determined the source of this trouble convinced his employees that the toilet paper he supplied had the same effect as placing a stone on top of the waste, and accordingly overcame his problem. The other had not contemplated the issue of toilet paper and abandoned any attempt to kcep the system working.

These two examples have been drawn specifically to show the importance of demonstration in the learning process of illiterate people. Unfortunately the opportunities for development of Aboriginal cultural patterns were considerably hampered by the physical conditions provided for them.

Apart from theory based on written language, or verbal instruction, the learning process is limited to experimentation with physical devices and encouragement, for example in the use of implements or materials. In Aboriginal circumstances on Northern Territory properties, I did not witness any attempt to instruct Aborigines in either employment requirements or community affairs.

Yet another common feature of every Aboriginal camp on the stations visited was the absence of virtually any type of civilised facility with which they might experiment. Cooking utensils were limited to one or two billycans per household, and an occasional frying pan. Frequently the billycans were merely discarded jam tins with a wire handle threaded through a hole in the side, which had been punctured with a nail. Some stations refused to issue any cooking utensils at all. Rarely had any furniture been provided. The most common mechanical device supplied by the station was a carbide lamp. Occasionally one or two members of the community possessed a kerosene lamp for which they normally found difficulty in acquiring fuel. Only two of the stations inspected provided electricity to the Aboriginal quarters. Although in one case the manager frankly admitted that his generator had sufficient capacity to light the whole area, he preferred the energy to run to waste, rather than to make a moderate investment in electrical wire to improve vastly the comfort of his employees.

The communities were, consequently, bereft of any of the appliances of modern living whereby skills could be acquired, or the basal nature of their existence elevated. 
A wife of one of the managers interviewed drew attention to this aspect of the Aborigines' position through the reaction of her trained domestic staff on returning to the Aboriginal camp after having spent the day at various chores at the homestead. Although they had completed those duties to the entire satisfaction of the woman of the house, she was amazed at the lack of endeavour on the part of her staff to transfer the same standards achieved during the day to the Aboriginal camp at night. The physical impossibility of accomplishing this seemed to escape her.

The women concerned took off their 'homestead' clothes at the end of each day's work and hung them in a shed. They then donned their loose fitting second-hand camp clothes for the evening. On returning to work in the morning they had a shower at the homestead, and dressed once again in their neat clothes for the day's work.

One further obstacle to learning from experience or example by Aborigines on Northern Territory cattle stations was the social and physical gap which had been created between the two communities. The extent and nature of this gap varied from station to station, but was noticed to exist everywhere visited.

To demonstrate this aspect of Aboriginal living it might be convenient to study the ground plan of a typical northern station and consider the opportunities for members of the Aboriginal community to be exposed to white influences. The plan is a composite sketch denoting what might be considered as a typical layout of a Northern Territory property. Although it had features in common with several of the properties visited it does not fully represent any of them. The general areas and locations of residences were sufficiently common to represent the normal milieu of race relations within the tiny communities scattered throughout the north.

In these situations there were, on an average, some sixty Aboriginal residents and ten whites. Occasionally stations also accommodated a number of half-caste families, which led a life somewhere in between the Aboriginal and white community, depending on the attitudes of the management towards them. Normally they were treated with more consideration than the Aborigines; but unless they were children of one of the European employees on the station, or of the manager or owner himself, never as liberally as a white employee, regardless of their contribution to, or position on, the station.

Of the ten white residents seven were normally males and three were females. Occasionally there were some very young European children in residence as well, but most children were sent away to school by the time they had reached the age of eight. 


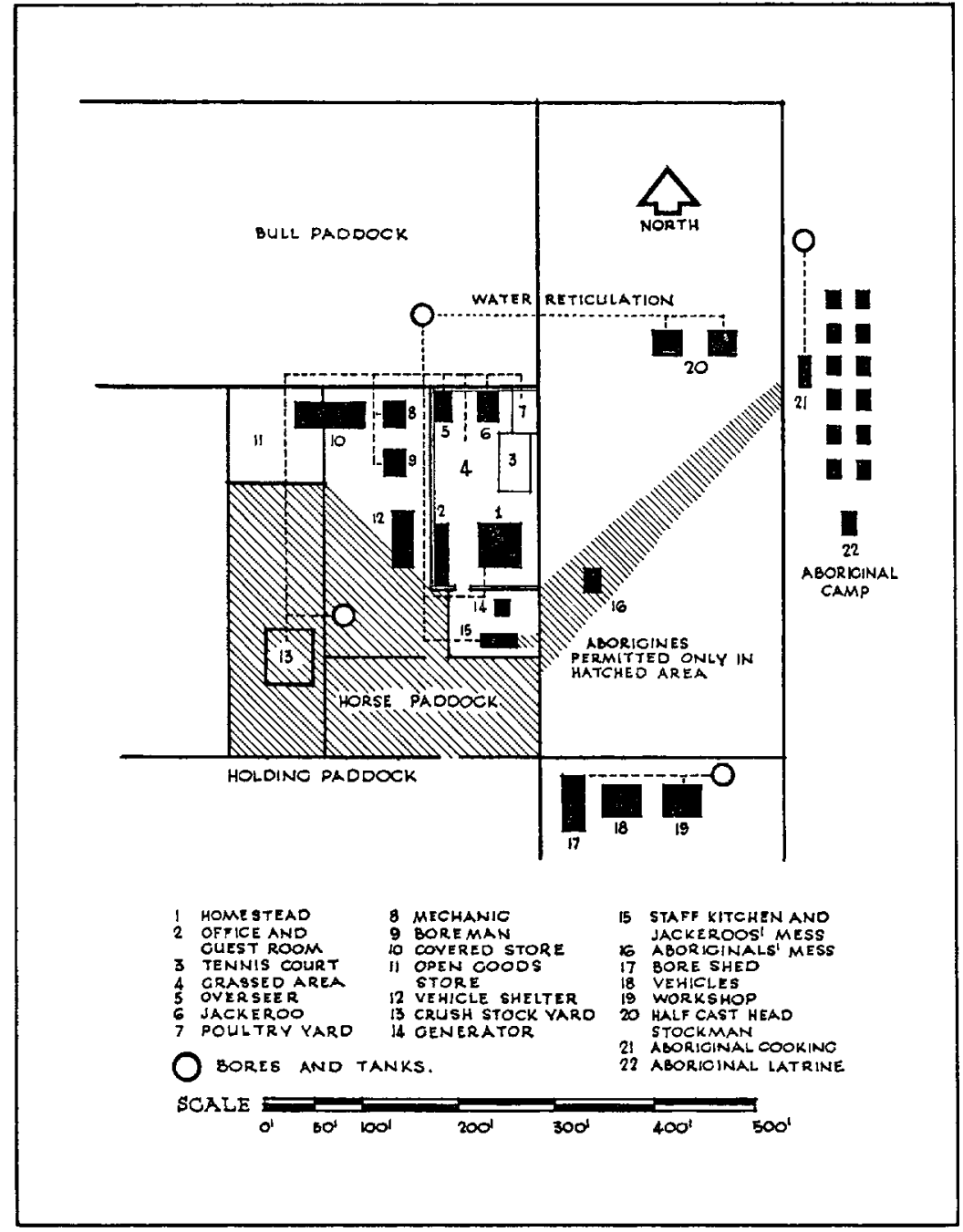

Map 5. A typical Northern Territory homestead community, 1965. Distance between homestead and Aboriginal camp halved.

The seven white males normally filled the functions of manager, mechanic, bore expert, overseer, bookkeeper and jackeroo. The distribution of these functions has been outlined earlier in the survey results.

As can be seen from Map 5, they lived mostly within a small perimeter 
around the main homestead buildings. Normally one or two of the white employees, as well as the manager, lived on the station with their wives, and married quarters were provided for them. They lived, however, within close proximity to the rest of the European community. The half-caste residents, if adult and specially favoured, were provided with European type accommodation, normally of an inferior standard and a considerable distance removed from the white complex. Occasionally this was in the direction of the Aboriginal quarters, but this seemed to depend more on whether the half-caste person was married to a full-blood Aboriginal or not.

The function of the main layout of the homestead area was to produce a convenient format for white employment and social intercourse, as well as to minimise the cost of the distribution of water and electricity services. In many cases the white enclave presented the image of a small walled town within a jungle of gates and fences.

In the composite case under study a high brick wall had been built around the western side of the homestead area, protecting it both from the harsh afternoon sun and from the gaze of visitors and employees who might be working in the public areas of the station yards. The inner circle of the homestead area was protected on the north by dormitory buildings and on the east by a tennis court and a tall clump of hedge-like bushes. The offices, visitors' quarters and homestead filled in the southern side of the quadrangle.

Within this cluster of buildings most of the interchange of managerial functions and delegation took place. It was the area from which Aborigines -other than the domestic servants-were excluded, except for such rare functions as the Christmas party.

Approaching the homestead area for an Aboriginal was strictly conditioned by his function on the property. The presence of an indigene in areas other than those authorised by management was frowned upon, and in certain circumstances might attract punishment.

In the composite property under consideration only those Aborigines who were officially on the pay-roll were allowed to come into the home paddocks. Even then their movement within those borders was confined. There was a well-worn track from the Aboriginal camp across to the staff kitchen area from which they were fed. The only time that nonemployees were allowed to traverse this road was once a week when their rations were handed out at the kitchen door. They were encouraged then to remove themselves back to the native compound.

Those male Aborigines employed by the station during the day 
assembled at the door of the staff kitchen and were handed out their simple meal of bread and beef, or an occasional stew. This was taken away some 20 or 30 feet outside the homestead area to be eaten. Frequently they squatted on their haunches to eat, or leaned against the wall of a shed. Occasionally an oil drum or a convenient stump served as a crude table, although I never witnessed the improvisation of chairs. As knives and forks were not provided, the food was either picked up with the fingers or between hunks of bread.

As well as could be determined, quantities of food distributed to working Aborigines in this way were never limited, as I witnessed several cases where the employees asked for more and were readily served. However, several complaints by Aboriginal employees concerning the quantity of food dispensed at various stations were recorded during the survey.

Single members of the white staff were served from the same kitchen but across a small counter separating their dining quarters from the cooking area. Regardless of the inclement nature of the weather, and the more than adequate areas devoted to the small white staff, Aborigines were never allowed to take their meal in comfort.

The white staff table normally displayed bread and butter, a variety of jams and other condiments, occasionally fruit, and the choice of tea or coffee. When available, the diet was broadened with greens in the form of hot vegetables, or salads with cold meat. Quantities were never restricted.

Following the early breakfast the manager or the white overseer delegated groups of Aborigines to various tasks or they assumed their accepted functions on the station. Nobody, however, seemed to be allowed his choice of jobs. Most specialist tasks had been occupied by the same person for some years. None of the Aboriginal workers on the stations varied their jobs during the visits.

As with the immediate homestead area, the machinery sheds and stores were 'out of bounds' to Aborigines and the only persons allowed to approach them, except in the company of a European superior, or on instructions, were the employees of the areas concerned. Consequently, the movement and experience of an Aboriginal was very clearly limited to his own specialist task. There was no possibility of transfer of function through the casual acquisition of additional skills.

The geographical exclusion of Aborigines from the homestead areas even applied to children. In one case of note, the native children were not supposed to be any closer to the station homestead than the border fence 
of the native camp. But, being children, they were frequently attracted by the movement at the station and were intrigued, no doubt, by its seemingly endless supply of food.

At one station I noticed that a number of children had begun to appear around the staff kitchen during meal times although the manager had informed me that this was strictly forbidden. Later during the visit I was sitting with the manager in the kitchen at the rear of the homestead, helping him to consume the usual case of beer which he allocated for the European community's daily thirst, when suddenly he sprang up from the table and grabbed a shot gun from the top of a cupboard. He slipped a cartridge into the breech and leapt out of the door bellowing at the top of his voice. There was a scatter of bodies as adults and children alike, raced for cover. He then discharged a shot into the air. He returned to his beer at the kitchen table with the explanation: 'That'll keep the little bastards away for a while'. As I lifted the neck of the cool bottle to my lips and tilted my head back I could see the last of the juvenile intruders scuttling back to the Aboriginal camp. The reaction of intruders and staff alike made it seem as though this had happened before.

The special nature of the confinement of the Aboriginal group was further strengthened by social distance. During my visits to many of the stations, the European community made frequent cause for social intercourse. At the most common level it embraced a beer 'on the house' at the end of the day, through to more formal functions including neighbours and interstate visitors. At none of the stations did I witness any members of the Aboriginal community being included in these diversions. The only concession which was made to any members of the Aboriginal community was an occasional beer handed out to a half-caste stockman at the kitchen door; he stood outside to drink it.

Social fraternisation between the racial groups during non-working time was also discouraged. For example, at one station I was informed by two jackeroos, who had been resident on the property for nine months, that they had never been to 'the blacks' camp' as the 'boss would frown upon it'. Both of these employees, however, displayed keen interest when I informed them that the indigenes were making preparation for a brolga dance corroboree, and expressed their desire to witness the performance. Later that evening I saw them watching the dance from the shadows of one of the Aboriginal huts.

On most stations the consumption or possession of alcohol by an Aboriginal was taken to be a serious breach of discipline. Instructions on this matter were either by management decree or through the posting of 
notices under the Northern Territory Licencing Ordinance. This gave the management power to prohibit the possession of liquor in the homestead area. Regardless of management intentions, the Europeans on most of the stations drank to excess. This practice was normally condoned.

Although management endeavoured to maintain a social and geographical barrier between the white employees and the native camp this was frequently crossed. The usual motive on the white side was the pursuit of sexual pleasure; such dalliance not being limited to employees alone. The method and circumstances of social contact in this respect were normally conditioned by alcohol, although an interview reproduced elsewhere in this study clearly shows that the system also functioned without this stimulant.

The attitude of management to sexual fraternisation in circumstances where they frowned on any other form of social intercourse was interesting. At best they seemed to accept it as part of the cost of isolation. On some stations it was considered to be part of a process of social deterioration of individuals who had been away from white female company for too long-to be tolerated but not encouraged. In these cases any person who had managerial aspirations usually reflected the manager's attitudes in his presence, regardless of his personal practices. In other circumstances managers took a more proprietory interest.

In two cases during the survey it was noted that management actually endeavoured to exercise discretion over the distribution of female Aborigines to various white employees on the station. The rationalisation of this process was that it assisted in decreasing the friction amongst the white staff. At one station management approved of a white head stockman taking a thirteen year old Aboriginal girl as his 'wife'. When I questioned the propriety of the association I was informed that it was 'better that way as he'd been knocking her off for quite a time'.

\section{PRODUCTIVITY OF ABORIGINES}

There was no evidence from either the first survey of management attitudes towards Aboriginal workers, or the second survey of employees' attitudes to their fellow workers, to suggest that Aborigines applied themselves at a lower level of endeavour in the positions for which they were engaged. Indeed, careful study of the results of the survey-the literature in the field as well as the observations of the Arbitration Commissionclearly indicate that, as the industry was organised, Aborigines were at least equal to European employees and some were superior. 
The only objective evidence beforc the Arbitration Commission concerning the work performance of Aborigines resulted from their inspections of properties in the Northern Territory. As might be imagined the visits made by the judges were restricted to those areas on the station where vehicle access was possible. None of the judges concerned was able to witness the most productive aspect of Aboriginal skills - - the locating and securing of cattle so that the process of herd management might be undcrtaken. On this aspect of Aboriginal performance there was virtually universal acclaim.

In the more confined operations of the cattle yards, where Aborigines did not have any particular preserve of skill, the court description of the contribution of Aborigines to the work process was obviously one of equality with whites. ${ }^{9}$

Praise of Aboriginal skills and contribution to the work process of northern properties has come from many sources and supports the balance of opinions expressed by employers in the survey. Indeed, except in the proceedings of the 1965 Arbitration Commission Casc, it has not been possible to establish any authoritative sources which are derogatory to native labour skills and application. Many of the complimentary remarks have been made by representatives of the industry; the comment by Sir William Gunn was typical. He claimed that he was not:

... one of those who considered Aborigines of no use.

We would not be able to handle a lot of Northern Australia without them ... They are prepared to live under conditions a white man would never tolerate. Don't dismiss thcir usefulness. ${ }^{10}$

Another authoritative comment by an experienced cattleman appeared in the scmi-official publication Cattle Country in 1960:

The station-bred black boy has no great love for a horse, although he rides well. He is smart in the things that matter and is a valuable force in the mustering camp. ${ }^{11}$

Aborigines were prepared to challenge the statements of their employers concerning any limitations on their value to the industry, as this response to my inquiry to a full-blood Aborigine as to who was the best stockman

\footnotetext{
'See evidence presented in Commonwealth Conciliation and Arbitration Commission, No. 830 of 1965 , detailed below.

${ }^{10}$ Austratian Financial Review, 15 February 1968. Sir William Gunn is Chairman of the Australian Wool Board as well as having interests or management responsibilities in some sixteen cattle properties in northern Australia.

${ }^{11}$ Rowand Murray, 'Station Management', in F. O'Loghlen and F.H. Johnston (eds.), Cattle Country: An Illustrated Survey of the Australian Beef Cattle Industry, Johnston Publishing, Sydney, 1960, p. 218. Murray had management experience on a number of northern properties.
} 
in the Territory indicates: 'The dark people treat the horses best. They are the best stockmen in the Territory'.

In support of the Aboriginal position an old white drover and stockman has summed up Aboriginal work value, independently, in the following way:

On the whole Aborigines make very good stockmen and have about the same proportion of extra good riders as you would find among white stockmen ... in spite of their indifference about ownership they get very fond of a horse, more so possibly than whites, and will share their last bit of bread with it.

Where they are distinctly better than whites [in dealing with horses] is that they are better tempered. Blacks, however, are often extremely cruel where this is not intentional; for instance neglecting to give a horse a drink or riding one too far where it is not physically fit for the distance...

With few exceptions, all the black riders that I have seen learnt to ride as kids on the stations where they grew up ... they rode all the year round with no school to attend, so they got a fair measure of experience.

... the reason for black boys always accepting a difficult mount was that they had such a strong objection to losing face, particularly amongst their own people.

Aborigines are, however, much worse than whites at giving a horse a sore back because they ride with their legs absolutely slack.

[There] was a young man called $[\mathrm{X}] \ldots$ He was $\ldots$ an all rounder and exceptionally reliable. The whites on the station reckoned he was equal to three average $\mathrm{mcn} . .$.

Every cattle station ... had black stockmen, varying in proportion to white from fifty per cent to more, and they must have done a colossal amount of work for the cattle industry ...

Wherever blacks were employed it was their job to do the horse tailing, and with few exceptions they were good at getting up carly for it. They knew quite a bit about the stars ... they could stand the cold better than we could ...

At horse breaking, a job most of them like, they are also as a rule very good...

For quick thinking and activity when in a tight corner an active young Aborigine is second to none.

The 'joys of the chase' seem to be more firmly ingrained into their makeup than ours. ${ }^{12}$

Aborigines were conscious and proud of their proficiency in the industry. The following piece of chanted verse composed by an Aboriginal stockman clearly referred to his own development:

Munnibuggi was driving along the lonely stock road

I can't see the money all time I know

Man himself is fifty five years of age

Many an outlaw he was riding in his young days

When I was thirteen years of age many a wild horse I broke in

Then they used to put me on the outlaw

${ }^{12}$ R.M. Barker, Droving Days, Pittman, Melbourne, 1966, pp. 133-9. 
Now they want to teach me the right way

That's how I became a horseman today

Now you want to teach me the right way

I was the best stockman in Australia

I used to ride everything I could. ${ }^{13}$

They werc also aware of the fact that occasionally some whites took advantage of their weak industrial position on the stations:

There was this ex-jockey fella they employed as a bore mechanic but he knew nothing about it. The manager asked him to become the bore mechanic but he told him that he knew nothing about it and did not want to know. [The manager] said: 'All right, you don't need to know anything. The black fellas have been doing it for years. They will show you all you need to know. All you do is go out and watch them do the job!' He went out in the truck and went to sleep or read books.

The indigenes were also aware of the inadequate training of some of the white employees alongside whom they were asked to work. One interviewee, after having insisted on his own proficiency as a bore mechanic and informing me of his ability to work on his own, completed his statement by saying:

I worked as a mechanic pulling bores and I only had a white bloke with me sometimes. One white fella I had along with me dropped the bore casing down the hole and got the sack.

There also seemed to be very little limit to Aborigines' confidence:

We can build yards without white fellas. We are already doing it. There are a couple of blokes over at $[\mathrm{X}]$ doing it. Look at our Council shed. We have a couple of blokes who can weld. We have a couple of blokes who can drive . . but thcy don't want to as they would get into trouble with the police.

Their confidence was not always without appreciation in white quarters-'one black is worth two white men in the stock camp' was one employer's comment. In another case an owner of a property cancelled his agreement to sell his holding on knowing that he would be able to obtain a full complement of Aboriginal stockmen because of their displacement from some properties through the strike:

This is the way that I have always wanted to run this place but I have never been able to get the good stockmen before.

He was willing to pay Award rates immediately Aborigines were available.

${ }^{13}$ Collected independently but also included in Frank Hardy, The Unlucky Australians, Nelson, Melbourne, 1968, pp. 120-1. 
Obviously there was a psychological factor in the reluctance of some managers to admit the benefits accruing to the stations from Aboriginal skills. This was clearly recognised by the Texan informant mentioned later in this study.

Texan: There is a lack of clear direction to individuals in the Northern Territory. If you've got to use that kind of labour you'd be surprised if you gave them half a chance and explained to them how you hoped to get there and what you want to do. They get a little better perspective this way.

Interviewer: It seems like management by instruction and not participation. There seems to be no intelligent understanding of what things are about.

Texan: Yes, I've seen this happen too. I've seen it in Mexico. A little Mexican comes up to you and you say go and get the horses. He says 'Yes, Sir; yes, Sir' and then he stumbles and staggers around and hasn't got the faintest idea of what it's all about. This is management's fault. I want respect, I get it by getting close to my men. I will get out and see where [they stand]. Follow them along.

Interviewer: Yes, the current managers seem to be fairly self-contained psychologically. Much of this seems to have resulted from the need for strength of personality in the past, but conditions have changed and their present attitudes are anachronistic.

Texan: That is for sure. Many of the present management are impervious to suggestion. There is stagnation of management in the Territory. There is no expectancy of change. What is more there is the feeling that if things did change they are not sure if they could handle it, and they would consequently lose prestige.

According to some European informants the traditional roles of industrial leadership were inverted because of the possession of skills by Aborigines. The most skilled employee was unlikely to gain recognition if he was an Aboriginal. The following quotations clearly show the pattern of prejudice involved:

The manager is incapable of running the station without [ $\mathrm{X}$-an Aboriginal's] assistance. He cannot run a stock camp and the station is entirely dependent on the Aboriginal foreman. But most of the white ringers would jack up if they knew how much he was getting paid. The manager at $[\mathrm{X}]$ learnt everything about cattle from the Aborigines. This is true of the manager at [Y] station as well.

The processes of elevation of whites on racial grounds alone were also clearly sketched out:

The same things happen with jackeroos. The Aborigines teach them everything and then they end up their boss.

But even the independence of whites after training had obvious limitations in the indigenes' eyes:

Aborigines do most of the work and they could do the job alright without the whites. These is no trouble [for Europeans] on the plains but in the forest country you have to follow the tracks [and they are lost]. 
Given the vast size of most of the Northern Territory cattle stations the turnover of whites was a critical factor in their continued employment. Until the person knew the station's geography he was highly dependent on the Aborigines for guidance in any work that was carried out away from the homestead.

The range type techniques of the industry also meant that most of the cattlc handled were wild. According to my informants, both black and white, there was a considerably greater degree of skill needed in the handling of wild cattle. The Aborigines because of their employment stability had become expert in handling these types of beasts.

Aborigines were quite conscious of the limitations of white stockmen who joined the station work force and frequently mentioned the need to cover up for them. The position of Aboriginal leadership, in this way, became critical in forest country. Persons interviewed referred to the need in these circumstances to lead some white stockworkers out of areas in which they might get lost.

Not only did the Aborigines believe themselves to be the best stockmen but they considered themselves the leaders in bravery and initiative. This gave them some claim to leadership, in their opinion. Further, many of the white stockmen interviewed believed that the general standard of horsemanship amongst whites had fallen considerably over the years and that, probably, Aborigines as a group were superior.

Aborigines felt that white stockmen were lacking in courage in some of the more dangerous tasks involved in stockwork. This prevented them taking the lead in situations which could get out of hand and place the employee in a difficult position.

Like a head stockman might get out in front of the mob and the boys might get out in front [with him] to keep the cattle in the mob but the white blokes don't like it. They get shit scared. Then they might go and have [an argument] with the boys, see, and [the Aborigines] don't like it. They walk out. Some of these white blokes come in and try and take over the camp and try and jerk [the boys] up and they don't like it. They tell them that they were here before them.

The skills of Aborigines were apparent to most practical white stockmen interviewed. Some felt, however, that the indigenes worked together better as a team than if they were employed individually:

Although it is better to have two or three whites in the camp the whites are no better than Aborigines. The Aborigines are born into the industry. They are better at tracking. They have an instinct. You are out on the run and you say 'where is the camp' and they will be right onto it. They have it born into them. They are better trackers than we are. You have to have two or three in the camp or they will not take any notice of you and you will not get your cattle. 
All of the Aborigines interviewed considered that not only did they work harder than the white employees but that many of the whites consciously made use of indigenes. This attitude was supported both by personal observation and the taped conversation with Aboriginal employees.

The white fella just sit down when they go out to work. White man get his money for just standing there. White man get $£ 100$ a month for just standing there.

We teachem the cattle business. How to gettem horse. Teachem the bridle. How to get on. How to hold bridle. You teachem but they don't want to live with you.

It's common practice for the white stockmen to sit on their arse whilst the Aborigines do all of the work. The boys do most of the work ... horse tailing, "broncoing', branding ... the dark boys do all this ... and when you come to forest country you need dark boys to lead you out.

There seemed to be few problems involved in the transfer of Aborigines between rural occupations as the following interview with a buffalo meatworks operator indicated:

The buffaloes [when they come into the works] are very heavy beasts and difficult to drag around. However, the Aborigines have their own winch and mechanical devices but it is still a difficult and heavy skin to pull off.

These Aborigines are expert at this. I have visited meat works in the south on different occasions. I would consider the speed at which these Aborigines work and the dexterity in relation to skinning, cutting and cutting down is really equal to anything I have seen down south. They are really fast workers. ${ }^{14}$

The superiority that Aborigines continued to retain over their white counterparts in the techniques of the bush were not limited to tracking and horsemanship, but affected many aspects of the day-to-day life of the cattle camps. The following description by a white stockman of a bush killing operation clearly indicates the acquisition of new skills to serve the general station community:

The [Aborigines] in the bush are clean people. They are always scrupulously clean. They'll kill as clean in the bush as they will in a [meathouse] with a floor. They kill in the hide. It's a noble art that has been lost [by Europeans]. The way they do it is they quarter the beast and halve its hide ... completely cut it down into the different cuts of meat ... it's all done on the hide. They get a gum bush or a wattle bush and use it to rest the meat on. This is something [the Aborigina'] taught the white man.

You can handle the meat this way without getting any taint in your meat. He just doesn't chuck the meat in the dirt ... The meat is then salted in the middle of the hide. Whilst you are salting the beef you are also salting the hide. The Aborigines are able to tuck the legs of the beast under the hide and make a little box and in there he has the brine solution. It's a very hygienic way.

${ }^{14}$ All the work at the buffalo meatworks was done by Aborigines. The ruling rate was $\mathcal{L}^{4}$ per week. 
Where a reasonable tolerance was shown by management in an endeavour to overcome the educational gap between the two racial groups, little difficulty was experienced in training Aborigines for mechanical tasks on the station. This has been adequately treated elsewhere. The point, however, is emphasised by the fact that more employers considered that Aborigines had mechanical aptitude than thought that lack of this aptitude limited their opportunities for employment. The difficulty for Aborigines in acquiring these skills was underlined by their complaints that management did not trust them. In the writer's opinion, the restraint placed on the movement of Aborigines into the mechanically skilled sections of station employment was more related to the position reserved for whites in the industrial hierarchy than to racial disparities. Illiteracy obviously placed certain restrictions on the carrying out of all mechanical tasks to the satisfaction of management. In the main, however, these were relatively minor in the overall demands made on station staff. Indeed, many of the whites holding down jobs as mechanics on the stations were only marginally more literate than some of the Aborigines and frequently less experienced.

\section{DISADVANTAGES OF EMPLOYING ABORIGINES}

The response of employers to our question in this regard produced only one significant complaint-that Aborigines needed more supervision than white workers. No doubt this need for supervision originated in the failure of Aborigines to reach desirable standards in the other twenty categories mentioned by them as being disadvantages in the employment of Aborigines.

It is interesting to note, however, that need for supervision was mentioned by a minority of employers and that very few agreed on the reasons for this need. The only exception to this was that four employers were of the opinion that Aborigines lacked mechanical aptitude.

Whether people believed that Aborigines need supervision is a subjective matter. However, Aborigines were conscious of the fact that many employers were not good managers, and that some of the other whites with authority on the properties were frequently misleading in their instructions. This opinion was supported by at least one white observer.

Aborigines also expressed concern about the inability of some white staff to communicate clearly. This was normally the result of whites' failure to comprehend fully the employees' needs in relation to instruction, or else on a basic ignorance of the job requirements. 
When the question of the need for additional supervision was put to Aborigines it was immediately rejected, and many of the whites' weaknesses highlighted. 'We don't have to be told by the boss what to do... bring in cattle and gib him water. We know all that. But what about white blokes? They can't do all the jobs on the station.'

However, there was obviously a balance between instruction, discipline and control. This was not clearly understood by all employers:

Where people are good employers Aborigines will go there and stay there. Take [X] for example, he has had Aborigines on his property for years and there's been no trouble with them. They are very stern but once that's over they joke with them.

Aborigines recognise that strong management could be tempered with equity. In reply to my inquiry about the standing of one extremely hectoring manager an informant replied 'he's a cunt, but fair'. Indeed, there even seemed to be a preference towards bluntness and physical aggression, as distinct from the more indirect and possibly sophisticated attitudes of discipline, as it was considered that this simply 'buggered them around'.

Occasionally there was complete affinity between Aborigines and their employers, with apparent advantages to all:

Interviewer: Who was the best boss you have worked for?

Aboriginal stockman: [X] at Brunette Downs. He likem boys and boys bin workcm good.

One of the more important reservations that employers had about Aborigines was their alleged inability to supervise one another. Some of the employers believed that this aspect of their failings had tribal associations, although they were reluctant to imply that this was a major cause. As a consequence the allegation normally arose as a secondary comment.

It was not possible for a person untrained in anthropology to determine exactly what vestiges of tribal influence remained amongst Aboriginal groups on the stations. It would have been even more difficult to determine, if tribal associations were still of importance, what bearing these relationships would have had on productivity. The comments of pastoralists in this regard were usually directed to the seniority order of decision-making in tribal society, and the inadequacy of such concepts in an industrial environment.

The limited work which has been done by anthropologists on cattle stations, or on the processes of adjustment of Aborigines to industrial or other changing inter-racial social and economic situations, suggest that this is not the case. Rose, for example, found in 1962 that gerontocracy 

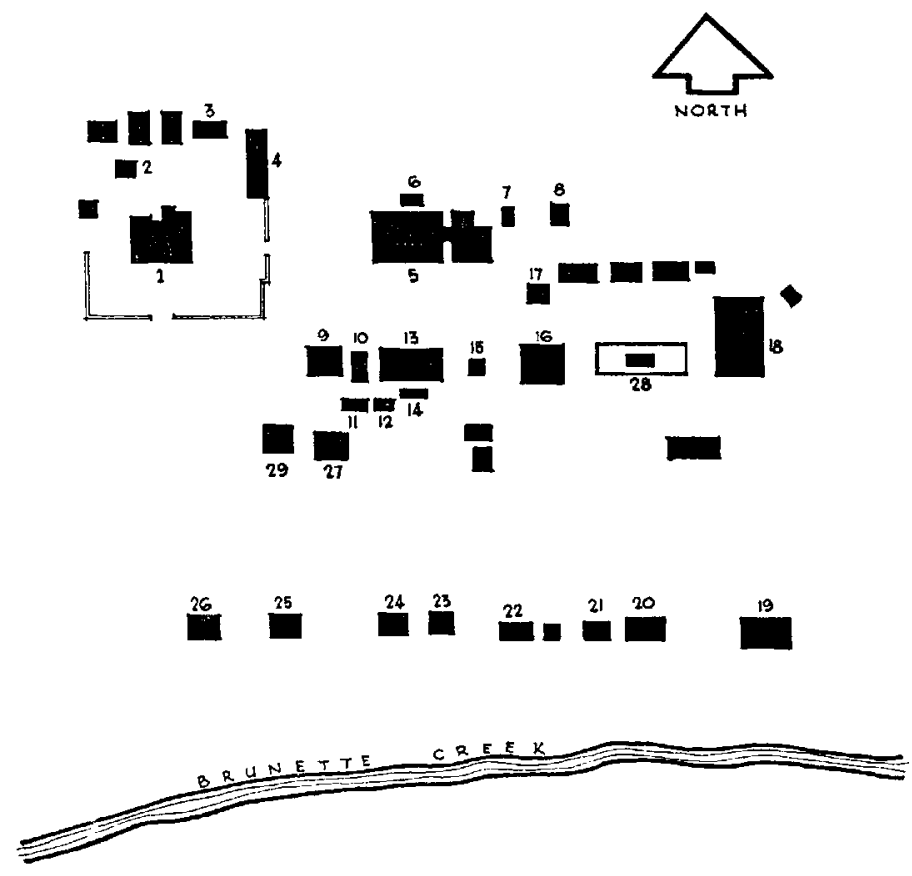

\section{BRUNETTE DOWNS HOMESTEAD AREA}

1 HOMESTEAD

2 aboricinal domestics

BATHROOM

LAUNORY

haNGER AND carage

JACKEROO'S QLARTERS

ANO KITCHEN

SEPTIC BLOCK/LAUNORY

BUTCHERS SHOP

ABORICINAL DOMESTICS

DININC ROOM

- aOMINISTRATIOM BLOCK

IO STORE
II SULK STORE

2 BULK STORE

IS MENS QUARTERS

14 SEPTIC BLOCK/LALNDRY

15 SADDLE SHOO

16 WORKSHOP

17 POWER hOUSE

19 STORACE SHED

19 SCHOOL

aboricinal school CHILOREN BATHROOM

21 ABORIGINAL BATHROOM

22 PETROL SHED
23 No4 COTtAGE

26 N!3 COTTACE

$25 N^{\circ} 2$ COTTACE

26 NaI COTTACE

27 HOSPITAL

28 BULL TRAIN SHED

29 NOS COTTACE

NOTE

PLAN IS NOT ORAWN TO SCALE

Map 6. Brunette Downs homestead area. Aboriginal camp not shown as it is outside the area.

was rapidly disappearing on a cattle station in Central Australia. ${ }^{15}$ Berndt also found in 1948 that tribal patterns and relationships had been broken down on cattle stations in the Victoria River District of the Northern

${ }^{15}$ F.G.G. Rose, The Wind of Change in Central Australia, Akademie-Verlag, Berlin, 1965, Chapter 10 , pp. 75-83. 
Territory to a point where the continuing practices had virtually no functional significance. ${ }^{16}$

Peter Hinton has noted similar developments in the industrialisation of an Aboriginal community at Weipa, Cape York. ${ }^{17}$ In this case tribal leadership patterns were observed to be of little consequence in the plant.

The only mention by Aborigines was that they had abandoned their 'old ways'. This comment was sufficiently general to embrace a range of subjects from nomadic hunting through to the settlement of inter-family disputes. However, supported by the anthropological evidence, together with the observation that leadership in the cattle camp was not based on age but skills, limitations of tribal traditions did not appear to affect the industrial situation.

Further, most Aborigines interviewed considered that a completely native stock-camp was the most efficient. One Torres Strait Islander head stockman claimed that although the stock-camp was better complemented with a percentage of white workers, it made little or no difference to turnoff or production. The main advantage of including Europeans in a working stock-camp was, he considered, to improve relationships with other European controlled groups working in the industry.

In every cattle camp visited it was noticed that where a white, or whites, was working alongside Aboriginal stockmen, the latter took a secondary role in the leadership function. This occurred regardless of the relative proficiency of the individuals in the two groups and was usually based on managerial instructions.

At one location I had the opportunity of interviewing a Texan cattleman who had spent two years in north Australia and had visited most of the stations involved in the survey. His comments on the question of supervision, gained on his experience in the cattle industry in Australia, Texas, Mexico and Guatemala, added considerably to the understanding of the situation.

Firstly, my informant believed that most stations in north Australia operated at a very low level of managerial efficiency.

Having had it so easy for so long they just drift along through the year ... Nobody seems to know much about where things are going, or what are the long run or short run aims of the operation.

A consequence of this was, he believed, a low appreciation amongst employees of management requirements. This led to confusion in the

${ }^{16}$ Berndt, 'A Northern Territory Problem', pp. 46-78.

${ }_{17}$ Peter Hinton, 'The Prosperous Aborigines: the Industrialisation of a Mission Community', Report to the Australian Institute of Aboriginal Studies, 1966. 
objectives of any particular task, and a void at the end of the job which could not be filled by the employee through prior knowledge of what was required to be done.

In this situation the employee accepted his instructions and applied himself to the best of his ability. If there was any obstruction or interruption to the accomplishment of his task then he just sat down and waited for additional management directives to fill the gap.

Further, he considered that the majority of managers of northern properties were unsuitable persons to be placed in charge of indigenes. They start out on the basis that 'the black man is a bastard' and that the only way to get him to work is to push him into it. He felt that the present day managers were too old for the changing social and economic circumstances of the industry. As a result of this they had an inflexible attitude to both the employment of native staff and property development. Most of them, he claimed, were 'verandah cowboys' who did not have a full grip on their operations. He considered that, where a manager was able to ride with his men and execute any of the tasks that he called upon them to complete, mutual respect was generated. This opinion was also confirmed by some Aboriginal informants.

During his experience in Central America, he had concluded that there was a definite technique in extracting work out of illiterate employees, and that most of the managers he had seen in Australia did not adhere to these principles. Firstly, one had to select the most intelligent individual and clcarly endorse his authority over the rest. Northern Territory cattle station managers, he believed, were reluctant to ascribe clear authority to any member of the Aboriginal camp lest it diminish their own power.

The need for supervision was frequently associated with the concept of reliability. Indeed, one might be readily considered the inverse of the other. Because of the established and continuing relationships between the two station communities the question of reliability was only assessed on a day-to-day basis. There was rarely any question of the Aborigines walking off the job in a manner similar to European labour.

Further, as many of the employers knew that there was a pool of labour available to them, the engagement of Aborigines for work on a daily basis did not appear to be of great concern. Indeed, I witnessed several cases of the employer visiting the Aboriginal camp to 'shake the boys up a bit'. The methods adopted ranged from abusive language to direct assault with a stockwhip or a stick. At most places, however, the Aboriginal staff presented themselves for employment each day at the prescribed time. 
The reservation that employers held about Aboriginal reliability was obviously directed towards their inability to sustain application commensurate with the employers' expectations. That these expectations were inordinately high, even for white employees, has already been demonstrated. The problem was clearly delineated during an interview with some miners who had used Aboriginal labour in some of their operations. They said that, initially, they were impressed with the physique of the indigenes they bad met in the north-western section of the Territory, and assumed that they would be good workers because of their size. However, in situations requiring a high degree of physical application they found them unable to sustain performance in keeping with white expectations:

They were all over six feet tall and very well built but when you started to work them they could not resist strain. When we began to drill by hand we would have one go for about five minutes but they could not do it for more than a minute or a minute and a half. They were sweating and showed strain on their faces. Again there was a case where a white bloke began to fight a native. He only lasted a few minutes before he was completely exhausted. We came to the conclusion eventually that, if we wanted to get more work out of them, we would have to let them live in the camp for upwards to three months on a kind of holiday so that we could build them up.

In the normal community, where the demands made upon workers are greater than their physical ability to respond, adjustment takes place either through the intervention of the Union or by the employee removing himself to another place of employment. Although whites in the Northern Territory were able to escape conflict in this way there was no such avenue available to indigenes. Firstly, the Wards Employment Ordinance made it an offence to 'entice or persuade an employee to leave his lawful employment'. Secondly, the major companies instructed their managers not to engage staff who had previously worked on other properties in case their services had been terminated because of a dispute. Thirdly, it was commonly accepted policy amongst employers that they would not poach each other's employees.

The end result of those restrictions was, of course, that the only method of protest available to the individual was through work output restraint. This feature of the response of Aboriginal employees to their situation merely added to the difficulties brought about by dietary deficiency. Given the virtual absence of communication between the two racial groups the basic grounds for resistance remained undetermined. Only the results were apparent: these confirmed the already established bias of racial disparity. The constant complaints by Aborigines about the demands 
made upon them, not only in hours of work but in the scope of employment, tended to confirm initial impressions.

The resistance of Aborigines to demands being made upon them was expressed in a different, but not necessarily unconnected, way when the subject of the reliability of Aboriginal female domestics was discussed. One informant referred to the 'inexplicable periods of depression' that these people seemed to suffer. They frequently took the form of the refusal of the person involved to take care of either her personal appearance, or the physical order of personal property in her bedroom. A trade union organiser summed it up in this way:

If conditions on the station are demoralised then the Aborigines became demoralised as well and things deteriorate. When the gins get the sulks they won't work. At one station I heard the boss bawling a gin out. 'When they get that way you have to hunt them', he claimed.

The comments of Aborigines on their work experiences in this regard were illuminating. On being questioned as to why he had left his previous employment, an Aboriginal made the point-strongly-that it was not because his employer had beaten him, necessitating hospital treatment, but that the employer was 'no good':

He did not treat you properly. A man bin working two jobs-on the pumping and on the grader. I would finish one and he would put me on the other. I didn't want a double job. I said that if you [the manager] give me a double job then I want more. He only pay me $f_{12}$ a month.

Another complaint was made in the following way:

The dark boys do all the throwing. They work from five in the morning to eight at night and they hardly ever get a weekend off.

The allegations that Aborigines lacked initiative seemed to be inextricably associated with the question of incentive. That initiative and incentive were lacking in the Aboriginal work force was commented upon by both management and white workers. The surrounding circumstances of employment clearly demonstrate the lack of incentive. However, whether Aborigines did lack initiative, and if so for what reason, was another matter.

As has been mentioned it was observed that at many locations complete Aboriginal work crews were employed and that these ranged through the whole spectrum of skills on the station. It was not possible to observe whether management supervision of these work crews was greater or less than of fully white complements. However, the fact that they had been established and that the Aboriginal crews continued to work in the field 
necessarily meant that a considerable degree of initiative was present. It was observed that, depending on the location, neither hourly, daily, nor even weekly, contact with management was always necessary.

Initiative, in normal industrial circumstances, is the response to reward and encouragement. In the pastoral industry in the Northern Territory both of these factors were either extremely limited or non-existent. In the words of a white stockman:

There is a very definite relationship between their attitudes to work and reward. Everybody works for reward; everybody has to have his reward and I tell you these poor bastards never get a pat on the back.

Indeed, in many circumstances practices had been developed which effectively placed restraint on the development of initiative. Not only was there little cash reward for the development of responsibility that initiative implies, but also errors of judgment were punished with physical and psychological violence:

Now there was the [bashing] at $[\mathrm{X}]$ station ... the Aborigines came in from the stock camp; the manager was at the homestead. They walked in and told the manager that [the head stockman] had shot the stock mule. They thought that they were doing the right thing ... he did it in a fit of temper. The manager asked them to come into the office and asked them why they left the stock camp. They replied 'We came to tell you, boss.' He got stuck into them; they offered no resistance at all. He bashed their heads against the iron door and then he got stuck into the other bloke and gave him a punch.

The second, and the only other really significant rescrvation, that management had about the ability of their Aboriginal employees was related to education. In the original survey it was noted that educational facilities for Aborigines were available on only 16.5 per cent of the properties, and that another two stations had endeavoured to make arrangements of some kind for the education of some of the Aboriginal children.

The need for European educational facilities in the pastoral industry was questionable. Whilst not wishing to denigrate the overall cultural advantage of an 'educated' person, for the purposes of the cattle industry, as it was organised at the time of the survey, education in the traditional European context may have been a disadvantage. The interview with the Torres Strait Islander, mentioned earlier, supported this contention. I asked him if education was necessary in the industry and he replied:

Many of the older people are starting to realise what education means. Education makes a bit of difference-you want education if you become a head stockman; but an uneducated person makes as good a ringer as an educated one. But experience is more important than education. 


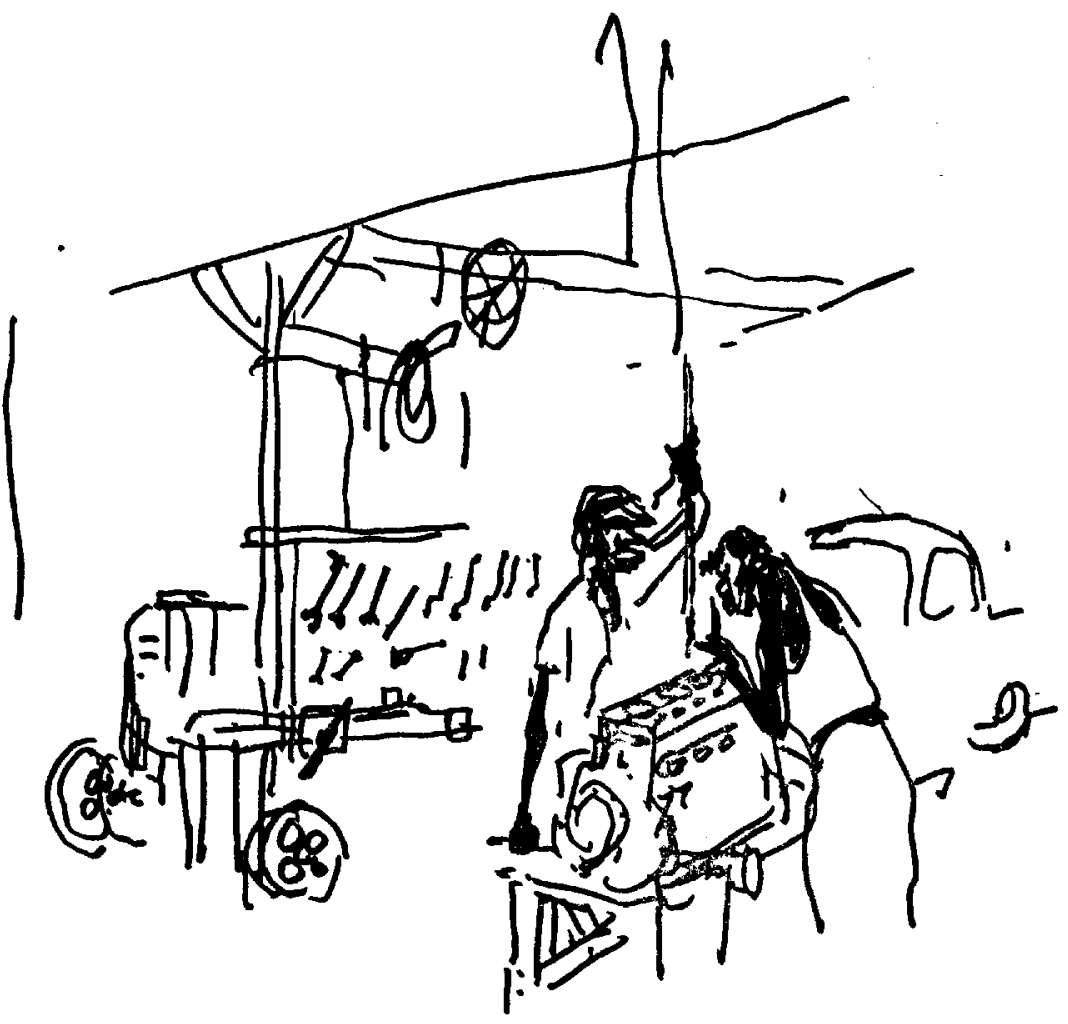

Aborigines were conscious of the advantages of European education, and some were contemplating removing themselves from the pastoral industry in order to gain this opportunity for their children. However, few of the people interviewed had any concept of other employment outlets than those which they then had; nor had they any ideas as to how this education would assist them in expanding job opportunity. In some cases-though these were isolated-Aborigines were critical of the standard of education available to their children and as a consequence conditioned their attitudes to it on these grounds:

The school business not much good around here. They don't teach him much. Just spellem his name, that's all. Don't teach him anything about the stock camp. There are better schools in other places.

Employers frequently remarked that the educational system, as it was currently operated by the Welfare Branch, was of little assistance to their operations. They believed that there was a concentration on the formal 
aspects of European education to the complete neglect of the teaching of skills useful to the industry. They believed also that the method of concentrating Aborigines on settlements for educational and other purposes precluded the continuation of their training in bushcraft, which had provided them with great intuitive advantage over Europeans.

The poor education of Aborigines, however, did not lead to any large number of complaints, reflecting no doubt the accuracy of the comments of the Torres Strait Islander mentioned earlier. The most frequent criticism of Aborigines was their lack of mechanical aptitude.

In relation to this aspect of Aboriginal employment it was noted that there was very little opportunity for other experiences amongst the Aboriginal employees on the stations. Outside the many tasks relating to working the cattle rarely was there any transfer of employees to different functions. Further, the camps were singularly devoid of mechanical appliances of any kind, and movement around the areas in which mechanical work was carried out was normally discouraged. This was probably a protective reaction on the part of management, which had lost materials and tools to the native camp intent on improving its own humble circumstances. Overall, however, it had the effect of strictly limiting the accumulation of mechanical skills other than those desired by management.

Aborigines, apparently, were taught just sufficient to be of use to their employers and no more. However, there was no evidence that they could not accumulate mechanical knowledge when properly trained. The results of this survey, and experience gained at other locations, suggest that Aborigines readily adapt themselves to mechanical situations when there is a reasonable degree of forbearance and understanding on the part of management concerning the method of trial and error by which illiterates educate themselves.

In those cases where skilled responses were desired by management, Aborigines were readily trained. Support for this observation is evident in the questions relating to the advantages of employing Aborigines. In this section a significant number of employers mentioned the ease with which one could train them to carry out mechanical tasks. However, there was little evidence that this was done in any organised way on the properties. ${ }^{18}$

Considering the open discouragement of Aborigines' access to motor vehicles, a surprising number of them could drive. At some locations

${ }^{18}$ European employees also readily conceded the innate intelligence of Aborigines. 
almost everybody in the camp could drive. In many cases this had been accomplished in defiance of managements' desires, and achieved through instruction from white workers who wanted relief from this task whilst away from the homestead.

Finally, in relation to the disadvantages of employing Aborigines, it was significant that all other criticisms were the result of particular experiences. There was no grouping of sufficient magnitude to be considered an important factor in the failure of management to engage Aborigines. 
$\mathrm{C}$ ommensurate with the Aborigines' appreciation of the relatively low level of skill of many Europeans in the industry was their belief that they were not paid sufficient for the services they provided for the station. 'Some Aboriginal people bin workin' hard, but they bin gettem low price.' This was a typical reaction to inquiries concerning wages.

When working in the station, black and white all the same together, but white men get the high price and Aborigines get the low price. That not fair.

Similar opinions were held by every Aboriginal interviewed, although only approximately 25 per cent of them knew how much they received for their contribution to the station economy.

I do not know how much I was getting at [X] but when I finish up they gibbit ninety quid. But they never tell anyone. They should tell everyone, shouldn't they? They should say four quid, seven quid or eight quid a week or ten quid a week, eh? That right eh?

A bloke bin workin' here like a dog. I don't know what price. All the workers will tell you the same.

Given the low level of cash reward, food and wages were somewhat synonymous.

There was plenty of tucker but not much money. Maggie bin workin' in the kitchen and she neber get any money, only food. I bin workin' there for [twenty years] and when I pulled out he gib me nothing. All he ever gib me was $£ 25$ at race time.

Because of the infrequency of communication about wage rates on the part of management, Aborigines were uncertain as to what they should get for any particular job. However, they were normally able to determine what was outstanding once the rate was struck. 
Aboriginal stockman: I've got a new job now, delivering horses. He gib me five quid already and said that he will gib me more when I deliver them. I bin working for about a fortnight now. How much should I get?

Interviewer: I reckon drover's rates. Say about twenty quid.

Aboriginal stockman: Then he owes me about another fifteen quid.

There was a reluctance on the part of Aborigines, however, to ask the managers or owners how much they were getting paid.

I didn't ask how much I bin going to get when I came to the station for a job. I was goin' to ask him how much price but he might not like it.

Part of the reluctance by employees to make inquiries about their earnings was the refusal of employers to divulge the information because 'managers don't like the boys to ask him about the price'. Indeed, inquiry about pay by indigenes was likely to lead to disciplinary action being taken as the employer might consider the employee 'cheeky'.

But once the question of wages was raised it was obvious that the native employces had considerable grievances about their method of payment, and they were preparing to do something about it. On one occasion it looked as though it could have been embarrassing to the interviewer:

I say to these boys it's no good to growl about your money. You've got a chance to do something about it-Now you boys got a chance to fight for your money. Now [the interviewer's] here you do it.

But the response in some areas was even more immediate and cast in terms which were obviously conditioned by the Arbitration Court hearing:

We were out mustering for two months-March and April-we went back for our pay and I asked the manager for my pay. He said: 'That's the first Aborigine to ever have asked me for his money.' 'Why shouldn't I ask you for my money?' I said. Two months pay and I only got eight shillings. One person with eight children put his thumb print on paper and he got none. I asked the manager why he didn't get more and the manager said that he got enough food. When he got back to the house there was no food. That was early this year. I couldn't put up with station owners any longer. I went up and saw him and said can't you do any better than that for Aboriginal stockmen. They do a good job for you. Why can't you give Aborigines a fair go? I am not going to start work tomorrow. I am going to stay here until I get equal wages. I am not going to work until 1968. I bin wait long enough. We bin starvin' since we first learnt to ride a horse. We bin wait too long. I bin want them legal wages now-this year.

Aboriginal drovers, who theoretically should have received approximately two-thirds of the European rates, were particularly concerned with the low reward. One person interviewed claimed that all he was paid, 
after a round journey of some 600 miles, was 'a bag of lollies'. Another had a series of inquiries when the issue of remuneration was raised.

Aboriginal drover: One time I used to work for [X station] and I bin drovin' [to the Queensland Channel country]. How much you reckon I bin get for that trip?

Interviewer: Well, it's a long way; maybe 800 miles. I reckon that you should have got at least $\mathcal{E}^{300}$.

Aboriginal drover: Well, I used to come back from that trip and I bin get thirty quid. You say that I should get one hundred quid or two hundred quid. Well, I bin not get that. I don't know where him bin goin'. It must have bin goin' to Welfare, I ouly bin get thirty or forty quid for that trip from $[\mathrm{X}]$ to Queensland. Well, I go on that trip all the same white fella and yella fella, ${ }^{1} \mathrm{eh}$ ? Well, we do the same work as yella fella, eh? And he get more money. I get nothin'-Well, I bin here thinking all the time. I bin saying nothing, but I bin thinking in my head. All the time I bin thinking in my head the Welfare bin takin' the money.

Many of the non-Aboriginal employees intervicwed could see the obvious connection between the low level of cash reward and application on the job:

Give them their rights and they won't be so cheeky. They realise that the boss won't sack them because he would have to pay higher wages. Bigger money would help them work harder. Wages won't break this station but the drought might.

Some Aborigines who were interviewed were fairly calculating in endeavouring to establish fraudulent activity on the part of managers and owners:

One fella said that he would gib me forty-five quid a month if I worked for him. I did this and watch him and he only gib me twenty four quid after three months.

Aborigines were aware of better pay being offered at other locations. During different interviews people mentioned the fact that Aborigines were better off for wages on certain named stations, as well as in Darwin, Queensland and Western Australia. The personal contact played an important part in the imparting of knowledge as one cx-manager of a property explained:

There are cars coming through from Port Hedland full of Aborigines, some of them getting forty or fifty quid a week. I used to pay them seven quid. The Aborigines from Port Hedland laughed at them and called them a bunch of 'myalls'. ${ }^{2}$ Owning a motor car was a status symbol and this was too much for them.

However, when questioned about why they did not leave the area in pursuit of more money, most did not offer any answer or merely claimed

${ }^{1}$ Half-caste Aboriginal.

${ }^{2}$ A colloquialism for an unsophisticated tribal person. 
that they 'never had a chance'. On the other hand many showed interest in the possibility of working elsewhere. Most had heard of and were favourably disposed to living in Darwin. Others had been interstate and did not look unfavourably on the possibility of moving.

The actions of a few of the people interviewed clearly indicated that Aborigines were capable of leaving their employment in protest against the conditions under which they lived. At the time of the survey, with the exception of those properties on strike, it was not possible to determine whether Aboriginal labour turnover had increased.

Finally, the allegations by some employers that Aborigines had little or no sense of money values were strongly attacked by a mission worker in the following terms:

The people who say that Aborigines do not know how to keep a tag on money do not know what they are talking about. If they want something bad enough they will produce the cash.

THE STORE, PRICES AND THE 'WAGES SYSTEM'

As none of the stations visited paid Aborigines the full amount owing to them, in cash, the operation of the system of the retention of earnings by management was an integral part of the wages system on the properties. It was necessary, therefore, to consider the level of appreciation by Aborigines of the standards applied by management.

In the previous section we have already seen that, once in possession of the facts, the native employees were able readily to discern either the adequacy of their remuneration, or the deficit between what they considered they should have been earning and what they in fact received. One should reflect, however, that complete information about the rates of remuneration was withheld from approximately 75 per cent of the employees. This meant, of course, that at no time were they fully aware of what was owing to them, or what they could spend in the store.

Indeed, given the uncertain method of charging through the company store it was difficult, if not impossible, for them to determine exactly where their account stood at any one time, even if they knew how much they should be credited with on a weekly basis. It will be seen elsewhere that the uncertainty in the bookkeeping system related not only to the determination of prices for individual items, but also to the system of the accumulation of funds by individual Aborigines. These might be adjusted according to the whim of the employer, and his view of the sufficiency of the sum accrued in their accounts. The adjustment took place, naturally, 
without any reference to the employee involved. The system, as it operated, was openly recognised to be fraudulent at least by one person who practised it.

He put it this way:

On this business of [the Aborigines] not getting their right money when they come with their thumb prints a bloke who works as a horse tailer and is not on the booksa bloke about fifteen-come the race meeting and he is going to get $f_{4} 4.0 .0$. The manager looks down the list and sees some bloke with enough money and they knock $f^{8.0 .0}$. off it. I was in this myself. I hesitated at first when I was instructed to do this and I still think that I was probably wrong. I realised if I did not do it I would be sacked, and it would continue. It was common practice for a bloke to sign for more money than he received. It was common practice on [X and $\mathrm{Y}$ and $\mathrm{C}]$. I had to sign the book as witness with the manager to the [Aborigines] thumb print.

In some company stores it was noted that Aborigines were not informed of the prices of the commodities that they received. In these cases the employee simply asked for goods, and if his account was in credit, he was handed them without reference to the price. A sum was then deducted from the employee's account.

In other situations prices were attached to goods purchased from the store and in many cases these were quite exorbitant. In some cases it was noted that the mark up for goods in the company store was 300 per cent above town prices. Hawkers occasionally added anywhere up to 1,000 per cent on wholesale costs. Where there was a consistent system of pricing Aboriginal employees were able to discuss individual commodities, and compare them with the prices charged for similar items in the nearest town. Several persons interviewed were even able to make a comparison between the charges by management, prices in the nearest town and those in Darwin. Where there was an unfavourable comparison the individuals were not slow to express their objections.

Very few were happy with the administration of the company stores, and most viewed them as vehicles through which they were defrauded by the employer. The limited information that was available supports the Aborigines' allegations.

In many cases it was also noted that, although the employers had a responsibility under the Wards Employment Ordinance to supply a specified issue of clothes to Aboriginal employees, their wives and one child per married couple employed, the full cash allowance stated was not paid, and the Aboriginal employee was expected to purchase his clothing requirements out of the meagre allowance given to him for more general purposes. 
In the handling of cash some of the older employees experienced difficulty. Indeed, in many cases money in a lump sum was proffered to the storekeeper regardless of the nature of the purchase. He retained whatever amount was sufficient to cover the purchase and handed back the rest to the employee who frequently pocketed it without counting the change. It was also noted that occasionally Aborigines engaged in a process of purchase through item by item diminution of their available money. In this system the required goods were obtained one at a time, the total available amount of cash being handed across the counter with each transaction; the employee would then wait until the change was handed back to him and another request made for an additional item and the process repeated until the total sum involved was consumed. The younger employees believed that the storekeepers 'bin robbin the old people'.

Although it might be considered that this system was the inevitable product of illiteracy it could have been equally dependent on the fluctuating price levels in the store, and the failure of storekeepers to inform their clients of the prices to be charged. As pointed out by Rose $e^{3}$ in 1962 owners, managers and storekeepers rounded out prices to the nearest highest silver coin. In other cases paper money was taken as the standard for all purchases. In these circumstances certain coins became redundant, and were accordingly discarded. This practice occasionally gave rise to derogatory comments by Europeans who were not fully aware of the reasons for discarding the cash in this way.

Although the legality of the decision was questionable, the Department of Social Services classified cattle stations on which Aboriginal pensioners were resident as institutions. Pensioners' funds were paid into the general account of the station, allowing the manager to administer the sums involved in accord with his own priorities. This meant that there was considerable variation from station to station as to what individual pensioners received in the form of cash.

The question of the propriety of the Department's decision in this regard is raised because of the failure of the stations to provide any form of reasonable accommodation for the money received. If pensioners lived under similar institutional circumstances in southern Australia the establishment would have been de-registered either as a health, or fire, risk-or both.

Although the interviewer had the greatest difficulty in talking to older

${ }^{3}$ Rose, Wind of Change, pp. 65-74. 
indigenes there was little doubt that most felt that deductions from their meagre pensions by the company were unwarranted. Some openly complained of the practice-which had the approval of the Welfare Branch--whereby the station was permitted to build pensioner housing out of the pension receipts, and illegally gain proprietory rights in the buildings so crected.

In another case it was alleged that pensioners on the station were continuing to be employed, and paid out of the pension funds received on their behalf from the Department of Social Services without their knowledge.

Finally, those Aborigines with whom the subject was discussed were aware of the concept of saving. In most cases the limited availability of cash precluded the accumulation of significant sums. However, those who were paid in cash realised that they could open a savings account and some took advantage of it:

Interviewer: Where did you get the $£_{100}$ to buy this house?

Aboriginal drover: Well, I. bin save him up. I got my bank book at the post office.

When I bin working on the station I would peel him off. Maybe three pounds and

I would put him in the bank. I bin do him a little bit at a time. I bin fill him up. Interviewer: How much have you got there now?

Aboriginal drover: I only got forty quid after I bought this place.

\section{THE UNION AND THE STRIKE}

The second field trip was made during a period in which the industry was feeling the effect of considerable industrial conflict. For, although the actual 'walkouts' were limited to stations situated in the Victoria River and Western Barkly Tablelands Districts, the repercussions were felt right throughout the Northern Territory. Aborigines on every station visited during the second year were in favour of the actions taken by workers in the north-west of the Territory, and had contemplated similar action. Several old stockmen explained that they had considered this type of action 'since [they] bin little boys'.

At one station on which there had been no strike, nor indeed any union contact, one old stockman warmly recounted strike action taken by some white employees many years ago:

One moming I bin going out mustering and the head stockman said 'gettem horse.' Then I see the white blokes pick swag and put em under tree. 'What wrong?' I say. 'We're on strike,' they say. I say 'I no go. I stay.' It's the only way to gettem [wages increased]. 
Although union organisation activity had been geographically very limited in the Territory, every Aboriginal employee interviewed was warmly disposed towards the Union.

There was also a fairly clear understanding of the relation between the processes of direct action and the possible rewards. The following interview describes the situation as envisaged by one disgruntled employee:

I saw this union fellow at [X]. He wanted the people to stop work. Told them to pull up and wait till your price is right. Go to the bloke and ask for your price up and wait. When your money's right enough go and work for them. But some of the pcople don't want to pull off the stations. The Union might not help you if the men stop. But I'll talk for myself. I don't know whether they'll do it. I tell some of the people that you should get on to the right station and you'll get the right money. But you'll have to talk up. But if you don't the manager will still rob you.

Talk of leadership in the bargaining process was quite common, and obviously the previous standards conditioned by gerontocracy had passed. An old age pensioner referred to the process in this way.

They wanted me to take the lead. But I can't take the lead, and go up to the boss and talk about wages. It's up to the workers. I am getting Government tucker and Govcrnment money while I am on my back. I can't speak up.

Even at some stations distant from the scene of the strikes there was complete confidence in the eventual outcome of the dispute, if the people would only hold out.

The strikers did the right thing and they will never go back. They will only go back if they get the same money as white men. The Union's supporting them, sending out tucker and tin beef.

Among illiterates it was interesting to note the diversity of ways in which the knowledge of union activity and the concepts of organisation were transmitted. Word of mouth was by far the most common method, although this was rapidly being replaced by the transistor radio. (Even employees who lived at the far end of some distant properties wanted a Union ticket once they realised the issues involved and what was happening.) Most cattle camps seemed to possess at least one radio, and at one homestead camp there were five radios amongst a population of about 150 .

Although there had been no Union organisation of any consequence on Northern Territory cattle stations since 1952,4 the native employees were patently sympathetically disposed towards it. One interesting aspect of the matter was why the North Australian Workers Union had not

${ }^{4}$ Discussion with Mr G. Gibbs, N.A.W.U. organiser, 1948-52, Darwin, 23 November 1966. 
bothered about the Territory's most depressed work force for nearly a decade and a half?

\section{THE POLICE}

In 1946 Berndt considered that the image of the police in the Aborigines' eyes was conditioned by "arrests, neck chaining of "criminals" and witnesses and physical violence'. As a result of this he considered that the police were undesirable agents for an organisation devoted to the elevation of the Aboriginal community. The police ceased to operate as representatives of the Welfare Branch in 1952.

If one is able to generalise on this subject, it would seem as though the attitudes of Aborigines to the police have improved since the date of Berndt's survey. However, the response of Aborigines to inquiries about their attitudes to the police was based almost entirely on their experiences with individual members of the force. This gave a somewhat regional bias to the results. In one or two areas where the police officer was known to be sympathetically disposed towards the Aboriginal population his popularity was clearly reflected in replies to my questions relating to their associations with officers of the law.

For example, in one of these areas Aborigines interviewed believed that the police treated indigenes and Europeans on an equal footing, and seemed to have forgotten the excesses of the past. Further, people in this area looked back nostalgically on the period when their personal affairs were controlled by the police, and viewed that period more favourably than the current Welfare Branch administration.

In another area, however, where it was alleged that the local officer had been engaged in illegal activities and was operating a business in conjunction with his constabularly duties, the Aboriginal residents believed that he would use any means possible to impress his will on the community. It was significant that, in discussion, there was constant reference by the Aborigines to previous outrages which had occurred at the hands of the police and European residents with apparent impunity.

In general terms there had been an improvement in Aboriginal attitudes towards the police force but it was also a generally held belief that the police would take the side of management in any industrial conflict. Several examples of police interference in the then current strike were mentioned. This was supported by comments to the effect that the police would force Aboriginal employees to return to their station if they left in the course of a dispute, and that they were the ultimate arm of authority behind the power of the Welfare Branch. 


\section{THE WELFARE BRANCH}

None of the native employees of the cattle stations who were interviewed had a favourable opinion of the work of the Welfare Branch. Their attitudes ranged from ignorance of its existence through to open hostility, mixed with fear. The most common complaint about officers of the department was that they never spoke to, or associated with, Aborigines during their visits to the stations:

We never see people from Welfare. When they come they do not sit down and talk to you. They don't stay long. Drive around and stay at the station. They could do things to help the people. They could find out what the troubles are. They don't do things now like they used to.

Most people interviewed believed that the Branch's lack of interest in their charges went much further than simply ignoring them. They felt that the interests of the Welfare Officers were more closely aligned with management:

We never see Welfare men. They never go near the camp. When they come they never talk about money. Maybe one or two in Welfare would help you but most are in with the manager.

In most cases the feeling was more personal:

Interviewer: What do you think about Welfare? Is it good for Aborigines?

Aboriginal stockman: Oh no. They not good for me; they were never any good. They used to do things that we don't want them to do. I reckon they bin robbin me too.

Further, it was alleged that experience had shown that it was no use seeking assistance from the Welfare Branch in trying to improve conditions on the properties:

People have asked Welfare but they have done nothing. Welfare takes no notice. Welfare never come to the camp. Every time they come they go to the manager. They supposed to be looking after us but they never come near us.

Some even believed that representatives of the Branch would interfere in relationships to the detriment of native employees:

Aboriginal stockman: Welfare would come to the station and say that Aborigines are getting too much money and get you cut off. They don't want dark people sitting around and if you do work and get the right price they will come along and get it cut out. Welfare not working for native people. No more. He'll cartem people around to Tennant Creek and places-but not feedem! Maybe on settlement but not around town. He sendem to station and he get paid for this.

Interviewer: Do you think Welfare is better than it was?

Aboriginal stockman: Well, it's no good now for native people. They got no time for Aboriginal people. 
Some indigenes had an impression of the Welfare Branch as a coercive body: 'Welfare doesn't help much. They might punish you. They stand over you and even take you away if you're cheeky'. Others were prepared to go further than this and give evidence of the actions of members of the Welfare Branch against what they considered were Aborigines' interests. These allegations ranged from one person who claimed that a Welfare Officer tried to interfere with his intended marriage to a half-caste girl by threats to remove him from the Northern Territory, to the failure of a Branch Officer to report a criminal assault by a manager on one of his employees.

Finally, a number of persons interviewed claimed that representatives of the Welfare Branch had acted as strike breakers during the then current dispute, by readily supplying labour to those properties from which Aboriginal employees had left in protest, or by directing wavering strikers against the wishes of their spokesmen. This attitude was supported by the refusal of some of the strike leaders to allow Welfare Branch officials to become involved in the settlement of their disputes with the pastoralists. 


\section{A WHITE RINGER'S WORLD}

Stockman: Overtime and workers' compensation would be two of the dirtiest words in the cattle industry. The only time that you know that a stockman is crook is when they are carrying him in and put him on the table. Before that they won't lie down. When they can't get up they admit they are buggered.

Interviewer: You have informed me that some Commissioner of the Arbitration Commission awarded ten shillings as a margin for skill for stockmen.

Stockman: This is ridiculous, sheer ridiculous. You say that there is no skill-well, let's look at it. A hell of a lot of wild cattle have to be thrown-all right-now what man can walk onto a place and start throwing wild cattle? There is a skill to it; there is an art.

Just for the record of your friends in Canberra we will go through the procedure of throwing a wild beast: You see a wild beast in the scrub-fair enough. You usually see seven or eight beasts. You try and run them into a mob and quieten them down. One breaks out; some man has to get that beast. He rides at full gallop behind that beast for about half an hour to knock the beast up. He then leaves his horse at full gallop; he runs behind that beast and grabs it by the tail and as the beast turns around to charge him he pulls the beast to the ground. If all things are are going well the beast comes down. If it doesn't-no don't get me wrong-you don't throw every beast you get hold of-they are hard to throw-to pull to the ground. Where the real danger comes is when the man is unable to throw the the beast-when it is too strong to pull down. You've then got to let go the tail and get behind a tree or try and run away from the beast. Sometimes you make it sometimes you don't. It's all danger. You cannot throw a beast unless he turns around to charge you-it throws him off balance. If you can get him on the ground you can tie him up and it is alright.

You can bring the other beasts over-what they call coachers-to bring him back into the mob. But somebody has to untie the beast on the ground. Now to be on the ground with the beast that has just been thrown is just like jumping into a pit of alligators. He's really snorting fury. All he wants to do is have a go at you. Sometimes you can get onto your horse. Sometimes you'll see [the stockman] 
behind a tree jumping around. They get him back into the mob and everything is right. But that takes skill.

The danger is greatly eliminated by skill. Commissioner Portus said that there is no skill. But you can eliminate the danger by skill-by knowledge of cattle. You'll watch these Aborigines up here. They will throw a beast-untie him and stand next to him and the beast will not do a thing. Because they know cattlehow they sum it up I don't know-no white man will understand these things.

Alright then, now let's have a look at tracking. We are mustering; we are trying to find cattle. This is where the white man misses out $100 \%$. A white man rides around all day looking for cattle; an Aborigine rides around all day looking for cattle tracks. When he finds the tracks he will find the beast; a white man might wander for days and not see a beast. But there could be fresh tracks there which, if he had followed, he would have found cattle. The Aborigine will find those tracks and he will track the beast down every time.

They're good. My bloody hell, they're good!

The Aborigine lacks one thing that the white man has-that is incentive. $\mathrm{He}$ hasn't got the incentive to take into his own hands to control situations which are over and above that which are directed to him for his job. It could be part of the psychological fear that the Aborigine has of the boss.

Interviewer: Well, you never know what the personal history of the individual is. I would like you to touch on the background of violence which you have mentioned previously as part of these places.

Stockman: Well, there is still the old school-the bullock chain school where you stroke an Aborigine down the forehead, with a bullock chain every morning. They exist-my word they exist. You don't ask questions, you just belt him. This is the old hard school.

It is funny but a lot of them gain more respect for a person who will treat them with physical violence. They would much rather have a bloke who would get stuck into them than to be mucked around with going to gaol and all that nonsense -mucked around with, fiddled atound with, red tape and all that nonsense; he would much rather be flogged. He's got more respect for a man who will flog him than one who will just gaol him. At least that way they know where they stand. The other way they don't have any idea of what might happen. They don't want to be mucked about by being sent to gaol-it means nothing to them. It has no fear for them.

Interviewer: Yes, you're right. This young fellow that is travelling with me has just been let out of gaol and he never stops talking about it: 'Geez, that's a good place down there boss. They make you eat. Come on, eat up, they say, eat up. Everything you can think of they make you eat up. They're pushing food into you all the time. And then do you know what-they even make you clean your teeth. Every day they ask you have you cleaned your teeth-have you cleaned your teeth? It's fantastic. Yes, it's a pretty good place [gaol]; a pretty good place.'

\section{A BLACK RINGER'S WORLD}

Interviewer: Where were you born?

Aboriginal stockman: I was born at Borroloola. 
Interviewer: And what stations have you worked on?

Aboriginal stockman: I have worked on most stations on the Tableland and over into Queensland.

Interviewer: Where are you working now?

Aboriginal stockman: I am not working anywhere now as I pulled out of my job last night. I was working as a lorry driver, getting wood, but the boss was pushing me too hard.

Intervicwer: You pulled out of your job you say?

Aboriginal stockman: Yes. I am always trying to help people but people won't stand and talk [for themselves]. They can't stand up and talk for their own living. I stood up to [X], the Manager at [A station]; that is why he does not like me. I have a landrover over there and it needs another part. He said that he would get it for me, but I wanted more money. I wanted $£, 10$ on top of the $f, 5$ I was getting. The boss said that the Company would not stand for it. Only two blokes were getting that money and they were [C] and [D]. ${ }^{1}$ They were getting $f 13$ or $f 14$ but no one at [A station] kncw that.

I went up with [F] and asked for it. He's now over at [V station]. The boss then abused us because we asked for more pay. He knew me well and that is why he didn't like me-because I asked for more pay, that's for sure.

Interviewer: Did he think that you were a trouble maker?

Aboriginal stockman: No, I'm not a trouble maker. I am not a stealer or a murderer but I have to fight for my living.

Interviewer: Have you heard of the strike amongst Aboriginal stockmen?

Aboriginal stockman: Yes. You mean the one over at Newcastle Waters and Wave Hill. Interviewer: What has happened there?

Aboriginal stockman: They are still out.

Interviewer: Why don't other Aborigines go on strike?

Aboriginal stockman: They won't do it because they crawl up to the Manager. The boss at [A station] was a hard bloke and he still is a hard boss today. When payday comes we go and ask for our pay and he say not yet. It's only a lousy ten or twelve quid but we can't get it. We worked on Saturday and Sunday and get nothing extra.

Interviewer: But the Manager at [A station] works hard himself.

Aboriginal stockman: Yes, that's right, he does. But he's the Manager and gets something for that-probably $£, 1,000$ a year I reckon, and he gets a bonus besides that. We were getting five quid a week and getting nothing out of that even. Working on Saturday and Sunday and getting nothing for it.

Interviewer: How much are white ringers paid?

Aboriginal stockman: The jackeroos get eleven or twelve quid and they are not worth feeding. Other white blokes get as much as twenty quid a week. No, sorry, twenty two quid a week.

Interviewer: Why do white blokes get more than Aborigines?

Aboriginal stockman: That's what we want to find out, see. You look-in the early days we used to keep the station going. When the work finished we used to roll our swags and carry them out to the bush, and when the job start again we would

1 The interviewee's statements concerning the wages of his fellow workers on the station were known to be accurate. 
carry them back to work. Now, when the rights came-the award-they don't like Aborigines and some of the stations say they are going to do away with native people. I don't know how their companies are going to do-get on I mean. I know all the white ringers and managers together won't do good. I reckon the companies will go broke.

Interviewer: Well, what was the problem over at [A station] then, when all you blokes walked off?

Aboriginal stockman: Well, they were getting a low price [wages] but they were still managing on it.

Interviewer: [A station] is doing away with Aborigines-why do you think that is so? Aboriginal stockman: The managers do not like native people getting high wages. Interviewer: Some of the managers say that Aborigines are not good workers. Aboriginal stockman: Is that right? Well, how about some of these useless jackeroos? You gotta tell 'em to get on this side or that side and still they gettem good money. Interviewer: Well, if you do have a problem about your wages, why don't you talk to Welfare about these things?

Aboriginal stockman: Look, talk; talk; talk until we talk our tongues out. That the trouble. Why couldn't Welfare have done something for us before the Canberra mob. Well, we tried and tried; tried and tried. A few of us spoke to Welfare and he go and see the Manager. The Manager put a bottle of whisky on the table and when he got the Welfare drunk he say well, what about that blackfella bloke. He's no good. The Welfare's on the Manager's side. That's for sure. After that the Welfare got to chase the boy away and the Manager say to the Welfare to shift him somewhere else. That's the trouble with doing that. Welfare carry 'em away.

Interviewer: Does Welfare come around to these properties?

Aboriginal stockman: $\mathrm{Oh}$, yes.

Interviewer: Do they ever come to talk to you people?

Aboriginal stockman: Very seldom. They call on the manager all the time. Today you can see that. You can go to see that on all the stations. The manager say this blackfella no good, that blackfella no good, and the Welfare get all that down. But there are a few good white fellas and a few good blackfellas all the same-just as bad in both. You can get a white fella and a black fella to go out and get a load of wood and the white fella has a sleep. You can't see it as Manager as you in the house. You can't see it unless you get behind him.

Interviewer: Did you hear of the judges coming around last year?

Aboriginal stockman: Yes, I heard of that but I never seen him-heard that two organisers at the races told the native people that the wages were going up to white men's wages.

Interviewer: What do you think will happen to those people on strike at Wave Hill? Aboriginal stockman: Well, if they stay out long enough they will win.

Interviewer: How did the boss at [A station] treat the Aboriginal stockman?

Aboriginal stockman: Pretty hard. He bashed one bloke up; [G] was his name. ${ }^{2} \mathrm{He}$ took him into the office with his son. They locked the door and bashed his head against the wall. They then put the dogs onto him. They then bashed him up again after they put the dogs onto him.

${ }^{2}$ The person mentioned in this allegation was later interviewed and corroborated the story. The assault was known to both the police and Welfare officers in the area. The victim was admitted to hospital. No action was taken against the manager. 
Interviewer: Well, what are you going to do now that you are out of work? Aboriginal stockman: I am going to go up to Tennant Creek and do some mining. Interviewer: What, work in the mine?

Aboriginal stockman: No, that mine don't employ Aborigines. It bin robbed off Aborigines. Aborigines found the mine and the management never give them nothing. That's [X Company] and the others. That was way back in 1918 sometime. But there is a better show than that one they are working. It is [X] miles out. I will get a taxi up there. It'll cost me only $£ 5$. I've got some money in the Bank. I've got $£ 10$ at the Welfare Office and $\mathcal{f} 40$ in the Savings Bank.

Interviewer: That won't last you long.

Aboriginal stockman: I'll be careful with it when I go mining. I won't waste it. I'll have enough tucker to do me for two or three days. I'll do a dolly up and then another dolly up and the sell it in Tennant. ${ }^{3}$

The manager at $[J]$ mine said don't talk too much. We'll sell the gold. The claim is [X] miles out and will cost me [Y] shillings each day in a cab.

Interviewer: What do you think of the Welfare program?

Aboriginal stockman: Well, they aren't getting good treatment at the settlements. They are living on bush tucker. Welfare no good for me. Welfare take the boys away. We bin thinking Welfare no good for us. The manager him say to Welfare them two boys no good to us you might as well takem away. We today bin sayin that Welfare no good for us. Police were better for us. In them days the police would look after us-good clothin'; good ration and even what money we had in Darwin bank the police would gettem for us.

The police bin better than Welfare. Well, Welfare bin no good at all, anyway. What I can see they been partner up with managers. Anywhere on this station you can see that there are bad boys-well, I'm a bad boy cos I stand up and fight for my own living.

\section{WHITE MECHANIC'S WORLD}

Mechanic: Many of the half-castes over the last fifteen years were treated almost as badly, but not quite as badly as the full-bloods. I just remember the 'dog collar'when they were still under the 'dog collar act'. ${ }^{4}$ Now I was actually here in the Territory when all half-castes-or anybody other than a full Aboriginal-got drinking rights. All the old timers threw their hands up in horror and said it would be ruination-damnation. That would be twelve years ago. Only two years ago the full-bloods got drinking rights. And once again the diehards said ruination. The fact that they had been drinking for years metho and God knows what did not seem to impress them in the slightest.

Interviewer: That is the same as I heard when I was up here last year, but I was never able to document it. People claimed that the same arguments that were used against granting half-castes equal rights in relation to drinking and wages in 1952 were used against full-bloods in 1965 when their tights were similarly under discussion. Mechanic: You are dead right.

Interviewer: It seems obvious from the situation up here that once you have given

${ }^{3} \mathrm{~A}$ 'dolly' is the local term for a crudely built ore treatment device.

${ }^{4}$ Aboriginals Ordinance, 1918-1954. 
them equality the Aboriginal people seem more able to fit into a normal situation than previously.

Mechanic: You are dead right. There is only one thing which is a problem, however: it is the old people. They are like Mahommed's coffin-half way between heaven and hell. I honestly don't think that they will be able [to make the grade]. Incidentally, the Aborigines don't want to be assimilated either. They want to be equal to the white fella, but they don't want to be submerged.

The results of the survey showed that there was a fairly distinct industrial elite working in the pastoral industry of the Northern Territory, and that this was made up entirely of white workers. This is not to say that whites had a monopoly on skills but that, where Aboriginal employees possessed these skills, they were not recognised or, if recognised, certainly not rewarded.

Although it was noted that some Aboriginal groups carried out work of equivalent standard to whites, at no time were they given recognition for the services involved. This was fairly obvious in the case of cattle workers, where the majority of persons interviewed conceded that Aborigines were marginally better suited to the work and more productive than Europeans. Their particular skills, however, were appropriate to the open range technique of cattle herding rather than to the more sophisticated aspects of animal husbandry.

As the increased capitalisation of the properties must bring with it greater dependence on mechanical devices-and it is partly mastery of mechanical skills which differentiates advanced from primitive forms of social organisation-the response of employers to the questions concerning the mechanical ability of Aborigines was of particular intercst. We might recall that 40 per cent of the managers interviewed claimed that Aborigines did possess mechanical aptitude.

It was of some interest then to look at this situation more closely, and considerable time was taken during station inspections to travel with mechanical crews and to visit isolated bore pumping stations manned by Aborigines. An impression of their life and their relationship with the rest of the station community was adequately summed up by a "windmill expert' who was interviewed in Darwin. The impressions he gave were not greatly dissimilar from several other mechanics who were interviewed but who, for reasons mentioned earlier on, were not favourably disposed to allowing their opinions to be recorded.

MECHANICAI APTITUDE

In any given situation the processes of adaptation of one racial group 
to another are somewhat complementary. Rarely is it the case that one group remains static whilst the other group adjusts to the impact of the new relationship. Through the process of acculturation both groups are forced to adjust in some way to the new conditions, although the effect on their previously established roles and relationships may only be minor. The extent of the impact of one group on the other depends considerably on such things as the history of the association, the cohesion of the groups and their relationship to the source of power. This, in turn, is further affected by the response of those in control of the economic resources to the demands which are made on them, from time to time, through changing conditions and their general interpretation of the needs of the operation for which they have responsibility. Each situation, however, is unique. ${ }^{5}$

The nuances of policy administration and objectives, as well as the immediacy of contact between managers and men, inter alia, considerably affect the contribution of each party to the job at hand as well as each individual's appraisal of the contribution of the other to the work process. The nature of management's day-to-day supervision of the details of any individual's contribution to the production process will, in normal situations, have considerable bearing on the employers' appreciation of the value of the services rendered. This in turn conditions the level of esteem in which the employee is held and the long run rewards which he may achieve from employment. However, the introduction of racial differences into industry provides an additional filter through which managers and men view their respective roles. In the initial stages of industrialisation in a race contact situation, beliefs about biological differences play an important part in the assignment of functions between the two groups. ${ }^{6}$ In the case of Aboriginal labour in the pastoral industry of the Northern Territory the contribution of Aboriginal skills to the working of cattle seemed to be a logical exploitation of their particular educational advantages. However, in the acquisition of white technical skills one witnessed an entirely new learning process. Accordingly, information concerning the sociology surrounding the acquisition of additional skills by Aborigines on cattle stations and their exploitation of this knowledge for their own advantage promised to cast additional light on the nature of the industrial hierarchy. The mechanic was able to add

${ }^{5}$ P.L. Van den Berghe, Race and Racism: A Comparative Perspective, John Wiley, New York, 1967, pp. 148-9.

${ }^{\text {в }}$ Herbert Blumer, 'Industrialisation and Race Relations', in Guy Hunter (ed.), Industrialisation and Race Relations, Oxford University Press, London, 1965, pp. 220-53. 
considerably to the understanding of the industrial role of Aborigines in this respect.

Although the person formally interviewed had worked in the outback as a garage mechanic since before World War II, he did not have any specific knowledge of windmill maintenance. This is a highly specialised job and persons who have mastered it were referred to as-rather untypically for the industry - 'windmill experts'. The mechanic related the way in which he acquired his own knowledge of windmills as follows:

\section{ABORIGINAL CONTRIBUTION}

Presenting himself for employment at a large station in the northern part of the Territory, he was requested to take over responsibility for the working of windmills on the station from the previous incumbent. He was informed that this man, a European, would introduce him to the operation and assist him during the period of induction. However, on presenting himself to the previous occupant of the position it was obvious that the person was drunk, and had been in this state for some considerable time. Further, he concluded that it was probably for this reason that the services of the person concerned had been terminated. He drew the manager's attention to the fact. The manager instructed him to go and introduce himself to two of the Aborigines who had assisted the previous employee, adding that 'they [would] show him the rounds'.

On leaving 'Gubment House' (the homestead) and walking across to the windmill shed he considered his predicament with a degree of hesitancy. The problem of not only assuming responsibility for a job for which he had no experience, but also for an unknown area of over 6,000 square miles, somewhat daunted him. He decided that he would be perfectly honest with his Aboriginal assistants and inform them of his problems. On introducing himself to the two Aborigines they said 'you must be the new windmill expert?' 'Yes', he replied, 'but the only thing wrong is that I don't know any bloody thing about windmills'. This 'rocked them', he claimed. He continued 'I don't know my way around [the property] either-know nothing about the country-know nothing about anything-so I am stuck to you fellas.' The Aborigines then proceeded to show him around the station and how to maintain and repair windmills. They did all the work. He just watched.

They became good mates on the basis that [he] asked them and was fair dinkum and honest with them to show [him] and they did ... Two full blood Aborigines taught [him] in the seven months [on the station] everything [he knew] about windmills. 
The Aborigines, he claimed, could get a job anywhere in Australia as windmill experts, and knew the idiosyncrasies of the various makes and how to correct their faults. Indeed, he had met many "white fellas who are paid big wages [for the same job] but who did not have a clue compared with [one of his assistants]'.

WHITE ROLE

The interviewer informed the mechanic that he had witnessed many situations (particularly on the Barkly Tablelands) where windmill and bore mechanics were completely dependent on the Aborigines' services, in many cases using them as a front for their own idleness. 'They would take them out and sit on their arse whilst [the Aborigines] did all the work'. 'That's true-my word that's true' was his response. 'Yes, I'll go into court and swear that on oath on a stack of bibles. Of course it's true.' Aborigines made similar complaints (see p. 137).

One particular company, he claimed, followed a policy of using Aboriginal labour in this way.

He then went on to discuss the role of a pumper. 'A most important job, but monotonous.' The cattle were dependent on his presence. The pumpers had to keep the troughs clean and, if there was insufficient wind, 'kick' the diesel motor 'in' to fill the troughs. If there were any minor repair problems they had to be attended to, as contact with the homestead was normally only made once in each week. In the meantime stock to the value of upwards to $f 75,000$ could perish. The lack of radio communication and the vast distances involved precluded any possibility of getting help.

\section{DRIVING}

It was the mechanic's experience also that Aborigines were fairly easily taught to drive, and that they became competent and responsible drivers. He was able to teach his assistants rudimentary running repairs to the vehicles.

One interesting aspect which was also commented on by other informants was that the management of many stations were strongly opposed to Aborigines travelling in the front seat of a vehicle. Their proper place was on the back of the truck. It was common for managers to instruct their staff to insist on Aborigines riding on the back regardless of the personal preference of their white employees. 
REWARDS FOR MECHANICAL APTITUDE

The company by which the mechanic was employed only had one white pumper. The European Award rate at the time was $\delta, 11$ per week and keep. 'The Aborigines were damned lucky if they got anything except their tucker.'

'Tucker' was distributed by the windmill expert to the pumpers every Friday. The fare consisted of 'bush corn beef' (beef rolled in salt), tea and sugar. Adult males were allowed $4 \mathrm{lb}$ of beef per week, adult females received $3 \mathrm{lb}$ and picanninies $1 \mathrm{lb}$. Although during his period on the station there was no shortage of beef, the manager reprimanded him for being over indulgent with the meat rations for the employees out on the run. The natural food resources of the Aborigines had also become depleted through competition with the cattle.

Some Aborigines endeavoured, however, to broaden their restricted diet by developing small vegetable gardens and were able to produce pumpkins, rockmelons and similar vine crops.

The provision for physical comfort was also rudimentary. At one bore there were two adult males, three adult females and five children. Their blanket ration for the year was four blankets; there were only five blankets in their shed, and these were of extremely poor quality. As it was very cold during the months of June and July, the mechanic approached the manager for additional blankets for the inhabitants at the bore, asking specifically for one dozen more. The manager claimed that

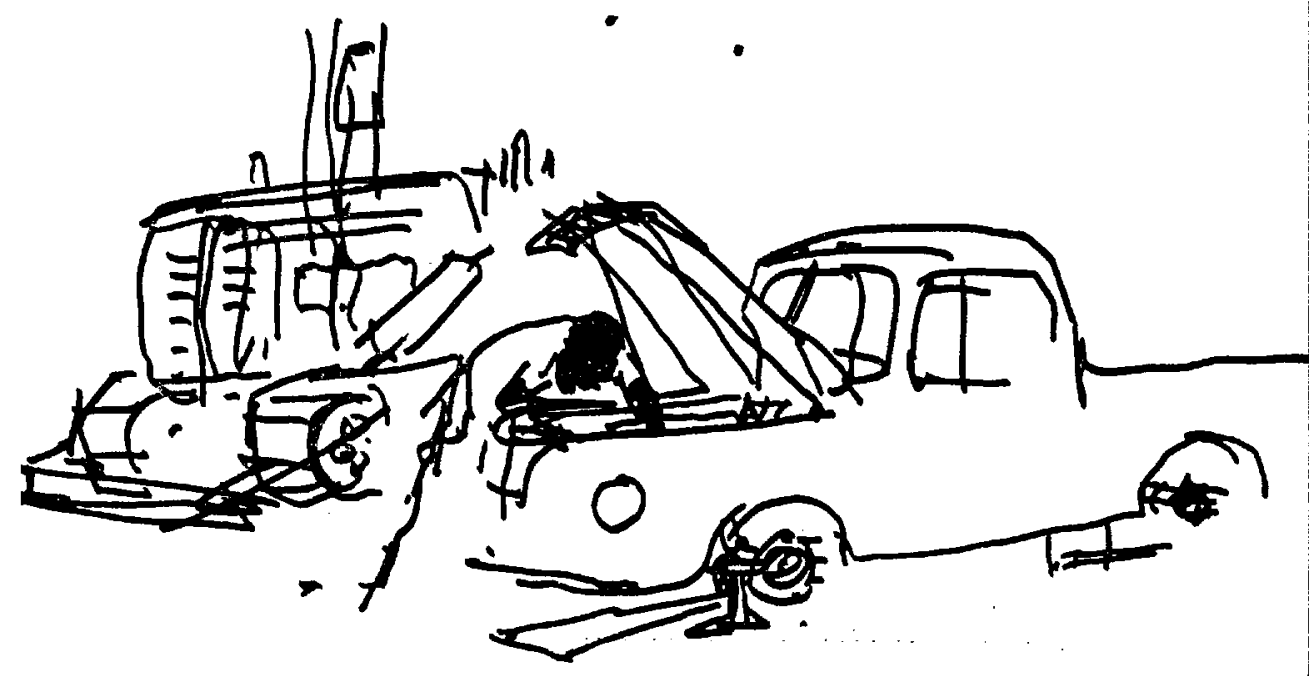


the issue had already been made and that there would not be any more given out. My informant asked why sufficient blankets for all people had not been issued, and was informed that 'picanninies don't get any blankets as they don't work'. The mechanic then abused the manager and purchased a dozen blankets from his own earnings.

He claimed that the withholding of adequate clothing and blanket issues to Aborigines was common practice on all large stations in the Northern Territory. To support his statement he referred to arguments that he had with other managers over the failure to issue Aborigines with 'ringer's boots' (ankle high elastic sided riding boots); the Aboriginal stockmen were forced to ride bare-footed.?

\section{MANAGEMENT ACCOUNTABILITY}

In most cases the mechanic believed that it was because of the virtually universal illiteracy amongst Aborigines that they were unappreciative of their position and of the lack of reward for their labour. A simple reference to the fact that 'it's in the book', or some similar term concerning the accumulation of credit was sufficient to allay their apprehension about any rewards which were coming to them. Because of this they were robbed 'hook, line and sinker'.

However, not all Aborigines accepted the final authority of a statement from the bookkeeper or the manager concerning the company's indebtedness to them. One particular person, displaying a greater degree of skill and persistence than others, made inquiries of the bookkeeper concerning their respective remuneration. The mechanic's Aboriginal offsider was downcast.

'What's wrong?', the mechanic asked.

'I've bin thinkin', was the reply.

'What ya bin thinkin' about?'

'I've bin thinkin' I'm a bloody fool, eh?'

'No, I don't think you're a bloody fool. I think you're a pretty bright man.'

'No, I bin thinkin' I'm a bloody fool. How much money you bin gettin' a week?'

The mechanic informed him that he was getting $£^{18}$ per week and keep.

'You know how much I bin gettin' old man? Twenty-five bob. Not fair, eh? Maybe you see that manager, eh? Get me some more money.'

${ }^{7}$ In November 1966, I gave an Aboriginal employee from a large Barkly Tablelands property a lift to Borroloola for his vacation. He wore a pair of boots of station issue. They were two sizes too small for him. To get them on he had had to cut two slits in the leather through which his toes protruded. 
The mechanic saw the manager and informed him that the Aboriginal offsider wanted more money. The manager replied that he could not do it, as he would have to give it to every other Aboriginal on the station. The mechanic assured him that this was not the case, and then listed a number of people that he thought should get higher remuneration. $\mathrm{He}$ was told that it was impossible as 'the Sydney office' would not allow it.

'Oh no', was the manager's final answer, 'finish him up-tell him that he cannot have it.'

The mechanic returned to his offsider and informed him of the result of his interview.

'Oh well, no more. I bin finish up altogether.'

'What are you going to do?'

'Well, I bin going to go to that Darwin town and sit down at Bagot and play cards. Any money I want I'll get off Welfare.'

In this way the mechanic claimed that the Aboriginal concerned was turned into a 'complete bludger'.

FINANCIAL IRRESPONSIBILITY

When questioned on the apparent irresponsibility with which Aborigines treat their accumulated funds when they are paid the mechanic replied:

Ever known a ringer who didn't react in the same way? The stories of the big sprees are part of the tradition of the bush. They come down with a roll of notes in their hand and they are determined to go through it, as they know it is only a matter of time before they have to go back to their mundane life on the station. Aboriginal attitudes to earnings in this way simply reflect what goes on around them.

\section{BRUTALITY}

The mechanic had experienced much evidence of brutality during his period on the station, although he belicved that it was a thing of the past. Various acts of violence that he referred to included the belting of an adult female over the head with a hobble strap and the enforced crouching of a group of adult females on a hot tin roof 'until they nearly died'.

\section{IMPACT OF THE WELFARE BRANCH}

The mechanic was appreciative of the work of the Welfare Branch in one aspect of their responsibilities. Although he considered Welfare officers were only 'career men who couldn't care less', they had 'put the fear of God into the managers about bashings and brutality'. For this he thought that they should be given some credit. 'But apart from that [he could not] give them any other credit.' 


\section{A BOOKKEEPER'S WORLD}

Interviewer: How long have you been in the Territory?

Bookkeeper: Since 1958. I answered an advertisement in the Sydney Morning Herald for a position as bookkeeper/storekeeper [for a large foreign owned company and served on five properties]-First of all when I was recruited down South I was told by the man at the Sydney Office that the blacks hated the white men and to treat them the same way-that will be the best way to get on with them-treat them as dirt sort of thing.

In the processes of the law some persons are in a more favourable position than others to pass comment on the nature of its application. Similarly, other persons are occasionally better placed because of their position, rank or location of their work to consider various aspects of social organisation.

On the northern properties the storekeeper filled the role of intermediary between the executive authority of the station manager and the practical application of his policies and attitudes towards the Aboriginal employees.

Because of the need for the continuing control of stock, and the dual function of the storekeeper as bookkeeper, this European employee was placed in a unique position. Not only was it necessary for him to understand fully management policy in relation to the victualling of Aborigines, but he was also able to witness the correlation between the company's legal obligations and their implementation. As well, because he was normally the prime source of sustenance for the Aboriginal community, he developed a unique relationship with individual indigenes, being, at times, the only person on the station who would not only know all of the Aborigines by name, but about whom he also had considerable personal knowledge. Because of this, information obtained from these employees was particularly valuable in understanding the details of the Aboriginal labour system as it operated on most company-controlled stations. Although frequently the informants involved one in a mass of detail which was impossible to digest for a study of this nature, they did occasionally throw some light on practices which seemed to be fairly common throughout the industry. Their information was particularly helpful in understanding the response of management to their liabilities under the Wards Employment Ordinance and the general administration of the community as a social unit.

However, the position of trust and confidence which they commonly shared with the station manager or owner made them particularly difficult people to interview in a formal sense. This difficulty was further com- 
pounded by the fact that they were often engaged in nefarious practices either relating to the administration of the store from the company's point of view, or over the handling of funds and commodities due to the Aborigines.

In these circumstances they were naturally loath to discuss the methods by which station property and accounts were handled, and when encouraged to speak on the actual operations of the station, as distinct from theory, they preferred to discuss matters by way of analogy-indicating that what they knew about malpractices was always happening at other stations.

I was fortunate in recording an interview with one bookkeeper-cumstorekeeper, and believe that his experiences were typical of the life of most of the other persons in similar positions throughout the industry. At least they present a picture of disturbing frankness as far as the personal activities of the individual are concerned. As such they must at least be taken as a serious conditioning factor in the communities over which he had influence. In a broader sense they add to our knowledge of the methods of operation of management and the Welfare Branch in a reasonably significant section of the Northern Territory pastoral industry.

\section{WAGE INCREASES}

In 1959 the cash wage of Aboriginal males was raised from $f^{1}$ per week, 'cash in hand', to $f^{2}$ per week plus 15s. in lieu of a clothing allowance. The bookkeeper considered that the "change was not as much as [the Administration] made out'. In fact, goods which had previously been issued, such as eating and cooking utensils, were withdrawn from the free list. Because of this they were worse off then than before their 'wages' were put up. The female 'wage' was also raised from $7 \mathrm{~s}$. $6 \mathrm{~d}$. per week to $£ 1$ per week plus 10 s. per week clothing allowance. But they, too, were 'no better off-they were worse off'. 'There was nothing given to them at all except Aboriginal tobacco.' The tobacco issued was marked 'For Aboriginal Use Only' and cost 17s. per lb as compared with European tobacco costing $\delta^{25}$ s. per lb. Coming in eleven plugs to the pound, the tobacco did not have great acceptance amongst Aborigines.

DIET

Although the Wards Employment Ordinance provided for a reasonably balanced diet to be provided to Aborigines, the bookkeeper found that some of the fundamental items mentioned in the ration scale were not issued. "When I got to [X] a woman asked for a tin of milk for her child. 
I was not supposed to give it to her but I did.' Although the ration scale contained a number of items representing vitamin balance the Aborigines rarely enjoyed such necessities.

There was provision in the Wards Employment Ordinance for fruit but none of them saw any. They did, however, get fruit from the store at 3s. per tin.

Some of the stations where he had been employed carried a herd of cows, but rarely were Aborigines allowed to enjoy the full benefit. 'White stockmen had full cream milk-the separated milk was given to the black children.'

No vegetables were issued at all. Managers reasoned that Aborigines would throw them away. They did, however, occasionally get some rice. The standard diet was meat and bread. Normally the beef with which they were issued was the left-over cuts available after the white community had taken their choice.

Although Aborigines usually received the poorest cuts of meat, occasionally amounting to little more than offal, there appeared to be one redeeming feature about the beef supplies: The bookkeeper claimed that there was an instruction on the company's file informing managers to kill only aged cows. However, this rarely happened. Wherever possible the stations endeavoured to slaughter beasts with the brands of neighbouring properties. He had himself 'gone out and killed other people's cattle. It all balances out I suppose because other people kill their cattle'.

\section{WELFARE ORGANISATION}

The bookkeeper found that it was very rare for Aborigines to complain to Welfare representatives in the freld, as there seemed to be a greater affinity between the Department's agent in the area with the employer than with the Aborigines. Whenever inspections were made of the Aborigines' camp it was normally in the presence of the employer. Aboriginal employees were expected to make their complaints in the face of the representatives of the Administration in Darwin and the manager of the community on which he was dependent for his sustenance.

In one incident described by the bookkeeper the manager accompanied the Welfare Officer to the Aborigines' camp and lined them all up; moving down the line with the manager he asked each individual if he had any complaints. There were none!

Only once did he discover an Aboriginal prepared to make a complaint during the visit of a Welfare Officer to a remote property. The person concerned considered that the pensioners were not receiving enough beef, 
although they were entitled under Welfare determination to several pounds per week. She made the complaint, which apparently was never acted upon by the Welfare Branch. The complainant was, in turn, reprimanded by the manager after the Branch's representative had left the station. No more was heard about the complaint and the victualling of pensioners remained in its usual poor state.

He believed that it was the Aborigines' attitudes to their employers that prevented them doing anything about their own position. "The boss and his wife were high up' and it wasn't right for indigenes to embarrass or inconvenience them in any way. On the other hand, Aborigines looked at the Welfare Branch 'not as an organisation to help them but to control them. They were more like policemen. They would not go to them if they were in trouble'.

One of the reasons for this attitude, he believed, was the fact that although the Welfare Branch was aware of the widespread nature of the abuse of management's power over the Aborigines they did nothing about the situation. This factor was further compounded by the close liaison between Welfare Officers and the employer as 'they stayed at the house and got on the grog with the boss'.

Finally, the bookkeeper considered that one reason why little had been done about the predicament of the Aborigines on the stations was that they were not able to communicate about their problems with the outside world. On one particular property where he had worked there were some mission educated indigenes. The station manager instructed him to ensure that no letters were posted by his Aboriginal employees before he had the opportunity to read them.

\section{CHARIT Y}

During the bookkeeper's stay at one property a carton of old clothing arrived at the station from an address in southern Australia. The manager's wife informed him that the items had been sent to her by her mother. Shortly after their receipt the manager got him to pay the Aborigines, and his wife began to sell the clothes to the indigenes. Old dresses fetched $\AA^{3}$ and old petticoats $£ 1$.

A half-caste Aboriginal married to a full-blood woman stopped her buying the articles as he considered them to be virtually useless. However, the manager's wife importuned them. One woman spent all the money she had. Another was encouraged to withdraw the money owing to her husband, a leper, who was absent in Darwin, and to spend it on clothing. Exploitation in this way was not limited to individuals on lower incomes. 
A pastoral inspector visited the bookkeeper's office one morning, and studied the Aboriginal wages list in an endeavour to determine which employee had the largest accumulation of funds to enable him to do business. He came to the conclusion that there was insufficient money in the full-bloods' accounts for his purposes. He then selected a half-caste employee, who, apparently, had close ties with the Aboriginal camp but, because of his higher rate of pay, had accumulated more reserves. The inspector approached this man and sold him a watch and a battery operated shaver. The shaver could be procured in Sydney for $\mathcal{L}^{4}$ and the watch never worked. The employee had $£^{33}$ in his account and the pastoral inspector encouraged him to sign a cheque for $f^{30}$.

\section{BRUTALITY}

The bookkeeper had witnessed many acts of brutality towards Aborigines, and confirmed evidence in this regard presented elsewhere. On one station at which he worked he claimed that the manager had come across a family of Aborigines proceeding from one location on the property to another, by foot. He noticed that they were carrying an unusual looking parcel wrapped in cloth, which he concluded was stolen beef. Galloping after them he pulled out his stockwhip and flayed the person with the parcel, forcing him to drop it. As it fell to the ground it came open and the body of an infant fell into the dust. This information was similar to material collected from Aboriginal informants.

In another description of disciplinary measures on the stations on which he worked, the bookkeeper was informed by the manager that he had just returned from the Aborigines' camp where he had administered a beating to two 'lubras', kicking them in the process. He was concerned about the incident because a representative of the Welfare Branch arrived about an hour after the beating, and he thought that they might have told the officer. The native women, however, did not confide in the officer about their problems. 'They never make any complaints', he continued. A girl at a particular station had a disagreement with the manager's wife who continued to object to the temperature of the milk in a bottle that the girl had to prepare for the wife's baby. In a fit of pique the Aboriginal house girl called the manager's wife a 'bastard'.

The girl was sent back to the camp and put off the books and was not allowed to work any more. [Aborigines] do [object] occasionally. They rise up and then [the management] cut them off.

In European circumstances conflict of this nature is usually contained 
by the individual removing himself from the immediate vicinity over which the employer has influence and by canvassing for another job. But the Aborigines' situation in northern Australia was entirely different. They could not move onto adjoining stations.

\section{PAYMENT OF WAGES}

The bookkeeper informed me that there were some people working on stations who were not paid. Some of them were not even on the company's books. He had known pastoralists to boast about this in some of the local hotels. One particular person claimed that he wanted to attract more pensioners to his property as they 'were better than cattle'.

On this business of them not getting their right money when they come with their thumbprints-a bloke who works as a horse tailer and is not on the books-a bloke about fifteen-come the race meeting and he is going to get $\mathcal{L}^{4}$. The manager looks down the list and sees some bloke with enough money and he may knock $£ 8$ off it. I was in this myself. I hesitated when I was instructed to do this, and I still think that I was probably wrong. I realised that if I did not do it I would be sacked, and it would continue. It was common practice for a bloke to sign for more than he received.

The defrauding of employees in this way continued although it was necessary for both the manager and the bookkeeper to sign as witnesses to the proper payment.

Because of the nature of the credit system which operated on the various stations, with Aborigines drawing commodities from the stores against their accrued wages, many opportunities arose for storekeepers to defraud the employees. Although my informant did not admit to engaging in these practices he was aware that they did take place, mentioning two properties. At one station the storekeeper was eighty tins of tobacco short in his stocktaking; these had been used by the whites associated with the homestead. The total cost of the shortage was distributed amongst the Aboriginal accounts. 'You could book down anything. They do not sign anything or even put their thumb print down.' Given the situation at the stations he considered that it would have been easy to book food out to the Aboriginal camp and keep it himself.

But the sharp practices were not the sole preserve of the bookkeeper. Although the Wards Employment Ordinance provided that the expense involved by Aborigines in travelling to station employment was to be borne by the employer, the interviewee discussed the details of a case in which an Aboriginal stockman who was living at the Bagot compound in Darwin, was forced to pay the cost of his journey to the Victoria River District for employment out of his own savings. 
They put him on the bus at Daley Waters and we picked him up. About a month

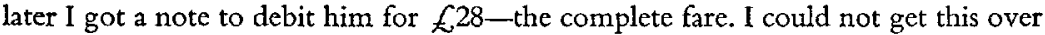
to him-he could not get things for his children and thought that I was robbing him. As he was only getting $\mathcal{K}^{2}$ per week and 15s. for clothing he had no chance of paying that.

The manager of one of the largest pastoral groups in the Northern Territory was encouraged to pursue practices which obviously had an oppressing effect on the resident Aboriginal population. Given the restraining influence of both the Wards Employment Ordinance-in making it illegal for persons to encourage indigenes to leave their employment-and the agreement between company managers not to employ persons normally resident on another station, any opportunities to leave with the object of improving their position were effectively circumscribed.

\section{RUNNING COSTS}

Managers on the station at which the bookkeeper informant was employed were rewarded partly according to how cheaply they were able to run the operation. This encouraged them, through the payment of bonuses, to engage in certain cost saving activities.

They were very conscious [of the bonus system]. They would cut down on trivial things such as food and even a few pounds on wages. There was a case there where a native who did not smoke, who had no wife to spend his money on, and his savings accumulated to about $£ 20$. The manager saw his balance and he told me to take him off the books. Leave him work. He has enough money there without paying him any more. He worked for about two or three months without credit. I would say that the manager did that as part of the way in which he would run the property cheaply. Although he would not have done it on instructions from the Head Office.

My informant believed, however, that there was a considerable degree of subterfuge on the part of management about this type of practice. Although the general manager of the company had made public statements concerning the payment of legal rates of pay on the properties, it was not difficult for him to determine that the labour costs were lower than the appropriate figure for comparable operations. He 'did not know what happened on the station and did not want to know'.

\section{SOCIAL SERVICES AND WELFARE BRANCH AID}

There were a lot of children at [X]. Twenty-five probably. But there was no school during my time although I believe that there is one now. The managers never wanted them educated-it was convenient that they could not read or write. Most of the people got child endowment. For the first child they were getting child endowment which was given to the station. For the others they were getting $16 \mathrm{~s}$. $6 \mathrm{~d}$. per week- 
little piccaninnies and so on-it was pure profit because they gave them nothing. The mother fed them on the breast and there was nothing given to them at all. In fact the father would buy a lot of clothes for them. There were issues given out every quarter but they were making a 'cop' on it. At [X] they were making about $\delta^{60}$ every four months on the children and old people-that is according to what I booked out and what I received from Welfare. This went into what they called an Aboriginal Account. There were two kinds of accounts: one kept locally and one at the head office. This one was kept at head office. This was money that was not devoted to housing; it was just surplus.

\section{HOUSING}

There was no Aboriginal housing at the station where he was mainly employed. One reason given for this was 'that there was no use in putting housing there; if a native died they did not want to live there any more'.

The buildings which were supplied consisted of four iron walls with no windows or floors.

They were buildings that you could hook a tractor on to and slide along and move to another place. If you pulled it to another place they would live in it. Whether this was true or not [he] did not know.

He had visited some of the stations since his departure and found that there had been no significant improvement.

One of the main housing problems, he believed, was the limited financial authority allowed the manager. All items in excess of $f^{50}$ had to be forwarded to London for approval.

\section{SEXUAL RELATIONS}

My informant claimed that sexual promiscuity was rife on all of the stations at which he worked, and that these activities were engaged in with the open knowledge and encouragement of the management. Although in different circumstances the private life of informants might not be considered an appropriate subject for discourse amongst economists, the socio-economic implications of these particular sexual activities add considerable depth to understanding of the situation which has developed and the responses of Aboriginal employees to impositions made on them and their women.

On his first posting it took the bookkeeper only two weeks to establish sexual liasion with the Aboriginal camp. The Aboriginal woman working in the store asked him if he wanted a woman as she had a particular person available for him. He accepted the invitation and a young single girl became his partner, spending many nights in his room near the homestead. 
It was the bookkeeper's opinion that there were very few 'celibate's Aboriginal women at the station. When the male Aboriginal employees were out working cattle and away from the homestead Aboriginal women made contact with white male employees with the object of soliciting sexual intercourse. I asked him if the relationship was normally concluded for cash consideration:

Yes-occasionally, but it was normally for a plug of tobacco or some tea and sugar. Was that a necessary part of the act?

Yes, I think it would have been. If I had refused it it would have been all over.

What about children in these circumstances? Do they ever happen?

Yes, I think they did. There are plenty of half caste children at $[\mathrm{X}]$-but I have never heard of anybody having to pay for them.

Sexual exploitation in this way was not limited to the white employees at the stations but involved all levels of personnel. At one station a company pastoral inspector who had acquired the colourful title of 'the Black Prince' because of his penchant for Aboriginal women, endeavoured to seduce the house girl who had been allocated to look after his needs. As the bookkeeper explained:

She did the unexpected thing and started howling and went off to the boss's wife and told her, singing out real loud. The manager's wife chased her off to the camp screaming out 'go on, go to the camp, go to the camp; you're a dirty beast'.

\footnotetext{
8 The surrounding circumstances of my informant's conversation indicate that he intended 'celibate' to mean 'non-promiscuous'.
} 
From the castrating of bulls through to the dispatch of beasts to the $F$ meatworks for dismembering, the cattle industry might be considered a more brutal pursuit than those followed on the rolling green hills of the dairying country, or by the occupants of suburban villas throughout Australia. Consequently one does not expect the same standards of social decorum to operate in two such widely different areas of society. However, it has been noted by some authors that the needs of the frontier, historically, have produced individuals with distinct personality traits. These have been variously a strong sense of independence and individualism; a preference for the immediate and pragmatic resolution of problems and a bias towards practical adjustment to conflict rather than the use of theory. ${ }^{1}$

At any one time, though, the behaviour of individuals towards others in the community is somewhat dependent on the past history of relationships, as well as the current standards of social approbation. That historically the standards of social behaviour between the different racial groups in the pastoral industry would not meet the approval of the present Australian community, might be clearly deduced from the work of Berndt in 1946-the use of the techniques 'of violence and threats of violence as the means of keeping the native under control' and active dislike of the Aborigines and 'indifference or positive pleasure at the thought of their extermination'. ${ }^{2}$

The overwhelming vote for constitutional change in the referendum

${ }^{1}$ See generally Allen, Bush and Backwoods.

2 Berndt, 'A Northern Territory Problem', p. 66. 
concerning the transfer of power over Aboriginal affairs to the Commonwealth Government in 1967 seems to indicate that at least the majority of voters in Australia desired to see the general standards of the community, and the opportunities available to themselves, also extended to Aborigines.

As a general impression of the industry in 1968, one must conclude that overt incidents of violence had considerably decreased since the earlier study in 1948. Most employers tried to give the impression that they were favourably disposed towards their Aboriginal employees. However, there was still an overtone of malice in many of the coarse jokes which were engaged in at the Aborigines' expense. For example, one employer who was interviewed considered that the resident population on his property was getting beyond control, and that he would have 'to cull a few of the bucks'. ${ }^{3}$ Another made reference to the possibility of 'a gift of a surprise packet of flour' to overcome a similar problem."

As a white bookkeeper pointed out, comments of this nature were often made in such a way as to lead one to believe that there was little gap between the frame of mind and possible action.

The aura of brutality on the properties, however, went much further than general reference to past atrocities and neglect and idle threats. It affected the day-to-day reactions of individuals to their industrial environment. It was the feeling of Aborigines that management might resort to violence over issues which would be considered legitimate complaints amongst whites.

For example, one Aboriginal stockman tendered the information that when he was working in the stock camp the station owner simply threw the meat allocated to the Aboriginal employees onto the ashes of the fire, after having prepared his own meal in more conventional European style. As the employee obviously objected to the continuation of what might have been considered the traditional Aboriginal way of cooking meat and pointed out, with approval, the more meticulous preparation of the employer's meal of meat and vegetables, I asked him why he did not protest. His response was 'that the boys would be beaten up'.

But on the Aboriginal side there were still constant reminders of the humiliations that had been suffered by the people in the distant, and not so distant, past. Most groups visited had their burial grounds which might ${ }^{3}$ Literally translated as removing some of the undesirable beasts from the herd, but colloquially interpreted as meaning castration.

4 The presentation of bags of flour containing strychnine was an earlier method used by pastoralists to decrease Aboriginal numbers on northern cattle stations. See Mary Durack, Kings in Grass Castles, Constable, London, 1959, p. 58. 
be inspected after a degree of rapport had been established. Usually on such journeys it was not long before the local residents were offering information about the more spectacular demise of some of their forebears, many of whom had 'finished up' as the result of open neglect on the part of management or of more overt conflict.

A typical example of this attitude was recorded in the interview with a striking Aboriginal stockman. After asking him when he thought the strikers would return to the property he simply replied: 'Never. Too late. Lot of people die'.

A similar attitude was shown in an old pensioner's story about his visit to a distant bore during his younger days on the property, and his discovery of the bodies of two Aboriginal employees. His conclusion was that 'white fellas killem. You couldn't stop 'em'. He then rounded out his experience of violence on the property by indicating an area where 'they bin killem over there'.

Another reminder of the history of violence on the properties was contained in the eye witness accounts of older people, who recalled two European stockmen shooting three Aborigines in an endeavour to obtain the services of their womenfolk for sexual purposes.

From interviews with employees and, indeed, general discussion with employers, it was obvious that resort to violence on the part of management during periods of conflict had not been completely eliminated. Evidence of this was collected on tape. The methods of assault used included stockwhips, sticks, a bridle piece and fists.

A similar response was indicated by Aborigines in reply to questions as to why they did not make claims for higher pay: "because [the boss] would kick you'.

The aura of brutality which exists on cattle stations in the Northern Territory is not limited to physical aggression alone. This can only be considered as the end product of the overt display of attitudes which are based, generally, on the social inferiority of the members of the native work force. Evidence of this might be gleaned from the discussion elsewhere of the standard of food, and of accommodation, provided. However, it is equally evident in the whites' attitudes to sexual relations with female members of the native community. In this process the women were used, callously, as the vehicle for dalliance or, in a more calculating sense, as a method by which the management attempted to decrease white labour turnover.

Given the basic knowledge of personal and public hygiene amongst Aboriginal women, illiteracy and absence of prophylactic devices, a 
common sense conclusion would lead one to believe that the rate of both conception and venereal disease was high.

Unlike evidence relating to brutality through physical aggression there seemed to have been very little reduction in the incidence of sexual exploitation since the time of Berndt's study. As Lockwood has pointed out more recently, Aboriginal women remained 'fair game' for any white desirous of sexual adventure..$^{5}$ Further observation would suggest that the incidence of first sexual contact between Aboriginal females and Caucasian males has only risen slightly above the seven year old females mentioned by Berndt. ${ }^{6}$

Although it was not possible to establish clear causal connections between the low rate of birth and abortion practices, it should be noted that at several locations Europeans believed that Aboriginal women continued to practice infanticide. Further, it might be considered significant in this respect that the writer is unaware of any paternity suits which have been executed on Aborigines' behalf by the Welfare Branch of the Northern Territory.

Aborigines were, naturally, incensed by the attitudes of the European community to their womenfolk. They believed that the European community was responsible for exploiting them in this way. Further, that the management would arrange for the absence of Aboriginal males when it was desired to gain access to their womenfolk.

The brutal and frequently inhuman attitudes adopted towards Aborigines were also shown in the small appreciation of the ravages of illness, accident and disease amongst them that was accorded by management. Given the poor dietary and accommodation standards of Aborigines they were obviously subjected to conditions which could only be considered as oppressive in their impact. Although access to statistics on the nature of Aboriginal ill-health in the Northern Territory has been refused by the Department of Health, peripheral evidence referred to earlier suggested that it is of scandalous proportions. Commensurate with, and possibly in part the cause of, this record was the low level of priority accorded to complaints arising from Aboriginal ill-health. Some of the evidence surrounding this aspect of life on Northern Territory cattle stations has been presented elsewhere (pp. 100-2).

The impact of the pattern of ill-health, however, was of some importance in appraising the industrial environment of the native employees. Unfortunately, because of the refusal of the Welfare Branch to co-operate

${ }^{5}$ Lockwood, 'Goodbye to God's Best Country'.

'Berndt, 'A Northern Territory Problem', p. 8. 
in any way with the survey, it was not possible to investigate the nature of the workers' compensation program which was its responsibility.

Regardless of this fact there were many obvious cases of potential workers' compensation claims observed. Few of these seemed to have been processed in any way. The situation is best demonstrated through the words of an Aboriginal employee who had been seriously injured during the period of the survey. In telling the story he clearly delineates the dangers and responsibilities of the job he was called upon to carry out, and the property owner's response to his suffering. The employee involved was the same person who alleged that he had been paid 8 s. for two months work:

Early this year I had to break in a young horse. I had to teach him to cut the bullock out. When I started to cut out the first bullock the young horse did not know and I had to hit him under the belly with a strap, and he went over too quick. I had to let the iron go and jump off. They called out as he rolled over and I saw the horse coming over on me and I saw the front leg coming over and hit me right in the part of the neck. I had a Christian friend there and he had to pray to God because I Christian myself now-When I wake up someone say 'Hey, there's something wrong with your eye'. I had to push the eye back into the socket. One of the men bring the horses back and I had to lead the horses back into the camp-I had to take the saddle off myself - tie his leg up because he was a bad horse. I laid down for about an hour and cut a piece of leather and tie it around my neck (to put my arm in) and I had to cut a shirt to tie my neck up to keep it still. I had to saddle up the same horse and went back to the cattle camp. I had to put up with that. We cut out 800 bullocks that day. Two days later I asked the manager if he would let me go back to the station and he said 'No. I want this job done now as we have 1,300 bullocks to go through to Queensland'. We had 1,000 head at B. Bore and one boy said that [owner] at the camp. When I went out with the cattle I couldn't see. All my face covered with dust. I was driving a camp horse. I went over and said Good day, [Boss]. He said 'Good day [X], you're looking well.' 'I not feeling good today', I said. 'Why not?' he asked. 'I can't see anything wrong with you'. My eye was covered with blood. I said to him 'What about taking me to hospital?' He said 'If I do that you mightn't come back. When I go back to the station I will look after you. I'll get medicine because if you go to the hospital who'll ride your horse because it's a bad horse'.

He brought the medicine that day-some linament. A week later I had to get that linament and rub it over my shoulder as I could feel pain. When I was mustering I could feel something wrong. I pulled my shirt off and all my skin peeled off. It was red raw. I had to take my shirt off and ride miles back to camp without my shirt on. I got back to the camp and work in the dust. A week later I went back to the station and went blind.

The person involved later visited Sydney where the basic cause of his blindness was diagnosed and corrected after an operation. To the writer's knowledge no claim for workers' compensation has ever been made on his behalf. 
B y 1965 Europeans had been in close contact with Aborigines for some 200 years. For at least 100 of these years constant attempts had been made to formalise the Aborigines' relationships with employers so that increased advantages might be gained from the industrial contact. During seventy-five of those years administrative arrangements had been designed to assist Aborigines in their dealings with the agents of the broader European community. At first, policy was aimed at controlling 'the Aboriginal problem'; however, in later years, it has been to increase the value of Aborigines to the European economy, and eventually to assist them in becoming 'self sustaining units in our economic structure'. During that time a broad canvas of administrative law and practice was developed, ostensibly with these objectives in mind. However, as can be seen from the descriptive material in the foregoing study, at the end of the period it might fairly be said that the Aboriginal labourer had neither been elevated nor become a 'self sustaining unit'. The most obvious reason for this is that at no stage was the native employee rewarded for the economic value of his labour. Indeed, this situation continued in spite of the important role he was playing in the development of northern industry, and in defiance of the whole series of laws and ordinances established to protect him in this respect. It is a remarkable thing, that his economic value should be overlooked in a society so otherwise concerned with concepts of industrial justice and equity.

In many respects the Conciliation and Arbitration system, developed to be available to the community as a whole but applied to European purposes only, was designed to ensure the application of new and con- 
sistent standards of industrial equity. The supporters of the system have sought to replace the traditional role of economic conflict and industrial struggle with forensic logic. For this purpose they, too, built up a formidable series of checks and balances to ensure that neither worker nor employer gained undue advantage from the other in their efforts to advance their own economic well-being. The system, as such, was intended to be all-pervading. Under Section 51 (XXXV) of the Commonwealth Constitution, the Federal Government was empowered to make laws for the peace, order, and good government of the Commonwealth in respect to 'Conciliation and Arbitration for the prevention and settlement of industrial disputes extending beyond the limits of any one State'. This section of the Constitution was designed to fill the void where the State's powers were considered to be insufficient. By the Northern Territory (Administration) Act, 1910-1959, the Commonwealth's powers in relation to conciliation and arbitration were extended to the Northern Territory. ${ }^{1}$

\section{JUDGMENT BY CONSENSUS}

Aborigines were excluded from the jurisdiction of the Commonwealth Arbitration Court by default. At no time has there been a searching inquiry into either their legal position before the tribunal or the desirability of coverage or exclusion. In 1924, the Court curtly ruled out an application by the Northern Territory Workers' Union to limit the number of indigenes employed on cattle stations. ${ }^{2}$ The union changed its tactics in 1928 and asked that Aborigines be included in the Award. This request met with the same result as the earlier application, but with even less explanation. ${ }^{3}$

The same position applied in the States. With as little evidence and argument as in the Northern Territory, the Court ruled in 1932 that, as the federal award did not mention Aborigines and it was not possible for them to join the Australian Workers' Union, 'quite clearly [they were] excluded'. 5 The same level of concern was apparent in the 1944 judgment of the Court. In that case it determined that 'natives have, because of their

\footnotetext{
'See also Annual Report of the Northern Territory, 1965, p. 61.

20 C.A.R. 511-12.

26 C.A.R. 623.

4 The Constitution of the Australian Workers' Union still includes racial prescription. See generally, G.W. Ford, 'Work' in A.F. Davies and S. Encel (eds.) Australian Sociery: A Sociological Introduction, Cheshire, Meibourne, 1970, 2nd ed., pp. 84-145, especially pp. 104-7.

31 C.A.R. 715.
} 
traditions ... habits ... incapacity [and] disinclination to compete with' whites. It again excluded them from its jurisdiction. ${ }^{6}$

Similarly, the Commission was given the opportunity to consider the matter in 1948, but ruled that it did not have the power to cover Aborigines in the Cattle Station Industry (Northern Territory) Award. However, the interrclationship between justice for indigenous workers and administrative convenience has been demonstrated by Rowley in quoting the Commissioner's reasons for the refusal of the application:

I must refuse the union's application that the award should apply to Aboriginals. As the result of a conference last year between the Pastoral Associations and the Northern Territory Administration, agreement was reached concerning the terms of employment and the maintenance of Aboriginals living on stations. From a perusal of this agreement it is clear that if the union's application were granted it would interfere with the policy of the administration. Such an interference would not be justified as the Administration is much better equipped than a court of arbitration to attend to the welfare of the Aboriginals living and working on cattle stations.?

As Rowley points out, 'this denial, or refusal to use the power of wage fixation which the Commonwealth had, left the way open for fixing separate Aboriginal wages later, under the Wards' Employment Ordinance'. ${ }^{8}$

Although the ruling of Commissioner Portus in the 1948 case was questionable at law, ${ }^{9}$ and both the Welfare Branch and the responsible Union were aware of this fact for some years before the matter was called into question by an application to the Full Bench of the Commission for review, neither of these parties, nor the Federal Government showed sufficient concern for the conditions of Aborigines to protect their interests. ${ }^{10}$ The Commission took its prejudiced position, and the Union and the Welfare Branch their role of non-intervention, in full knowledge of the desperate conditions of the indigenous employees. The Welfare Branch's case was further compounded by the disastrous impact that its

53 C.A.R. 214.

'Quoted by C.D. Rowley, The Destruction of Aboriginal Society, vol. I of Aboriginal Policy and Practice, Australian National University Press, Canberra, 1970, p. 338.

${ }^{8}$ Ibid.

${ }^{8}$ Federated Seamen's Union of Australia v. Commonwealth Steamship Owners' Association, 19 C.A.R. 53, and in re Waterside Workers' Award, 7 October 1959, O.I.L.R., 31 October 1959.

${ }^{10}$ The Crown Solicitor for the Northern Territory rejected the Commissioner's ruling (Transcript of the Proceedings of the Select Committee on Social Welfare Legislation, Legislative Council of the Northern Territory, 1964, p. 163). In private discussions the Crown Sclicitor informed me that he had held this opinion for some years and had informed both the Union and the Welfare Branch, Darwin, 13 July 1965. 
traditional policies were having on the very existence of the rural communities. If the Berndt Report was either not available, or not sufficient, for their purposes, adequate evidence of the failure of policy existed in the departmental files on Darwin..1 It would seem that only public pressure would move either party. In 1963 the biennial Conference of the Australian Council of Trade Unions passed a resolution calling on all the parties concerned to redress the situation and bring Aborigines into the mainstream of industrial decision-making. ${ }^{12}$ By this time, as has been pointed out, Aborigines had been given the right to vote in the Commonwealth elections, and the specialist nature of the Welfare Ordinance had begun to crumble. The Director of Welfare, however, intended to continue to apply the Wards' Employment Ordinance to those who were wards for the purpose of the Welfare Ordinance 1953-63. ${ }^{13}$

In response to the A.C.T.U. resolution, which was passed in similar terms again in $1965,{ }^{14}$ and a certain degree of pressure from the Northern Territory Council for Aboriginal Rights (which worked closely with the officers of the Union deposed in 1952), ${ }^{15}$ the North Australian Workers Union made a successful application to the Commonwealth Conciliation and Arbitration Commission in 1965 to vary the Cattle Station Industry (Northern Territory) Award, by deleting references excluding Aborigines from its conditions. ${ }^{16}$

The hearing of the Union's claim began before the Full Bench of the Commission in July of that year, and during the following six months the Commission sat in Sydney, Melbourne, Darwin, and Alice Springs, and visited some thirty-six cattle stations, five government settlements, and one mission in the Northern Territory.

Although the Union admitted having very few Aboriginal members, and despite another application seeking leave to intervene in the interests of the broader body of Australian employees, ${ }^{17}$ the Commission conceded

11 Bill Jeffreys, 'Why Welfare is a Dirty Word to Aborigines', Australian, 28 October 1967. ${ }^{12}$ Australian Council of Trade Unions, Decisions of the Australian Congress of Trade Unions, Melbourne, 1963, p. 4.

${ }^{13}$ No. 46 of 1964, S. 4 (b).

14 Australian Council of Trade Unions, Decisions of the Australian Congress of Trade Unions, Sydney, 1965 , pp. 4, 5 .

${ }^{15}$ Tatz, Aboriginal Administration, pp. 210-19.

${ }^{16}$ Commonwealth Conciliation and Arbitration Commission, No. 830 of 1965, the transcript of evidence of which is hereafter referred to as 'Hearing'. The transcript relating to the Application for Listing, 19 February 1965, is referred to as 'Application'. The judgment of the Commission in the case is similarly marked.

${ }^{17}$ The Association of Architects, Engineers, Surveyors and Draughtsmen of Australia, Application, p. 2. 
it the right of appearing on the indigenes' behalf. This, together with the fact that no Aboriginal witnesses were called to give evidence, seemed to reflect the Commission's previous handling of Aboriginal interests. Precedent was treated in a similar way. Indeed, the advocate for the Union gave the question as much of his time as it had ever attracted from the Commission in the past. He simply assumed that 'until some argument [was] submitted to the contrary, it [was] clear that the Commission [had the] power'. ${ }^{18} \mathrm{He}$ was only slightly less circumspect in his consideration of the decision of $\mathrm{Mr}$ Commissioner Portus in 1949 not to include Aborigines in the Award:

I do not know, I confess, and I regarded it of no importance and not worth examining whether or not $\mathrm{Mr}$ Commissioner Portus was right or wrong. He was very dogmatic about it in the transcript of the proceedings. He ruled very promptly that he had no power to do certain things in relation to Aborigines, and that he said that he would not, so the argument ceased at that point. If anyone seeks to challenge that I will be prepared to submit argument, but until it is raised against me I do not propose to offer any discussion of it. ${ }^{19}$

\section{THE UNION CASE}

The question of jurisdiction, however, was clearly placed before the Commission in the application. The broad statement of claim by the Union embraced the following points:

1. That Aborigines were excluded from the award because the Conciliation Commisjoner formed the opinion that he did not have the power to fix rates for Aborigines.

2. The Commission [had] power to make an award on industrial matters for employees engaged in the industry to which the award applies.

3. The continued exclusion of Aborigines from the benefit of the award [was] wholly without justification and [was] contrary to the principles in accordance with which the Commission acts or ought to act.

4. The immediate application of the award [was] necessary and just. ${ }^{20}$

The Union case before the Commission was based primarily on tactical considerations. The advocate tried to contain the hearing within the confines of what he considered to be an 'orthodox arbitration case', ${ }^{21}$ extending an 'award proved by long experience to be appropriate to the industry', ${ }^{22}$ to employees who were mainly responsible for its continuity

${ }^{18}$ Hearing, p. 17.

${ }^{19}$ Application, p. 10.

${ }^{20}$ Ibid., p. 17.

${ }^{21}$ Ibid, p. 8.

${ }^{22}$ Hearing, p. 56. 
and economic well-being. The Union did not envisage a case occupying a very great length of time ... [as it] substantially depend[ed] on the adoption by the Commission of an attitude of mind in consonance with that of the better thinking community today'. ${ }^{23}$ More specifically, it objected to 'any attempt to devise some new scheme of industrial prescription allegedly suitable for Aborigines treated as a class' ${ }^{24}$ Aborigines, it claimed, were 'part of the Australian economy', and an 'overwhelming number' had become 'money conscious' in the process of integration into the economy, and had 'acquired the same standards' as other members of the community. ${ }^{25}$ If any differences existed between Aborigines and European workers, they were not caused by racial disparities, but primarily by 'the failure to solve the Aborigines' economic problem'. The Union believed, further, that it was this failure which doomed all attempts to elevate the Aboriginal community socially. 'They are part of the Australian economy in all things except that they are denied the full realisation of what would be their position, i.e. as employees . . an award of [the] Commission' ${ }^{26}$

The Union 'strongly [opposed] any form of machinery, any form of complicated prescription, which [was] based upon some assumption of the incapacities to work of the Aborigines'. ${ }^{27}$ Further, there were two problems closely related to the granting of Award wages to Aborigines which the Union felt should not concern the Commission. One was the Aborigines' pattern of consumption and the other was the impact that any decision of the Commission might have on the program of the Welfare Branch. 'This [was] not a case about consumption-what the pastoral employee ... does with his money ... it [was] a question of his income and control of that income.'28 For white people to prescribe what Aborigines should do with their income amounted to little less than impertinence, the Union claimed. ${ }^{29}$

The Union also believed that the Commission was faced with fairly strict limitations as to what factors it might take into evidence:

If the Commission [was] asked to make pronouncements and to make decisions ... [on] consequential matters, outside the industrial sphere ... [it] should [refuse] to do that ... It [was] assumed that the Legislative Council [would] act in a responsible way

\footnotetext{
${ }^{23}$ Application, p. 10.

24 Ibid., p. 8.

${ }^{25}$ Hearing, p. 39.

${ }^{26}$ Application, p. 8.

${ }^{27}$ Hearing, p. 52.

28 Ibid., p. 41.

${ }^{28}$ Application, p. 8.
} 
as a parliament of the Northern Territory and deal with those things which become necessary for it to deal with in the public interest ... the Commission [did not have] to undertake the solution of all of the problems [affecting] Aborigines ... It [did not] matter what policy [was] adopted [by the government] ... whatever was done, the economic foundation must be first solved. ${ }^{30}$

The Union was prepared to concede, however, that 'there [would] be consequences of an economic character to the employers' by the granting of Award wages to Aborigines and that it intended that 'there should be such consequences'. Indeed, 'the purpose of [the] application [was] to impose upon employers as employers the proper obligations which belong to employers when they are engaging employees, be they white or black, to perform a class of work prescribed in the award', to pay the worker the legal rate applicable to all employees for the duties performed.

[To deal] with the conditions of employment of Aborigines by a welfare process as a prelude of the prescription of standard Australian industrial conditions [was] a sort of hot-house way of dealing with [it] ... As long as the opportunity [was] given to the pastoralists to appeal to the welfare machinery... there [would] not be the acquisition of the necessary knowledge and technique [for Aborigines to compete on equal terms with Europeans] . . . there [was] only one way to deal with [the] matter $\ldots$ and that [was] to throw both [the Aborigines and the employers] into the water and let them learn to swim.

The Chief Justice, however, objected to the last statement:

it [struck him] that this [was] an application by the North Australian Workers' Union ... [and that it was not an application] by the Aborigines. [The Union said that] both parties ... should be thrown into the economic swimming pool and learn to swim that way. That is what the Union [said] . . but what about the Aborigines themselves? Do they want it that way or should [the Commission] not worry about that one way or the other? ?1 $^{\mathbf{3 1}}$

The case proceeded without the inquiry being answered.

\section{THE EMPLOYERS' CASE}

In opposition to the Union's presentation of what it considered a simple case, the employers were able to marshall a formidable collection of material which they hoped would dissuade the Commission from the case before it. With this purpose in mind, the employers presented the Commission with the views of anthropologists and similar experts, representatives of the Federal Government, missionaries, and pastoralists

${ }^{30}$ Hearing, pp. 48, 52 .

${ }^{31}$ Ibid., p. 54. 
which, they claimed, proved that the bulk of the Aborigines in northern Australia were not able to work 'at the level of a member of the white community'. ${ }^{32}$

The employers' advocate concentrated on two main themes. First, he presented a kaleidoscope of views of eminent persons concerning the problems of racial and cultural contact as they affected the clash between European and Aboriginal societies. He then examined verbal evidence, given mainly by employers of Aboriginal labour in the pastoral industry. The employers' objective of disparaging Aboriginal labour in the face of widespread sympathy for the indigenes was made much easier by virtual withdrawal of the Union from tendering evidence in support of its claims. Representatives of the Commonwealth Government, although reservedly supporting the Union's claims, also found that they had little room to manoeuvre, as the employers' counsel reminded them of the edicts of half a century of policy based on the assumption that Aborigines were unable to compete in society on equal terms with Europeans because of racial impediments. ${ }^{33}$ Employers' counsel aptly demonstrated that as late as 1964 the Federal Government was still pursuing a labour policy in relation to Aborigines founded on the belief that they were psychologically unfit to take part in the normal processes of the labour market. They then set out to leave the Commission in a position where it would "have all the material [that they could] find that [would] enable it to see how precisely those who administered policy ... [understood] the differences in working capacity of different [groups] of workers' ${ }^{34}$

The employers considered that there were four propositions basic to their case. They expressed them in the following way:

1. ... that a place should be kept for the Aborigines in the pastoral industry for the period during which they [would] gradually and in increasing numbers [become] culturally adjusted to the level of efficiency and the type of demands that industry normally makes of those for whom award wages are prescribed.

2. ... they should have the right, with educational assistance, to make the adjustment, so that in the years to come ... considerable numbers of them would be fully and permanently integrated into the pastoral industry on a genuinely equal basis.

3. ... they should not be put in peril of separation from that industry by the operation of economic forces before they ... had time to make that adjustment.

32 Johns, 'Beyond Kalumburu'.

${ }^{83}$ See Long, 'Administration of Part Aboriginals'. One Chief Protector was concerned with 'the incalculable future menace to purity of race'. See also Hearing, pp. 182-3, where the Welfare Branch's submissions to the Select Committee on the Social Welfare Ordinance of the Northern Territory Legislative Council is considered.

${ }^{34}$ Hearing, p. 150. 
4. ... they should be remunerated on a fair but not an artificial standard for what they ... do, because economically speaking, proper and realistic evaluation of their work during the transitional period and acculturation will best protect their future in the pastoral industry. ${ }^{35}$

\section{THE COMMONWEALTH'S SUBMISSIONS}

The Commonwealth intervened in the case on two grounds: first, as an employer of Aboriginal labour in the cattle industry and elsewhere, and second, to 'assist the Commission in its difficult task by providing information in full and as accurate as possible about the issues that [arose] in [the] application'. ${ }^{36}$ In particular, they took responsibility for providing an exhibit book covering a number of sources of information of interest to the Commission. In the main this covered historical or factual material, and its impact was of either marginal or statistical interest to the Commission. One aspect of the submission drew considerable interest from the Commission. This related to the current rates and costs of maintaining Aboriginal employees on the stations. ${ }^{37}$

Exhibit E (III) (see Table 10) showed an equivalence between the costs of maintaining an Aboriginal employee, his wife, and child, and the then current basic rate for a European employee under the Award wage ( $f, 11$ 12s. 6d. for a European stockman compared with $f_{113}$ 3s. 3d. for an Aboriginal stockman, his wife, and one child). The qualifications of the submission read:

In the case of the Ordinance, the cash value ascribed to payments in kind is given on the basis that all the detailed requirements prescribed are applied; the costing has been given by the Welfare Branch of the Northern Territory Administration having regard to its inspection activity in the field and its experience in applying the same rationing and clothing scales on Government settlements. ${ }^{38}$

Further to this, it was claimed, the Commonwealth view had been well presented in the statements of objective of the assimilation program mentioned earlier in this study. 'The field of labour relations [was] the last major area requiring attention.' 39 Accordingly, it believed that the conditions of the Award should be applied to Aborigines, but hoped that they would be introduced over a period of time and after conciliation

35 Ibid., p. 82.

${ }^{36}$ Ibid., p. 132.

s? Ibid., pp. 121 et seg.

3s Ibid., Explanation 2, attached to Item E of the Exhibit Book.

${ }^{39}$ Ibid., p. 133. 


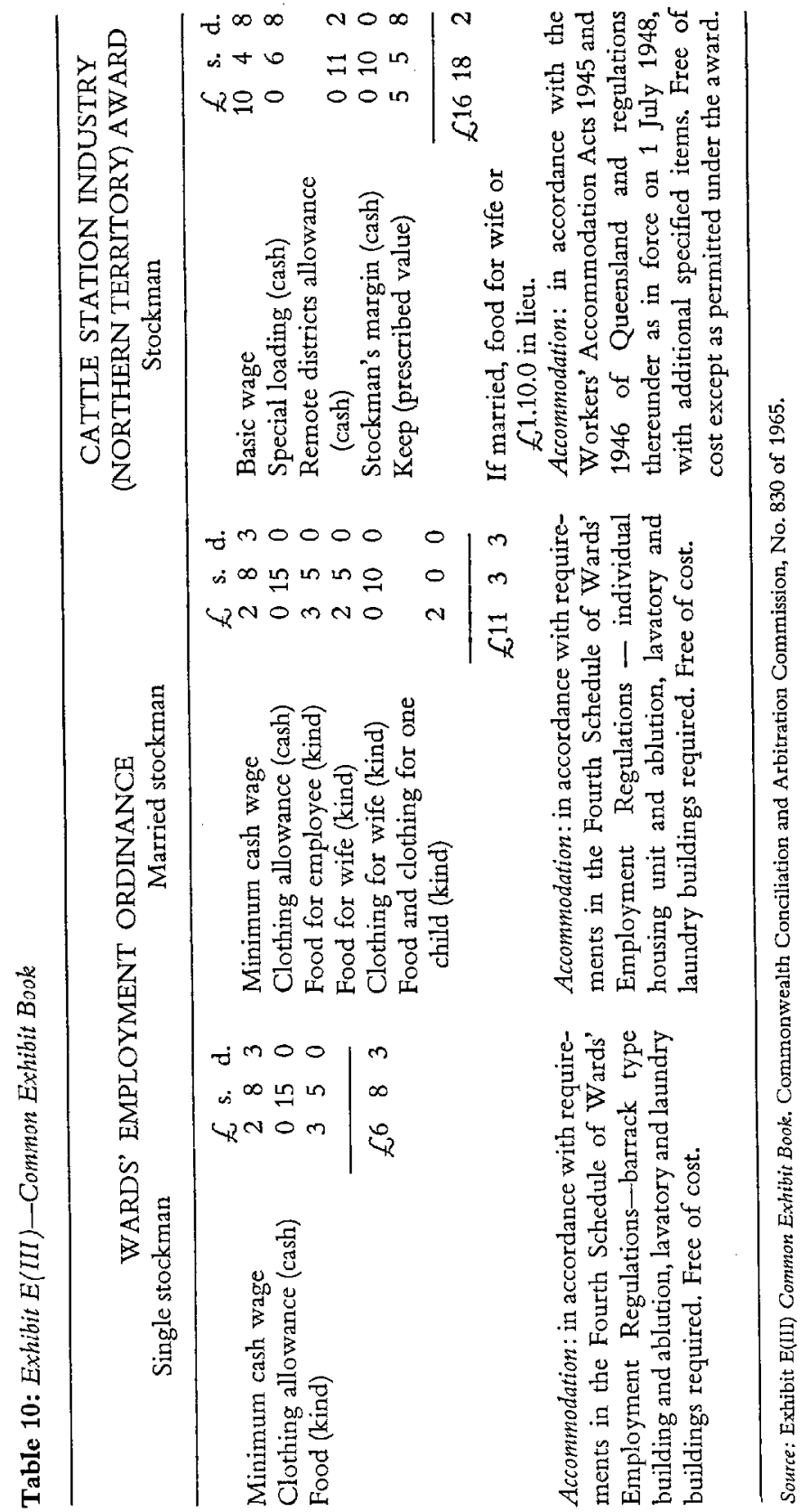


between the various parties had been attempted. ${ }^{40}$ The program of transitionary appraisal of the level of skill of Aborigines, put forward by the Director of Welfare as Commonwealth policy in 1964, was specifically rejected. ${ }^{41}$

\section{ANTHROPOLOGICAL EVIDENCE}

The question of cultural differences between Aborigines and European workers was considered by the Commission to be of considerable importance. The Commission agreed with the proposition put to it, 'that these Aborigines are unable to work as well as whites because of cultural and tribal factors' ${ }^{42}$ At other times this consideration was associated with cultural differences and 'lack of education', or alternatively, 'the lack of education ... particularly when it is linked with tribal attitudes towards work'. ${ }^{43}$

Whichever way it was put, the tribal association of the resident groups of Aborigines on Northern Territory cattle stations was the key issue in the employers' submissions. The Commission succumbed to 'the overwhelming evidence given to [it by the employers' advocates that] tribal influences are still quite active in Aborigines on cattle stations'. It was the acceptance of this evidence that encouraged the Commission to conclude that 'the great majority were unable to work in a way which employers' would expect of white employees. ${ }^{44}$

The anthropological arguments of the employers' submissions rested on flimsy grounds. From the very beginning of the Commission's judgment it was obvious that it allowed errors of fact to condition its opinion. One of these related to the situation of part-A boriginal employees. Their conclusion that "virtually all those of mixed blood are treated as white on the stations', ${ }^{45}$ could be refuted by even the most casual observer. It was certainly not borne out by the 1965-7 survey. There were, apparently, no grounds for their opinions in this regard. Again, without any positive evidence being produced as to the cultural organisation of Aboriginal station employees, they deduced 'many' to be 'semi-tribalised' and stated that 'Aborigines live on the stations in their old tribal

${ }^{40}$ Ibid, p. 135.

${ }^{41}$ Ibid., p. 182.

\$2 Judgment, p. 11.

${ }^{43}$ Ibid., pp. 22, 21.

${ }^{44}$ Ibid., Pp. 18, 20.

45 Ibid., p. 1. 
grounds' ${ }^{46}$ None of these assertions was supported either by authoritative evidence or by the proferred writings of experts in the field in any definitive way. Although it had little effect on the outcome of the 1965 Arbitration Court hearing, the misconception of the actual situation on Northern Territory pastoral stations was readily used by the Commission to give credence to the employers' situation. As Stanner has put it:

I was surprised to discover ... just how conservative, capitalistic and favourable to long continued paternalism the writings [of anthropologists] seemed to be under counsel's artful presentation. One could almost draw the conclusion that the writers had known in advance, in one case by as much as twenty years, what the pastoralists' case would be, and had decided to be helpful. 47

Stanner's criticism of the anthropological evidence is worthy of further consideration, and must surely strike at the very basis of the Commission's judicial procedures in cases where evidence is led from one side only. It must also reflect on the ability of legal practitioners to appraise such material:

[The anthropological evidence] ... at second hand gave an allusive authority to points central to the pastoralists' case; e.g. the very long period of time needed for the success of assimilation, the Aborigines' difficulty with our ideas of time, space, causation, number and so on-in short, with the categories of European thought and culture; their inability or unwillingness to accept work discipline, or to do any complicated task efficiently without supervision; and other things of the kind ... It would not be difficult to show that a certain amount of what I call innocent misinformation was put in evidence (e.g. that station Aborigines are living on their tribal land) and that some major propositions (e.g. 'in tribal society the idea of cause and effect was not known') were either plainly wrong or illegitimately wrangled into a causal connection with defects of native performance. ${ }^{48}$

Whilst the Commission was not prepared to attach 'much weight' to evidence relating to Aborigines engaged in other industries, ${ }^{49}$ it was prepared to base its judgment on material collected, in the main, from the experience of anthropologists and ethno-psychiatrists working outside the cattle industry. ${ }^{50}$ Indeed, it was even prepared to accept 'anthropological' information from persons who had no anthropological training at all and whose education had not progressed beyond lower secondary school standards. ${ }^{51}$

${ }^{48}$ Ibid.

47 W.E.H. Stanner, 'Industrial Justice in the Never Never', Australian Quarterly, vol. 39, No. 1, 1967, p. 47.

48 Ibid., pp. 47-8.

${ }^{49}$ Judgment, p. 21.

50 Ibid., p. 16.

51 Ibid., p. 17. 
The Commission claimed to have based part of its decision on evidence of witnesses called by the employers' advocates as men of experience in the industry who were used to handling Aboriginal labour. As many of the witnesses called had also been interviewed privately in 1965 before the Commission hearing had got under way, the conflict between the evidence they presented to the Commission and their earlier opinions calls for some comment.

Berndt had contact with a similar group of employers in 1946 and found them less than honest, especially when dealing with official bodies or on matters designed for the public record. ${ }^{52}$ In addition to the attitude of the more extreme, who were not even concerned about the possibility of the extermination of the native people, ${ }^{53}$ most were prepared to exploit Aboriginal ignorance and illiteracy to their own advantage. In addition to the material obtained during the 1965 survey this position is upheld in the work of Berndt, Rose, and Lockwood. Even the Welfare Branch felt obliged to comment on the employers' short-sighted policies in relation to the provision of adequate living standards and their unwillingness to co-operate with the Branch in this regard. ${ }^{54}$ Indeed, during the year of the hearing, the Welfare Branch found that it 'was still undeniably evident that many pastoral property managements saw no human or long term economic reason for improving employment conditions', ${ }^{55}$ and that virtually none of the properties met the conditions of the law in relation to accommodation. ${ }^{56}$ Despite this, the Commission was impressed by the expressed desire of many employers to help their Aboriginal employees and by the warmth of the feeling which they had for them'. ${ }^{57}$

The veracity of the employers' witnesses before the Commission might be judged by the further fact that few of the employers tendering evidence were sympathetically disposed to Aboriginal labour or appreciated the unique skills they were able to apply. Not only was this in conflict with the findings of the 1965 survcy: it also seemed to contradict the evidence accepted by the Commission itself. Following a visit to one nothern

${ }^{52}$ Berndt, 'A Northern Territory Problem', p. 56; Rose, Wind of Change, pp. 66, 69; Lockwood, 'Goodbye to God's Best Country'.

53 Berndt, 'A Northern Territory Problem', p. 66.

54 Anrual Report of the Welfare Branch, 1959-60, p. 21.

55 Ibid., 1965, p. 84.

${ }^{56}$ The Age, Melbourne, 19 October 1965.

${ }^{57}$ Judgment, p. 26. 
property, the two parties to the hearing agreed on a description of work site relationships to be included in the transcript of evidence:

In the mustering yard there were between 300 and 400 animals and the stock camp team was working on the younger animals which had not been branded. This work comprised the branding of the animals, the dehorning where necessary, earmarking, castrating the bulls and an injection in each case for pleuropneumonia. In order to do these tasks two of the stockmen mounted on heavy horses roped the animals to be dealt with. In his turn each mounted stockman hauled the animal to the bronco panel in most cases against the wishes of the animal. When the animal came to the bronco panel the remaining stockmen secured it with ropes by at least one leg and sometimes two legs. The animal was then thrown to the ground where it was held in a prostrate position, one stockman holding the head with his foot, another straining on the back legs to hold them apart, this being done by one leg being pulled by the arms and the other being forced wide with the feet. This exposed the belly of the animal and also positioned it for branding.

One of the stockmen then innoculated the animal in the tail. Another brought the branding irons from the fire and did the branding, another did the earmarking and another the dehorning. In the case of the bulls another member of the team did the castrating. At this stage the animal was released and it joined the herd in the yard.

From the time of the animal being dragged to the bronco panel to the completion of the operation not more than a minute or two elapsed. Each member of the team had his job to do and immediately the animal was thrown each moved in to commence his work...

The team performing this work comprised both white men and Aborigines ... there were two youngsters from the Aboriginal camp present ... and they were assisting in ... some of the smaller operations, such as using the injection syringe on occasions and carrying the branding irons backwards and forwards to the fire and keeping the fire burning.

Throughout the work at the bronco panel the air was full of dust and there was also some smoke from the branding iron fire. The work here proceeded systematically and no orders appeared to be necessary ... It was also noted that there was a change of duties from time to time, but whether this was a complete exchange was not apparent. ${ }^{58}$

Before the Commission the employers' denigration of Aboriginal labour was virtually unanimous. However, the evidence presented conflicts not only with the 1965 survey results, but also with the opinions of the 1964 Select Committee of the Legislative Council of the Northern Territory inquiring into the operation of the Social Welfare Ordinance, ${ }^{59}$ the survey on the contribution of Aboriginal labour during World War $I I,{ }^{60}$ the views of authoritative reseatch workers in the field, ${ }^{61}$ of ${ }^{58}$ Hearing, pp. 1058-9.

${ }^{59}$ Northern Territory of Australia, Report of Select Committee on Social Welfare Legislation, Government Printer, Darwin, 1964, p. 7.

${ }^{60}$ F.R. Morris, 'The War Effort of Northern Territory Aborigines', Australian Territories, vol. 5-1, 1965, pp. 2-10.

${ }^{61}$ Kelly, Report on the Beef Cattle Industry, pp. 171-3; Struggle for the North, pp. 120-50. 
leaders of the pastoral industry, ${ }^{\mathbf{6}}$ and of the majority of reputable writers on the subject.

The general structure and presentation of the case, amounting to a virtual filibuster, served the pastoral interests well, as the Centralian Pastoralists' Association, one of the employer respondents, pointed out:

had [the case] not been fought at the time, the basic wage would have been instituted in April 1965, and all native labour would have been eligible. On a conservative estimate from April 1965 to November 1966 the saving per stockman in award wages [was] $\$ 1600.63$

But the interests of impartiality and justice emerged considerably damaged. The benefit to the Northern Territory pastoral industry, based on the calculations of one of its representative bodies, amounted to a sum in excess of $\$ 2,000,000$ in the short run, and probably as much as $\$ 6,000,000$ up to introduction of Award conditions in December 1968. Rarcly have the Commission's procedures been so patently used for the short run advantages of one of the parties. ${ }^{64}$ Given the prejudiced position of Aborigines in the Northern Territory cattle industry it would be impossible for them to institute contempt of court proceedings. As well, based on past experience, neither the Welfare Branch nor the union might be expected to protect Aboriginal interests in this way.

\section{THE DECISION}

Generally speaking [they accepted] the uncontradicted evidence given by the pastoralists to the work ability of the Aborigines, supported as it was by what [they] saw [themselves] and the anthropological and other material. ${ }^{65}$

The judgment of the Commission stated that its usual procedures had been applied'. ${ }^{66}$ It noted, however, that although the Union had the right to call witnesses to refute the employers' evidence as to the work value of Aborigines, it had failed to do so. In its place the Commission

62 Sir William Gunn, Australian Financial Review, 15 February 1968; Murray, 'Station Management', p. 218.

${ }^{63}$ Circular of the Centralian Pastoralists' Association on private file, undated, but probably November 1966.

64 A simple arithmetic extension of what the pastoralists claimed to have saved on the wages of each Aboriginal worker, multiplied by the number of workers in the industry and the periods of delay in introducing Award conditions. The savings were even greater since the Award, which was scheduled to apply from December 1968, had not been reviewed since 1956 and was considerably out of keeping with other awards and rates of pay for whites in the industry.

${ }^{65}$ Judgment, p. 17.

${ }^{60}$ Ibid., p. 10. 


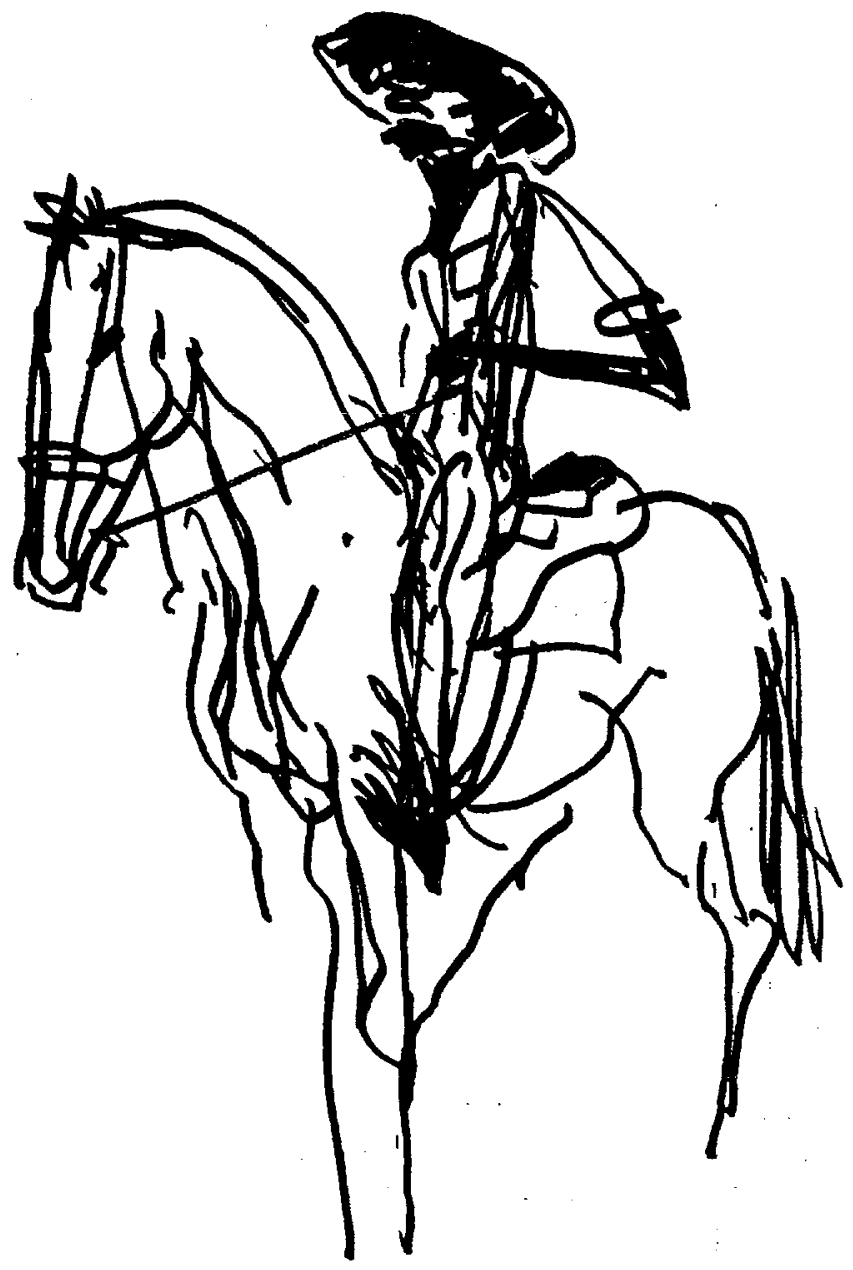

was presented with the experience of selected people who had gained knowledge of Aborigines through many years of contact. As might well have been expected in the circumstances, the witnesses and material selected by counsel were those most favourable to their position. It is significant, in this respect, that neither of the two existing anthropological studies of station communities was tabled for their consideration. ${ }^{67}$ It is of further interest that none of the academic experts, whose material

${ }^{67}$ Berndt, 'A Northern Territory Problem', and Rose, Wind of Change. 
was freely drawn upon, was called. Accordingly, the interpretation and application of this work to the problems before the Commission were left to persons untrained and unskilled in the relevant frelds. Fortunately for both the pastoralists and the Welfare Branch (if the information relating to costs in the 1965 survey is accepted) the small amount of evidence tendered which was subject to arithmetic appraisal was not scrutinised by the Commission.

The Commission stated, however, that, within the confines of its jurisdiction and the standards of industrial justice which had been developed by the court, the employers' defence amounted to a request to include some 80 per cent of the Aboriginal workers on Northern Territory cattle stations under a 'slow worker' clause, ${ }^{68}$ and thus subject them to restricted wage rates. The Commission was being asked to deviate from its normally accepted standards of applying the basic wage to all adult male employees-or not to award Aborigines

that wage, or part of a wage, which is just and reasonable for an adult male, without regard to any circumstances pertaining to the work upon which, or the industry in which, he is employed. ${ }^{69}$

This it refused to do, and decreed that by 1 December 1968 all male Aboriginal employees on cattle stations in the Northern Territory were to become subject to the awards and determinations of the Commission. In just six lines of its decision two hundred years of prejudice and discrimination in industrial law was removed.

68 See Section 48 of Commonwealth Conciliation and Arbitration Act, 1904-1964.

${ }^{69}$ Ibid., S. 33, Judgment, p. 8. 
APPENDIX I

INTERVIEW GUIDE

Selected Cattle Stations, Northern Territory, May-June 1965

A. General

1. Name of station

2. Pastoral district

3. Nearest town

4. Ownership classification

5. How managed

6. Other properties owned

7. Size of property

8. Classification of 'country'

\section{B. Numbers Employed and Wages Paid}

1. In current year, how many whites on the station? Trend in previous years?

2. How many whites actually employed? Trend in previous years?

3. In current year, how many Aborigines employed? In past years?

4. How many employed Aborigines lived on the station all year?

5. In current year, categories of white workers?

6. In current year, weekly wage rates for white employees?

7. Categories of Aboriginal workers?

8. In current year, weekly wage rates for Aborigines? 


\section{Labour Suttability}

1. In the past five years, have you tended to employ more whites?

fewer? Why?

the same number?

2. Can you get sufficient suitable white labour?

3. Sufficient suitable Aboriginal labour?

4. If you could get sufficient suitable white labour, would you replace your Aboriginal labour

$$
\begin{aligned}
& \text { wholly? } \\
& \text { partially? } \\
& \text { not at all? }
\end{aligned}
$$

5. In your opinion, are Aborigines more valuable and productive workers than whites?

less valuable and productive?

the same?

6. If you feel that Aborigines fall short of the mark, can you say why and in what respects?

7. If you feel Aborigines superior in value and productivity, can you say why and in what respects?

8. If Aborigines are not up to the mark, what do you think can be done about it?

\section{Aboriginal Wage Future}

1. Are you in favour of keeping Aboriginal wages and rations as they are at present?

Why?

2. Are you in favour of Award wages for them? Why?

3. Are you in favour of a graduated system, starting midway between the present and Award wages?

Why?

4. If Aborigines were to get Award wages this year, would you employ the same number, more or less?

5. If you reduced numbers, would you keep able-bodied males and females on the station throughout the year, or would you introduce a migrant, seasonal labour system?

6. How many of your present Aboriginal workers do you consider worth an Award wage? 
7. In the event of Award wages, will you try to replace Aboriginal labour with white labour wholly? partially?

8. If they get 'midway' wages this year, will you employ the same number more?

less?

9. If you reduce Aboriginal numbers, what do you think should happen to the rest of them?

10. Do you think Aborigines could ever successfully run small cattle stations on thcir own?

If not, why not?

\section{Dependants}

1. In the current year, how many Aboriginal dependants are there on your station?

2. What ages and sexes?

3. What rations do you give Aboriginal workers?

4. What rations do you give dependants?

5. Can you give some idea of the cost to you of maintaining workers?

6. Cost of maintaining dependants?

7. Do you get any government assistance in maintaining Aborigines? If so, in what ways

for workers?

for dependants?

8. Do you think that wages plus rations for Aborigines is more suitable for them than wages only? If so, why?

\section{F. Social Service Benefts}

1. Are you in favour of continuing the present system of payment of social service benefits to Aborigines?

2. If you are not in favour, would you be in favour of full payment to them? half payment? some other scheme?

3. How do you apportion the moneys you receive at present, that is, what do you give in pocket money?

spend on feeding?

spend on housing? 


\section{G. Canteens or Stores}

1. Do you run a store or canteen?

2. In your experience, what do Aborigines do with their wages:

save most?

save some?

save nothing?

spend most in the store?

spend some?

spend none?

\section{H. Sursidies}

1. Do you favour government subsidies based on the number of Aboriginal workers and dependants:
for wages?
rations?
housing?
health?
education?

\section{Housing}

1. Do you provide housing for whites?

For Aborigines?

How many?

2. Do you get any government assistance for Aboriginal housing? To what extent?

3. What has been the cost to you of Aboriginal housing?

4. How many housing units for Aborigines are temporary? Permanent?

\section{J. Health}

1. Are there any particular health problems on your station?

2. Any special problems relating to Aborigines?

3. Are the health services to your station adequate? If not, what suggestions can you make for their improvement? 


\section{K. Education}

1. What are the educational arrangements on your station

for whites?

for Aborigines?

2. Who pays for these arrangements?

3. Do you think government subsidised schools should be set up on your station?

4. If a school were erected on your station, would you favour mixed schooling?

\section{LIQUOR}

1. Would you be prepared to allow Aborigines to drink on your station definitely not? Why?

freely?

at certain times and places?

only certain types of liquor?

\section{Trade Unionism}

1. Are your white workers trade union members?

2. What are your views on Aborigines joining trade unions? 


\section{APPENDIX II}

MAIL SURVEY

\begin{tabular}{|c|c|c|c|c|}
\hline \multirow[b]{2}{*}{ RESIDENT WHITE POPULATION } & $\begin{array}{l}\text { Pro } \\
\text { Adult } \\
\text { Female }\end{array}$ & $\begin{array}{l}\text { ty } \\
\text { Aduit } \\
\text { Male }\end{array}$ & Children & $\begin{array}{l}\text { Date } \\
\text { Total }\end{array}$ \\
\hline & & & & \\
\hline $\begin{array}{l}\text { RESIDENT PART-COLOURED } \\
\text { POPULATION }\end{array}$ & & & & \\
\hline $\begin{array}{l}\text { RESIDENT FULL-BLOOD } \\
\text { ABORIGINES POPULATION }\end{array}$ & & & & \\
\hline
\end{tabular}


EMPLOYED

WHITE

PART-COLOURED

\begin{tabular}{|c|c|c|c|c|c|}
\hline FEMALE & NUMBER & $\begin{array}{l}\text { RATE PER } \\
\text { WEEK }\end{array}$ & FEMALE & NUMBER & $\begin{array}{l}\text { RATE PER } \\
\text { WEEK }\end{array}$ \\
\hline Cook & & & Cook & & \\
\hline Housekeeper & & & Housekeeper & & \\
\hline Domestic & & & Domestic & & \\
\hline \multicolumn{3}{|l|}{ Teacher } & \multirow{2}{*}{ Other (state which) } & & \\
\hline \multicolumn{5}{|c|}{ 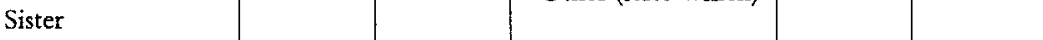 } & \\
\hline \multicolumn{6}{|l|}{ Other (state which) } \\
\hline TOTAL: & & & TOTAL: & & \\
\hline MALE & & & MALE & & \\
\hline \multicolumn{3}{|l|}{ Manager } & \multirow{2}{*}{ Head stockman } & & \\
\hline \multicolumn{5}{|l|}{ Bookkeeper } & \\
\hline Storekeeper & & & Leading hand & & \\
\hline Garage mechanic & & & Stockman & & \\
\hline Bore mechanic & & & General hand & & \\
\hline Plant operator & & & Driver & & \\
\hline Carpenter & & & Mechanic & & \\
\hline Handyman & & & Mechanic's offsider & & \\
\hline Cook & & & Fencer & & \\
\hline Saddler & & & Yard builder & & \\
\hline Head stockman & & & Other (state which) & & \\
\hline \multicolumn{6}{|l|}{ Stockman } \\
\hline \multicolumn{6}{|l|}{ Jackeroo } \\
\hline \multicolumn{6}{|l|}{ Horse-breaker } \\
\hline \multicolumn{6}{|l|}{ General hand } \\
\hline \multicolumn{6}{|l|}{ Other (state which) } \\
\hline TOTAL: & & & TOTAL: & & \\
\hline
\end{tabular}


FULL-BLOOD ABORIGINES

\begin{tabular}{|c|c|c|c|c|c|}
\hline & & RATE PER & & & RATE PER \\
\hline MALE & NUMBER & WEEK & FEMALE & NUMBER & WEEK \\
\hline Head stockman & & & Cook & & \\
\hline Leading hand & & & Housekeeper & & \\
\hline Stockman & & & Domestic & & \\
\hline Cowboy & & & Garden worker & & \\
\hline Mechanic's offsider & & & Other (state which) & & \\
\hline Driver & & & & & \\
\hline Pumper & & & & & \\
\hline Fencer & & & & & \\
\hline General hand & & & & & \\
\hline Gardener & & & & & \\
\hline Other (state which) & & & & & \\
\hline TOTAL: & & & TOTAL: & & \\
\hline
\end{tabular}

WHITE

NON-EMPLOYED

PART-COLOURED

\begin{tabular}{l|l}
\hline Pensioners & Pensioners \\
\hline School age children & School age children \\
\hline Preschool age children & Preschool age children \\
\hline
\end{tabular}

\section{ABORIGINES}

\section{Adult male}

Adult female

Pensioners
School age children

Preschool age children

Child Endowment is received for.......... (number of) Children.

In the event of full Award wages being granted to Aborigines the station would probably retain the following workers:

Male.............................

Female..........................

and allow-not allow (strike out which) their relatives to reside on the station. 


\section{REFERENCES}

BOOKS

Aвbotт, C.L.A. Australia's Frontier Province (The Northern Territory), Angus and Robertson, Sydney, 1950.

Adorno, T.W., Frenkel-Brunswik, Else, Levinson, Daniel J., and NevitT, Sanford, R. The Authoritarian Personality, Harper, New York, 1950.

Alien, H.C. Bush and Backwoods: $A$ Comparison of the Frontier in Australia and the United States, Michigan University Press, East Lansing, 1959.

Banton, Michael. Race Relationts, Social Science Paperbacks, London, 1967.

Barker, R.M. Droving Days, Pittman, Melbourne, 1966.

Barton, R. Institutional Neurosis, John Wright, Bristol, 1st ed., 1966.

Berry, Brewton. Race and Ethnic Relations, Houghton Mifflin, Boston, 1958.

Docker, E.G. Simply Human Beings, Jacaranda Press, Brisbane, 1964.

Doyt., B.W. The Etiquette of Race Relations in the South, Chicago University Press, Chicago, 1937.

Duguid, Charles. No Dying Race, Rigby, Adelaide, 1963.

Duncan, Ross. The Northern Territory Pastoral Industry: 1863-1910, Melbourne University Press, Melbourne, 1967.

Durack, Mary. Kings in Grass Castles, Constable, London, 1959.

Elkin, A.P. The Australian Aborigines: How to Understand Them, Angus and Robertson, Sydney, 1938, 1954.

Encel, S. Equality and Authority: a Study of Class, Status and Power in Australia, Tavistock, London, 1970.

Finlayson, H.H. The Red Centre, Angus and Robertson, Sydney, 1952.

Goffman, Erving. Asylums: Essays on the Social Situation of Mental Patients and Other Inmates, Anchor Books, New York, 1961.

Hardy, Frank. The Unlucky Australians, Nelson, Melbourne, 1968.

Hartz, Louis. The Founding of New Societies, Harcourt Brace, New York, 1964.

Hasluck, Paul. Black Australians, Melbourne University Press, Melbourne, 2nd ed, 1970.

Hassell, K. The Relations Between the Settlers and Aborigines in South Australia, 1836-1860, Library Board of South Australia, Adelaide, 1966. 
Hunter, Guy (ed.). Industrialisation and Race Relations, Oxford University Press, London, 1965.

- The New Societies of Tropical Africa: A Selective Study, Oxford University Press, London, 1962.

KeLlY, J.H. Struggle for the North, Australasian Book Society, Sydney, 1966.

-. Beef in Northern Australia, Australian National University Press, Canberra, 1971.

Leighton, Alexander H. The Governing of Men: General Principles and Recommendations Based on Experience at a Japanese Relocation Canp, Princeton Press, Princeton, 1945.

Levi-Strauss, Claude. The Savage Mind, Weidenfeld and Nicolson, London, 1962. Malnnowski, Bronislaw. Argonauts of the Western Pacific, Routledge, London, 1922. - The Dynamics of Culture Change, Yale University Press, New Haven, 1945.

Mnis, C.P. Nolan and Cohen's Federal Industrial Laws, Butterworths, Sydney, 3rd ed, 1963.

Moorehead, Alan. The Fatal Impact, Penguin Books, Harmondsworth, 1968.

O'Loghten, F. and Johnston, F.H. (eds.), Cattle Country, Johnston Publishing, Sydney, 1960.

Price, A. Grenfell. White Settlers and Native Peoples: a Historical Study of Racial Contacts between Whites and Aboriginal Peoples in the United States, Canada, Australia and New Zealand, Georgian House, Melbourne, 1949.

Rose, Frederick, G.G. The Wind of Change in Central Australia, Akademie-Verlag, Berlin, 1965.

Rowley, C.D. The Destruction of Aboriginal Society, vol. 1 of Aboriginal Policy and Practice, Australian National University Press, Canberra, 1970.

SeArcy, A. In Australian Tropics, Kegan Paul Trench Trubner, London, 1907.

Sharp, Ian G. and Tatz, C.M. (eds.). Aborigines in the Economy, Jacaranda Press, Melbourne, 1966.

Stevens, Frank (ed.). Racism: The Australian Experience, vol. I, Prejudice and Xenophobia, vol. II, Black versus White, vol. III, Colonialism, Australia and New Zealand Book Co., Sydney, 1971.

Van den Berghe, Pierre L. Race and Racism: A Comparative Perspective, John Wiley, New York, 1967.

MONOGRAPHS

Aborignnes Protection Soctety. England and Her Colonies. Considered in Relation to the Aborigines With A Proposal for Affording Then Medical Relief, Aborigines Protection Society, London, c. 1841.

ANDrews, Shirley. Social Service Benefits Still Denied to Aborigines, Unitarian Church, Melbourne, 1962 [?].

Austrailan Council of Trade Unions. Decisions of the Australian Congress of Trade Unions, Australian Council of Trade Unions, Melbourne, 1963, 1965.

Counctl for Aboriginal Righrs. The Struggle for Dignity, Council for Aboriginal Rights, Melbourne, 1962.

D'Abrs, Peter. The Vestey Story, Australian Meat Industries Employees Union, Melbourne, 1970 [?]. 
Federal Council for Advancement of Aborigines. 'Details of Discrimination in Payment of Social Service Benefits to Aborigines', Federal Council for the Advancement of Aborigines and Torres Strait Islanders, Sydney, 1965. Mimeo.

Gribsle, J.B. Dark Deeds in a Sunny Land or Blacks and Whites in North West Australia, Sterling Bros., Perth, 1886.

Hasluck, Paul. Native Welfare in Australia: Speeches and Addresses by the Hon. Paul Hasluck, M.P., Minister for Territories, Paterson Brokensha, Perth, 1953.

Jones, F. Lancaster. A Demographic Survey of the Aboriginal Population of the Northern Territory, with special reference to Bathurst Island Mission, Australian Institute of Aboriginal Studies, Occasional Papers in Aboriginal Studies no. 1, Canberra, 1963.

KeLLy, J.H. Report on the Beef Cattle Industry in Northern Australia, Bureau of Agricultural Economics, Canberra, 1952.

Stanner, W.E.H. After the Dreaming, The Boyer Lectures, 1968, Australian Broadcasting Commission, Sydney, 1968.

STREHLow, R.G.H. The Sustaining Ideals of Australian Aboriginal Societies, Melbourne, 1956. Republished, Aborigines Advancement League of South Australia, Adelaide, 1966.

\section{ARTICLES AND CHAPTERS}

Blumer, Herbert. 'Industrialisation and Race Relations', in Guy Hunter (ed.), Industrialisation and Race Relations, Oxford University Press, London, 1965, pp. 220-53.

CARTER, Keff and Mare. 'Beswick Leads the Way', Walkabout, February 1965, pp. $12-16$.

Christophers, B.E. 'Northern Territory', in The Struggle for Dignity, Council for Aboriginal Rights, Melbourne, 1962. (No editor.)

Cook, C.E. 'Medicine and the Australian Aboriginal: a Century of Contact in the Northern Territory', Medical Journal of Australia, vol. 1, no. 14, 1966, pp. 559-65.

EıkIN, A.P. 'Aboriginal Policy 1930-1950: Some Personal Associations', Quadrant, vol. 1, no. 4, 1957, pp. 27-34.

- 'Reaction and Interaction: A Food Gathering People and European Settlement in Australia', American Anthropologist, vol. 53, no. 2, 1951, pp. 164-86.

ElliotT, R.B. and Maxwell, G.M. 'Lactose Maldigestion in Australian Aboriginal Children', Medical Journal of Australia, vol. 1, no. 2, 1967, pp. 46-9.

$\longrightarrow$ and - ' Predominance of Lactose of Small Molecular Size in Duodenal and Jejunal Mucosa of Australian Aboriginal Children', Australian Journal of Experimental Biology and Medical Science, vol. XIV, 1966, p. 709.

GANDEvia, Brian. 'Chronic Respiratory Disease in Pintubi and Walbiri Aborigines', Medical Journal of Australia, vol. 2, no. 6, 1967, pp. 237-44.

GALE, Fay. 'Aborigines and the Normal Social Welfare Channels', Australian Journal of Social Work, vol. 19, no. 2, 1966, pp. 5-9.

Gruen, F.H. 'Aborigines and the Northern Cattle Industry', in Ian G. Sharp and C.M. Tatz (eds.), Aborigines in the Economy, Jacaranda Press, Melbourne, 1966, pp. 197-215.

Hartwig, M. 'Aborigines and Racism: An Historical Perspective', in F.S. Stevens (ed.), Racism: The Australian Experience, vol. II, Black versus White, Australia and New Zealand Book Co., Sydney, 1971, pp. 9-24. 
Jefrreys, Bill. 'Why Welfare is a Dirty Word to Aborigines', Australlian, 28 October 1967.

JoHss, Brian. 'Beyond Kalumburu', Bulletin, Sydney, 21 August 1965, pp. 17-18.

Jose, D.G. and WeLCH, J.S. 'Protein-Calorie Malnutrition in Australian Aboriginal Children', Medical Journal of Australia, vol. 1, no. 8, 1970, pp. 349-56.

Litrue, J. 'Legal Status of Aboriginal People: Slaves or Citizens?', in F.S. Stevens (ed.), Racism: The Australian Experience, vol. II, Black versus White, Australia and New Zealand Book Co., Sydney, 1971, pp. 77-87.

Lockwood, Douglas. 'Goodbye to God's Best Country', Sydney Morning Herald, Sydney, 2 November 1968.

LONG, J.P.M. 'The Administration and the Part Aboriginals of the Northern Territory', Oceania, vol. 37, no. 3, 1967, pp. 186-201.

Maxwell, G.M., ElliotT, R.B., MCCoy, W.T., and LANGSFord, W.A. 'Respiratory Infections in Australian Aboriginal Children', Medical Journal of Australia, vol. 2, no. 22, 1968, pp. 990-3.

Moodie, P.M. 'Mortality and Morbidity in Australian Aboriginal Children', Medical Journal of Australia, vol. 1, no. 4, 1969, pp. 180-5.

Morris, F.R. 'The War Effort of the Northern Territory Aborigines', Australian Territories, vol. 5, no. 1, 1965, pp. 2-10.

MurRaY, Rowland. 'Station Management', in F. O'Loghlen and F.H. Johnston (eds.), Cattle Country, Johnston Publishing, Sydney, 1960, pp. 212-19.

Stanner, W.E.H. 'Industrial Justice in the Never Never', Australian Quarterly, vol. 39, no. 1, 1967, pp. 39-65.

Stevens, Frank. 'Aboriginal Policy and the Labour Movement', Origin, vol. 3, no. 2, October 1970, pp. 10-11.

- Introduction, in F.S. Stevens (ed.), Racism: The Australian Experience, vol. II, Black versus White, Australia and New Zealand Book Co., Sydney, 1971, pp. 1-5.

—. 'Parliamentary Attitudes to Aboriginal Affairs', in F.S. Stevens (ed.), Racism:

The Australian Experience, vol. II, Black versus White, Australia and New Zealand Book Co., Sydney, 1971, pp. 110-49.

TAtz, C.M. 'The Relationship Between Aboriginal Health and Employment', in I.G. Sharp and C.M. Tatz (eds.), Aborigines in the Economy, Jacaranda Press, Melbourne, 1966, pp. 51-68.

'The Unpermitted Man', The Territorian, December 1967. (No Author.)

\section{MANUSCRIPTS}

Bernot, Ronald M. and Catherine H. 'A Northern Territory Problem: Aboriginal Labour in a Cattle Industry', Department of Anthropology, University of Sydney, 1948. Typescript.

Docker, E.G. 'Native Administration in the Northern Territory', Australian National University, Canberra, 1956. Mimeo.

Hinton, Peter. 'The Prosperous Aborigines: the Industrialisation of a Mission Community', Report to the Australian Institute of Aboriginal Studies, 1966. Mimeo. 
KeiLy, J.H. 'Absentee Holding of Cattle Lands in Northern Australia', a paper presented at a Symposium on the Development of Northern Australia, University of New South Wales, 15 February 1966. Mimeo.

Strevens, Frank. 'Aboriginal Labour Policy in the Northern Territory', Department of Economic History, Australian National University, Canberra, 1967. Mimeo.

- 'Native Policy in Western Australia', Department of Economic History, Australian National University, Canberra, 1967. Mimeo.

Tatz, C.M. 'Aboriginal Administration in the Northern Territory', Ph.D, thesis, Australian National University, 1964.

\section{GOVERNMENT PUBLICATIONS}

COMMONWEAITH OF AUSTRALIA

Bleakiey, J.W. The Aboriginals and Half Castes of Central and North Australia, Report, Commonwealth Parliamentary Papers, No. 21 of 1929 (Volume II, pp. 1159-225).

Dietary Survey of Aboriginals in the Northern Territory, Department of Health, Canberra, 1946.

Labour Market Studies, No. 1, Aborigines, Department of Labour and National Service, Canberra, 1969.

Northern Territory Statistical Summary, 1965, Bureau of Census and Statistics, Darwin, 1965.

Prospects of Agriculture in the Northern Territory, Department of Territories, Minister for Territories, Government Printer, Canberra, 1961.

Report on an Investigation into the Curriculum and Teaching Used in Aboriginal Schools in the Northern Territory, Department of Territories, Darwin, 1964.

The Policy of Assimilation: Decisions of the Commonwealth and State Ministers at the Native Welfare Conference, Department of Territories, Government Printer, Canberra, 1961.

The Northern Territory Investigation Committee Report (Payne-Fletcher Report), Government Printer, Canberra, 1937.

Yearbooks, No. 37, 1946-7; No. 39, 1953; No. 47, 1961; No. 51, 1965; No. 52, 1966; No. 54, 1968.

\section{NORTHERN TERRITORY}

Annual Report of the Welfare Branch, 1958-59 to 1964-65.

Annual Report of the Administration, 1933 to 1938, 1945-60.

Government Gazette, 13 May 1957, No. 19B; 16 Sept. 1959, No. 40; 19 Dec. 1962, No. 59.

Report of the Select Committee on Social Welfare Legislation, Government Printer, Darwin, 1964.

WELFARE BRANCH OF THE NORTHERN TERRITORY ADMINISTRATION

Beswick Aboriginal Reserve, Welfare Branch, Darwin, 1965.

QUEENSLAND

Industrial Gazette, vol. 56, pp. 683-4. 
COMMONWEALTH CONCILIATION AND ARBITRATION COMMISSION

CASES CITED

2 C.A.R. 1

13 C.A.R. 437

19 C.A.R. 53

20 C.A.R. 511,512

26 C.A.R. 613, 616, 623 In the matter of The North Australian Pastoral Lessees Association, pp. 607-36.

31 C.A.R. 125

53 C.A.R. 212,214

71 C.A.R. 319,320

74 C.A.R. 511

97 C.A.R. 713

106 C.A.R. 1124

830 of 1965 ex parte H.V. McKay (1907), pp. 1-25.

The Federated Gas Employees Industrial Union. The Geelong Gas Company et al., pp. 437-511.

Federated Seamen's Union of Australia $v$. Commonwealth Steamship Owners, pp. 53-147.

North Australian Workers Union and J.A. Ambrose et al., pp. 507-25.
North Australian Workers Union v. The Northern Territory Pastoral Lessees Association.

The Australian Workers Union v. E.A. Abbey et al, pp. 212-57.

The North Australian Workers Union $y$. Alcoota Pastoral Company et al., pp. 319-30.

In the matter of the North Australian Workers Union and of Bovril Estates Ltd et al., pp. 510-14.

In the matter of ... The Cattle Station Industry (Northern Territory) Award, 1951.

In the matter of the Pastoral Industry (Northern Territory) Award, 1956, pp. 1107-38.

In the matter of Cattle Industry (Northern Territory) Award, 1951 (1965 reports not completely bound, Public Library of N.S.W., November 1971).

\section{OBSERVER INDUSTRIAL LAW REPORTS}

31 October 1959, in re Waterside Workers Award, headed Jurisdiction of Commission to Regulate Subject Matters Already Covered by Commonwealth Legislation ...', unreported: in re Metal Trades Award, 29 July 1959, quoted in C.P. Mills, Nolan and Cohen's Federal Industrial Laws, p. 192.

\section{ARCHIVES}

Australian National University Archives, Bovril Australian Estates, File No. 42-14-1.

\section{PARLTAMENTARY DEBATES}

COMMONWBALTH OF AUSTRALIA

Parliamentary Debates, House of Representatives, vol. 36, 1962, pp. 415-16.

NORTHERN TERRITORY OF AUSTRALIA

Legislative Council Debates, No. 4, 2 September 1952; No. 55, 21 January 1953; No. 5, 22 January 1953 ; No. 6, 8 June 1953; No. 6, 9 June 1953; No. 7, 23 September 1953 ; No. 3, 6 November 1957 ; No. 4, 16 May 1959; No. 5, 28 October 1959; 
No. 6, 29 October 1959; No. 1, 13 April 1960; No. 2, 1 June 1960; No. 3, 20 September 1960; No. 10, 15 August 1962; No. 10, 22 August 1962; No. 6, 19 February 1964; No. 7, 14 May 1964; No. 7, 18 May 1964.

\section{SELECT COMMITTEES-ROYAL COMMISSIONS}

COMMONWEALTH OF AUSTRALIA

House of Representatives, Parliamentary Select Committee on the Grievances of the Yirkalla Aborigines, Proceedings, Government Printer, Canberra, 1964.

Report of the Board of Enquiry . . . into Land and Land Industries of the Northern Territory (Payne-Fletcher Committee), Commonwealth Parliamentary Papers, No. 4 of 1938.

NORTHERN TERRITORY OF AUSTRALIA

Legislative Council, Select Committee on Social Welfare Legislation, 1964. Minutes of Evidence, Transcript of Proceedings.

Report of the Select Committee on Political Rights, Government Printer, Darwin, 1963. Report of the Select Committee on Social Welfare Legislation, 12 May 1964.

\section{ORDINANCES}

NORTHERN TERRITORY OF AUSTRALIA

Welfare-Social Welfare Ordinance, No. 16 of 1953, No. 5 of 1956, No. 29 of 1957 , No. 42 of 1957, No. 22 of 1959, No. 27 of 1959, No. 10 of 1960, No. 12 of 1962 , No. 38 of 1963, No. 31 of 1964.

Wards Employment Ordinance, No. 24 of 1953, No. 9 of 1958, No. 6 of 1959, No. 2 of 1961, No. 2 of 1963, No. 18 of 1963, No. 46 of 1964.

Aboriginals Ordinance 1918-1954, No. 4 of 1933, No. 2 of 1953, No. 7 of 1953, No. 9 of 1953, No. 6 of 1955.

Licensing Ordinance (No. 35 of 1964).

Apprentices Ordinance, 1948-1952 (No. 40 of 1952).

\section{Acrs}

COMMONWEALTH OF AUSTRALIA

Electoral Act, 1962 (No. 31 of 1962).

Northern Territory (Administration) Act, 1910-1962 (No. 77 of 1962).

\section{REGULATIONS}

NORTHERN TERRITORY OF AUSTRALIA

Regulations under the Wards Employment Ordinance, No. 4 of 1959, No. 17 of 1961, No. 15 of 1966.

Regulations under the Welfare Ordinance, No. 9 of 1957, No. 3 of 1959, No. 14 of 1965.

Regulations under the Aboriginals Ordinance, 1918-1933, Gazetted, 29 June 1933, Commonwealth of Australia Gazette, No. 40. 
TRANSCRIPTS OF PROCEEDINGS

COMMONWEALTH OF AUSTRALIA

House of Representatives, Parliamentary Select Committee of Enquiry into the Grievances of the Yirkalla Aborigines, 1964.

Commonwealth Conciliation and Arbitration Commission, No. 830 of 1965.

NORTHERN TERRITORY OF AUSTRALIA

Legislative Council, Transcript of the Proceedings of the Select Committee on Social Welfare Legislation, 1964.

Milirrpun v. Nabalco Pty Ltd and the Commonwealth of Australia (Gove Land Rights Case), unreported, 15 December 1971. 


\section{INDEX}

'Aboriginal', definitions, 11-12, 20, 39 Aboriginals Ordinance, 20, 38-9, 167

Aborigines, attitudes: to conditions, $122-$ 34, 163-83 passim; to diet, 124-5; to European labour, 135-55 passim, 16383 passim; to management, 9, 72, 135-55 passim, 150-78; to stores, 155-8; to unions, $158-60,189-205$ passim; to wages, $123-4,151-8,165-7$; to welfare, 161-2, 166-7, 177-8, 181-92

Absentee landholding, 35-6

Alcohol and Aborigines, 81, 95-7, 133-4, 167

American influence on Aborigines, 58-9

Arbitration, suitability for Aborigines, 59-60; see also Equal Wages Case, Industrial action, Unions, Wages, Working conditions

Arnhem Land Reserve, 3

Australian Council of Trade Unions, 192

Australian Half-Castes' Association, 39

Australian Workers' Union, 190-1

Awards, see Wages

\section{'Beetaloo Bill', 93}

Beswick Settlement, 115

Borroloola, 113

Brutality towards Aborigines, 104, 16383 passim, 184-8; see also Police

Bushcraft, Aboriginal, 72, 73, 122, 140, 150

Carrol, P., 91n.

Cattle Station Industry (Northern Territory) Award, 21, 23, 45, 60, 191, 192

Cattle stations, way of life, 29-33, 102-9; see also Living conditions, Working conditions

Census 1961, 16

Centralian Pastoralists Association, 3

Child labour, 53, 114
Climate, effects, 30-4, 64, 115

Clothing, Aboriginal, 84-95 passim, $156-7,172-3,178 \mathrm{n}$.; see also Hawkers, Stores

Commonwealth Conciliation and Arbitration Commission, 11, 20, 21, 79, 80, 189-205 passim; Act, 59; see also Equal Wages Case, Industrial action, Unions Commonwealth of Australia: Departments (Health) 187, (Native Affairs) 38, (Social Services) 158; responsibility for Aboriginal affairs, 184-5

Commonwealth Pastoral Industry Award, 22

Conciliation and arbitration, see Commonwealth Conciliation and Arbitration Commission, Equal Wages Case, Industrial action, Unions, Wages, Working conditions

Dependants, Aboriginal, 55-6, 82-90; see also Pensions, Welfare

Diet, Aboriginal, 23, 70, 84-95 passim, $110-11,116-17,152,172,176-7$; Aboriginal attitude, $124-5$; ration subsidy, 100-1; see also Stores

Driving, see Mechanical aptitude

Drought, see Climate

Education, Aboriginal, 71, 76, 99-100, $117,148-50$; trade training, $122-3$

Employment patterns, 115-17; see also Labour

Equal Wages Case 1965, 1, 11, 29, 39, 57, $65,71,80,135,153,189-205$

Exploitation, of Aborigines: financial, 163-83 passim; sexual, 42, 104, 134, $182-3$, 186-7; see also Brutality, Hawkers, Living conditions, Pensions, Stores, Working conditions 
Forster Committee 1960, 36, 61

Fraud, see Exploitation

Gambling, among Aborigines, 78, 81

Geoffreys, C., 3

Gibbs, G., $159 \mathrm{n}$.

Gruen, F, 2

Gunn, Sir William, 133

Half-caste Aborigines, 11-12, 38-42, 129, 167-8; see also Australian Half-Castes' Association

Harvester Judgement, 59

Hasluck, Sir Paul, 12

Hawkers, 95, 156

Health, Aboriginal, 82, 100-2, 187-8; infant mortality, 107; venereal disease, 186-7; see also Diet, Living conditions

Hinton, P., 144

Hooker Creek, 115

Horsemanship and stock handling, Aboriginal, 71-2, 73, 135-41 passin, $163-4$

Illiteracy, Aboriginal, 16, 39, 67, 69, 71, $78,92-3,94-5,114,128,141,145,157$, $159,173,181$; see also Education

Incentives for Aborigines, 71, 77-8, 147-8

Industrial action, $1,57,79-81,103,158-$ 60; suitability of arbitration system for Aborigines, 59-60; see also Equal Wages Case, Unions

Infanticide, 42, 187

Isolation, effects, 118-19, 121

Kelly, J.H., 33

'King Brumby', 6, 7, 93

Kinship, see Tribal associations

Kirby, Chief Justice, 71

Labour: Aboriginal, 26-9, 43-54, 189-205 passim, (attitudes to management) 9, 72, 135-55 passim, 150-78, (attitudes to European labour) $135-55$ passim, (attitudes to conditions) 123-34, 163-83 passim, (availability) 122-3, (disadvantages) 141-51, see also Supervision, (European Labour's attitude to) $108-9,120-1,167-8,170-1$, (management's attitude to) $8-9,11-12,43-54$ passim, 58-102 passim, 103-4, 108-9, 123-51 passim, 169-74 passim, 201-3, see also Brutality, Exploitation, (productivity) 63-102 passim, 134-41, (replaced by European) 61, 117, (suitability); 57-102 European, 34-5, 38-9, (availability) 118-19, (productivity) 65-102 passim; future demand in N.T., $33-4$; halfcaste, $39-42$; structure on cattle stations, 34-7; see also Incentives, Working conditions

Laws governing Aborigines, 11, 12-13; see also names of Acts and Ordinances

Living conditions: Aboriginal, 36-7, 43-54 passim, 68-9, 77, 89-90, 98-9, $123-5,163-83$ passim, (attitudes to) 123-34, 155-8, (on settlements) 115-17; European, 37-8, 120-1; half-caste, 38-42; on cattle stations, 105-9; see also Diet, Clothing, Education, Exploitation, Health

Lockwood, R., 201

Management: Aboriginal attitudes to, $9,72,135-55$ passim, 150-78; attitudes to Aborigines, 8-9, 11-12, 43-54 passim, 58-102 passim, 103-4, 108-9, 123-51 passim, 169-74 passim, 201-3; conditions, 35-42; deficiencies, 144-5; see also Brutality, Labour, Supervision

Mechanical aptitude, Aboriginal, 46-8, $50,66,67,68,73,74,141,150-1$, 168-71

Money, Aboriginal handling of, 78, 92-3, 155-8, 174; see also Exploitation, Pensions

Nationality and Citizenship Act, 13

New South Wales Pastoral Employees (State) Award, 22

'Nigger farming', 90-1

North Australian Workers' Union, $159-60,190$

Northern Territory Administration Act, 20

Northern Territory Administration, Welfare Branch, 7-8, 11-16 passim, $26-9,39,43,54,82-101$ passim, 149, $160,161-2,174-6,187,191-205$ passim; Aboriginal attitude to, 161-2, 166-7, 177-8, 181-2, 192; settlements, 115-17; see also Dependants, Pensions 
Northern Territory Cattle Producers' Council, 3

Northern Territory Council for Aboriginal Rights, 192

Northern Territory Electoral Regulations, 13

Northern Territory Licensing Ordinance 96n., 134

Northern Territory Pastoral Lessees' Association, 2, 7

Northern Territory Workers' Union, 91n., 190-205 passim

Part-Aborigines, see Half-caste Aborigines

Pensions, Aboriginal, 82-90 passim, 1578; see also Dependants, Exploitation, Northern Territory Administration, Welfare Branch

Police, relations with Aborigines, 117, 160,178 ; see also Brutality

Population, Northern Territory cattle stations: of Aborigines, 16-17, 26-9, $43,54-5$; of Europeans, 34, 96; of cattle, 30-4

Portus, Commissioner, 21, 45, 164, 191, 193

Queensland Station Hands Award, 22

\section{Rations, see Diet}

Register of Wards, 12-13, 15-16, 17, 20, 21; see also Wards Employment Ordinance, Welfare Ordinance

Responsibility, see Incentives

Rose, F., 142, 201

Rowley, C.D., 191

Rustling, 36

\section{Savings, Aboriginal, 95}

Select Committee of the Legislative Council of the Northern Territory, 202

Settlements, government, see Northern Territory Administration, Welfare Branch

Sexual liaisons, see Exploitation

Skills, Aboriginal, see Bushcraft, Horsemanship, Mechanical Aptitude
Social Welfare Ordinance, 13-15, 82, 192, 202

Stanner, W.E.H., 200

Stock handling, Aboriginal, see Horsemanship

Stores for Aborigines, 93-7; Aboriginal attitudes to, 155-8; role of storekeeper, 175-6

Subsidies for Aborigines, 90-1, 97-102

Supervision of Aboriginal labour, 66-71, $73,74,141$

Tatz, C.M., 2, 75

Taxation, 31

Tobacco allowance to Aborigines, 88,89

Tribal associations, effects, 45, 73, 74, $112,142-4,199-200$

Unions, and Aborigines, 158-60, 189-205 passim

United Graziers' Association of Queensland, 2,80

Victoria River district, 42, 115, 143, 158

Violence, see Brutality

Voss, L. de, 2n.

Wages: Aboriginal, 18-21, 43-102 passim, 117, 163-83 passim, (attitude to) $123-4,151-8,165-7$, (future prospects) 79-82, (rates for slow workers) 23-4, 53; basic (Harvester Judgement), 89; European, 21-3, 3442, (contrasted with Aboriginal) 23-5, $61,163-83$ passim; see also Equal Wages Case, Working conditions

'Walkabout', 67, 69, 113

Wards Employment Ordinance, 15-16, $18-19,20-1,23-5,29,53,68,81,82$, $90,94,98,124,125,127,146,156$, 175-7, 180, 181, 191, 192; Regulations, $18-19,23-5,29,98$

Wardship, sce Register of Wards, Wards Employment Ordinance

Watts, B., 55, 117

Wave Hill, 1, 3

Welfare Ordinance, $12-13,15,192$

Welfare policy, 75-6, 82-4, 84-91, 174, $177-8,181-2$, (Aboriginal attitude to) $161-2,166-7,177-8,181-2,192$; see 
Welfare policy (continued) also Dependants, Northern Territory Administration, Welfare Branch, Register of Wards, Social Welfare Ordinance, Pensions, Wards Employment Ordinance, Welfare Ordinance
Work force, see Labour

Working conditions: Aboriginal, 18-19, 20-1, 43-54; European, 21-3, 34-8, 118-19; half-castes, 38-42; compared, 23-5, 61-102 passim, 109-14, 163-83 passim; see also Wages 
Frank Stevens graduated in history at Sydney University. He then took an M.A. in economics at Stanford University and studied law at the University of California and at Gray's Inn, London. He was awarded a Ph.D. at the University of New South Wales. Since 1968 he has worked in the Department of Industrial Relations at the University of New South Wales.

Dr Stevens is the author of Equal Wages for Aborigines: The Background to Industrial Discrimination in the Northern Territory and editor of Racism: The Australian Experience (3 vols.).

Designed by Philippa Walker

Text set in 11 point Bembo one point leaded and printed on $85 \mathrm{gsm}$ Burnie English Finish at The Griffin Press, Adelaide, South Australia 
Frank Stevens graduated in history at Sydney University. He then took an M.A in economics at Stanford University and studied law at the University of California and at Gray's Inn, London. He was awarded a Ph.D. at the University of New South Wales. Since 1968 he has worked in the Department of Industrial Relations at the University of New South Wales.

Dr Stevens is the author of Equal Wages for Aborigines: The Background to Industrial Discrimination in the Northern Territory and editor of Racism: The Australian Experience (3 vols.). 


\section{ABORIGINES IN AUSTRALIAN SOCIETY}

F. Lancaster Jones,

The Structure and Growth of Australia's

Aboriginal Population

\section{Ronald Taft, John L.M. Dawson,}

Pamela Beasley,

Attitudes and Social Conditions

J.P.M. Long,

Aboriginal Settlements: A Survey of

Institutional Communities in Eastern Australia

C.D. Rowley,

The Destruction of Aboriginal Society

\section{H.P. Schapper,}

Aboriginal Advancement to Integration:

Conditions and Plans for Western Australia

\section{C.D. Rowley,}

Outcasts in White Australia

C.D. Rowley,

The Remote Aborigines

Fay Gale, assisted by Alison Brookman, Urban Aborigines

\section{Frank Stevens,}

Aborigines in the Northern Territory Cattle Industry

Peter M. Moodie, Aboriginal Health 